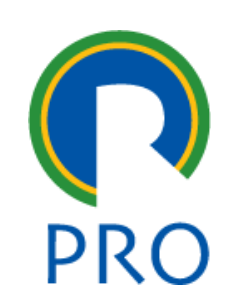

ESCOLA POLITÉCNICA - USP

DePartamento de EngEnHaRia de PRODUÇão

AlUnO: Bruno César Pino Oliveira de AraúJo

TRAJETÓRIAS OCUPACIONAIS DE ENGENHEIROS JOVENS NO BRASIL

São Paulo, janeiro de 2016 
Bruno César Pino Oliveira de Araújo

\title{
TRAJETÓRIAS OCUPACIONAIS DE ENGENHEIROS JOVENS NO BRASIL
}

\author{
Tese apresentada à Escola \\ Politécnica da Universidade de São \\ Paulo como requisito parcial para a \\ obtenção do título de Doutor em \\ Engenharia. \\ Área de concentração: Engenharia \\ de Produção. \\ Orientador: Prof. Dr. Mario Sergio \\ Salerno.
}

São Paulo, janeiro de 2016 


\section{Ficha catalográfica}

Araújo, Bruno César

Trajetórias ocupacionais de engenheiros jovens no Brasil / B. C. Araújo -São Paulo, 2016.

$150 \mathrm{p}$.

Tese (Doutorado) - Escola Politécnica da Universidade de São Paulo.

Departamento de Engenharia de Produção.

1.trajetórias ocupacionais 2.engenheiros 3.resultados de mercado de trabalho 4.optimal matching analysis I.Universidade de São Paulo. Escola

Politécnica. Departamento de Engenharia de Produção II.t. 
"We shall not cease from exploration, and the end of all our exploring will be to arrive where we started and know the place for the first time."

Little Gidding V,

Four Quartets.

T.S. Elliot (1942) 


\section{AgRADECIMENTOS}

Gratidão é uma benção; compartilhar alegria é uma daquelas coisas que fazem a vida valer a pena.

Agradeço e dedico este trabalho a Deus, cujos planos para esta etapa da minha vida foram se revelando e me propiciaram uma travessia mais serena e recompensadora do que eu havia previsto.

À minha esposa Claude e aos pequenos Heitor e Vitor, pelo amor, apoio e paciência inesgotáveis.

À minha mãe Ana, que se sacrificou tanto para que eu fosse cada vez mais longe. Ao meu pai Jason, pelos sábios conselhos e por sempre acreditar em mim.

Ao meu irmão Luís André, pela acolhida em São Paulo, pelo carinho. Este doutorado não teria sido possível sem você.

Ao meu Instituto de Pesquisa Econômica Aplicada (Ipea), que não só autorizou minha licença para capacitação como me franqueou o acesso aos dados utilizados. Além disso, o Ipea é a casa de vários colegas com os quais tive o prazer de debater técnicas e resultados desde o início desta tese. Assumindo o risco de injustiças, agradeço nominalmente aos amigos Aguinaldo Maciente, Paulo Nascimento, Divonsir Gusso (in memoriam), Fernanda e João De Negri, Lenita Turchi e Luiz Ricardo Cavalcante.

Agradeço profundamente ao meu orientador Prof. Dr. Mario Sergio Salerno. Se no começo não sabíamos muito bem qual caminho trilhar, é com muita satisfação que ao final chegamos ao ponto de partida para conhece-lo pela primeira vez, tal qual no poema de Elliot.

À Prof. Dra. Nadya Guimarães (FFLCH/USP) e sua equipe da Oficina de Sociologia Econômica e do Trabalho (OSET) e ao Prof. Dr. Donald Pianto (EST/UnB), por terem contribuído desde o início deste trabalho com ideias, sugestões e apoio.

Aos colegas do Observatório de Inovação e Competitividade (IEA/USP), pelo companheirismo, pelos artigos que fizemos juntos e frutíferas discussões que ajudaram a formatar esta pesquisa.

Finalmente, agradeço aos colegas e professores das disciplinas que cursei na USP, pelo alto nível do ensino e das discussões em sala de aula. Aprendi demais com vocês. 


\section{RESUMO}

Esta tese analisa 9.041 trajetórias ocupacionais de jovens engenheiros como empregados formais no Brasil entre 2003-2012, a partir da técnica de Optimal Matching Analysis (OMA). Estas trajetórias foram comparadas às de uma geração anterior de jovens engenheiros, tanto em seu período-base (1995-2002) como entre 2003-2012, a fim de identificar efeitos de idade e período. Os principais resultados são: (i) conforme esperado, trajetórias ocupacionais ligadas à gestão (em áreas correlatas à engenharia ou não) são as que oferecem remuneração mais alta em todos os períodos analisados; (ii) nos anos 2000, o terceiro padrão mais atrativo para os jovens daquela geração foi permanecer como engenheiro típico, caminho perseguido por praticamente metade deles, enquanto tal atratividade não foi verificada nos anos 1990; (iii) o salário de entrada dos jovens engenheiros subiu 24\% em termos reais entre 1995 e 2003; (iv) há pouca mobilidade de trajetória ocupacional por parte da geração dos engenheiros de 1995 após 2003; (v) os jovens engenheiros de 1995 que permaneceram como engenheiros típicos durante os anos 2000 chegaram a 2012 ganhando apenas $14 \%$ a mais do que os jovens engenheiros de 2003 (com 8 anos a menos de experiência); para comparação, os gestores da geração 90 ganhavam em torno de 50\% a mais do que os da geração 2000; (vi) há dois momentos de definição de trajetória ocupacional: um primeiro ocorre até 3 anos após o primeiro emprego, mas promoções a cargos de gestão podem ocorrer entre 8 e 10 anos. Estes resultados indicam que, se por um lado houve uma revalorização dos profissionais de engenharia na última década, por outro lado esta revalorização não trouxe engenheiros anteriormente formados a carreiras típicas em engenharia. Isto, aliado à baixa demanda pelos cursos de engenharia durante os anos 80 e 90, corrobora a hipótese de um hiato geracional entre os engenheiros, documentado em artigos anteriores.

Palavras-chave: trajetórias ocupacionais, engenheiros, resultados de mercado de trabalho, optimal matching analysis. 


\begin{abstract}
This $\mathrm{PhD}$ dissertation analyzes 9,041 occupational trajectories of young engineers as formal employees in Brazil in 2003-2012, using Optimal Matching Analysis (OMA). These trajectories were compared to those of a previous generation of young engineers, both in its base period (1995-2002) and in 2003-2012, to identify age and period effects. The main results are: (i) as expected, management occupational trajectories (in areas related to engineering or not) pay higher wages, in all periods; (ii) in the 2000s, the third most attractive trajectory was to remain as typical engineer, path pursued by nearly half of young engineers, however, this was not verified in the 1990s; (iii) entry wages of young engineers rose 24\% in real terms between 1995 and 2003; (iv) there is little occupational mobility by the generation of 1995 engineers after 2003; (v) young engineers of 1995 who remained as typical engineers during the 2000s earned only 14\% more in 2012 than young engineers of 2003; for comparison, in 2012 managers from the 90s earned about $50 \%$ more those from the 2000s; (vi) there are two defining moments of occupational trajectory: a first occurs until three years after the first job, but promotions to management positions can take place between 8 and 10 years. These results indicate that, on the one hand, there was a revaluation of engineers over the past decade; on the other hand, this did not attracted former bachelors back to typical careers in Engineering. This, combined with low demand for engineering courses during the 80s and 90s, supports the hypothesis of a generational gap among engineers, documented in previous articles.
\end{abstract}

Keywords: occupational trajectories, engineers, labor market outcomes, optimal matching analysis. 


\section{SUMÁRIO}

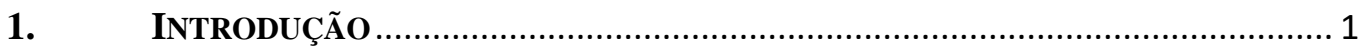

1.1. Contextualização e definição do problema …….......................................... 1

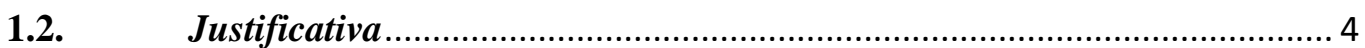

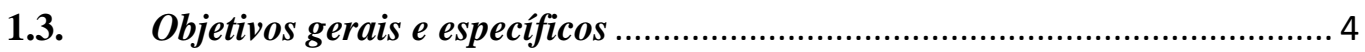

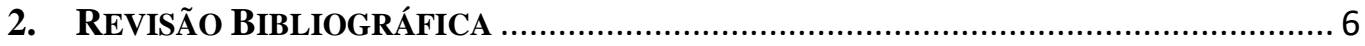

2.1. Trajetórias ocupacionais como sequências …………………………........... 6

2.2. Análise bibliométrica do Optimal Matching Analysis................................. 10

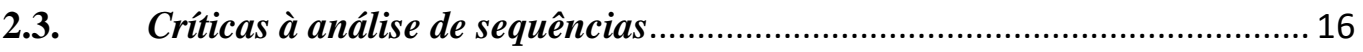

2.4. Questões metodológicas em análise de sequências ..................................... 18

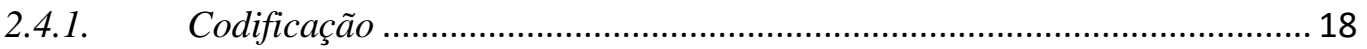

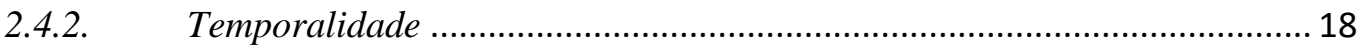

2.4.3. Custos de substituição entre estados........................................................... 21

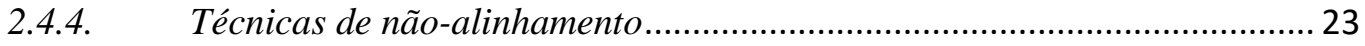

2.4.5. Métodos de agrupamento de sequências .................................................... 24

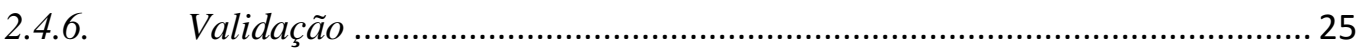

2.5 Análise de sequências em ciências sociais: um balanço parcial ............................ 25

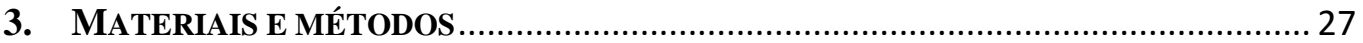

3.1. Dados e estatísticas descritivas preliminares .................................................. 27

3.1.1. Mobilidade entre regiões, macrossetores e portes de empresas ................. 31

3.1.2. Resultados de mercado de trabalho: por gênero, região, setor e porte...... 37

3.2. Operacionalização: definição de trajetórias ocupacionais ........................... 42

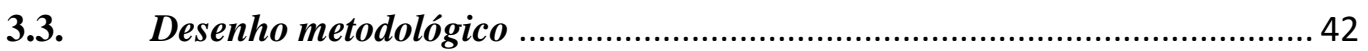

3.4. Opções metodológicas para o alinhamento de sequências ............................ 44

4.1. Comparação entre os algoritmos de alinhamento de sequências .................. 59

4.2. Resultados de mercado de trabalho (labor market outcomes) e trajetórias 61

4.3. Gênero, características do emprego e trajetórias ............................................ 69

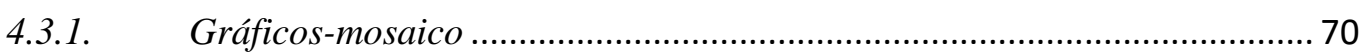

4.3.2. Modelo multinomial logístico ....................................................................... 76 
5. OS ENGENHEIROS JOVENS ENTRE 1995 E 2002: A GERAÇÃO 90 EM 90 ........ 81

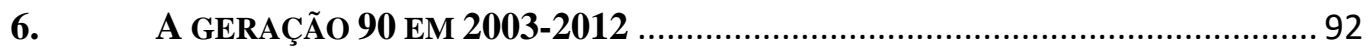

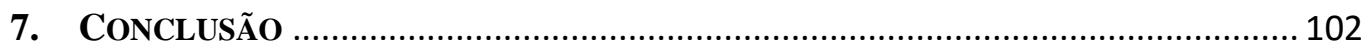

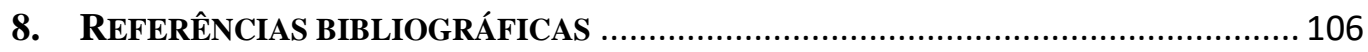

9. ANEXo 1: SitUAÇÃo OCUPACIONAL DOS PROFISSIONAIS FORMAdOS EM ENGENHARIA A PARTIR DOS CENSOS 2010 E 2000 ............................................. 110

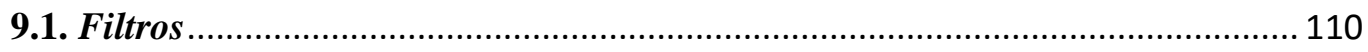

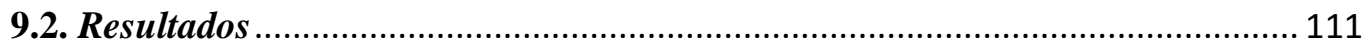

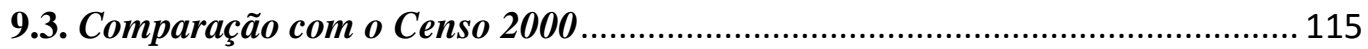

9.4. Conclusão-o que acontece com os profissionais que saem da Rais? ............... 118

10. ANEXO 2: OMA COM DISTÂNCIA DE HAMMING E COM OS FORA DA RAIS COMO

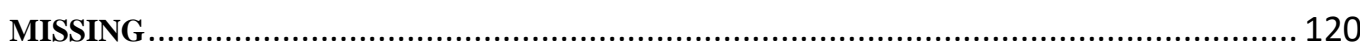

11. ANEXO 3: ESTADOS BIDIMENSIONAIS - OCUPAÇÃO E MACROSSETOR ............... 125

12. ANeXo 4: ClassifiCaÇões Alternativas da GERAÇão 90 EM 2003-2012.. 129 


\section{ÍNDICE DE TABELAS}

Tabela 1 - Análise do histórico de eventos e Análise de sequências em Sociologia do ciclo de vida

Tabela 2 - Exemplo de trajetórias ocupacionais

Tabela 3 - Matriz de distância entre as sequências do exemplo (nãonormalizada e normalizada) ................................................................................ 9

Tabela 4 - Exemplo de trajetórias ocupacionais (com indivíduos fora do mercado de trabalho por alguns períodos)

Tabela 5 - Distribuição setorial dos jovens engenheiros entre as CNAEs em 2003

Tabela 6 - Matrizes de transição geográfica dos jovens engenheiros, 2003 e 2012 .

Tabela 7 - Matrizes de transição entre os macrossetores dos jovens engenheiros, 2003 e 2012.

Tabela 8 - Matrizes de transição entre os macrossetores e aqueles jovens engenheiros que saem da Rais, 2003 e 2012.

Tabela 9 - Matrizes de transição entre o porte das empresas dos jovens engenheiros, 2003 e 2012.

Tabela 10 - Remuneração mensal e tempo de emprego por gênero, 2003 e 2012

Tabela 11 - Remuneração mensal e tempo de emprego por região, 2003 e 2012

Tabela 12 - Remuneração mensal e tempo de emprego por macrossetor, 2003 e 2012

Tabela 13 - Remuneração mensal e tempo de emprego por porte, 2003 e 2012

Tabela 14 - Desenho metodológico

Tabela 15 - Cenário Econômico, 1995-2002 vs. 2003-2012. .44

Tabela 16 - Exemplos de CBO em cada codificação .45

Tabela 17 - Matriz com os custos de transição entre os estados

Tabela 18 - Medida de complexidade: OMA (caso-base), Distância de Hamming e OMA com fora da Rais como missing.

Tabela 19 - Características do emprego, por tipo de trajetória, 2003-2012 
Tabela 20 - Eta-quadrado das trajetórias e fatores sobre as características do emprego, 2003-2012.

Tabela 21 - Teste LR dos fatores no modelo multinomial logístico, 20032012

Tabela 22 - Modelo multinomial logístico de previsão das trajetórias ocupacionais, 2003-2012

Tabela 23 - Características do emprego, por tipo de trajetória, 1995-2002

Tabela 24 - Eta-quadrado das trajetórias e fatores sobre as características do emprego, 1995-2002

Tabela 25 - Teste LR dos fatores no modelo multinomial logístico, 19952002

Tabela 26 - Modelo multinomial logístico de previsão das trajetórias ocupacionais, 1995-2002 89

Tabela 27 - Matriz de transição entre as classificações: 1995-2002 vs. Geração 90 em 2003-2012 96

Tabela 28 - Características do emprego, geração 90 em 2000, por tipo de trajetória, 2003-2012. 100

Tabela 29 - Remuneração média por diferentes tipos de trajetória: geração 90 em 90, geração 2000 em 2000 e geração 90 em 2000 (em R\$ de 2012) 104

Tabela 30 - Situação de trabalho na semana de referência do Censo 2010

Tabela 31 - Posição na ocupação e categoria do emprego no trabalho principal, Censo 2010.

Tabela 32 - Remuneração por categoria do emprego no trabalho principal, Censo 2010

Tabela 33 - Situação de trabalho por gênero na semana de referência do Censo 2010.

Tabela 34 - Número de filhos/mulher por situação ocupacional, Censo 2010

Tabela 35 - Posição na ocupação e categoria do emprego no trabalho principal, Censo 2000.

Tabela 36 - Remuneração por categoria do emprego no trabalho principal, Censo 2000

Tabela 37 - Remuneração, seu crescimento e tempo de emprego de acordo com classificação bidimensional, 2003 e 2012

Tabela 38 - Remuneração média por diferentes tipos de trajetória: geração 90 em 90, geração 2000 em 2000 e geração 90 em 2000 segundo duas classificações (em $R \$$ de 2012) 
Tabela 39 - Matriz de transição: classificação original de 1995-2002 vs. Classificação 1995-2012

Tabela 40 - Matriz de transição: classificação da geração 90 em 2000 (realinhamento das sequências) vs. Classificação 1995-2012. 


\section{ÍNDICE DE GRÁFICOS}

Gráfico 1 - Pirâmides demográficas de formados em engenharia, Censos de 2000 e 2010

Gráfico 2 - Produção e impacto de citações dos artigos que utilizam Optimal Matching Analyis, 1990-2015

Gráfico 3 - Mapa historiográfico da produção científica em OMA, 1986-2008 (20 artigos mais citados da área)

Gráfico 4 - Histograma da idade de formatura em engenharia (Enade, 2011)

Gráfico 5 - Primeira ocupação dos jovens engenheiros, 2003 29

Gráfico 6 - Distribuição setorial dos jovens engenheiros entre os macrossetores, 2003

Gráfico 7 - Distribuição dos jovens engenheiros de acordo com as faixas de tamanho, 2003 e 2012

Gráfico 8 - Esquema de classificação das ocupações................................... 45

Gráfico 9 - Sequências mais frequentes, 2004-2012 …............................... 49

Gráfico 10 - Distribuição dos estados por ano, 2004-2012 ........................... 50

Gráfico 11 - Medidas de complexidade das trajetórias: entropia e complexidade, 2004-2012 ................................................................................. 51

Gráfico 12 - Silhouette médio e mediano e número de clusters: OMA, 20042012

Gráfico 13 - Gráfico Silhouette por cluster: OMA, 2004-2012 ..................... 54

Gráfico 14 - Dendograma para análise de cluster, 2004-2012 …................. 54

Gráfico 15 - Tipos de trajetórias ocupacionais, 2004-2012 …..................... 56

Gráfico 16 - Trajetórias mais frequentes por tipo de trajetória ocupacional, 2004-2012

Gráfico 17 - Box plot das medidas de complexidade: OMA (caso-base), distância de Hamming e OMA com fora da Rais como missing.

Gráfico 18 - Remuneração média, crescimento da remuneração e tempo de emprego (em R\$ de 2012 e em meses).

Gráfico 19 - Remunerações relativas e crescimento da remuneração, 20032012 
Gráfico 20 - Gráfico-mosaico da distribuição do gênero por tipo de trajetória.

Gráfico 21 - Gráfico-mosaico da distribuição do porte por tipo de trajetória

Gráfico 22 - Gráfico-mosaico da distribuição da Região, em 2003 e 2012, por tipo de trajetória

Gráfico 23 - Gráfico-mosaico da distribuição macrossetorial, em 2003 e 2012, por tipo de trajetória.

Gráfico 24 - Gráfico-mosaico das CBOs do primeiro emprego (2003) por tipo de trajetória. 75

Gráfico 25 - Sequências mais frequentes, 1996-2002 .................................. 81

Gráfico 26 - Distribuição dos estados, 1996-2002 ....................................... 82

Gráfico 27 - Dendograma para análise de cluster, 1996-2002 ..................... 83

Gráfico 28 - Tipos de trajetórias ocupacionais, 1996-2002 …..................... 84

Gráfico 29 - Trajetórias mais frequentes por tipo de trajetória ocupacional,

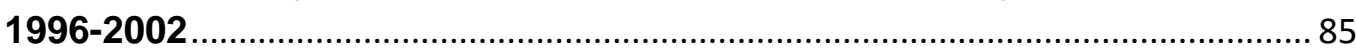

Gráfico 30 - Remunerações relativas, 1995-2002 _.......................................... 87

Gráfico 31 - Sequências mais frequentes, geração 90 em 2003-2012 ........ 93

Gráfico 32 - Distribuição dos estados, geração 90 em 2003-2012 ............. 94

Gráfico 33 - Complexidade das trajetórias: geração 90 em 2003-2012, 1995-

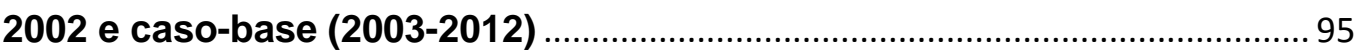

Gráfico 34 - Dendograma para análise de cluster, geração 90 em 2003-2012

Gráfico 35 - Tipos de trajetórias ocupacionais, geração 90 em 2003-2012

Gráfico 36 - Trajetórias mais frequentes por tipo de trajetória ocupacional, geração 90 em 2003-2012.

Gráfico 37 - Dendograma do Hamming Dinâmico (esq.) e do OMA com os fora da Rais como missing (dir.)

Gráfico 38 - Tempograma do Hamming Dinâmico, por tipo de trajetória, 2004-2012.

Gráfico 39 - Sequências mais comuns do Hamming Dinâmico, por tipo de trajetória, 2004-2012.

Gráfico 40 - Tempograma do OMA com fora da Rais como missing, por tipo de trajetória, 2004-2012

Gráfico 41 - Sequências mais comuns do OMA com o fora da Rais como missing, por tipo de trajetória, 2004-2012. 
Gráfico 42 - Gráfico Silhouette por cluster: Classificação bidimensional (ocupação e macrossetor), 2004-2012

Gráfico 43 - Dendograma para análise de cluster - classificação bidimensional, 2004-2012.

Gráfico 44 - Tipos de trajetórias ocupacionais - classificação bidimensional, 2004-2012.

Gráfico 45 - Sequências mais frequentes, 1996-2012

Gráfico 46 - Distribuição dos estados, 1996-2012

Gráfico 47 - Gráfico Silhouette por cluster: OMA, 1996-2012

Gráfico 48 - Dendograma para análise de cluster, 1996-2012

Gráfico 49 - Tempograma do OMA, por tipo de trajetória, 1996-2012

Gráfico 50 - Sequências mais comuns do OMA com o fora da Rais como missing, por tipo de trajetória, 2004-2012. 


\section{INTRODUÇÃO}

\subsection{Contextualização e definição do problema}

Há um debate em curso no Brasil sobre a possibilidade ou não de um cenário de falta de mão de obra qualificada para sustentar o crescimento econômico. ${ }^{1}$ Ainda que arrefecido recentemente pela perspectiva de baixo crescimento, este é um debate que permeia a academia e a sociedade há pelo menos uma década, e serviu de justificativa para políticas educacionais como o Programa de Apoio a Planos de Reestruturação e Expansão das Universidades Federais (ReUni), o Programa Universidade para Todos (ProUni), a expansão do Financiamento Estudantil (Fies) e o Programa Nacional de Acesso ao Ensino Técnico e Emprego (Pronatec).

Este debate tem natureza tanto quantitativa - notadamente diante do grande crescimento do acesso ao ensino fundamental na década de 90 e na consequente demanda atual por continuidade dos estudos -, quanto qualitativa - considerando o desempenho relativamente baixo da educação brasileira, em todos os níveis, em exames nacionais e internacionais. Igualmente, esse debate sobre falta de mão de obra qualificada é amplo no que tange às áreas de formação, embora seja notável a ênfase nas áreas de saúde e engenharia, apontadas como mais carentes de profissionais.

Os engenheiros têm papel decisivo para a elevação da produtividade, tanto via inovação quanto por meio da adoção de melhores práticas (catch-up). Lins et al. (2014) documentam, a partir de dados da OCDE, que a correlação linear entre a porcentagem de Recursos Humanos em Ciência e Tecnologia (HRST) no total de empregados ${ }^{2}$ e o PIB per capita em 2012 era de $67 \%$. Adicionalmente, um modelo econométrico de painel com controle para efeitos fixos indicou que o aumento em 1 ponto percentual na proporção HRST de nível superior aumentava a renda per capita em US\$ 712. Naturalmente, correlação não necessariamente significa causalidade, mas estes resultados indicam que crescimento do PIB per capita guarda relação estatística com o fortalecimento das carreiras científicas e tecnológicas em nível mundial.

O debate sobre escassez de mão de obra em uma determinada área de formação passa por aspectos demográficos, gerais e específicos à área: cada área de formação tem sua

${ }^{1} \mathrm{O}$ leitor interessado encontrará em (Lins et al., 2014) uma coletânea de reportagens e artigos na mídia sobre este debate.

${ }^{2}$ Apesar desse indicador incluir outros profissionais além dos engenheiros, é a abertura mais desagregada possível para comparações internacionais. Estes profissionais dos grupos 2 e 3 da ISCO (International Standard Classification of Occupations) incluem físicos, matemáticos, engenheiros, cientistas da vida e profissionais da saúde, profissionais de ensino, e outros profissionais (grupo 2); e profissionais das mesmas áreas do grupo 2, só que de nível educacional intermediário. Para maiores detalhes, veja o artigo de Lins et al. (2014). 
própria demografia, geralmente mais volúvel do que a demografia geral. Esta demografia dependerá tanto de fatores de demanda quanto de oferta de formação e trabalho.

Do lado da demanda, podem-se destacar:

- A demanda quantitativa específica por profissionais com aquela formação; e

- O sistema de recompensas formais e informais para estes profissionais atuarem naquela área de formação (atratividade).

Do lado da oferta:

- $\quad$ O contingente atual de profissionais, exercendo ocupações típicas ou não;

- $\quad$ O grau de flexibilidade para transições de emprego. Esta flexibilidade tem tanto uma dimensão institucional, condicionada pelas restrições do mercado de trabalho (formais ou não), quanto pessoal, conforme idade e momento do ciclo de vida;

- $\quad$ A qualidade e atualidade da formação dos profissionais ativos;

- $\quad$ As taxas de entrada (formação) e de saída (aposentadoria).

Pereira, Nascimento e Araújo (2011) e Lins et al. (2014) avaliam estes aspectos demográficos dos engenheiros no Brasil. Pereira, Nascimento e Araújo (2011) projetam, a partir de técnicas clássicas em demografia, a oferta de engenheiros no Brasil até 2020. Estes autores concluíram que, a não ser em cenários muito favoráveis de crescimento (superiores a 7,8\% ao ano), não haveria escassez quantitativa de engenheiros no Brasil. A principal razão seria a aceleração tanto no número de calouros quanto de formandos em engenharia durante os anos 2000. Sobre isso, Gusso e Nascimento (2014) documentam que enquanto o número de formandos em engenharia cresceu 2,5 vezes entre 2000 e 2011, o número de matrículas cresceu 3 vezes e o número de vestibulandos, 3,5 vezes. Com efeito, em 2011 o número de calouros em engenharia superou o de calouros em direito. ${ }^{3}$

Lins et al. (2014) também rejeitam a hipótese de escassez generalizada de engenheiros no Brasil. No entanto, estes autores identificam um importante hiato geracional na faixa de 35 a 49 anos - exatamente uma faixa de engenheiros com experiência intermediária capaz de liderar e gerenciar projetos. Estes engenheiros deveriam ter se formado nos anos 1980 e 1990, quando o cenário econômico instável e recessivo afetou a atratividade das carreiras em engenharia e, por consequência, a própria demanda pelos cursos.

A partir da análise das pirâmides demográficas dos censos decenais de 1970 a 2010, os autores notam que nos censos de 1970 e 1980, mais de 30\% dos engenheiros compunham a base da pirâmide, entre 25 e 29 anos. A partir desse momento, essa geração foi envelhecendo, e nos dois censos seguintes - 1991 e 2000 - é ela que vai continuar a ser a parcela mais importante da distribuição etária, pois não houve reposição na base.

3 “Pela primeira vez, engenharia tem mais calouros do que direito" (Folha de São Paulo, 14/04/2013, disponível em: http://www1.folha.uol.com.br/educacao/1262233-pela-primeira-vezengenharia-tem-mais-calouros-do-que-direito.shtml). 
Somente no censo de 2010 a base volta a crescer. Mas a faixa intermediária entre 35 e 49 - que deveriam compor a base nos dois censos anteriores - formam um "vale" na pirâmide demográfica, como pode ser visto no Gráfico 1.

\section{Gráfico 1 - Pirâmides demográficas de formados em engenharia, Censos de 2000 e 2010}

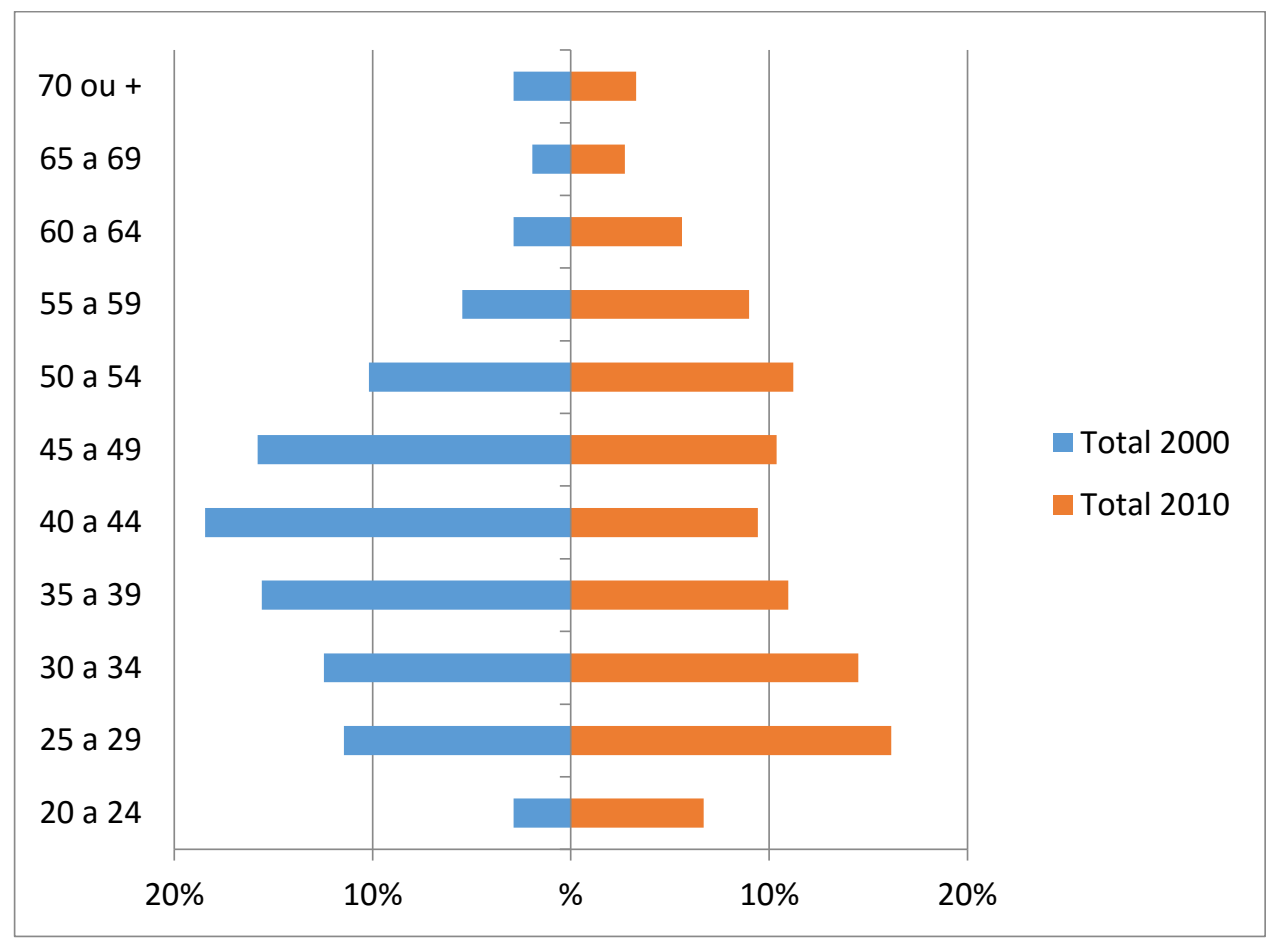

Fonte: Lins et al. (2014). Número de pessoas com diploma de engenharia: $2000=567$ mil, $2010=$ 937 mil.

Estes resultados indicam que os efeitos demográficos induzidos pela dinâmica das oportunidades de trabalho podem ser não apenas intensos como duradouros, por duas razões: (i) o hiato temporal entre a decisão de estudar engenharia e se formar; e (ii) a existência de eventuais "gerações perdidas", ou seja, hiatos geracionais de faixas etárias específicas, com prejuízo à experiência e capacidade de liderança.

Considerando esse contexto, a presente tese adiciona mais uma dimensão nesse debate. Se, por um lado, o engenheiro é um tipo de profissional fundamental para a elevação da produtividade e para a inovação, por outro, ele é um profissional que tem bastante flexibilidade com respeito às opções ocupacionais, devido à formação versátil em ciências e matemática (POMPERMAYER et al., 2011). Essa nova dimensão resulta exatamente da possibilidade dos engenheiros exercerem ocupações que não as típicas de engenharia. Uma determinada economia pode, em um determinado momento, não estar enfrentando exatamente um problema de escassez de engenheiros, e sim, um problema de atratividade das carreiras típicas de engenharia, de forma que isso não afete apenas a demanda por formação em engenharia como também o próprio exercício profissional daqueles engenheiros já formados.

Nesse sentido, o problema de pesquisa deste projeto de tese é identificar e caracterizar trajetórias típicas de ocupações formais de engenheiros jovens no 


\section{Brasil, em diferentes períodos e diferentes coortes, bem como os resultados e determinantes destas trajetórias típicas.}

As ocupações são definidas de acordo com a CBO (Classificação Brasileira de Ocupações), e o mercado de trabalho é o formal, tal como definido na Relação Anual de Informações Sociais (Rais), do Ministério do Trabalho e Emprego. Ainda que restrita ao trabalho com carteira assinada - portanto, a análise não engloba o mercado informal, o trabalho como conta-própria ou empregador - a análise se refere ao total dos engenheiros jovens trabalhando em empresas como empregados formais, pois o preenchimento da Rais é obrigatório para todas as empresas. Ao todo, 9.041 trajetórias profissionais de engenheiros com menos de 25 anos foram acompanhadas ao longo do período 2003-2012, e 5.045 no período 1995-2002. As trajetórias dos 5.045 engenheiros jovens dos anos 1990 também serão caracterizadas durante os anos 2000.

\subsection{Justificativa}

Caracterizar padrões de trajetórias ocupacionais, seus resultados para o trabalhador e seus determinantes é importante para:

- Os próprios profissionais, que podem compreender melhor sua posição relativa frente ao mercado, as opções possíveis e seus resultados;

- Empreendedores e profissionais de recursos humanos, que podem adequar os planos de carreira das empresas considerando tanto seu direcionamento estratégico quanto a realidade do mercado;

- A academia, que, além de mais trabalho sobre trajetórias ocupacionais, terá a oportunidade de considerar os resultados deste estudo para eventualmente readequar os currículos dos cursos de graduação em engenharia. Além disso, as técnicas aqui empregadas podem ser replicadas sem dificuldade para outros grupos ocupacionais.

\subsection{Objetivos gerais e específicos}

Tendo em mente o objetivo geral de identificar e caracterizar trajetórias típicas de ocupações formais de engenheiros jovens no Brasil, em diferentes períodos e diferentes coortes, bem como os resultados determinantes destas trajetórias típicas, as questões de pesquisa específicas deste projeto de tese são as seguintes:

1. Quais são os grandes padrões de trajetórias de ocupações dos jovens engenheiros entre 2003 e 2012 ?

2. Quais são as sequências de ocupações mais comuns em cada trajetória?

3. Em que momento do tempo ocorre a definição destes padrões?

4. Quais são as características de remuneração e estabilidade no emprego referente a cada trajetória no final do período analisado? Em outras palavras, quais são os resultados de mercado de trabalho (labor market outcomes) de cada trajetória? 
5. Como gênero e características do primeiro emprego (ocupação, região, tamanho do estabelecimento empregador, setor de atividade) se relacionam com as trajetórias subsequentes? Em que medida estas características determinam estas trajetórias?

6. Como comparar estes padrões de trajetórias, suas características e determinantes com os de uma geração anterior de engenheiros jovens (1995-2002)?

7. Como as trajetórias ocupacionais desta geração anterior de engenheiros jovens se comportaram durante os anos 2000? Em que medida isto se relaciona aos aspectos demográficos dos engenheiros apontados em outros estudos?

A tese se estrutura da seguinte forma. O próximo capítulo traz uma revisão bibliográfica sobre o tratamento de trajetórias ocupacionais como sequências. O capítulo 3 apresenta os dados e as escolhas metodológicas, e o capitulo 4 traz os resultados do caso-base (2003-2012). O capítulo 5 compara os resultados do caso-base com os de uma geração anterior de jovens engenheiros em período anterior (1995-2002), enquanto o capítulo 6 avalia as trajetórias ocupacionais desta geração anterior no período-base. Por fim, o capítulo 7 discute as principais conclusões e possíveis extensões deste trabalho. 


\section{REVISÃo BIBLIOGRÁFICA}

\subsection{Trajetórias ocupacionais como sequências}

Trajetórias ocupacionais são sequências de ocupações. ${ }^{4}$ E, ao analisar sequências, há basicamente duas abordagens possíveis.

A primeira delas guarda ligação teórica com a análise da história de eventos (event history analysis). A análise do histórico de eventos é "uma forma de estudo longitudinal em que a unidade de análise não é o indivíduo ou grupo social, mas o evento socialmente significativo, por exemplo, mudança de ocupação, período de desemprego, mudança de estado civil, ou outro evento significativo de vida" (MARSHALL, 1998).

De forma direta, esta abordagem se preocupa com a análise das transições entre os estados, duração em cada estado e seus determinantes. Do ponto de vista metodológico, esta tradição se relaciona à aplicação processos markovianos de transição, análise de sobrevivência e seus desdobramentos em estudos longitudinais.

Abbott e Hrycak (1990, p. 148) argumentam que a análise do histórico de eventos tem a vantagem de explicar como as sequências são geradas (respondendo, portanto, ao que os autores denominam generation question), modelando as transições entre estados e a duração em cada um. A partir da suposição de que os dados são gerados estocasticamente ponto a ponto no tempo, geram-se sequências a partir destes processos estocásticos e verifica-se quão bem as sequências geradas conseguem replicar os padrões observados (BRZINSKY-FAY; KOHLER, 2010).

Contudo, há dois problemas com esta abordagem. O primeiro, de ordem prática, é que ela pode se tornar torna intratável do ponto de vista computacional à medida em que se aumenta o número de estados possíveis, de sequências ou períodos sob análise. $\mathrm{O}$ segundo, de ordem conceitual, é que certas sequências devem ser modeladas com toda a informação, e não como decisões estocásticas passo-a-passo. Esse é um problema, por exemplo, das análises a partir das cadeias de Markov. As cadeias de Markov modelam decisões passo-a-passo a partir de regras e probabilidades pré-definidas. Pegue um exemplo, sugerido em Abbott e Hrycak (1990, p. 148), de um professor que abandona a profissão para se tornar taxista. Uma abordagem clássica de cadeias de Markov suporia que, a cada período (ano, mês ou outra medida) a probabilidade deste professor desistente continuar como taxista é a mesma. Contudo, é razoável supor que a probabilidade de um professor desistente voltar à carreira depois de, por exemplo, dois anos como taxista, é diferente desta probabilidade depois de dez anos. Ainda que se alterem as probabilidades de transição período a período - gerando os chamados processos markovianos nãohomogêneos - o problema em se modelar decisões passo-a-passo persiste.

\footnotetext{
${ }^{4}$ No próximo capítulo é discutido brevemente como esta definição se relaciona a conceitos como emprego e carreira.
} 
A segunda abordagem, conhecida como análise de sequências, busca a máxima verossimilhança entre um conjunto de sequências a fim de identificar padrões comuns usando a distinção de Abbott e Hrycak (1990), a análise de sequências busca responder à pattern question. Se, por um lado, a análise de sequências não se preocupa com o processo subjacente de geração das sequências, por outro lado seus algoritmos são bastante eficientes para agrupar sequências semelhantes e identificar padrões para uso analítico posterior. A análise de sequências deixa de lado a modelagem de transições e durações em prol da análise da sequência como um todo. Assim, esta abordagem é mais flexível para refletir fenômenos como a dependência da trajetória (path dependency) e do contexto. Segundo Aisenbrey e Fasang (2010, p. 424) "a mudança social no nível micro pode ser conceitualizada de dois modos: pelo exame do momento e frequência das durações e 'transições' discretas que marcam eventos cruciais no curso da vida ou por uma perspectiva holística sobre como as 'trajetórias' como um todo mudam entre as coortes e entre países." Ainda segundo as autoras, "a análise de sequências representa uma tendência em ciências sociais em direção a pensar os 'eventos em contexto' ao invés de 'entidades com atributos variáveis"” (AISENBREY; FASANG, 2010, p. 422).

Enfim, Aisenbrey e Fasang (2010) elaboram uma tabela-resumo (Tabela 1) com as diferenças entre a análise do histórico de eventos e análise de sequências.

\section{Tabela 1 - Análise do histórico de eventos e Análise de sequências em Sociologia do ciclo de vida}

\begin{tabular}{lcc}
\hline & $\begin{array}{c}\text { Análise do histórico de } \\
\text { eventos }\end{array}$ & Análise de sequências \\
\hline Conceito teórico & Transição/duração & Trajetória \\
\hline Objetivo analítico & $\begin{array}{c}\text { Probabilidades de } \\
\text { transição/duração }\end{array}$ & $\begin{array}{c}\text { Padrões temporais de } \\
\text { equivalência das sequências }\end{array}$ \\
\hline $\begin{array}{c}\text { Tultura de modelagem } \\
\text { estocástica }\end{array}$ & Cultura de modelagem algorítmica \\
\hline $\begin{array}{l}\text { Suposições } \\
\text { os dadífica }\end{array}$ & $\begin{array}{c}\text { Gerados por processo } \\
\text { estocástico }\end{array}$ & Tratamento não-paramétrico \\
\hline
\end{tabular}

Fonte: adaptado de Aisenbrey e Fasang (2010, tabela 1).

Métodos de análise de sequências são aplicados em diversos ramos do conhecimento. De fato, uma aplicação bastante tradicional vem da genética, onde é preciso medir o grau de semelhança ou diferença entre literalmente bilhões de sequências possíveis. Estes métodos têm sido adaptados para as ciências sociais, para estudar problemas de pesquisa relacionados a basicamente quatro campos de estudo (BRZINSKY-FAY; KOHLER, 2010, p. 359): (i) análises de carreiras ou biografias de empregos; (ii) histórias familiares; (iii) transição da escola para o trabalho; e (iv) estudos de ciclo de vida. Há outras aplicações interessantes, ainda que isoladas, no sentido que não conseguiram induzir um conjunto de artigos: por exemplo, o estudo de Stovel (2001) sobre o padrão de linchamentos de negros no sul dos EUA entre 1882 e 1930; o de Stovel e Bolan (2004) sobre mobilidade residencial; o de Shoval e Isaacson (2007) sobre o padrão de visitação 
(tempo/local) de 40 turistas na cidade de Acre (Akko, Israel); o de Lesnard e Kan (2011), que tipificou cinco tipos de jornada diária e sete de jornada semanal de trabalho no Reino Unido; ou mesmo o tradicional artigo de Abbott e Forrest (1986) sobre sequência de eventos em processos de reformas políticas ou revoluções.

Abbott e Forrest (1986) e, notadamente, Abbott e Hrycak (1990) em seu célebre artigo sobre padrões de carreira de músicos alemães no século XVIII (citado mais de 200 vezes tanto nas bases Scopus quanto Web of Science), sugeriram a técnica de Optimal Matching Analysis (OMA) para a análise de sequências. Posteriormente, surgiram outros algoritmos para comparação de sequências, mas o OMA é, de longe, o mais popular.

Todo estudo de sequências a partir da abordagem de máxima semelhança enfrenta um problema fundamental: a existência de um número muito grande de combinações possíveis. No problema de pesquisa proposto nesta tese, os jovens engenheiros em 2003 exercem, entre 2003-2012, 504 ocupações diferentes. Como a ordem importa, isso significa 3,6*10 ${ }^{25}$ trajetórias possíveis. ${ }^{5}$ Mesmo com a agregação das ocupações CBOs em 8 possibilidades (apresentada a seguir), são $8^{9}=134.217 .728$ possibilidades. $^{6}$ Considerar todas as possibilidades é impraticável.

No entanto, o Optimal Matching Analysis parte de uma noção de distância entre sequências, compreendida, em sua maneira mais simples, como o número de mudanças necessárias para transformar uma sequência em outra. Quanto menor este "custo", mais semelhantes são estas sequências. As operações permitidas para transformar uma sequência em outra são a substituição, a inserção e eliminação ((indel operations, ou operações indel) de um determinado estado.

Um exemplo ilustrará uma aplicação da técnica. Por simplicidade, suponha que todas as sequências sejam completas e que só sejam necessárias substituições entre os estados (portanto, não há operações indel). A Tabela 2 a seguir traz 5 sequências de ocupações retiradas aleatoriamente da base de dados aqui utilizada (as opções de codificação são descritas no capítulo 3).

${ }^{5}$ Em 2003, como todos eram engenheiros típicos, são apenas 17 possibilidades. Nos anos seguintes, 504. Então, $17 * 504^{9}=3,6 * 10^{25}$.

${ }^{6}$ Em 2003, todos eram engenheiros típicos. 
Tabela 2 - Exemplo de trajetórias ocupacionais

\begin{tabular}{|c|c|c|c|c|c|c|c|c|c|c|}
\hline id & 2003 & 2004 & 2005 & 2006 & 2007 & 2008 & 2009 & 2010 & 2011 & 2012 \\
\hline 1 & $\begin{array}{l}\text { Engo }^{\circ} \\
\text { típico }\end{array}$ & $\begin{array}{l}\text { Engo } \\
\text { típico }\end{array}$ & $\begin{array}{l}\text { Engo } \\
\text { típico }\end{array}$ & $\begin{array}{l}\text { Engo } \\
\text { típico }\end{array}$ & $\begin{array}{l}\text { Engo } \\
\text { típico }\end{array}$ & $\begin{array}{l}\text { Engo } \\
\text { típico }\end{array}$ & $\begin{array}{l}\text { Engo } \\
\text { típico }\end{array}$ & $\begin{array}{l}\text { Engo } \\
\text { típico }\end{array}$ & $\begin{array}{l}\text { Engo } \\
\text { típico }\end{array}$ & $\begin{array}{l}\text { Engo } \\
\text { típico }\end{array}$ \\
\hline 54 & $\begin{array}{l}\text { Engo } \\
\text { típico }\end{array}$ & $\begin{array}{l}\text { N-eng }{ }^{\circ}: \\
\text { prof. }\end{array}$ & $\begin{array}{l}\mathrm{N} \text {-engo: } \\
\text { prof. }\end{array}$ & $\begin{array}{l}\text { N-engo: } \\
\text { técnico }\end{array}$ & $\begin{array}{l}\text { Eng }{ }^{0} \\
\text { típico } \\
\end{array}$ & $\begin{array}{l}\text { Engo } \\
\text { típico } \\
\end{array}$ & $\begin{array}{l}\text { Engo: } \\
\text { técnico }\end{array}$ & $\begin{array}{l}\text { Eng } \\
\text { típico } \\
\end{array}$ & $\begin{array}{l}\text { Engo } \\
\text { típico }\end{array}$ & $\begin{array}{l}\text { Engo } \\
\text { típico }\end{array}$ \\
\hline 5307 & $\begin{array}{l}\text { Engo } \\
\text { típico }\end{array}$ & $\begin{array}{l}\text { Engo } \\
\text { típico }\end{array}$ & $\begin{array}{l}\text { Engo } \\
\text { típico }\end{array}$ & $\begin{array}{l}\text { N-engo: } \\
\text { técnico }\end{array}$ & $\begin{array}{l}\text { N-engo: } \\
\text { técnico }\end{array}$ & $\begin{array}{l}\text { N-engo: } \\
\text { técnico }\end{array}$ & $\begin{array}{l}\text { N-engo: } \\
\text { técnico }\end{array}$ & $\begin{array}{l}\text { Engo: } \\
\text { técnico }\end{array}$ & $\begin{array}{l}\text { Engo: } \\
\text { técnico }\end{array}$ & $\begin{array}{l}\text { Engo: } \\
\text { técnico }\end{array}$ \\
\hline 6205 & $\begin{array}{l}\text { Engo }^{\circ} \\
\text { típico }\end{array}$ & $\begin{array}{l}\text { Engo: } \\
\text { gestor }\end{array}$ & $\begin{array}{l}\text { Engo: } \\
\text { gestor }\end{array}$ & $\begin{array}{l}\text { Engo:: } \\
\text { técnico }\end{array}$ & $\begin{array}{l}\text { Engo:: } \\
\text { técnico }\end{array}$ & $\begin{array}{l}\text { Engo:: } \\
\text { técnico }\end{array}$ & $\begin{array}{l}\text { Engo:: } \\
\text { técnico }\end{array}$ & $\begin{array}{l}\text { Engo:: } \\
\text { técnico }\end{array}$ & $\begin{array}{l}\text { Engo } \\
\text { típico }\end{array}$ & $\begin{array}{l}\text { Engo } \\
\text { típico }\end{array}$ \\
\hline 9010 & $\begin{array}{l}\text { Engo } \\
\text { típico }\end{array}$ & $\begin{array}{l}\text { Engo } \\
\text { típico }\end{array}$ & $\begin{array}{l}\text { Engo } \\
\text { típico }\end{array}$ & $\begin{array}{l}\text { Engo } \\
\text { típico }\end{array}$ & $\begin{array}{l}\text { Engo } \\
\text { típico }\end{array}$ & $\begin{array}{l}\text { Engo } \\
\text { típico }\end{array}$ & $\begin{array}{l}\text { Engo } \\
\text { típico }\end{array}$ & $\begin{array}{l}\text { Engo: } \\
\text { gestor }\end{array}$ & $\begin{array}{l}\text { Engo: } \\
\text { gestor }\end{array}$ & $\begin{array}{l}\text { Engo: } \\
\text { gestor }\end{array}$ \\
\hline
\end{tabular}

Fonte: Elaboração própria a partir da Rais.

O primeiro passo é calcular o número mínimo de mudanças necessárias para transformar uma sequência em outra, atribuindo-se ou não pesos diferentes às diferentes mudanças de estado envolvidas. Ainda por simplicidade, os custos de transição dos estados são arbitrados como iguais a 1. Assim, há uma matriz quadrada e simétrica que representa os custos (distância) de transformar as sequências nas outras, representada na Tabela 3. Esta tabela indica que transformar a sequência 1 na 54 envolve 4 mudanças, transformar a 1 na 5037 envolve 7 mudanças, e assim por diante. ${ }^{7} \mathrm{O}$ máximo de mudanças entre as sequências é 9 (entre as sequências 6205 e 9010), que pode ser usado para uma normalização. De todo modo, o algoritmo de cluster é indiferente à matriz ser normalizada ou não. Naturalmente, a diagonal principal da matriz indica que o custo de transformar uma sequência nela mesma é zero.

\section{Tabela 3 - Matriz de distância entre as sequências do exemplo (não- normalizada e normalizada)}

\begin{tabular}{r|c|c|c|c|c}
\hline ID & 1 & 54 & 5307 & 6205 & 9010 \\
\hline 1 & 0 & & & & \\
\hline 54 & 4 & 0 & & & \\
\hline 5307 & 7 & 8 & 0 & & \\
\hline 6205 & 7 & 6 & 8 & 0 & \\
\hline 9010 & 3 & 7 & 7 & 9 & 0 \\
\hline
\end{tabular}

\begin{tabular}{r|c|c|c|c|c}
\hline \multicolumn{1}{|c|}{ ID } & 1 & 65 & 5307 & 6205 & 9010 \\
\hline 1 & 0 & & & & \\
\hline 65 & 0,44 & 0 & & & \\
\hline 5307 & 0,78 & 0,89 & 0 & & \\
\hline
\end{tabular}

${ }^{7}$ É possível haver mais de uma maneira de se alinhar sequências. Para a aplicação da técnica, o que importa é o número mínimo de operações, ou o menor custo possível de se transformar uma sequência em outra. 


\begin{tabular}{l|c|c|c|c|c}
6205 & 0,78 & 0,67 & 0,89 & 0 & \\
\hline 9010 & 0,33 & 0,78 & 0,78 & 1,00 & 0 \\
\hline
\end{tabular}

Fonte: Elaboração própria a partir da Rais.

O próximo passo do OMA é, a partir dessa matriz de distâncias, proceder a uma análise de agrupamento para a identificação de grupos de sequências semelhantes. Geralmente, isto é feito a partir de técnicas de cluster ou análise de correspondência.

Há diversos aspectos técnicos envolvidos na aplicação do OMA. Há, inclusive, algoritmos alternativos ao OMA para comparação de sequências, conforme mencionado. Estes aspectos serão discutidos adiante. Porém, antes, a subseção a seguir traz uma análise bibliométrica a respeito dos artigos que empregaram (ou criticaram) o OMA, em diversos campos de estudo.

\subsection{Análise bibliométrica do Optimal Matching Analysis}

O OMA tem tido aceitação crescente na literatura, tendo sido identificados 83 artigos indexados na base de dados Web of Science a partir da combinação das palavras Optimal Matching Analysis e career $^{8}$, a grande maioria datando de 2000 em diante. É este conjunto de artigos que embasará a análise bibliométrica desta subseção, que tem por objetivo auxiliar na identificação dos artigos mais relevantes para esta literatura, os principais campos de estudo e as questões metodológicas mais importantes. No entanto, vale ressaltar que a seleção dos artigos revisados e discutidos não é totalmente determinada por estes critérios, e o conhecido método "bola-de-neve" também foi empregado na seleção dos artigos discutidos nesta e na próxima seção.

Os indicadores bibliométricos foram gerados com o auxílio da ferramenta HistCite $^{\mathrm{TM}}$, desenvolvida pelo Prof. Eugene Garfield, da Universidade da Pennsylvania, e compatível com o Web of Science. ${ }^{9}$

Os 83 artigos indexados envolvem 152 autores e 56 periódicos desde o artigo seminal de Abbott e Forrest (1986), e cobrem o período de 1986 a 2015. Trata-se de literatura recente, considerando que há dois hiatos - um entre 1986 e 1990 e outro entre 1990 e 1995.

\footnotetext{
8 Buscas realizadas em 29/04/2015, sem aspas e na aba "tópicos".
}

9 O leitor interessado pode conhecer e baixar a ferramenta em http://interest.science.thomsonreuters.com/forms/HistCite/ . A ferramenta é gratuita, mas ela requer a tabulação dos dados de entrada em um formato provido mais facilmente pelo portal Web of Science. Há outras opções de softwares de análise bibliométrica, tais como descritos e comparados no Bibliometrics in Translational Research Project, da universidade de Cornell. Para uma matriz comparativa entre algumas opções disponíveis, consulte https://confluence.cornell.edu/display/TLC/Decision+Matrix+of+Bibliometric+Tools. 
O Gráfico 2 a seguir mostra a produção e o impacto de citações dos artigos desta literatura. O TLCS é o Total Local Citation Score, um índice total de citações entre os 83 artigos sob análise, enquanto o TGCS é o Total Global Citation Score e mede as citações destes artigos em toda a base Web of Science. De toda forma, a correlação entre os índices é bem alta (76\%). Dentre os 20 artigos mais citados por esta coleção, 10 pertencem a ela mesma.

Primeiramente, o Gráfico 2 mostra que o número de artigos publicados desta literatura cresce ao longo dos anos, principalmente a partir de 2005. Em segundo lugar, há maior relevância em termos de citações dos artigos mais antigos. Esta relevância se deve a dois fatores. O primeiro se deve ao próprio critério de citações, que privilegia os artigos mais antigos. Num exemplo extremo, um artigo muito relevante publicado no ano de 2015 não teria o mesmo impacto bibliométrico se o mesmo artigo fosse escrito em 1990, simplesmente porque não daria tempo deste artigo ser lido e citado em revistas acadêmicas. $\mathrm{O}$ segundo fator é que estes artigos mais antigos têm cunho não só empírico como metodológico, como será demonstrado no mapa historiográfico da literatura. A relevância em termos de TGCS dos anos de 1999, 2003 e 2007 também pode ser explicada a partir deste mapa historiográfico.

\section{Gráfico 2 - Produção e impacto de citações dos artigos que utilizam Optimal Matching Analyis, 1990-2015}

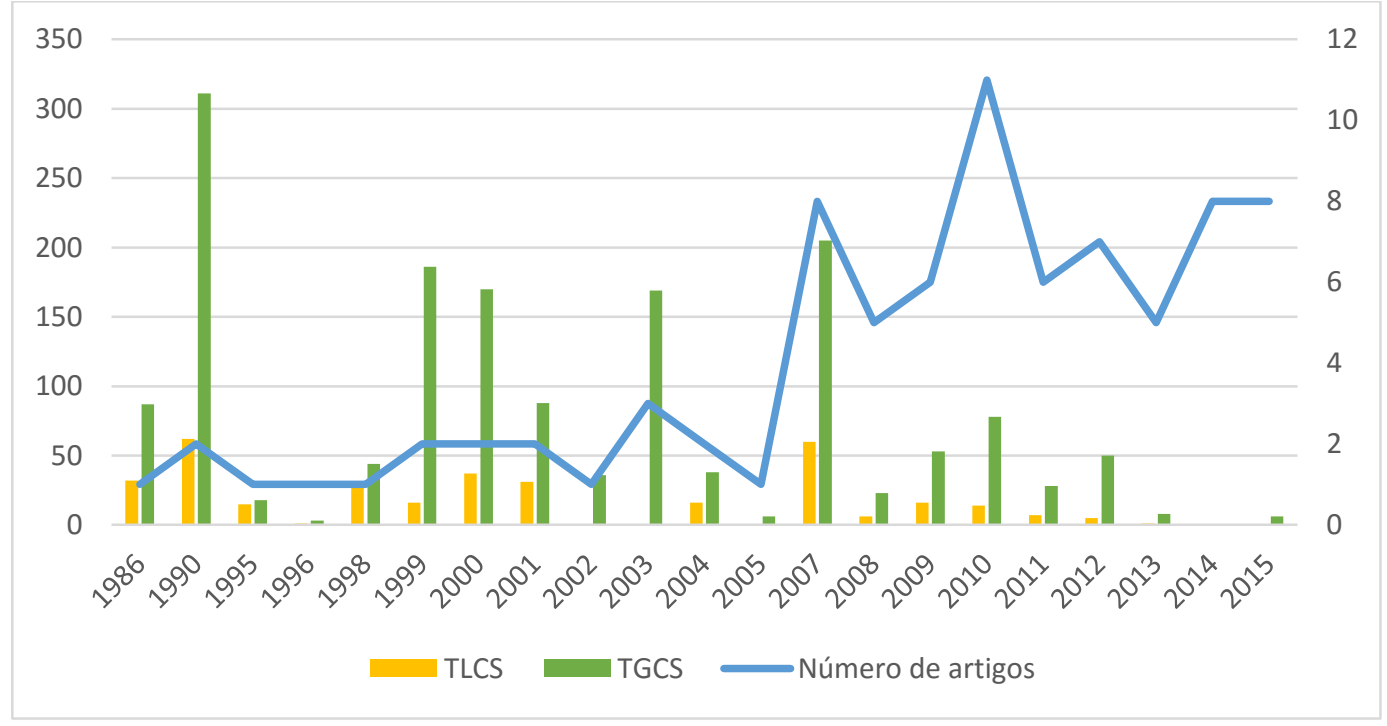

Fonte: Elaboração própria a partir do Web of Science e HistCite.

O mapa historiográfico (Gráfico 3) mostra os 20 artigos desta literatura mais citados na base Web of Science segundo o critério TGCS. No eixo y estão os anos, o tamanho dos nós é proporcional ao TGCS e as setas indicam a direção das citações.

Percebe-se que os artigos publicados até 1995 tendem a ser bastante influentes na literatura subsequente. Combinando teoria e prática, os já referidos artigos de Abbott e Forrest (1986) (TLCS=32, TLGS=87), Abbott e Hrycak (1990) (TLCS=56, TLGS=221), e os de Abbott (1990) (TLCS=6, TLGS=90) e Chan (1995) (TLCS=15, TLGS=18) 
discutiram aspectos metodológicos importantes sobre o OMA, suas diferenças com respeito à tradição da análise do histórico de eventos e ilustraram seus pontos com exemplos de aplicação.

O artigo mais relevante em termos bibliométricos - Abbott e Hrycak (1990) - discorre sobre trajetórias profissionais de músicos germânicos no século XVIII. Foram analisadas 595 carreiras de músicos germânicos entre 1650 e 1810. Os estados foram combinados de forma a refletir a ocupação (músico, kantor, regente etc.) e o empregador (corte, igreja ou município). Ao todo, de 135 trajetórias possíveis, os autores identificaram 20 padrões de carreiras diferentes. Basicamente, estes padrões podem ser agrupados em três: carreiras de organistas (independentemente do empregador), carreiras na corte e carreiras na igreja. Outro conjunto de resultados se refere ao time-wrapping (esta técnica será discutida na próxima seção). Os resultados são bastante semelhantes. Adicionalmente, este artigo tem a peculiaridade de testar a validação da classificação a partir de 3 amostras de 94 sequências cada, e os resultados são também bastante semelhantes. Este artigo seminal discute aspectos metodológicos como vantagens do OMA sobre análise do histórico de eventos, definição de custos, validação etc.

Em 1998, destaca-se o artigo de Halpin e Chan (1998) (TLCS=30, TLGS=44), com impacto relevante porém localizado na própria literatura de OMA. Este artigo analisa a transição da escola para o trabalho - um tópico tratado por vários outros artigos dessa literatura - a partir da análise de mais de 1.000 sequências em cada um dos painéis compostos pelos Irish Mobility Study e pelo British Household Panel Study, respectivamente. Em verdade, estes autores estavam menos interessados em documentar os padrões do que em investigar o poder do OMA e seus aspectos computacionais em painéis maiores. Sua conclusão é de que o OMA é realmente poderoso em encontrar padrões, mas a análise precisa ser complementada por técnicas mais tradicionais - com efeito, estes autores relatam ter encontrado importantes efeitos de período e efeitos de coorte.

O artigo de Blair-Loy (1999) sobre carreiras de mulheres no segmento de finanças teve bastante impacto geral, mas não repercutiu muito na própria literatura do OMA. Isto explica a discrepância observada em 1999 entre o TLCS e o TGCS. Trata-se de um artigo de amostra reduzida, pois a autora combina análise de sequências com entrevistas com estas executivas. O mais interessante deste estudo foi a identificação de um efeito-coorte bastante significativo nas trajetórias, ao dividir as profissionais em três coortes: aquelas que começaram suas carreiras antes de 1969, entre 1970 e 1973 e após 1974. A autora credita estas diferenças à adoção, nos anos 1970, de políticas afirmativas para as mulheres em grandes empresas. Este artigo propõe uma codificação bidimensional, que leva em conta a ocupação e o tipo de empregador.

O ano de 2000 marcou a literatura do OMA devido à edição da Sociological Methods \& Research v. 29, n. 1, que trouxe a controvérsia Abbott e Tsay (2000) vs. Wu (2000) e Levine (2000). Esta controvérsia tratou tanto de aspectos específicos quanto d a conveniência ou não da análise de sequências como método de análise em ciências sociais. Ainda que Abbott e Tsay (2000) tenham conseguido responder parcialmente a 
algumas das críticas, o fato é que as contundentes críticas de Wu (2000) e Levine (2000) estimularam importantes desenvolvimentos metodológicos posteriores, sumarizados em uma edição especial do mesmo periódico: a Sociological Methods \& Research v. 38, n. 3: New Developments in Sequence Analysis, de 2010.

A partir de 2000, a literatura de maior impacto pareceu se desenvolver em dois caminhos: o estudo da transição da escola para o trabalho, seguindo a tradição de Halpin e Chan (1998), e o estudo da combinação entre família e trabalho. Ambos os aspectos são bastante caros à sociologia do ciclo de vida. Exemplos do primeiro tipo de estudo são Scherer (2001) e McVicar e Anyadike-Danes (2002), e exemplos de artigos que estudam a combinação entre família e trabalho são Aassve, Billari e Piccarreta, (2007), Piccarreta e Billari (2007) e Pollock (2007).

Além destes 3 últimos, 2007 foi um ano em que houve a publicação de mais dois artigos bibliometricamente relevantes, tanto para a literatura do OMA quanto em geral: Kogan (2007) sobre as carreiras de imigrantes na parte ocidental da Alemanha e o já referido artigo de Shoval e Isaacson (2007) sobre padrões de visitação turística. O ano de 2003, a exemplo de 1999, é um ano atípico, com a publicação de um artigo de grande repercussão geral mas pouca reverberação dentro da literatura específica (no caso, o artigo de Zuckerman et al. (2003) sobre a questão da identidade no mercado de trabalho cinematográfico).

Considerando o impacto bibliométrico dos artigos, o periódico mais importante é o American Journal of Sociology (TLCS=72, TGCS=552), seguido pelo Sociological Methods and Research (TLCS=79, TGCS=246). No entanto, há de se considerar que o American Journal of Sociology é o periódico do artigo de Abbott e Hrycak (1990), e se este outlier for desconsiderado, o periódico Sociological Methods and Research passa a ser o mais importante para a literatura de análise de sequências. Cabe lembrar que este periódico abrigou o debate entre Abbott e Tsay (2000) vs. Wu (2000) e Levine (2000) e sumarizou os principais avanços da chamada "segunda onda" da análise de sequências em um número especial de 2010. 


\section{Gráfico 3 - Mapa historiográfico da produção científica em OMA, 1986-2008 (20 artigos mais citados da área)}

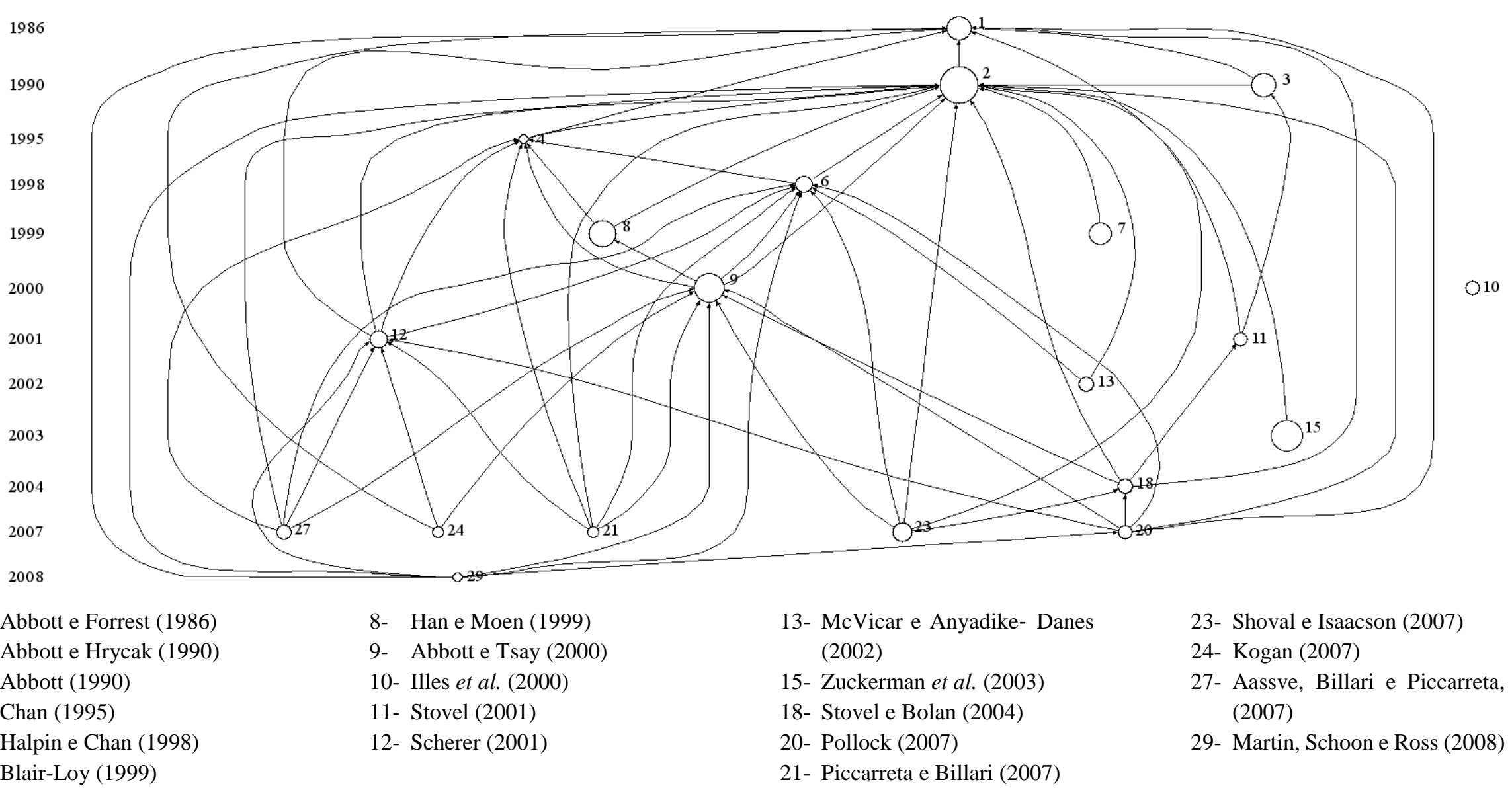

Fonte: Elaboração própria a partir do Web of Science e do software HistCite ${ }^{T M}$. 
A literatura específica sobre carreiras ou trajetórias profissionais não é tão forte, em termos bibliométricos, quanto a literatura sobre transição da escola para o trabalho ou sobre família e trabalho. ${ }^{10}$ Artigos específicos sobre carreiras começam a aparecer no mapa historiográfico quando o corte passa a ser os 50 artigos mais relevantes; mas neste caso a visualização do mapa com este corte é confusa.

Especificamente sobre carreiras, o autor com mais artigos é Torsten Biemann, atualmente na Universidade de Manheim. Com outros colegas, ele é coautor de 3 artigos entre os 50 mais citados nesta literatura.

Biemann, Zacher e Feldman, (2012) analisam trajetórias profissionais com base em um painel de 1.259 trabalhadores alemães com 20 anos de duração. A partir da codificação dos estados como trabalho em tempo integral, meio-período, desemprego ou conta-própria, estes autores identificam seis padrões de carreira. O mais interessante é que os autores utilizaram preditores sociodemográficos como gênero, estado civil, número de filhos, educação e início da carreira no setor público em um modelo probabilístico multivariado. Com base neste modelo, os autores concluem que os homens, os indivíduos mais educados e mais velhos são mais propensos às trajetórias de trabalho em tempo integral, enquanto mulheres, especialmente com mais filhos e casadas, tendem a não seguir este padrão.

Biemann e Wolf (2009) estudam as trajetórias profissionais de 166 membros de alta administração de 42 empresas originárias de 5 países. Os autores codificam cada estado como uma combinação simples de "sempre na atual empresa" ou não e "no país de origem da empresa" ou não, resultando em 4 estados. Utilizando OMA combinado à análise de cluster, eles derivam seis padrões (gestor com experiência média vindo de outra empresa, fast tracker, o gestor internacional, o gestor com experiência média vindo da própria empresa, o gestor experiente vindo de outra empresa e o experiente vindo de dentro). Os autores correlacionam estes padrões com outras variáveis, e testam eventuais diferenças entre os países. Por exemplo, a experiência pareceu ser mais relevante para promoções no Japão do que em outros países.

Por seu turno, a inovação metodológica de Biemann, Fasang e Grunow (2011) é utilizar uma medida de complexidade das carreiras, baseada em Elzinga (2010), a fim de verificar se a globalização e o crescimento setorial afetam esta medida de complexidade. Esta medida de complexidade se refere não à similaridade/diferença entre estados, mas ao número de estados, ordem e duração dentro de uma mesma sequência, para um determinado indivíduo. Recorrendo a uma (grosseira) analogia, a medida de complexidade está para as sequências assim como as medidas de dispersão (desviopadrão, desvio mediano) estão para as medidas de tendência central (média, mediana etc). Estas medidas de complexidade serão debatidas na próxima seção.

\footnotetext{
10 Naturalmente, exceção feita a Abbott e Hrycak (1990), sobre as carreiras dos músicos germânicos do século XVIII.
} 
De todo modo, utilizando uma medida de globalização (abertura econômica) como a razão entre importações mais exportações e o consumo aparente (produção + importações - exportações) de um determinado setor, os autores concluem não haver nenhuma evidencia entre o nível de globalização e complexidade das carreiras. Por seu turno, parece haver uma relação em forma de $U$ entre crescimento da indústria e da complexidade carreira - setores que crescem pouco ou que crescem muito rapidamente tendem a apresentar carreiras mais complexas.

Por fim, dentre os artigos pesquisados, o que mais se assemelha à proposição desta tese é o artigo de Joseph, Boh e Slaughter (2012) sobre carreiras em tecnologia da informação. A amostra é composta por 500 indivíduos que tiveram alguma ocupação de TI no espaço de 1979 a 2006 de acordo com a National Longitudinal Survey of Youth de 1979 dos EUA. O estudo é essencialmente descritivo dos padrões e seus resultados. Utilizando uma codificação de 9 estados possíveis, os autores identificam 3 padrões de carreira: uma típica de TI, com mais tempo em ocupações típicas, outra de "primeira linha" em ocupações fora de TI e outra no mercado de trabalho secundário (técnicos e auxiliares administrativos, por exemplo). Em média, as carreiras típicas de TI pagam um pouco mais do que as dos profissionais de primeira linha, além de apresentarem menor dispersão. Sem surpresas, os dois primeiros padrões pagam melhores salários do que as carreiras no mercado de trabalho secundário. Ao decomporem a mobilidade entre de ocupação e de empregador, os autores observam que praticamente metade da mobilidade é de ocupação, $25 \%$ de empregador e outros $25 \%$ de ambos.

\subsection{Críticas à análise de sequências}

Como já mencionado, as críticas mais contundentes à abordagem de carreiras como sequências estão no debate do periódico Sociological Methods \& Research v. 29, n. 1, de 2000, e são de autoria de Lawrence Wu (2000), em comentário ao artigo de Abbott e Tsay (2000) na mesma edição. Em resumo, as principais críticas de Wu (2000) são:

- Os resultados práticos desta abordagem não são tão promissores quanto sustentado por Abbott e Tsay (2000). Àquela época, Wu (2000) tinha identificado poucos artigos publicados em comparação a outras metodologias mais consagradas;

- As técnicas de alinhamento de sequências implicam em muitas escolhas arbitrárias a serem tomadas: definição dos estados, períodos, custos de transição entre estados e corte dos agrupamentos. Segundo Wu (2000), a simplicidade do algoritmo vem às custas de muitas decisões que precisam ser tomadas ex-ante, e não há garantia de que os resultados não sejam crucialmente sensíveis a estas decisões;

- O método impõe simetria de custos, isto é, sair do estado A para o estado B necessariamente custa o mesmo de sair do B para o A. Isto pode ser inadequado em ciências sociais. Como exemplo, Wu (2000) argumenta que 
transição do emprego (estado A) para o desemprego (estado B) pode não ser equivalente à transição inversa;

- Com respeito à temporalidade, Wu (2000) critica a linearidade. Conforme comentado anteriormente, alguns anos - como o de formatura, de casamento, do nascimento de um filho - são mais especiais que outros.

Ainda, na mesma edição, Levine (2000) critica as decisões a respeito da codificação. Para este autor, as taxonomias em ciências sociais são difusas (fuzzy), e esta difusão é mal adaptada a codificações rígidas como as exigidas pela análise de sequências. ${ }^{11}$

King (2011), por sua vez, expressa seu descontentamento com respeito: (i) ao personalismo com respeito a Andrew Abbott nas diversas aplicações, (ii) ao fato de que muitos analistas tomam como certas as bases epistemológicas da análise de sequências, e (iii) à hipótese de que a disseminação do uso destas técnicas se deveu mais à disponibilidade de suas rotinas em pacotes estatísticos do que, necessariamente, à relevância dos resultados de pesquisa e à solidez epistemológica da abordagem.

Aisenbrey e Fasang (2010) sumarizam as críticas à análise de sequências em quatro grandes grupos, discutindo em seu artigo de revisão da "segunda onda" em análise de sequências as respostas metodológicas a estas críticas. Os grupos de críticas são:

- A fraca ligação entre teoria e os custos de substituição: por exemplo, como dizer que sair de uma ocupação como músico para professor universitário custa $x$ vezes uma transição de economista para engenheiro?;

- Fraca validação ex-post dos grupos formados. Boa parte dos críticos consideram que a interpretabilidade analítica dos resultados e a validade de construtos não são critérios suficientes de validação;

- Há problemas metodológicos com as sequências incompletas ou de diferentes durações. Operações de inserção e eliminação de estados a fim de comparar uma sequência à outra nas aplicações do OMA podem não fazer nenhum sentido em ciências sociais;

- Temporalidade e ordem das sequências. Em suas aplicações originais, os custos de transformação entre estados eram os mesmos em cada estágio da sequência e, mais ainda, a técnica impunha simetria entre as trocas de estados. Novamente, isto pode não fazer nenhum sentido em ciências sociais.

A seção a seguir discute as questões metodológicas acerca da análise de sequências e o estado da arte das soluções destas questões.

1 Entretanto, como argumenta Elzinga (2003), esta crítica não se aplica a qualquer campo científico? 


\subsection{Questões metodológicas em análise de sequências}

\subsubsection{Codificação}

A definição dos estados possíveis é o primeiro passo da análise OMA. Abbott e Tsay (2000) apontam para o caráter essencialmente unilinear do OMA, mas alguns autores conseguiram superar essa limitação. Por exemplo, Abbott e Hrycak (1990) e Blair-Loy (1999), cada qual ao seu modo, codificaram os estados possíveis combinando as ocupações e o tipo de organização. Em resumo, é perfeitamente possível incorporar novas dimensões na codificação, ainda que isto leve (literalmente) à multiplicação de estados possíveis.

Entretanto, cabe lembrar que a codificação dos estados relevantes envolve um tradeoff fundamental entre detalhamento e tratabilidade analítica, e não há um critério definitivo para balizar esta decisão. É sensível a queda no número de estados sob análise ao longo dos artigos: comparando extremos, o artigo de Abbott e Hrycak (1990) tinha 135 estados possíveis, enquanto o artigo de Biemann e Wolf (2009) parte de apenas quatro.

\subsubsection{Temporalidade}

O tratamento do tempo nas análises de sequências merece uma reflexão especial, principalmente no que tange a inversões de ordem das sequências, inserções e eliminações de estados.

Em primeiro lugar, há a crítica que o tempo é tratado de forma linear - a passagem de dois períodos equivale à soma de um período mais outro período. Alguns críticos apontam que isto pode não ser adequado em ciências sociais. Por exemplo, o ano de uma formatura, de um casamento, do nascimento de um filho não é equivalente, sob a perspectiva das teorias de ciclo de vida, a mais um ano após a aposentadoria. No entanto, esta crítica é tratável analiticamente no arcabouço da análise de sequências.

Uma alternativa é codificar transições, tal qual em Biemann (2011). Utilizando o exemplo das trajetórias ocupacionais dos engenheiros, uma sequência na qual o engenheiro jovem permanece como engenheiro típico durante todo o período seria codificada como um estado, enquanto uma sequência na qual o engenheiro jovem faz uma transição para outra ocupação depois de quatro anos seria codificada como dois estados. Adicionalmente, a sequência do segundo indivíduo (que faz a transição para outra ocupação após quatro anos) seria codificada da mesma maneira que a de um terceiro indivíduo que eventualmente faça esta transição depois de seis anos, por exemplo. O que importa, neste tipo de abordagem, são as transições.

Alternativamente, Abbott e Hrycak (1990) propuseram codificar as proporções em cada estado ao invés do número de períodos em que cada indivíduo permanece em cada 
estado (time-wrapping). Embora esta abordagem não tenha se transformado em um padrão na literatura, os autores propuseram este método para tratar sequências de durações diferentes. Novamente utilizando o problema de pesquisa tratado nesta tese, uma sequência de dois anos de duração em que um engenheiro passasse um ano como engenheiro típico e depois virasse gerente de recursos humanos seria equivalente a uma sequência de oito anos em que o engenheiro passasse quatro como engenheiro típico e depois quatro anos como gerente de $\mathrm{RH}$. O que importaria, segundo esta abordagem, seria o fato que ambos teriam passado $50 \%$ de suas sequências como engenheiros típicos e os outros $50 \%$ como gerentes de $\mathrm{RH}$.

No que tange à ordem das sequências, de fato o OMA, em sua formulação original, propõe uma simetria que pode ser inaceitável em determinados estudos. Isto, combinado com a crítica à arbitrariedade na atribuição dos custos de transição entre os estados e à questão das inserções e eliminações, deu origem a outras abordagens algorítmicas discutidas adiante.

As operações indel são uma questão de importante debate. Para ilustração, recorrese a uma versão modificada da Tabela 2, exposta na Tabela 4. Nesta versão, os indivíduos 70 e 2151 passam alguns períodos fora do mercado de trabalho, suponha que por desemprego. Como alinhar as sequências destes indivíduos com os demais?

A única diferença entre as trajetórias dos indivíduos 1 e 70 é o ano de 2007 - o indivíduo 1 trabalha todos os anos, e o 70 passa o ano de 2007 desempregado. Lançando mão das opções de inserção e eliminação, pode-se alinhar as duas sequências de duas maneiras: (i) elimina-se o estado referente ao ano de 2007 na sequência do indivíduo 1; ou (ii) insere-se o estado "engenheiro típico" em 2007 para o indivíduo 70.

\section{Tabela 4 - Exemplo de trajetórias ocupacionais (com indivíduos fora do mercado de trabalho por alguns períodos)}

\begin{tabular}{|c|c|c|c|c|c|c|c|c|c|c|}
\hline id & 2003 & 2004 & 2005 & 2006 & 2007 & 2008 & 2009 & 2010 & 2011 & 2012 \\
\hline 1 & $\begin{array}{l}\text { Engo } \\
\text { típico }\end{array}$ & $\begin{array}{l}\text { Engo } \\
\text { típico }\end{array}$ & $\begin{array}{l}\text { Engo } \\
\text { típico }\end{array}$ & $\begin{array}{l}\text { Engo } \\
\text { típico }\end{array}$ & $\begin{array}{l}\text { Engo } \\
\text { típico }\end{array}$ & $\begin{array}{l}\text { Eng }^{\circ} \\
\text { típico }\end{array}$ & $\begin{array}{l}\text { Engo } \\
\text { típico }\end{array}$ & $\begin{array}{l}\text { Engo } \\
\text { típico }\end{array}$ & $\begin{array}{l}\text { Engo } \\
\text { típico }\end{array}$ & $\begin{array}{l}\text { Engo } \\
\text { típico }\end{array}$ \\
\hline 70 & $\begin{array}{l}\text { Engo } \\
\text { típico }\end{array}$ & $\begin{array}{l}\text { Eng }^{\circ} \\
\text { típico }\end{array}$ & $\begin{array}{l}\text { Eng }^{\circ} \\
\text { típico }\end{array}$ & $\begin{array}{l}\text { Eng }^{\circ} \\
\text { típico }\end{array}$ & $\begin{array}{l}\text { Fora do } \\
\text { mercado }\end{array}$ & $\begin{array}{l}\text { Engo }^{\circ} \\
\text { típico }\end{array}$ & $\begin{array}{l}\text { Engo }^{\circ} \\
\text { típico }\end{array}$ & $\begin{array}{l}\text { Engo }^{\circ} \\
\text { típico }\end{array}$ & $\begin{array}{l}\text { Eng }^{\circ} \\
\text { típico }\end{array}$ & $\begin{array}{l}\text { Eng }^{\circ} \\
\text { típico }\end{array}$ \\
\hline 2151 & $\begin{array}{l}\text { Engo } \\
\text { típíco }\end{array}$ & $\begin{array}{l}\text { Fora do } \\
\text { mercado }\end{array}$ & $\begin{array}{l}\text { Fora do } \\
\text { mercado }\end{array}$ & $\begin{array}{l}\text { Fora do } \\
\text { mercado }\end{array}$ & $\begin{array}{l}\text { Fora do } \\
\text { mercado }\end{array}$ & $\begin{array}{l}\text { Fora do } \\
\text { mercado }\end{array}$ & $\begin{array}{l}\mathrm{N}- \\
\text { engo: } \\
\text { técnico }\end{array}$ & $\begin{array}{l}\text { Engo: } \\
\text { gestor }\end{array}$ & $\begin{array}{l}\text { Engo: } \\
\text { gestor }\end{array}$ & $\begin{array}{l}\text { Engo: } \\
\text { gestor }\end{array}$ \\
\hline 6205 & $\begin{array}{l}\text { Engo } \\
\text { típico }\end{array}$ & $\begin{array}{l}\text { Engo: } \\
\text { gestor }\end{array}$ & $\begin{array}{l}\text { Engo: } \\
\text { gestor }\end{array}$ & $\begin{array}{l}\text { Conta- } \\
\text { própria }\end{array}$ & $\begin{array}{l}\text { Engo-: } \\
\text { técnico }\end{array}$ & $\begin{array}{l}\text { Engo:: } \\
\text { técnico }\end{array}$ & $\begin{array}{l}\text { Engo:: } \\
\text { técnico }\end{array}$ & $\begin{array}{l}\text { Engo:: } \\
\text { técnico }\end{array}$ & $\begin{array}{l}\text { Eng }^{\circ} \\
\text { típico }\end{array}$ & $\begin{array}{l}\text { Eng }^{\circ} \\
\text { típico }\end{array}$ \\
\hline 9010 & $\begin{array}{l}\text { Engo } \\
\text { típico }\end{array}$ & $\begin{array}{l}\text { Engo } \\
\text { típico }\end{array}$ & $\begin{array}{l}\text { Engo } \\
\text { típico }\end{array}$ & $\begin{array}{l}\text { Eng }^{\circ} \\
\text { típico }\end{array}$ & $\begin{array}{l}\text { Engo } \\
\text { típico }\end{array}$ & $\begin{array}{l}\text { Eng }^{\circ} \\
\text { típico }\end{array}$ & $\begin{array}{l}\text { Eng }^{\circ} \\
\text { típico }\end{array}$ & $\begin{array}{l}\text { Engo: } \\
\text { gestor }\end{array}$ & $\begin{array}{l}\text { Engo: } \\
\text { gestor }\end{array}$ & $\begin{array}{l}\text { Engo: } \\
\text { gestor }\end{array}$ \\
\hline
\end{tabular}

Fonte: Elaboração própria a partir da Rais.

O problema é: quanto esta modificação vai “custar"? Ela custará o mesmo que as operações de substituição? Aliás, estas operações de inserção e deleção fazem sentido em sequências de eventos sociais? Como eles alteram a comparação de sequências de tamanhos diferentes? 
Em suas primeiras aplicações, estes custos eram calibrados da mesma forma dos custos de substituição. A substituição entre os estados, quando possível, sempre seria preferível a operações de inserção e deleção, pois eliminar um estado para reinseri-lo custaria o dobro do que a operação de substituição. Aliás, uma recomendação tradicional era estabelecer o custo indel em pelo menos a metade do custo máximo de transição entre os estados, o que evitaria que o algoritmo de alinhamento realizasse "pseudosubstituições" - justamente, eliminações seguidas de reinserções, por estas custarem mais "barato" que a substituição (HOLLISTER, 2009).

Entretanto, Abbott e Tsay (2000, p. 12) sugeriram que a regra da metade do custo, na verdade, levaria à nunca utilização das operações de inserção ou eliminação. ${ }^{12}$ De toda forma, Abbott e Tsay (2000) fizeram algumas simulações e sugerem a adoção dos custos indel em torno $10 \%$ do custo de substituição máximo, pois isto melhora o alinhamento de sequências e dá possibilita a identificação de regularidades interessantes.

O fato é que esta recomendação não é muito popular na literatura. A imensa maioria dos artigos prefere seguir a tradicional regra da metade do custo. As operações indel implicam em movimentos temporais ao longo das sequências, o que distorce o tempo (AISENBREY; FASANG, 2010, p. 126). Se o interesse analítico for sobre o tempo e a ordem dos eventos, então as operações indel devem ser utilizadas com parcimônia, pois elas dificultam o alinhamento de subsequências que podem ser de interesse de pesquisa.

Outra questão referente à temporalidade das sequências diz respeito à sua complexidade. Como sugerido na seção anterior, a complexidade é uma espécie de medida de dispersão das sequências. Alguns autores a medem a partir de medidas como entropia (GABADINHO et al., 2011) ou turbulência (ELZINGA, 2010). Ambos os conceitos consideram duas características das sequências: o número de estados e a duração nos mesmos.

A medida de entropia em Gabadinho et al. (2011) - em verdade, esta é uma versão da entropia de Shannon da teoria da informação - é expressa pela fórmula:

$$
h(x)=-\sum_{i=1}^{s} \pi_{i} \log \pi_{i}
$$

onde $s$ é o total de estados da sequência $x$ e $\pi$ é a proporção do tempo passado em cada estado. Assim, a entropia mínima $(h(x)=0)$ é atingida quando um indivíduo passa todo o tempo em um mesmo estado (pois $\pi=1$ e $\log (1)=0$ ), e sua máxima depende do número de estados, mas é atingida quando uma sequência contém todos os estados possíveis e se passa igual período em cada estado.

A medida de turbulência de Elzinga (2010) trabalha com a variância das durações em cada estado de uma determinada sequência. Em verdade, se indivíduo passar muito tempo em um estado e pouco tempo nos demais esta variância será alta - excetuando-se, claro, o caso extremo em que ele passa todo o tempo em apenas um estado, quando esta

${ }^{12} \mathrm{~A}$ afirmação é verdadeira quando as sequências são completas e de mesma duração, mas não parece ser verdade em todos os casos. Como nota Hollister (2009), às vezes operações de inserção ou eliminação, ainda que custosas, podem economizar operações de substituição em série. 
variância é zero. Inversamente, se um indivíduo passar período igual em todos os estados, esta variância será zero. A fim de capturar a ideia de que a complexidade da carreira aumenta à razão inversa da variância (no exemplo, o primeiro caso tem uma carreira mais "simples" que o segundo) e para lidar com os casos extremos, Elzinga (2010) propôs a seguinte medida de "variância relativa inversa":

$$
1 \leq T(x)=\frac{V_{\max }-V_{\min }+1}{V(x)-V_{\min }+1}
$$

E a complexidade ou turbulência é medida por

$$
C(x)=\log _{2}(\varnothing(x) \cdot T(x))
$$

onde $V(x)$ é a variância das durações das subsequências da observação $x, V_{\max } \mathrm{e} V_{\min }$ são os limites inferior e superior para $V(x)$, e $\phi(x)$ é o número de subsequências diferentes de $x$. Aqui aparece uma diferença fundamental entre a medida de entropia e de complexidade: a última é afetada por mudanças de ordem nas subsequências, pois $\phi(x)$ cresce, e a medida de entropia não, porque para esta medida o que interessa são os diferentes estados.

\subsubsection{Custos de substituição entre estados}

Além dos custos de inserção e eliminação, os custos de substituição têm sido objeto de intenso debate na literatura. Naturalmente, a medida de distância entre as sequências é fortemente influenciada pela maneira como se codifica o "custo" de transição entre os estados. Ainda que nas primeiras aplicações do OMA as substituições tinham o mesmo custo, isto não precisa ser a regra: por exemplo, pode-se arbitrar que uma transição de engenheiro típico para gestor em engenharia seja menos custosa do que uma transição deste engenheiro típico para um cargo de gestão fora da engenharia.

Vários críticos argumentam que estes custos são arbitrários, que apresentam pouca ligação com a teoria e que, por isso, as distâncias entre sequências carecem de sentido (LEVINE, 2000). Entretanto, a literatura evoluiu no sentido de explorar diferentes métodos de arbitragem para estes custos.

Às vezes, os estados das sequências trazem informação quantitativa que pode balizar a arbitragem de custos. Por exemplo, no estudo de Stovel (2001) sobre os padrões temporais de linchamentos no Sul dos EUA, o próprio número de linchamentos no condado em um dado período poderia representar os estados possíveis, e a diferença entre os números poderia representar os custos entre os estados.

Porém, a autora vai além e propõe uma interessante medida de "memória" nos estados possíveis, a partir de uma função de decaimento (decay function). Em sua análise sobre os padrões temporais de linchamentos no Sul dos EUA, um ano sem linchamentos em um condado após um ano com 5 linchamentos não é o mesmo do que um ano sem linchamentos seguinte a um ano também sem linchamentos. Matematicamente, o índice de linchamentos no ano $i$ é dado por 


$$
V_{i}=l_{i}+\sqrt{\frac{l_{j}}{j-i}}
$$

Onde $l_{i}$ é o número efetivo de linchamentos no ano $i, l_{j}$ é o número de linchamentos em um ano base $j$ e $j$ - $i$ é o tempo entre o ano e o ano base (max $j-i=3$ ). Os custos de transição são as diferenças entre os estados medidos por $V$, e não mais por $l$.

Entretanto, nem sempre a caracterização dos estados traz informação quantitativa. Nestes casos, a forma mais popular é utilizar as transições observadas entre os estados como parâmetro para arbitrar os custos. Esta é, inclusive a abordagem utilizada nesta tese. Matematicamente, o custo de transição do estado $i$ para o estado $j(i \neq j)$ é igual a:

$$
2-p(i \mid j)-p(j \mid i)
$$

Onde $p(i \mid j)$ é a taxa de transição entre os estados $i$ e $j$ na amostra.

A intuição por trás desta abordagem é que as transições observadas com mais frequência são menos custosas que as transições menos frequentes. Cabe notar, contudo, que trata-se de uma abordagem essencialmente estacionária, isto é, os custos são independentes de quando esta transição ocorre (KING, 2011, p. 182).

Uma forma de superar esta limitação e introduzir alguma dependência temporal em estados quantitativos foi proposta por Lesnard (2008), em seu estudo sobre jornadas de trabalho de casais em que ambos trabalham. Lesnard (2008) propôs usar a medida dinâmica de Hamming para calcular custos de transição que dependessem do tempo. Na pratica, esta aplicação da distância de Hamming implica em calcular matrizes de custos de substituição em cada ponto do tempo, baseado nas frequências de transição entre estados - ou seja, calcular os custos de acordo com a equação (4) em cada período do tempo.

Entretanto, há de se destacar duas importantes limitações desta aplicação. A primeira é que ela não utiliza operações de inserção e eliminação, e, mais ainda, a segunda é que as sequências precisam ter igual tamanho.

De todo modo, esta estratégia empírica pode ser aplicada em casos em que as transições entre estados possam ter diferentes significados sociais quando ocorrem em diferentes momentos do tempo. Em nosso exemplo, isso equivaleria a hipotetizar que a transição de engenheiro típico para gestor em engenharia em 3 anos teria significado diferente da mesma transição em 7 anos.

\footnotetext{
13 O leitor interessado no artigo de Stovel (2001) notará que a equação na página 875 está com $V_{j}$ ao invés de $V_{i}$, o que parece ser um erro de digitação.
} 


\subsubsection{Técnicas de não-alinhamento}

As técnicas de não-alinhamento, ao contrário do OMA, não utilizam operações de substituição, inserção e eliminação. Por consequência, inexistem questões relativas à especificação dos custos destas operações. Alternativamente, estes algoritmos focalizam propriedades comuns entre sequências, como número de estados, ordem e subsequências. Os algoritmos mais famosos deste tipo de abordagem são os de Dijkstra e Taris (1995) e o de Elzinga (2003).

A abordagem de Dijkstra e Taris (1995) parte de quatro axiomas: (i) sequências sem estados em comum são maximamente dissimilares; (ii) sequências que apresentam os mesmos estados na mesma ordem são maximamente similares; (iii) quanto mais estados em comum as sequências tiverem, mais similares serão; (iv) quanto mais comum for a ordem entre estados comuns, mais semelhantes duas sequências serão (AISENBREY; FASANG, 2010, p. 438).

A partir destes axiomas, a técnica compara duas sequências em 3 passos. O primeiro consiste em eliminar todos os estados que não são comuns às duas sequências. $\mathrm{O}$ segundo reduz as sequências a um número igual de estados comuns, a partir do descarte dos estados que ocorrem em frequências diferentes entre asa duas sequências. O terceiro passo é calcular o número mínimo de movimentos necessários para transformar uma sequência na outra alterando a ordem dos estados, considerando que os passos 1 e 2 já deixaram as sequências com os mesmos estados e as mesmas frequências.

Estes passos provêm três características da sequência: (i) o número de movimentos necessários (somando os três passos); (ii) o número de movimentos que diz respeito à ordem da sequência; e (iii) o número de estados removidos quando da comparação entre duas sequências. Os autores propõem três medidas de (dis)similaridade baseadas nestas características. A primeira dá mais peso ao número de estados em comum em relação à ordem; a segunda, mais peso às subsequências comuns (estados e ordem em comum) e pouco peso aos estados que ocorrem em ordens diferentes; e a terceira é uma medida intermediária entre as duas primeiras. Qual a medida é mais adequada depende do problema de pesquisa (AISENBREY; FASANG, 2010, p. 439). No entanto, a abordagem de Dijkstra e Taris (1995) é criticada pelos passos 1 e 2 da aplicação descartarem muita informação.

Algoritmos de não-alinhamento mais complexo foram sugeridos por Elzinga (2003). As técnicas deste autor partem da caracterização das subsequências: o número de estados em comum, ou o tamanho da primeira ou da última subsequência em comum entre duas sequências, ou diversas combinações entre estas medidas. $\mathrm{O}$ importante a destacar é que as medidas de Elzinga (2003) nem descartam informação e tampouco utilizam as operações de substituição, inserção e eliminação do OMA, e dá forte peso à presença de subsequências em comum.

Utilizando uma base de dados de 500 sequências sobre transição da escola para o trabalho, com 5 estados possíveis (educação superior, emprego, treinamento profissional, 
desemprego e inatividade) durante 36 meses, Aisenbrey e Fasang (2010) compararam os algoritmos OMA com custos baseados nas probabilidades de transição, a medida dinâmica de Hamming e o de Elzinga (2003) (número de subsequências comuns). Em todos os casos, foram escolhidos 8 clusters de sequências. De uma forma geral, as autoras concluíram que o OMA e o Hamming obtiveram resultados bem semelhantes: os clusters formados tiveram tamanho e complexidade (ELZINGA, 2010) muito parecidos. No entanto, ao privilegiar a identificação de subsequências comuns, o algoritmo de Elzinga (2003) resultou em 7 clusters extremamente homogêneos, porém pequenos em tamanho, e um grande cluster com mais da metade das observações que pode ser interpretado como a categoria "outros", mais heterogêneo. No exemplo em tela, a última aplicação pareceu de pequeno valor analítico, mas Aisenbrey e Fasang (2010) advertem que as "métricas de Elzinga têm sido frutiferamente aplicadas em um vários estudos guiados pela teoria sociológica", e que "nenhuma técnica é adequada a todos as aplicações. A seleção da métrica de sequências adequada deve ser guiada pela teoria e pela questão substantiva em mãos" (AISENBREY; FASANG, 2010, p. 444-445).

\subsubsection{Métodos de agrupamento de sequências}

Até o momento, foram discutidos os algoritmos de alinhamento (ou nãoalinhamento) das sequências e suas decisões metodológicas implicadas. Porém, uma vez criada uma matriz de similaridade (ou distância) entre sequências, o passo seguinte é um algoritmo de agrupamento para formar grupos de sequências semelhantes. A técnica mais utilizada é a de cluster, ainda que o escalonamento multidimensional (também conhecido como análise de correspondência) seja também utilizado em alguns casos.

Recentemente, Piccarreta e Billari (2007) e Studer et al. (2011) propuseram técnicas alternativas para o estágio do agrupamento e interpretação dos padrões. Piccarreta e Billari (2007) propõem um critério objetivo baseado em árvores de regressão (regression trees) e regras de poda para separar os clusters; no entanto, a técnica exige a escolha de uma variável auxiliar quantitativa para calibrar o algoritmo (no caso, os autores utilizaram o tempo em cada estado). Já Studer et al. (2011), ao invés de se preocuparem com os padrões evidenciados pelos agrupamentos, propõem um tipo de análise que relaciona variáveis explicativas à discrepância entre as sequências, em um tipo de análise análogo à ANOVA. Contudo, estas técnicas ainda não se tornaram populares.

Sem embargo, a análise de cluster é de longe o método mais comum, sendo o adotado nesta tese. Com respeito a esta técnica, cabe notar que a única possiblidade é o agrupamento hierárquico, uma vez que não se tem valores absolutos para caracterizar as sequências a fim de formar centróides, por exemplo. A informação básica para os agrupamentos é a distância entre as sequências. ${ }^{14}$

\footnotetext{
et al., 2009).
}

${ }^{14}$ A respeito das técnicas de agrupamento cluster e escalonamento multidimensional, veja (Hair 
Entretanto, há de se lembrar que há diversos parâmetros para a aplicação da técnica de clusters e, ainda que haja critérios estatísticos, não há testes definitivos para concluir a superioridade de uma solução sobre a outra. A obrigatoriedade de se aplicar métodos de agrupamento hierárquicos já limita bastante o escopo de decisões, mas a questão do número de clusters - isto é, a quantidade de padrões de sequências - permanece, e talvez seja a mais importante neste passo da análise de sequências, guardando relação com a próxima e última questão metodológica, a validação.

\subsubsection{Validação}

Talvez, esta seja a questão mais relevante, do ponto de vista epistemológico, às aplicações de análises de sequências. Afinal, como se dá a validação dos agrupamentos formados?

Embora não haja um teste definitivo, há algumas estatísticas que auxiliam na tomada de decisão sobre o número de clusters. Por exemplo, o pacote clusterCrit do R traz nada menos que 42 critérios para decisão. Entretanto, autores como Abbott e Hrycak (1990) e Halpin e Chan (1998) consideram a interpretabilidade e a validade de construto como o critério mais importante para orientar esta decisão. Ainda, Abbott e Hrycak (1990) utilizaram jacknife para particionar sua amostra, a fim de verificar semelhança de resultados finais em termos de agrupamentos em subamostras diferentes.

De toda forma, esta discussão passa pelas intenções metodológicas do que se deseja fazer com a classificação. Como argumentam Abbott e Tsay (2000), alguns estudos se contentam com um bom estudo exploratório, descritivo, enquanto outros utilizam estas classificações para análises causais.

\subsection{Análise de sequências em ciências sociais: um balanço parcial}

Abbott e Tsay (2000) e Aisenbrey e Fasang (2010) notam que, apesar de todas as nuances metodológicas e do fato de que o pesquisador deve arbitrar uma série de parâmetros, os resultados finais de aplicações alternativas do OMA e de outros métodos de alinhamento para as mesmas bases de dados são surpreendentemente semelhantes.

Talvez isto resulte daquilo que Hendry (1987) chama, em análise econométrica, de "processo gerador de dados". Pode ser que o processo intrínseco que gera os comportamentos observados das sequências analisadas já torne algumas sequências mais semelhantes do que as outras, restando às diferentes aplicações de técnicas de sequências apenas a função de serem diferentes lentes para uma mesma foto. Em outras palavras, a similaridade destas sequências reais entre si é tão latente que ela é retratada sempre de maneira muito semelhante, independentemente da técnica. Muito destas similaridades reais deriva do fato da dependência da trajetória (path dependency) em várias sequências sociais: como será mostrado na aplicação desta tese, a escolha de uma determinada 
trajetória se dá relativamente cedo e movimentos de volta para a ocupação inicial não são comuns. Provavelmente, se o processo gerador destas sequências sociais fosse mais estocástico, os retratos das sequências poderiam ser mais sensíveis às escolhas metodológicas.

Por fim, esta seção mostrou que: (i) a aplicação da análise de sequências em ciências sociais é um campo em franco desenvolvimento; e, principalmente, (ii) as diversas aplicações e as decisões metodológicas indicam que a análise de sequências está longe de ser uma panaceia, one-size-fits-all. Cada problema de pesquisa demanda reflexão sobre as escolhas metodológicas e seus benefícios e custos, inclusive sobre a própria conveniência do uso de análise de sequências ou não. 


\section{MATERIAIS E MÉTODOS}

\subsection{Dados e estatísticas descritivas preliminares}

A tese utiliza a Rais para mapear as trajetórias profissionais dos jovens engenheiros brasileiros. A Rais é um registro administrativo de todos os empregados formais do país, uma vez que toda empresa formal é obrigada a declarar a Rais. A partir da Rais, é possível saber características dos trabalhadores formais brasileiros como gênero e idade, a ocupação (CBO), a remuneração e horas trabalhadas, o nível de escolaridade e o tamanho e a localização do empregador, entre outras informações.

Portanto, os dados se referem à população (universo) dos engenheiros jovens empregados em empresas formais no Brasil entre 2003-2012. Os engenheiros jovens são definidos como profissionais de nível superior com 25 anos ou menos que exerceram alguma ocupação típica em engenharia no ano 2003.

O corte etário de 25 anos se justifica, pois, segundo o Enade 2011, a idade de 25 anos é a mediana dos formandos em engenharia. Como a moda é 23 anos (com 13,9\% dos alunos se formando com esta idade), a distribuição é assimétrica à esquerda, como pode ser visto no Gráfico 4. Adicionalmente, a Confederação Nacional da Indústria (2014) considera como 5 anos o tempo ideal de formação em um curso de engenharia. Levando em consideração a alta concorrência dos cursos de engenharia - que pode retardar a entrada no curso - e o fato de que alguns alunos reprovam em disciplinas, considera-se o corte de 25 anos como adequado. Mais ainda, provavelmente os jovens engenheiros que entram no mercado de trabalho com esta idade estão em seu primeiro emprego, ou seja, no início de suas trajetórias profissionais.

\section{Gráfico 4 - Histograma da idade de formatura em engenharia} (Enade, 2011)

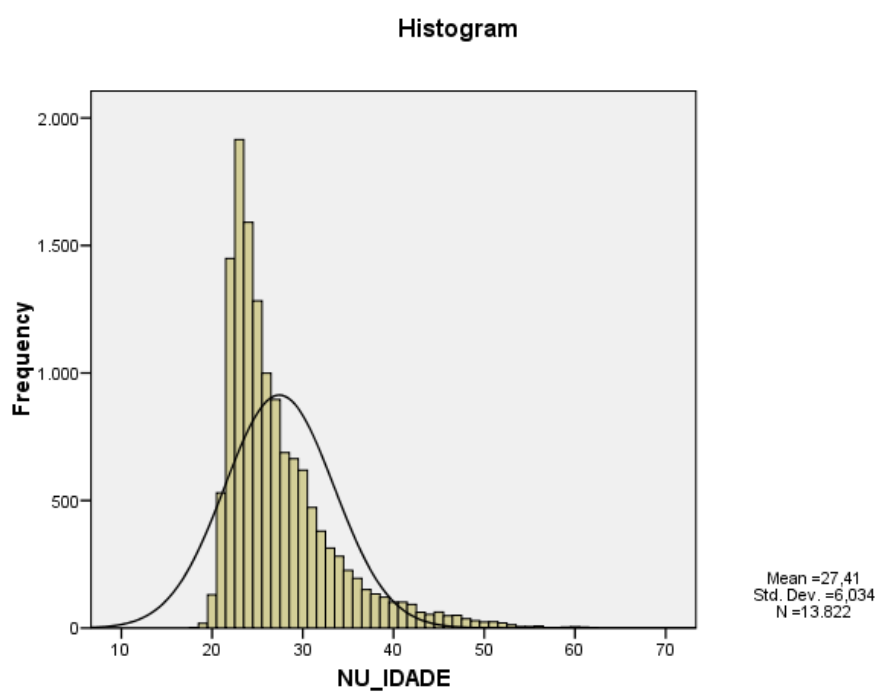

Fonte: Elaboração própria a partir do Enade 2011. 
As ocupações são definidas de acordo com a Classificação Brasileira de Ocupações (CBO 2002), a quatro dígitos. A definição de engenheiros típicos e outras possibilidades será discutida mais adiante.

A partir da Rais, é possível saber características de cada trabalhador formal brasileiro, como gênero e idade, ocupação (CBO), remuneração e horas trabalhadas, nível de escolaridade, tamanho e a localização do empregador, entre outras informações.

Porém, uma limitação da Rais é que ela se refere apenas ao trabalho com carteira assinada, não conseguindo caracterizar os empregadores, conta-própria ou os informais.

Dos 9.041 engenheiros jovens sob análise:

- $78 \%$ são do sexo masculino e $22 \%$ do sexo feminino;

- $43 \%$ deles conseguem seu primeiro emprego em SP, seguidos por $11 \%$ no RJ e $8 \%$ em MG;

- $58 \%$ dos jovens engenheiros iniciam suas trajetórias em empresas com mais de 100 empregados. Em particular, 17\% o fazem em empresas com mais de 1000 empregados;

- A primeira ocupação mais comum é como engenheiro civil (24\%), seguida pelos engenheiros eletricistas e eletrônicos $(21 \%)$ e pelos engenheiros mecânicos (14\%), conforme o Gráfico 5 a seguir. 


\section{Gráfico 5 - Primeira ocupação dos jovens engenheiros, 2003}

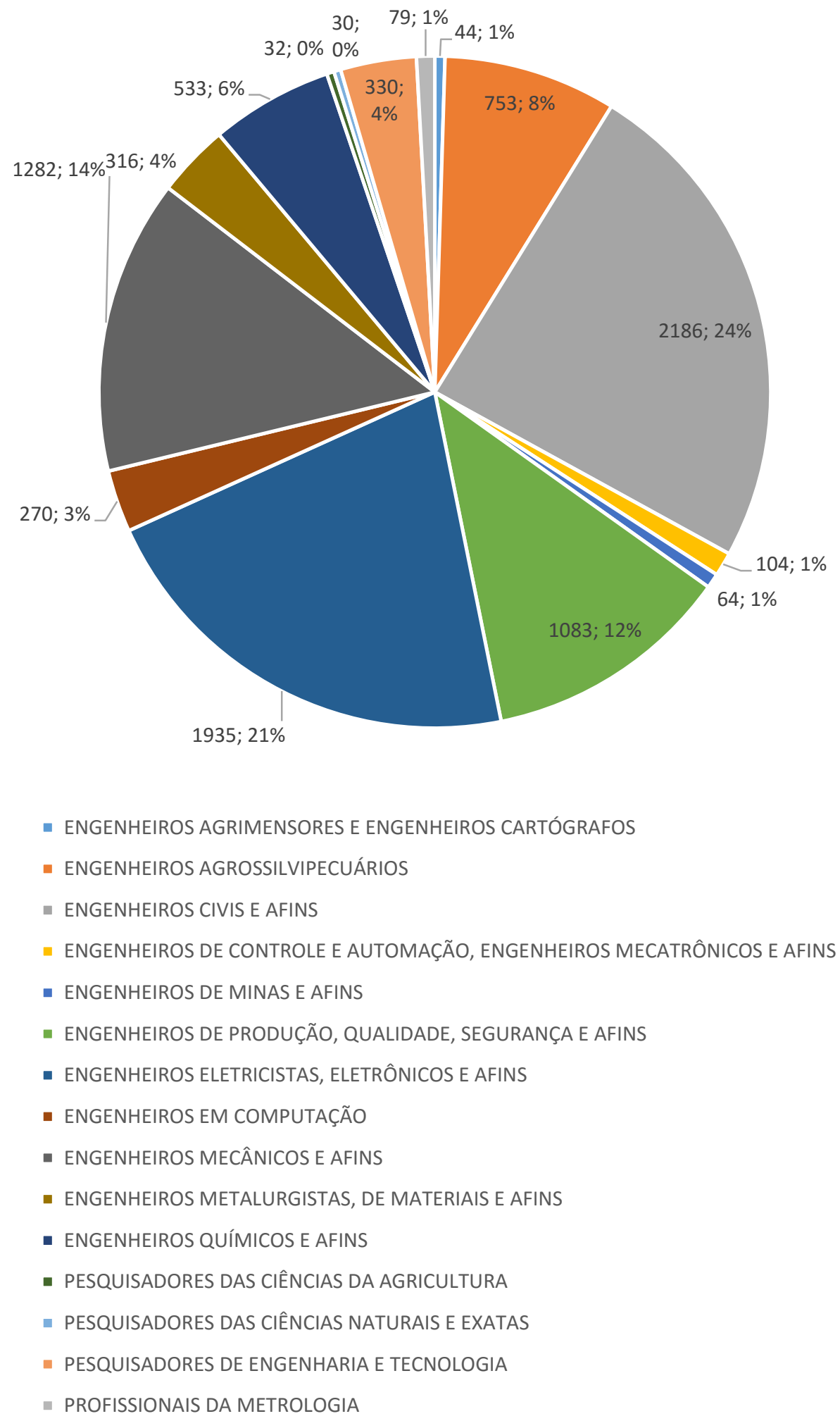

- ENGENHEIROS AGRIMENSORES E ENGENHEIROS CARTÓGRAFOS

- ENGENHEIROS AGROSSILVIPECUÁRIOS

- ENGENHEIROS CIVIS E AFINS

- ENGENHEIROS DE CONTROLE E AUTOMAÇÃO, ENGENHEIROS MECATRÔNICOS E AFINS

- ENGENHEIROS DE MINAS E AFINS

- ENGENHEIROS DE PRODUÇÃO, QUALIDADE, SEGURANÇA E AFINS

- ENGENHEIROS ELETRICISTAS, ELETRÔNICOS E AFINS

- eNGENHEIROS EM COMPUTAÇÃo

- ENGENHEIROS MECÂNICOS E AFINS

- ENGENHEIROS METALURGISTAS, DE MATERIAIS E AFINS

- ENGENHEIROS QUÍMICOS E AFINS

- PESQUISADORES DAS CIÊNCIAS DA AGRICULTURA

- PESQUISADORES DAS CIÊNCIAS NATURAIS E EXATAS

- PESQUISADORES DE ENGENHARIA E TECNOLOGIA

- PROFISSIONAIS DA METROLOGIA

Fonte: Elaboração própria a partir da Rais. 
Do ponto de vista setorial, a Tabela 5 a seguir sugere que os 10 setores CNAE (Classificação Nacional de Atividade Econômica, versão 1.0) mais importantes absorviam em 20035.760 profissionais, ou seja, 64\% dos jovens engenheiros (há um indivíduo com CNAE em branco em 2003). Somente os 2 primeiros (serviços prestados às empresas e construção) absorviam 2.820 profissionais. A partir disso, sugere-se uma categorização que leva em conta 4 macrossetores: (i) serviços às empresas; (ii) construção; (iii) indústria; e (iv) demais serviços, agropecuária e pesca, doravante denominados como "serviços". A distribuição segundo estes agrupamentos macrossetoriais encontra-se no Gráfico 6.

\section{Tabela 5 - Distribuição setorial dos jovens engenheiros entre as CNAEs em 2003}

\begin{tabular}{lr}
\hline \multicolumn{1}{c}{ Descrição } & Total \\
\hline SERVIÇOS PRESTADOS PRINCIPALMENTE ÀS EMPRESAS & 1616 \\
CONSTRUÇÃO & 1204 \\
FABRICAÇÃO DE MÁQUINAS E EQUIPAMENTOS & 439 \\
FABRICAÇÃO E MONTAGEM DE VEÍCULOS AUTOMOTORES, REBOQUES E CARROCERIAS & 421 \\
COMÉRCIO POR ATACADO E REP. COMERCIAIS E AGENTES DO COMÉRCIO & 401 \\
CORREIO E TELECOMUNICAÇÕES & 389 \\
FABRICAÇÃO DE PRODUTOS ALIMENTÍCIOS E BEBIDAS & 355 \\
FABRICAÇÃO DE PRODUTOS QUÍMICOS & 330 \\
COMÉRCIO VAREJISTA E REPARAÇÃO DE OBJETOS PESSOAIS E DOMÉSTICOS & 315 \\
FABRICAÇÃO DE OUTROS EQUIPAMENTOS DE TRANSPORTE & 290 \\
OutroS Setores & 3280 \\
\hline Total Geral & 9040 \\
\hline
\end{tabular}

Fonte: Elaboração própria a partir da Rais.

\section{Gráfico 6 - Distribuição setorial dos jovens engenheiros entre os macrossetores, 2003}

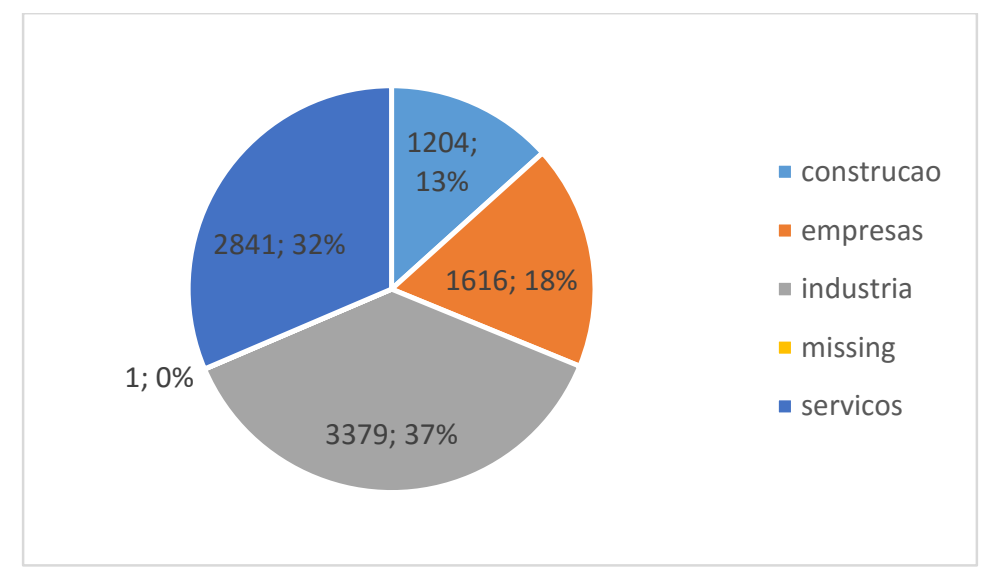

Fonte: Elaboração própria a partir da Rais. 


\subsubsection{Mobilidade entre regiões, macrossetores e portes de empresas}

A análise das migrações dos profissionais entre as regiões geográficas, os macrossetores e as categorias de porte se dá a partir das matrizes de transição. Estas matrizes indicam o número de indivíduos que permanecem em uma categoria ou migram para outras categorias entre dois pontos no tempo. Nestas matrizes, se o período inicial $\left(t_{0}\right)$ estiver representado nas linhas e o posterior $\left(t_{1}\right)$ nas colunas, então as proporções referentes às somas nas linhas indicarão o destino dos indivíduos de $t_{0}$ para $t_{1}$, enquanto as proporções referentes às somas nas colunas indicarão a origem dos indivíduos em $t_{1}$ em relação a $t_{0}$.

As matrizes de transição geográfica estão dispostas a seguir. As observações faltantes em 2012 (indivíduos fora da Rais) foram excluídas desta análise regional, como também da macrossetorial e por porte da empresa, pois não há tais informações sobre estes indivíduos. A matriz com as proporções de destino (cuja soma na linha é 100\%) indica que, por exemplo, daqueles que começaram suas trajetórias ocupacionais em São Paulo, 86\% permaneceram no Estado, 6\% migraram para outros Estados da região Sudeste, 3\% para a região Sul, e assim por diante. A matriz com as proporções de origem indica que daqueles que trabalhavam em São Paulo em 2012, 85\% tinham começado suas trajetórias no Estado, 6\% em outros estados do Sudeste, $4 \%$ na região Sul e assim por diante. De todo modo, cabe notar que a matriz de transição original é a mesma, os percentuais é que mudam de acordo com o referencial (linha ou coluna). A conclusão mais importante da tabela a seguir é que 5.738 (80\%) dos engenheiros jovens habitam na mesma região em 2003 e 2012, o que sugere baixa mobilidade inter-regional. 


\section{Tabela 6 - Matrizes de transição geográfica dos jovens engenheiros, 2003 e 2012}

\begin{tabular}{|c|c|c|c|c|c|c|c|}
\hline \multirow[b]{2}{*}{ Região em 2003} & \multicolumn{6}{|c|}{ Região em 2012} & \multirow[b]{2}{*}{ Total Geral } \\
\hline & $\mathrm{CO}$ & NE & NO & $\mathrm{S}$ & SE & SP & \\
\hline $\mathrm{CO}$ & 285 & 14 & 16 & 21 & 41 & 61 & 438 \\
\hline NE & 25 & 477 & 13 & 10 & 67 & 41 & 633 \\
\hline NO & 14 & 10 & 143 & 5 & 22 & 24 & 218 \\
\hline S & 37 & 15 & 9 & 981 & 46 & 136 & 1224 \\
\hline SE & 45 & 49 & 13 & 32 & 1164 & 205 & 1508 \\
\hline SP & 64 & 69 & 19 & 100 & 183 & 2688 & 3123 \\
\hline Total Geral & 470 & 634 & 213 & 1149 & 1523 & 3155 & 7144 \\
\hline \multicolumn{8}{|c|}{ Matriz de transição - destino (soma na linha $=100 \%$ ) } \\
\hline & \multicolumn{6}{|c|}{ Região 2012} & \\
\hline Região em 2003 & $\mathrm{CO}$ & NE & NO & S & SE & SP & Total Geral \\
\hline $\mathrm{CO}$ & $65 \%$ & $3 \%$ & $4 \%$ & $5 \%$ & $9 \%$ & $14 \%$ & 438 \\
\hline NE & $4 \%$ & $75 \%$ & $2 \%$ & $2 \%$ & $11 \%$ & $6 \%$ & 633 \\
\hline NO & $6 \%$ & $5 \%$ & $66 \%$ & $2 \%$ & $10 \%$ & $11 \%$ & 218 \\
\hline S & $3 \%$ & $1 \%$ & $1 \%$ & $80 \%$ & $4 \%$ & $11 \%$ & 1224 \\
\hline SE & $3 \%$ & $3 \%$ & $1 \%$ & $2 \%$ & $77 \%$ & $14 \%$ & 1508 \\
\hline SP & $2 \%$ & $2 \%$ & $1 \%$ & $3 \%$ & $6 \%$ & $86 \%$ & 3123 \\
\hline Total Geral & 470 & 634 & 213 & 1149 & 1523 & 3155 & 7144 \\
\hline \multicolumn{8}{|c|}{ Matriz de transição - origem (soma na coluna $=100 \%$ ) } \\
\hline & \multicolumn{6}{|c|}{ Região em 2012} & \\
\hline Região em 2003 & $\mathrm{CO}$ & NE & NO & $S$ & SE & $\mathrm{SP}$ & Total Geral \\
\hline $\mathrm{CO}$ & $61 \%$ & $2 \%$ & $8 \%$ & $2 \%$ & $3 \%$ & $2 \%$ & 438 \\
\hline NE & $5 \%$ & $75 \%$ & $6 \%$ & $1 \%$ & $4 \%$ & $1 \%$ & 633 \\
\hline NO & $3 \%$ & $2 \%$ & $67 \%$ & $0 \%$ & $1 \%$ & $1 \%$ & 218 \\
\hline S & $8 \%$ & $2 \%$ & $4 \%$ & $85 \%$ & $3 \%$ & $4 \%$ & 1224 \\
\hline SE & $10 \%$ & $8 \%$ & $6 \%$ & $3 \%$ & $76 \%$ & $6 \%$ & 1508 \\
\hline SP & $14 \%$ & $11 \%$ & $9 \%$ & $9 \%$ & $12 \%$ & $85 \%$ & 3123 \\
\hline Total Geral & 470 & 634 & 213 & 1149 & 1523 & 3155 & 7144 \\
\hline
\end{tabular}

Fonte: Elaboração própria a partir da Rais.

A matriz de transição dos macrossetores indica também uma baixa mobilidade intersetorial geral - 59\% dos jovens engenheiros permanecem no mesmo macrossetor entre 2003 e 2012. Entretanto, esta alta taxa geral se deve à alta retenção dos segmentos indústria e serviços, mais numerosos. A indústria consegue reter $67 \%$ dos jovens engenheiros entre 2003 e 2012, e os serviços, 75\%. Por sua vez, a construção consegue reter $45 \%$ e o segmento de serviços a empresas apenas $24 \%$ dos jovens engenheiros.

Porém, desconsiderando os trabalhadores fora da Rais - tratados adiante - daqueles jovens engenheiros que decidem migrar de macrossetor, a maioria opta pelos serviços. A categoria absorve 24\% dos que deixam a indústria, 39\% dos que trabalhavam no segmento de serviços às empresas e $38 \%$ dos que deixam a construção. O segmento de serviços se torna o mais relevante entre 2003 e 2012, suplantando a indústria no período: 
mesmo considerando-se os trabalhadores que saem da Rais no denominador, em 2012 $35 \%$ dos jovens engenheiros trabalhavam neste macrossetor.

Tabela 7 - Matrizes de transição entre os macrossetores dos jovens engenheiros, 2003 e 2012

\begin{tabular}{|c|c|c|c|c|c|}
\hline \multirow[b]{2}{*}{ Macrossetor em 2003} & \multicolumn{5}{|c|}{ Macrossetor em 2012} \\
\hline & Construção & $\begin{array}{c}\text { Serv. a } \\
\text { empresas }\end{array}$ & Indústria & Serviços & Total Geral \\
\hline Construção & 399 & 84 & 64 & 337 & 884 \\
\hline Serv. a empresas & 87 & 300 & 385 & 497 & 1269 \\
\hline Indústria & 67 & 198 & 1861 & 672 & 2798 \\
\hline Serviços & 86 & 152 & 318 & 1636 & 2192 \\
\hline Total Geral & 639 & 734 & 2628 & 3142 & 7143 \\
\hline \multicolumn{6}{|c|}{ Matriz de transição - destino (soma na linha $=100 \%$ ) } \\
\hline & \multicolumn{5}{|c|}{ Macrossetor em 2012} \\
\hline Macrossetor em 2003 & Construção & $\begin{array}{c}\text { Serv. a } \\
\text { empresas }\end{array}$ & Indústria & Serviços & Total Geral \\
\hline Construção & $45 \%$ & $10 \%$ & $7 \%$ & $38 \%$ & 884 \\
\hline Serv. a empresas & $7 \%$ & $24 \%$ & $30 \%$ & $39 \%$ & 1269 \\
\hline Indústria & $2 \%$ & $7 \%$ & $67 \%$ & $24 \%$ & 2798 \\
\hline Serviços & $4 \%$ & $7 \%$ & $15 \%$ & $75 \%$ & 2192 \\
\hline Total Geral & 639 & 734 & 2628 & 3142 & 7143 \\
\hline \multicolumn{6}{|c|}{ Matriz de transição - origem (soma na coluna = 100\%) } \\
\hline & \multicolumn{5}{|c|}{ Macrossetor em 2012} \\
\hline Macrossetor em 2003 & Construção & $\begin{array}{c}\text { Serv. a } \\
\text { empresas }\end{array}$ & Indústria & Serviços & Total Geral \\
\hline Construção & $62 \%$ & $11 \%$ & $2 \%$ & $11 \%$ & 884 \\
\hline Serv. a empresas & $14 \%$ & $41 \%$ & $15 \%$ & $16 \%$ & 1269 \\
\hline Indústria & $10 \%$ & $27 \%$ & $71 \%$ & $21 \%$ & 2798 \\
\hline Serviços & $13 \%$ & $21 \%$ & $12 \%$ & $52 \%$ & 2192 \\
\hline Total Geral & 639 & 734 & 2628 & 3142 & 7143 \\
\hline
\end{tabular}

Fonte: Elaboração própria a partir da Rais.

Com respeito aos 1.897 trabalhadores que não trabalharam com carteira assinada em 2012 (fora da Rais), a maior parte deles em termos absolutos é oriunda dos segmentos indústria e serviços, segundo a Tabela 8 . Entretanto, há de se considerar que estas eram as categorias mais numerosas em 2003. Sem embargo, 27\% dos trabalhadores no macrossetor de construção em 2003 não estão na Rais em 2012, o que significa a maior perda relativa entre os macrossetores. 


\section{Tabela 8 - Matrizes de transição entre os macrossetores e aqueles jovens engenheiros que saem da Rais, 2003 e 2012}

\begin{tabular}{lcc}
\hline Macrossetores em 2003 & Fora da Rais em 2012 & $\begin{array}{l}\text { \% em relação aos } \\
\text { macrossetores 2003 }\end{array}$ \\
\hline Construção & 320 & $27 \%$ \\
Serv. a empresas & 347 & $21 \%$ \\
Indústria & 581 & $17 \%$ \\
Serviços & 649 & $23 \%$ \\
\hline Total Geral & 1.897 & \\
\hline
\end{tabular}

Fonte: Elaboração própria a partir da Rais.

Quando se consideram estes trabalhadores que saem da Rais, a taxa de retenção intrassetorial cai de $59 \%$ para $46 \%$. Entretanto, dos $54 \%$ dos trabalhadores que mudam de macrossetor, 20 pontos percentuais correspondem aos que saem da Rais entre 2003 e 2012, para os quais não há informação. Admitindo que uma boa parte destes trabalhadores continua a trabalhar como conta-própria (questão discutida mais adiante, na seção que trata da codificação das ocupações), e não raro no mesmo segmento de antes, $46 \%$ constitui em um piso relativamente alto para a verdadeira taxa de retenção intrassetorial.

A mobilidade entre as 9 faixas de tamanho originais da Rais é alta - apenas 24,5\% dos profissionais se mantém na mesma faixa de tamanho de empresa entre 2003 e 2012. Contudo, as faixas de menor tamanho são bem estreitas, o que leva a mudanças relativamente constantes entre elas. De fato, a taxa de retenção sobe de patamar a partir da faixa de 100 ou mais empregados, e, em especial, ela é de $65 \%$ para os jovens engenheiros que começaram a trabalhar em empresas com mais de 1.000 empregados.

Por seu turno, a distribuição entre as categorias de tamanho não é tão diferente entre os anos de 2003 e 2012 quanto a alta mobilidade entre as classes poderia sugerir. Ao se considerar a categoria dos trabalhadores fora da Rais, o Gráfico 7 a seguir mostra que a parcela dos jovens a trabalhar em empresas com mais de 100 empregados praticamente não se alterou entre 2003 e 2012, passando de 58 para $60 \%$. Isto pode ser explicado pelo fato de que, a despeito da alta mobilidade entre as classes de tamanho, os trabalhadores parecem trocar de faixas entre si, mantendo basicamente as mesmas proporções. 


\section{Gráfico 7 - Distribuição dos jovens engenheiros de acordo com as faixas de tamanho, 2003 e 2012}

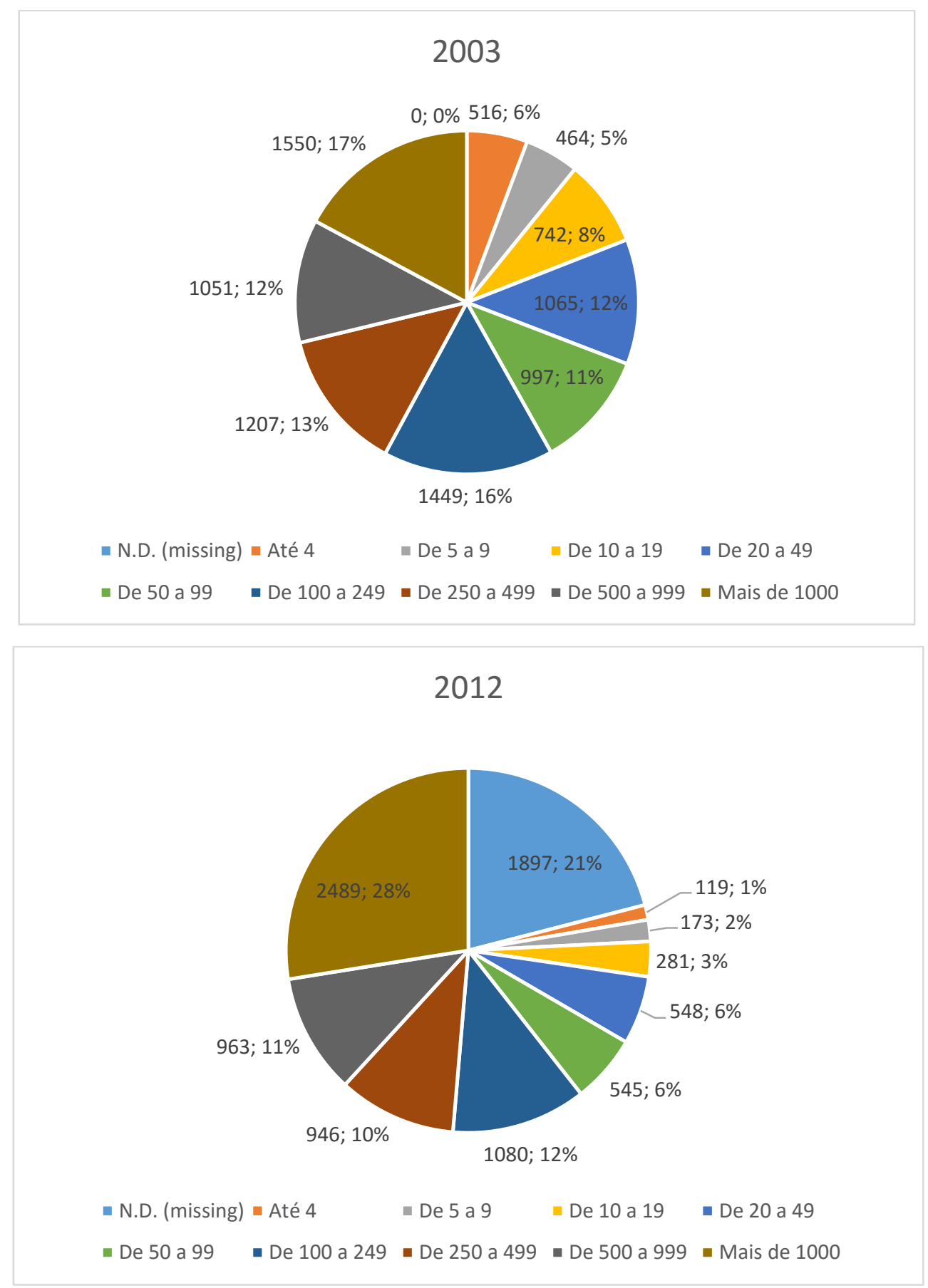

Fonte: Elaboração própria a partir da Rais.

Porém, cabe notar dois interessantes movimentos. O primeiro é que, dentre os jovens engenheiros em empresas com mais de 100 empregados, a faixa de mais de 1.000 empregados se destaca não apenas pela alta taxa de retenção, mas também pela atração de trabalhadores de outras categorias. Ela é o destino preferido dos trabalhadores que mudam de faixa de tamanho, de forma que $65 \%$ dos trabalhadores que a compõem são oriundos de outras faixas de tamanho em 2003. Isto, aliado à alta taxa de retenção, faz com que categoria cresça praticamente em 1.000 profissionais entre 2003 e 2012, 
passando a responder por $28 \%$ do total de jovens engenheiros, mesmo considerando aqueles fora da Rais no denominador.

O segundo é que os engenheiros que começam suas trajetórias em empresas menores têm mais chances de estarem fora da Rais em 2012. Para mostrar isso, as 9 faixas de tamanho da Rais foram divididas em apenas duas categorias de porte: pequeno (até 99 empregados) e grande (100 ou mais empregados). A Tabela 9 mostra uma matriz de transição entre estes estados (excluindo aqueles que saem da Rais) e a origem dos trabalhadores fora da Rais, no que tange ao tamanho. Observa-se que entre 2003 e 2012, grande parte dos trabalhadores em grandes empresas permaneceu nesta categoria de tamanho, mas a maioria dos profissionais que começaram em pequenas empresas migrou para empresas de maior porte. Dentre aqueles que saem da Rais, apesar das proporções entre originários das firmas grandes e pequenas não ser tão diferente, $27 \%$ dos jovens engenheiros que começaram a trabalhar em empresas pequenas estão fora da Rais em 2012. Assim, dos 3.784 jovens engenheiros que começam a trabalhar em empresas pequenas (com menos de 100 empregados) em 2003, 1.791 passam a trabalhar em empresas grandes, 1.016 saem da Rais e apenas 977 continuam a trabalhar em empresas de pequeno porte 9 anos depois.

\section{Tabela 9 - Matrizes de transição entre o porte das empresas dos jovens engenheiros, 2003 e 2012}

\begin{tabular}{lrcc}
\hline & \multicolumn{3}{c}{ Porte em 2012 } \\
\hline $\begin{array}{l}\text { Porte em } \\
2003\end{array}$ & grande & pequeno & Total Geral \\
\hline grande & 3687 & 689 & 4376 \\
pequeno & 1791 & 977 & 2768 \\
\hline Total Geral & 5478 & 1666 & 7144 \\
\hline
\end{tabular}

\begin{tabular}{lcc}
\hline $\begin{array}{c}\text { Porte em } \\
2003\end{array}$ & $\begin{array}{c}\text { Fora da Rais } \\
\text { em 2012 }\end{array}$ & $\begin{array}{c}\text { \% relação ao } \\
\text { porte em 2003 }\end{array}$ \\
\hline grande & 881 & $17 \%$ \\
pequeno & 1016 & $27 \%$ \\
\hline Total Geral & 1897 & \\
\hline
\end{tabular}

Fonte: Elaboração própria a partir da Rais.

Em resumo, esta seção mostrou que há pouca mobilidade inter-regional entre os jovens engenheiros no período 2003-2012, há alguma mobilidade intersetorial, mas ela superestimada pela presença dos trabalhadores fora da Rais - ainda que alguns setores apresentem alta retenção, como indústria e serviços -, e há maior mobilidade no que diz respeito ao porte das empresas, com os trabalhadores inicialmente em empresas pequenas migrando para empresas grandes ou saindo da Rais. 


\subsubsection{Resultados de mercado de trabalho: por gênero, região, setor e porte}

Esta subseção apresenta os resultados de mercado de trabalho (labor market outcomes) de acordo com as categorias gênero, região, porte e macrossetor. A Rais permite avaliar remuneração ${ }^{15}$ e número de meses no emprego atual, uma medida de estabilidade no emprego.

Os resultados de mercado de trabalho conforme gênero, na Tabela 10, estão de acordo com o previsto pela literatura sobre mercado de trabalho: os homens começam e terminam o período ganhando mais do que as mulheres. Contudo, este diferencial aumenta com o tempo, pois se os homens em 2003 ganhavam 9,6\% a mais que as mulheres, em 2012 este diferencial era de $19,3 \%$. De fato, a remuneração dos homens cresce $\mathrm{R} \$ 6.226$ no período, enquanto a das mulheres cresce $\mathrm{R} \$$ 5.704. Apesar de crescente, este diferencial ainda é um pouco menor que a média brasileira. Segundo a Pesquisa Nacional por Amostragem Domiciliar (PNAD) de 2013, os homens ganham em média 26,3\% a mais que as mulheres. Em termos de estabilidade no emprego, não se observam diferenças importantes, ambos os gêneros estão há 56 meses no emprego atual em média, e o teste $\mathrm{F}$ da ANOVA que compara a remuneração por gênero não é significativo.

\section{Tabela 10 - Remuneração mensal e tempo de emprego por gênero, 2003 e 2012}

\begin{tabular}{lccc}
\hline Gênero & Masculino & Feminino & Total Geral \\
\hline $\mathrm{N}$ & 7.085 & 1.956 & 9.041 \\
\hline Remuneração em 2003 (R\$ de 2012) & $3.913,40$ & $3.568,74$ & $3.838,83$ \\
Desvio-padrão & $2.372,45$ & $2.201,91$ & $2.340,80$ \\
Estatística F - ANOVA & & $33,351^{* * \star}$ & \\
\hline Remuneração em 2012 (em R\$ de 2012) & $10.460,90$ & $8.766,52$ & $10.106,07$ \\
Desvio-padrão & $6.211,56$ & $5.381,16$ & $6.085,93$ \\
Estatística F - ANOVA & & $92,481^{* * *}$ & \\
\hline Crescimento da remuneração-2003-2012 & $6.225,76$ & $5.106,98$ & $6.228,64$ \\
Desvio-padrão & $5.703,74$ & $4.828,64$ & $5.561,68$ \\
Estatística F - ANOVA & & $77,481^{* * *}$ & \\
\hline
\end{tabular}

${ }^{15}$ Nem todos os trabalhadores da Rais trabalham a jornada integral da CLT, tampouco nem todos têm apenas um empregador. Foram realizados dois procedimentos no banco de dados a fim de lidar com isso: (i) foi definido como empregador aquele para quem o profissional trabalha mais horas - isso é fundamental para definir setor, porte e outras características do empregador; (ii) todas as jornadas foram ajustadas para a jornada integral da CLT (44 horas semanais). Na prática, este último procedimento faz com que a variável de remuneração seja igual ao (salário do emprego principal/hora)*44. Os valores para 2003 foram deflacionados de acordo com o IPCA (Índice de Preços ao Consumidor Amplo), do Instituto Brasileiro de Geografia e Estatística (IBGE). 


\begin{tabular}{lccc}
\hline Tempo de emprego em 2012 (meses) & 56,54 & 56 & 56,43 \\
Desvio-padrão & 44 & 43,04 & 43,8 \\
Estatística F - ANOVA & & $0,185^{\text {n.s. }}$ & \\
\hline
\end{tabular}

Fonte: Elaboração própria a partir da Rais. *** - Estatística significante a 1\%, em teste ANOVA com intercepto. N.s. - não significante a $10 \%$.

Com respeito à região, a Tabela 11 indicam que os jovens engenheiros que iniciam suas trajetórias no Estado de São Paulo ganham $11 \%$ a mais que a média nacional, $\mathrm{R} \$$ 4.264 mensais. Os profissionais dos demais estados do Sudeste ganham a média enquanto aqueles que iniciam suas trajetórias nos estados no Centro-Oeste, Nordeste, Norte e Sul ganham até $18 \%$ a menos do que a média nacional. Contudo, esta realidade se altera ao longo do tempo. Os trabalhadores que habitavam o Centro-Oeste, Nordeste e Norte reduzem o diferencial com respeito à média nacional e passam a ganhar $8 \%$ a menos que a média; a região Sudeste (exceto São Paulo) passa a pagar, em média, R \$ 12.014 para os jovens engenheiros, $18 \%$ a mais que a média nacional, e o Estado de São Paulo paga praticamente a média. De fato, os profissionais na região Sudeste são os que experienciam o maior crescimento da renda ( $\mathrm{R} \$ 8.005)$. A região Sul passa a ser a que apresenta menor remuneração em 2012 pois é onde a renda menos cresce no período. Na região sul, a remuneração era $24 \%$ menor que a média nacional. Com relação à estabilidade no emprego, pode-se identificar três estratos. Os Estados do Centro-Oeste, Nordeste e Norte com trabalhadores há 52 meses no emprego, os do Sudeste e São Paulo com a média nacional de 56 meses, e os Estados do Sul apresentando a maior estabilidade, com 60 meses de tempo no emprego atual. 
Tabela 11 - Remuneração mensal e tempo de emprego por região, 2003 e 2012

\begin{tabular}{|c|c|c|c|c|c|c|c|}
\hline Região & $\mathrm{CO}$ & NE & NO & $\mathrm{S}$ & SE & SP & Total Gera \\
\hline $\mathrm{N}$ & 601 & 778 & 269 & 1.626 & 1.855 & 3.912 & 9.041 \\
\hline $\begin{array}{l}\text { Remuneração em } \\
2003 \text { ( } \mathrm{R} \$ \text { de } 2012)\end{array}$ & $3.257,40$ & $3.156,89$ & $3.522,20$ & $3.326,79$ & $3.911,12$ & $4.264,11$ & $3.838,83$ \\
\hline Desvio-padrão & $2.176,16$ & $2.078,14$ & $2.283,28$ & $1.871,97$ & $2.730,33$ & $2.299,93$ & $2.340,80$ \\
\hline Estatística F - ANOVA & \multicolumn{7}{|c|}{$65,611^{* * *}$} \\
\hline $\mathrm{N}$ & 468 & 633 & 211 & 1.146 & 1.518 & 3.139 & 7.115 \\
\hline $\begin{array}{l}\text { Remuneração em } \\
2012 \text { (em R\$ de 2012) }\end{array}$ & $9.430,61$ & $9.306,93$ & $9.397,22$ & $7.715,54$ & $12.014,80$ & $10.365,27$ & $10.106,07$ \\
\hline Desvio-padrão & $5.911,29$ & $6.125,34$ & $6.081,59$ & $4.413,71$ & $7.536,79$ & $5.479,09$ & $6.085,93$ \\
\hline Estatística F - ANOVA & \multicolumn{7}{|c|}{$73,872^{\star \star *}$} \\
\hline $\mathrm{N}$ & 468 & 633 & 211 & 1.146 & 1.518 & 3.139 & 7.115 \\
\hline $\begin{array}{l}\text { Crescimento da } \\
\text { remuneração - 2003- } \\
2012\end{array}$ & $6.109,03$ & $5.984,41$ & $5.965,31$ & $4.322,00$ & $8.004,88$ & $6.150,55$ & $6.228,65$ \\
\hline Desvio-padrão & $5.577,49$ & $5.859,83$ & $5.600,01$ & $3.995,10$ & $6.726,68$ & $5.089,62$ & $5.561,68$ \\
\hline Estatística F - ANOVA & \multicolumn{7}{|c|}{$60,86^{* * *}$} \\
\hline $\mathrm{N}$ & 470 & 634 & 213 & 1149 & 1523 & 3155 & 7144 \\
\hline $\begin{array}{l}\text { Tempo de emprego } \\
\text { em } 2012 \text { (meses) }\end{array}$ & 52,75 & 52,02 & 52,5 & 60,47 & 56,49 & 56,63 & 56,43 \\
\hline Desvio-padrão & 40,13 & 43,95 & 39,85 & 44,64 & 43,49 & 44,27 & 43,8 \\
\hline Estatística F - ANOVA & \multicolumn{7}{|c|}{$4,272^{\star *}$} \\
\hline
\end{tabular}

Fonte: Elaboração própria a partir da Rais. *** - Estatística significante a 1\%, em teste ANOVA com intercepto; $* *$ - Estatística significante a $5 \%$.

No que tange à distribuição da remuneração de acordo com os macrossetores, acontece um fenômeno interessante: a convergência, entre 2003 e 2012, para a média geral. Em 2003, além de ser a categoria mais numerosa, apenas a indústria pagava mais que a média nacional, apresentando remuneração de $\mathrm{R} \$ 4.239$ ou $10 \%$ a mais que a média. Todos os outros macrossetores pagavam menos que a média nacional de $\mathrm{R} \$ 3.839$ mensais e este diferencial era maior na construção civil, que apresentava remuneração $17 \%$ menor que a média nacional. Já em 2012, os macrossetores não apresentavam variação maior que $7 \%$ - para cima ou para baixo - com respeito à média nacional, e a construção foi o macrossetor que apresentou maior crescimento da remuneração no período (R \$ 7.036). De acordo com a Tabela 12, em 2012 a indústria continuou sendo o macrossetor a apresentar maior remuneração, $7 \%$ acima da média nacional ou $\mathrm{R} \$ 10.859$ em média, enquanto os serviços passaram a ser o de menor remuneração, $7 \%$ abaixo da média nacional.Com respeito ao tempo de emprego, a indústria também é o segmento mais estável, com seus engenheiros com 66 meses em média de tempo de empresa; e a construção, o mais instável, com 45 meses de tempo médio de emprego em 2012. 


\section{Tabela 12 - Remuneração mensal e tempo de emprego por macrossetor, 2003 e 2012}

\begin{tabular}{lccccc}
\hline Macrossetor & Construção & $\begin{array}{c}\text { Serv. a } \\
\text { empresas }\end{array}$ & Indústria & Serviços & Total Geral \\
\hline $\mathrm{N}$ & 1.204 & 1.616 & 3.379 & 2.841 & 9.040 \\
\hline Remuneração em 2003 (R\$ de 2012) & $3.200,50$ & $3.721,97$ & $4.239,28$ & $3.699,59$ & $3.838,84$ \\
Desvio-padrão & $1.492,30$ & $2.372,29$ & $2.240,78$ & $2.633,38$ & $2.340,93$ \\
Estatística F - ANOVA & & & $51,764^{* * *}$ & & \\
\hline $\mathrm{N}$ & 636 & 730 & 2615 & 3134 & 7115 \\
Remuneração em 2012 (em R\$ de 2012) & $10.392,99$ & $10.137,93$ & $10.859,40$ & $9.411,85$ & $10.106,07$ \\
Desvio-padrão & $6.427,99$ & $6.078,93$ & $5.362,90$ & $6.493,08$ & $6.085,93$ \\
Estatística F - ANOVA & & & $27,736 * *$ & & \\
\hline $\mathrm{N}$ & 636 & 730 & 2615 & 3134 & 7115 \\
Crescimento da remuneração - 2003-2012 & $7.036,40$ & $6.423,95$ & $6.592,93$ & $5.715,29$ & $6.228,65$ \\
Desvio-padrão & $6.081,15$ & $5.746,53$ & $4.971,32$ & $5.824,27$ & $5.561,68$ \\
Estatística F - ANOVA & & & $17,533^{* * *}$ & & \\
\hline $\mathrm{N}$ & 639 & 734 & 2629 & 3142 & 7144 \\
Tempo de emprego em 2012 (meses) & 45,1 & 46,99 & 66,02 & 52,91 & 56,43 \\
Desvio-padrão & 42,96 & 41,87 & 45,82 & 41,05 & 43,8 \\
Estatística F - ANOVA & & & $76,758 * * *$ & & \\
\hline
\end{tabular}

Fonte: Elaboração própria a partir da Rais. *** - Estatística significante a 1\%, em teste ANOVA com intercepto.

Como esperado, as firmas maiores tendem a pagar mais e a ter postos de trabalho mais estáveis, de acordo com a Tabela 13 a seguir. Em 2003, um jovem engenheiro que ingressasse em uma grande empresa (com mais de 100 empregados) tendia a ganhar $34 \%$ a mais do que um colega que ingressasse numa empresa de pequeno porte. Ao longo do tempo, este diferencial percentual caiu um pouco e passou a ser de $27 \%$ em 2012, mas o diferencial absoluto aumentou. Cabe notar que a média é mais influenciada pela remuneração vigente nas grandes empresas, pois, como visto, a participação de pequenos empregadores cai ao longo do tempo. Em 2012, um engenheiro empregado em uma empresa grande tendia a apresentar 14 meses a mais de tempo de casa na mesma empresa que um engenheiro em uma pequena empresa.

Tabela 13 - Remuneração mensal e tempo de emprego por porte, 2003 e 2012

\begin{tabular}{lccc}
\hline Porte & Grande & Pequeno & Total Geral \\
\hline $\mathrm{N}$ & 5.257 & 3.784 & 9.041 \\
\hline Remuneração em 2003 (R\$ de 2012) & $4.293,75$ & $3.206,84$ & $3.838,83$ \\
Desvio-padrão & $2.479,90$ & $1.965,20$ & $2.340,80$ \\
Estatística F - Anova & & $500,607^{* \star *}$ & \\
\hline $\mathrm{N}$ & 5.453 & 1.662 & 7.115 \\
Remuneração em 2012 (em R\$ de 2012) & $10.644,06$ & $8.340,92$ & $10.106,07$ \\
Desvio-padrão & $5.911,12$ & $6.314,82$ & $6.085,93$ \\
Estatística F - Anova & & $187,197^{* * *}$ & \\
\hline $\mathrm{N}$ & 5.453 & 1.662 & 7.115
\end{tabular}




\begin{tabular}{lccc} 
Crescimento da remuneração & $6.596,47$ & $5.021,85$ & $6.228,65$ \\
Desvio-padrão & $5.425,34$ & $5.828,07$ & $5.561,68$ \\
Estatística F - Anova & & $103,573^{\star \star *}$ & \\
\hline N & 5.478 & 1.666 & 7.144 \\
Tempo de emprego em 2012 (meses) & 59,56 & 46,12 & 56,43 \\
Desvio-padrão & 43,74 & 42,39 & 43,80 \\
Estatística F - Anova & & $122,338^{\star * *}$ &
\end{tabular}

Fonte: Elaboração própria a partir da Rais. *** - Estatística significante a 1\%, em teste ANOVA com intercepto.

Enfim, as estatísticas descritivas mostram um viés negativo contra as jovens engenheiras no que tange à remuneração, ainda que este viés seja um pouco menor do que o representado na média do mercado de trabalho como um todo. Também mostram que a região Sudeste (exceto SP) é onde os salários mais cresceram entre 2003-2012, e os menores salários estão na região Sul. Em compensação, nesta região há maior estabilidade no emprego no período analisado. O diferencial de remuneração entre os macrossetores diminui, mas a indústria é tanto em 2003 quanto em 2012 o macrossetor a pagar maiores remunerações e a apresentar maior estabilidade no emprego. Como esperado, os engenheiros em grandes empresas tendem a ganhar mais e a ter empregos mais estáveis. Todavia há de se lembrar que a informação sobre o emprego em pequenos estabelecimentos (menos de 100 empregados) se perde ao longo do tempo, pois os empregados nestas empresas são mais propensos a sair da Rais, conforme discutido na subseção anterior. 


\subsection{Operacionalização: definição de trajetórias ocupacionais}

Trajetórias ocupacionais são, para efeito desta tese, as sequências individuais de ocupações de acordo com a Classificação Brasileira de Ocupações (CBO) presentes na Relação Anual de Informações Sociais (Rais).

Esta tese utiliza o conceito de "trajetórias ocupacionais" em detrimento a conceitos mais complexos como "trajetórias de emprego" ou mesmo "carreiras". Existe uma literatura específica sobre carreiras que foge ao escopo desta tese. ${ }^{16}$ Pode-se argumentar, como em Rosenfeld (1992), que uma carreira é uma sucessão de empregos; e emprego é "tipo particular de trabalho para um tipo particular de empregador" (ROSENFELD, 1992, p. 40). O tipo particular de trabalho poderia ser operacionalizado, conceitualmente, a partir da CBO, e várias características do empregador estão na Rais. Entretanto, as séries de trajetórias ocupacionais são truncadas à direita. Ou seja, não se sabe o que acontece com os engenheiros jovens depois de 2012. É possível argumentar que uma carreira é composta por trajetórias ocupacionais; porém, o fato é que só se tem uma parte do todo.

De toda forma, o próximo capítulo debate a conveniência ou não de se tratar as características do empregador de maneira endógena - isto é, como uma dimensão da codificação, tal qual em Blair-Loy (1999) - ou de maneira exógena - ou seja, como parte da caracterização dos resultados.

\subsection{Desenho metodológico}

Independentemente das opções metodológicas da aplicação do OMA às trajetórias profissionais - discutidas na próxima seção -, o desenho geral de pesquisa proposto segue, mutatus mutandis, o que é feito em análise estatística com respeito à identificação dos efeitos de idade, período e coorte.

Estes efeitos têm origem em estudos demográficos, de larga aplicação em epidemiologia e em ciências sociais. ${ }^{17} \mathrm{O}$ efeito idade está associado à própria evolução de uma variável-resposta com respeito à idade. Por exemplo, pessoas mais idosas são, em termos gerais, mais suscetíveis a doenças como o Mal de Alzheimer; a remuneração tende a crescer com a idade devido à valorização da experiência. O efeito período se referem ao contexto relevante a um determinado problema em uma determinada época. Por exemplo, para indivíduos da mesma idade, a expectativa de vida durante a Idade Média era certamente menor do que nos dias atuais. Da mesma forma que, independentemente da faixa etária, as taxas de desemprego vivenciadas no Brasil dos anos 1990 foram

${ }^{16} \mathrm{O}$ leitor interessado nesta literatura pode recorrer às revisões de Rosenfeld (1992), Feldman e $\mathrm{Ng}$ (2007) ou Vinkenburg e Weber (2012).

17 Para uma aplicação pioneira em epidemiologia, veja Frost (1940). Em ciências sociais, veja Mason et al. (1973). Para alguns aspectos metodológicos e alternativas envolvendo a aplicação da técnica, veja Guimarães e Rios-Neto (2011). 
maiores do que as dos anos 2000. Já o efeito coorte diz respeito a mudanças vivenciadas por grupos de indivíduos de mesma idade. Este efeito coorte, em ciências sociais, pode ser resumido por uma frase dita por nossos avós: "os jovens de hoje não são como os de antigamente". Ou seja, um adolescente de 17 anos em 2015 provavelmente não pensa, não vive e não tem as mesmas expectativas de um adolescente de 17 em 1915, mesmo que fosse possível trocarem de papel entre si - tendo, portanto, mesma idade e vivenciando o mesmo período. ${ }^{18}$

O desenho metodológico proposto para a tese segue o seguinte esquema disposto na Tabela 14:

- O caso-base são os engenheiros jovens entre 2003 e 2012 (geração 2000). Conforme argumentado na introdução, o interesse básico é mapear os grandes padrões de trajetórias de ocupações dos jovens engenheiros entre 2003 e 2012 , e quais são os resultados e determinantes destas trajetórias.

- Este resultado será comparado a uma coorte de jovens engenheiros (definidos da mesma maneira) nos anos 1995-2002 (geração 90).

- Analogamente, o caso-base será comparado aos engenheiros da "geração 90" nos anos 2000.

Tabela 14 - Desenho metodológico

\begin{tabular}{l|l|l}
\hline & O que fica & O que muda \\
\hline Engenheiros jovens, 2003-2012: geração 2000 em 2000 & caso-base & caso-base \\
\hline Engenheiros jovens, 1995-2002: geração 90 em 90 & idade & período e coorte \\
\hline Engenheiros da geração 90, 2003-2012: geração 90 em 2000 & período & idade e coorte \\
\hline
\end{tabular}

Fonte: elaboração própria.

Formalmente, este desenho metodológico não permite isolar totalmente o efeito coorte. No caso, este efeito coorte poderia surgir de características intrínsecas às diferentes gerações, ou de mudanças significativas no acesso à educação ou nos currículos educacionais. Entretanto, pode-se supor que as duas gerações de engenheiros são suficientemente próximas para que este efeito coorte não seja tão significativo. Se o efeito coorte for desconsiderado, então nos dois últimos exercícios é possível identificar o efeito período e o efeito idade, respectivamente.

De todo modo, há boas razões para supor que o efeito período seja forte. O cenário de mercado de trabalho para os engenheiros durante a década de 1990 foi bem diferente do cenário dos anos 2000. Por suposição, o engenheiro é mais demandado em situações de crescimento econômico em geral e da indústria e da construção civil em particular. Como mostrado na Tabela 15, durante o período 2003-2012 houve crescimento mais

${ }^{18}$ Em epidemiologia, o efeito coorte poderia indicar, por exemplo, a evolução da imunidade de uma população com respeito a uma determinada doença ao longo do tempo, independentemente da faixa etária. 
acelerado tanto do PIB geral quanto da construção civil e da indústria, com criação de postos de trabalho e redução da taxa de desemprego. ${ }^{19}$

Tabela 15 - Cenário Econômico, 1995-2002 vs. 2003-2012

\begin{tabular}{lrr}
\hline & 1995-2002 & 2003-2012 \\
\hline Crescimento médio do PIB (\% a.a.) & 2,00 & 3,47 \\
Crescimento médio do PIB da construção civil (\% a.a.) & 1,04 & 3,77 \\
Crescimento médio do PIB da indústria (\% a.a.) & 1,44 & 3,94 \\
Taxa de investimento (\% do PIB) & 16,93 & 17,52 \\
Taxa de desemprego (PNAD) (\%) & 8,99 & 8,82 \\
Nível de emprego na indústria paulista (jun 2005=100) & 93,41 & 100,79 \\
Criação média de vagas formais (em milhares por ano) & 99,41 & $1.328,69$ \\
Engenheiros jovens no mercado de trabalho & 5.046 & 9.041 \\
\hline
\end{tabular}

Fonte: elaboração própria a partir do Ipeadata.

Sem embargo, o Sindicato dos Engenheiros do Estado de São Paulo (SEESP, 2014) indica que o número de engenheiros com carteira assinada no Estado cresceu 80\%, entre 2003 e 2013. Enquanto isso, o emprego formal no Estado cresceu 60\%. Para comparação, o mesmo estudo indica que o crescimento dos engenheiros com carteira assinada entre 1995 e 2005 foi de somente $18 \%$.

Outro indicador de aceleração na demanda dos engenheiros é a própria demanda dos cursos de engenharia. Conforme comentado na introdução, ela se acelerou fortemente nos anos 2000, indicando uma expectativa de uma boa carreira por parte dos jovens.

\subsection{Opções metodológicas para o alinhamento de sequências}

O software estatístico utilizado para aplicar de análise de sequências foi o $\mathrm{R}$ em sua versão 3.02, e o pacote que possibilitou a análise de sequências foi o TraMineR, tal qual descrito em Gabadinho et al. (2011).

$\mathrm{Na}$ aplicação de análise de sequências, há cinco etapas fundamentais: (i) a codificação dos estados possíveis; (ii) a definição dos períodos sob análise (e a

${ }^{19}$ O leitor pode questionar se a redução da taxa de desemprego, tal qual mensurada pela Pesquisa Nacional por Amostragem Domiciliar (PNAD), não deveria ter sido maior nos anos 2000. Em verdade, há três hipóteses para explicar porque a taxa de desemprego não caiu tão fortemente. A primeira é que a intensa geração de postos de trabalho no mercado formal atraiu trabalhadores do setor informal. Isto é, os informais dos anos 90 passaram à formalização nos anos 2000 , sem que isso tivesse impacto significativo na taxa de desemprego geral. A segunda é que, durante o período, pelo momento demográfico brasileiro, havia muitos indivíduos jovens entrando no mercado de trabalho. De acordo com esta hipótese, a geração de novos postos de trabalho absorveu estes jovens sem reduzir de forma tão significativa a taxa de desemprego. A terceira hipótese é que o aquecimento do mercado de trabalho pode ter estimulado muitas pessoas a sair da inatividade ou do desalento, situação em que o indivíduo não trabalha, mas também não procura emprego, não se enquadrando, portanto, no conceito de desempregado. 
consequente duração das sequências); (iii) a definição do algoritmo de análise de sequências; (iv) a arbitragem dos custos indel e de substituição entre os estados, quando for o caso; e (v) o critério para o agrupamento das sequências.

Quanto à codificação, optou-se por codificar as centenas de CBOs 4 dígitos em 8 grupos, conforme o seguinte esquema:

\section{Gráfico 8 - Esquema de classificação das ocupações}

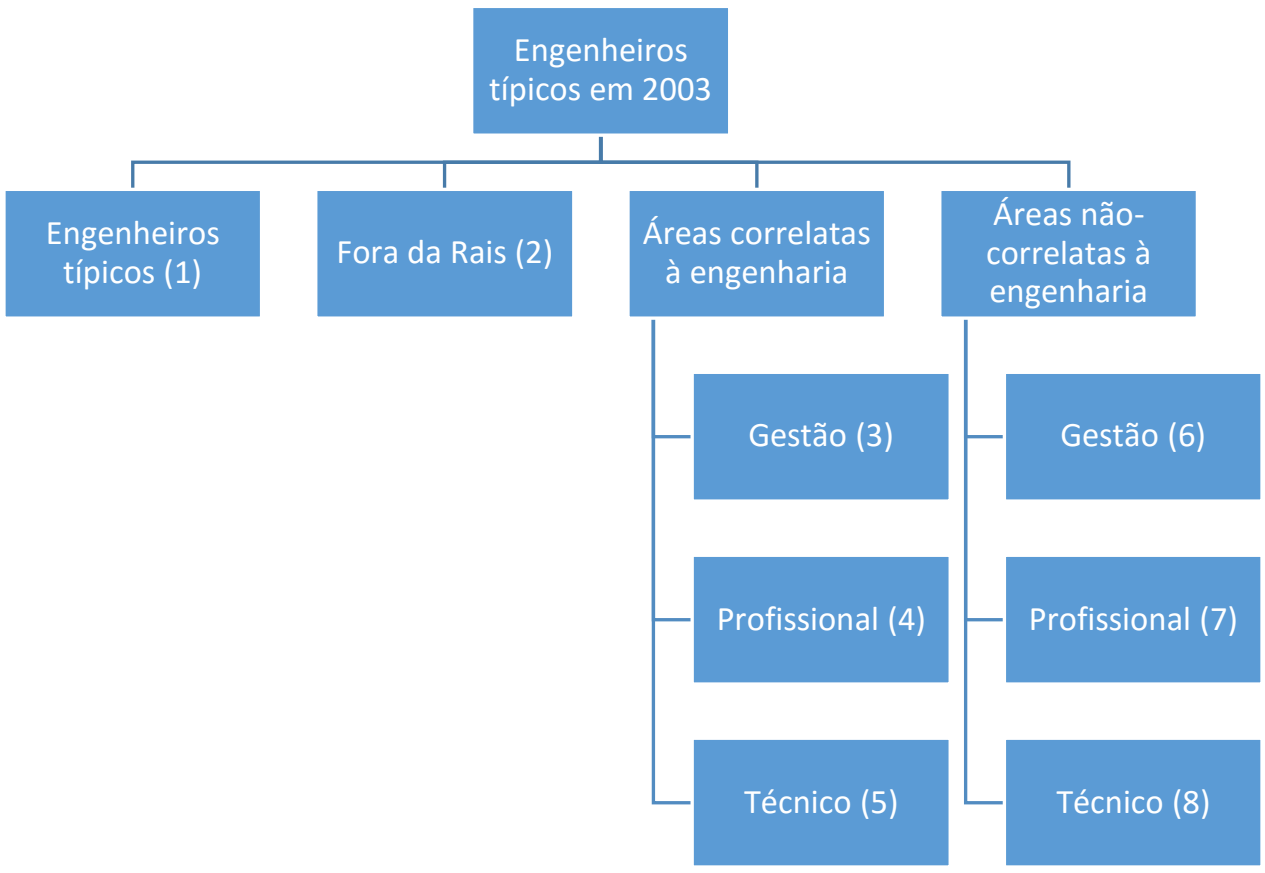

Fonte: Elaboração própria.

Sabendo que, por definição, todos os profissionais da base eram engenheiros típicos em 2003, a primeira codificação é justamente a dos (1) engenheiros em ocupações típicas. Estes são aqueles profissionais em CBOs da lista do Gráfico 5. A partir de uma definição hierárquica, separaram-se os engenheiros que seguiram em ocupações correlatas à engenharia ou não. Dentro de cada possibilidade, há uma separação entre os níveis de gestão $(3,6)$, profissional $(4,7)$ e técnico $(5,8)$. A classificação de todas as 504 CBOs diferentes que os jovens engenheiros exercem entre 2003 e 2012 está à disposição sob solicitação. Exemplos das CBOs em cada classificação encontram-se na Tabela 16 abaixo.

Tabela 16 - Exemplos de CBO em cada codificação

\begin{tabular}{|c|c|c|c|}
\hline $\begin{array}{l}\text { Engenharia ou } \\
\text { Não-engenharia }\end{array}$ & Nível & $\mathrm{CBO}$ & Descrição \\
\hline Engenharia & gestor & 1234 & DIRETORES DE SUPRIMENTOS E AFINS \\
\hline Engenharia & gestor & 1413 & $\begin{array}{l}\text { GERENTES DE OBRAS EM EMPRESA DE } \\
\text { CONSTRUÇÃO }\end{array}$ \\
\hline Engenharia & profissional & 2041 & PERITOS CRIMINAIS \\
\hline Engenharia & profissional & 2111 & PROFISSIONAIS DA MATEMÁTICA \\
\hline Engenharia & técnico & 3003 & TÉCNICOS EM ELETROMECÂNICA \\
\hline Engenharia & técnico & 3011 & TÉCNICOS DE LABORATÓRIO INDUSTRIAL \\
\hline
\end{tabular}




\begin{tabular}{|c|c|c|c|}
\hline Não-engenharia & gestor & 1225 & $\begin{array}{l}\text { DIRETORES DE SERVIÇOS DE TURISMO, DE } \\
\text { ALOJAMENTO E DE ALIMENTAÇÃO }\end{array}$ \\
\hline Não-engenharia & gestor & 1421 & $\begin{array}{l}\text { GERENTES ADMINISTRATIVOS, FINANCEIROS, DE } \\
\text { RISCOS E AFINS }\end{array}$ \\
\hline Não-engenharia & profissional & 2033 & PESQUISADORES DAS CIÊNCIAS DA SAÚDE \\
\hline Não-engenharia & profissional & 2035 & $\begin{array}{l}\text { PESQUISADORES DAS CIÊNCIAS SOCIAIS E } \\
\text { HUMANAS }\end{array}$ \\
\hline Não-engenharia & técnico & 3513 & TÉCNICOS EM ADMINISTRAÇÃO \\
\hline Não-engenharia & técnico & 3514 & SERVENTUÁRIOS DA JUSTIÇA E AFINS \\
\hline Engenheiro típico & $\begin{array}{l}\text { Engenheiro } \\
\text { típico }\end{array}$ & 2142 & ENGENHEIROS CIVIS E AFINS \\
\hline Engenheiro típico & $\begin{array}{l}\text { Engenheiro } \\
\text { típico }\end{array}$ & 2144 & ENGENHEIROS MECÂNICOS E AFINS \\
\hline
\end{tabular}

Fonte: elaboração própria a partir da Rais.

Resta classificar aqueles profissionais que saem da Rais. Este mapeamento foi feito a partir de uma análise dos Censos 2010 (para retratar a “geração 2000”) e de 2000 (para retratar a geração 90). Os Censos são as únicas bases de dados que permitem combinar a área de formação do curso superior e a situação profissional, inclusive desemprego, autoemprego ou informalidade. Todos os detalhes desta comparação estão no anexo 1.

Cabe alertar, porém, que a comparação direta entre o Censo 2010 e a amostra de engenheiros na Rais entre 2003 e 2012 não é possível devido a basicamente dois fatores:

a) A definição dos engenheiros é diferente. No Censo de 2010, os engenheiros foram definidos a partir da área de formação do curso superior, enquanto na Rais os engenheiros jovens foram definidos a partir do exercício de CBOs em engenharia em 2003. A definição da Rais é mais restritiva, pois como se trata de uma profissão regulamentada por órgão de classe, o exercício de CBO de engenharia geralmente está vinculado ao curso superior em engenharia, mas o inverso não necessariamente é verdadeiro. Em outras palavras, aqueles indivíduos jovens que começaram suas trajetórias profissionais fora da engenharia não foram capturados pelo estudo com a Rais;

b) O Censo não permite recuperar a história profissional em 2003. Embora tenha-se optado por cortes etários compatíveis, o Censo não traz o ano de formatura dos profissionais, então pode ocorrer que alguns dos engenheiros entre 29 e 32 anos em 2010 tenham se formado depois de 2003.

Feito este alerta, resumidamente, os passos da comparação foram os seguintes:

1. Como a análise a partir da Rais estabelece como engenheiro jovem os profissionais com 25 anos ou menos que exerciam uma CBO de engenharia em 2003, o filtro etário para a análise a partir do Censo foi entre 29 e 32 anos engenheiros que em 2003 tinham entre 22 e 25 anos, assumindo 22 anos uma idade mínima para se formar em engenharia. Entretanto, como mencionado, estes profissionais podem ter se formado posteriormente a 2003. 
2. Os engenheiros foram definidos como profissionais com nível superior formados na grande área 5 ("engenharia, produção e construção") e 62 ("agricultura, florestas e recursos pesqueiros”), exceto a área 581, qual seja, "arquitetura e urbanismo", de acordo com o arquivo "Cursos Superiores_Estrutura 2010.xls", presente da documentação de apoio do Censo 2010. A estrutura de códigos de cursos superiores em 2000 é diferente, mas buscou-se manter a comparabilidade entre os dois Censos, como explicado no anexo 1.

Desta forma, foram identificados dos 8.976 profissionais formados em engenharia potencialmente fora da Rais em um determinado ano - por razões como desemprego, conta-própria, negócio próprio e informalidade. Estes profissionais representavam $42 \%$ do total de engenheiros diplomados entre 29 e 32 anos em 2010: Destes:

1) 447 ou $5 \%$ estavam desempregados ${ }^{20}$;

2) 2.046 ou $23 \%$ estavam sem trabalhar e também não procuraram emprego;

3) 3.559 ou $40 \%$ eram conta-própria;

4) 1.778 ou $20 \%$ eram empregadores;

5) 1.072 ou $12 \%$ eram empregados sem carteira assinada.

6) 74 ou menos de $1 \%$ trabalhava para o próprio consumo ou sem remuneração.

Deste modo, $72 \%$ dos trabalhadores potencialmente fora da Rais continuavam no mercado de trabalho como conta-própria, empregadores ou sem carteira assinada.

Para comparação, utilizando critérios semelhantes em 2000, 2.147 ou 43,5\% dos engenheiros estavam potencialmente fora da Rais. Destes:

1) 256 ou $12 \%$ estavam desempregados;

2) 175 ou $8 \%$ estavam sem trabalhar e também não procuraram emprego;

3) 631 ou $29 \%$ eram conta-própria;

4) 394 ou $18 \%$ eram empregadores;

5) 659 ou $31 \%$ eram empregados sem carteira assinada.

6) 32 ou $2 \%$ trabalhava para o próprio consumo, sem remuneração ou como empregado doméstico (com carteira ou sem carteira).

Portanto, $78 \%$ trabalhadores potencialmente fora da Rais continuavam no mercado de trabalho como conta-própria, empregadores ou sem carteira assinada.

Assim, deduz-se que a grande parte dos trabalhadores que saem da Rais continuam no mercado de trabalho de algum modo. Esta constatação dá suporte a duas decisões.

Uma, mais simples, diz respeito ao nome da categoria: neste trabalho, ela será denominada simplesmente "fora da Rais", pois não é possível afirmar com segurança se estes trabalhadores se transformaram em conta-própria, empregadores ou mesmo informais sem carteira assinada.

\footnotetext{
${ }^{20}$ Este valor representa 2\% do total, e é correspondente à cifra reportada por Menezes-Filho,
} (2012). 
A segunda guarda relação com inserções e eliminações de estados em análises de sequências - as operações indel. Nos estudos revisados no capítulo 2, as transições entre emprego e inatividade ou desemprego são tratadas como inserções ou eliminações de estados, e, portanto, como demandantes de arbitragem para os custos indel. Caso se considere que os fora da Rais não saem do mercado de trabalho, então isto implica que as trajetórias ocupacionais dos jovens engenheiros são completas e não há operações indel, portanto, a questão da arbitragem destes custos de eliminação e inserção não é crucial. ${ }^{21}$ Ademais, estas características abrem espaço para a comparação do Optimal Matching com a medida dinâmica de Hamming, aplicada em Lesnard (2008) e discutida no capítulo anterior, e só aplicável a sequências completas. De toda forma, uma comparação entre o OMA considerando o fora da Rais como um estado e o OMA considerando sair da Rais como indel está no próximo capítulo e no anexo 2.

O intervalo de tempo é anual, então cada sequência é composta de 9 estados (vale lembrar que todos os jovens engenheiros em 2003 exerciam ocupação típica).

As 10 sequências mais comuns estão no Gráfico 9. Estas 10 sequências respondem por $30 \%$ do total das sequências observadas, e aproximadamente $15 \%$ dos jovens engenheiros permanecem como engenheiros típicos durante todo o período. Com efeito, ao todo são 3.610 sequências diferentes.

${ }^{21}$ Em realidade, a aplicação do OMA no pacote TraMineR demanda que se arbitre um valor de referência para os custos indel, mas como não há operações de tal tipo na aplicação, estes alteram apenas a escala dos custos de substituição entre os estados. 


\section{Gráfico 9 - Sequências mais frequentes, 2004-2012}

\section{Sequências mais frequentes}

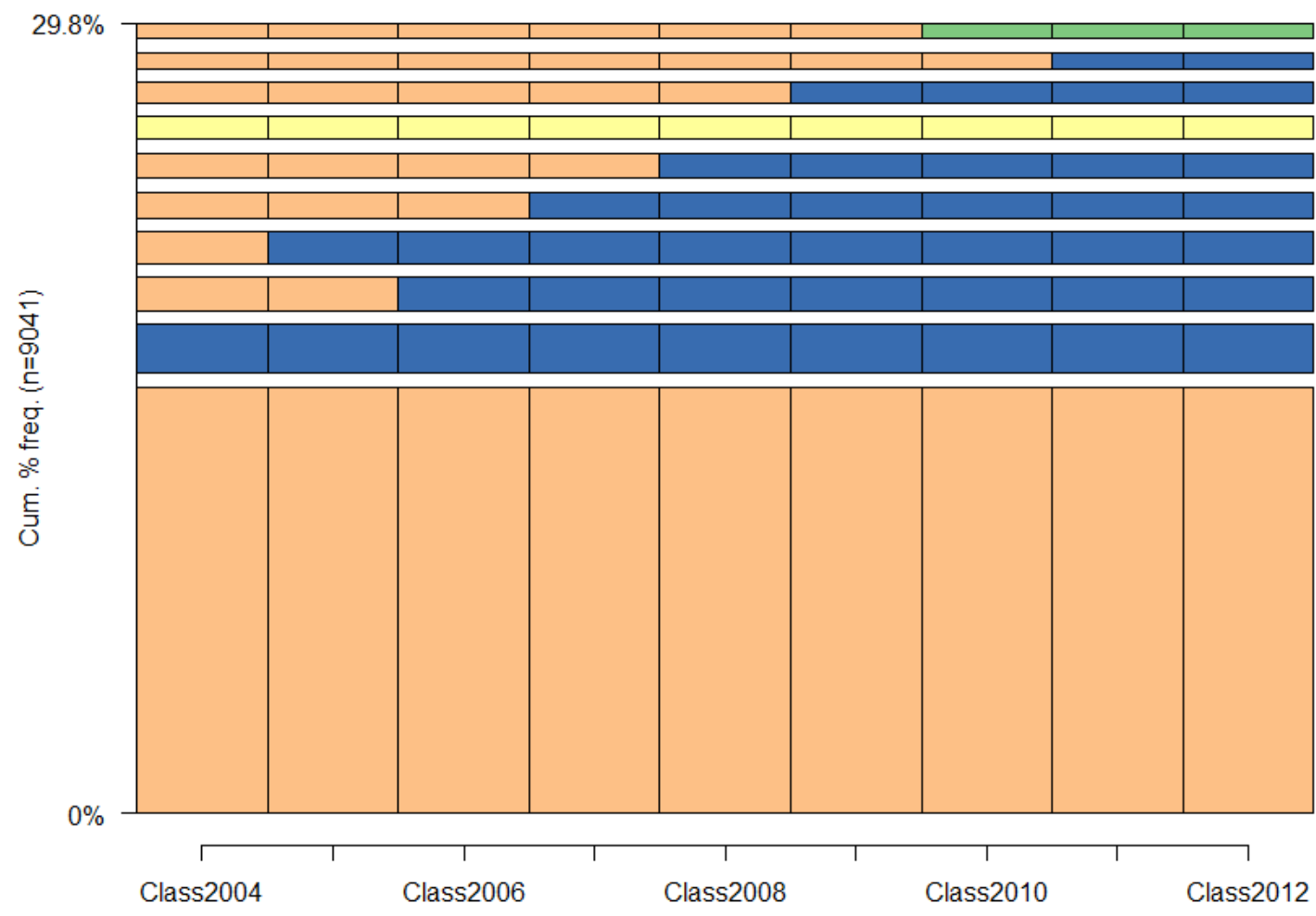

Fonte: elaboração própria a partir da Rais.

O Gráfico 10 é o tempograma, que representa a distribuição dos estados possíveis por ano de todas as observações. Como esperado, uma proporção cada vez menor permanece como engenheiro típico conforme os anos vão passando. A categoria que mais absorve estes engenheiros típicos é a dos fora da Rais. 


\section{Gráfico 10 - Distribuição dos estados por ano, 2004-2012}

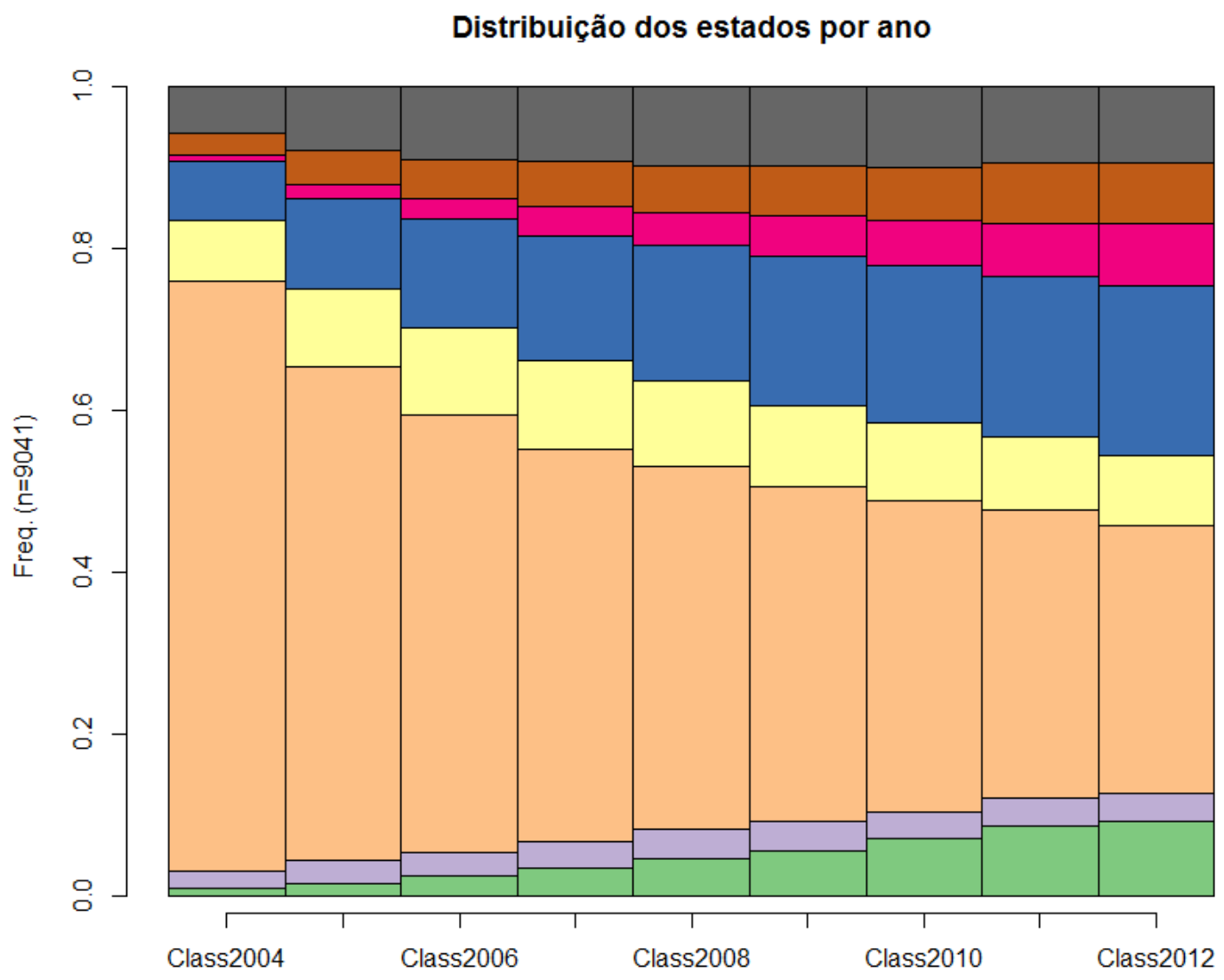

Fonte: elaboração própria a partir da Rais.

O Gráfico 11 mostra a distribuição de duas medidas complexidade das sequências, a entropia e a complexidade de Elzinga (2010). Estas medidas são calculadas para cada indivíduo, conforme discutido no capítulo anterior. Tanto a entropia quanto a complexidade apresentam distribuição assimétrica à esquerda, indicando maior presença relativa das sequências mais simples. Este, porém, era um resultado esperado, pois a trajetória mais comum é exatamente permanecer como engenheiro típico durante todo o período. O gráfico ainda mostra que entropia e complexidade são fortemente relacionadas (a correlação entre as duas é 0,91). 


\section{Gráfico 11 - Medidas de complexidade das trajetórias: entropia e complexidade, 2004-2012}
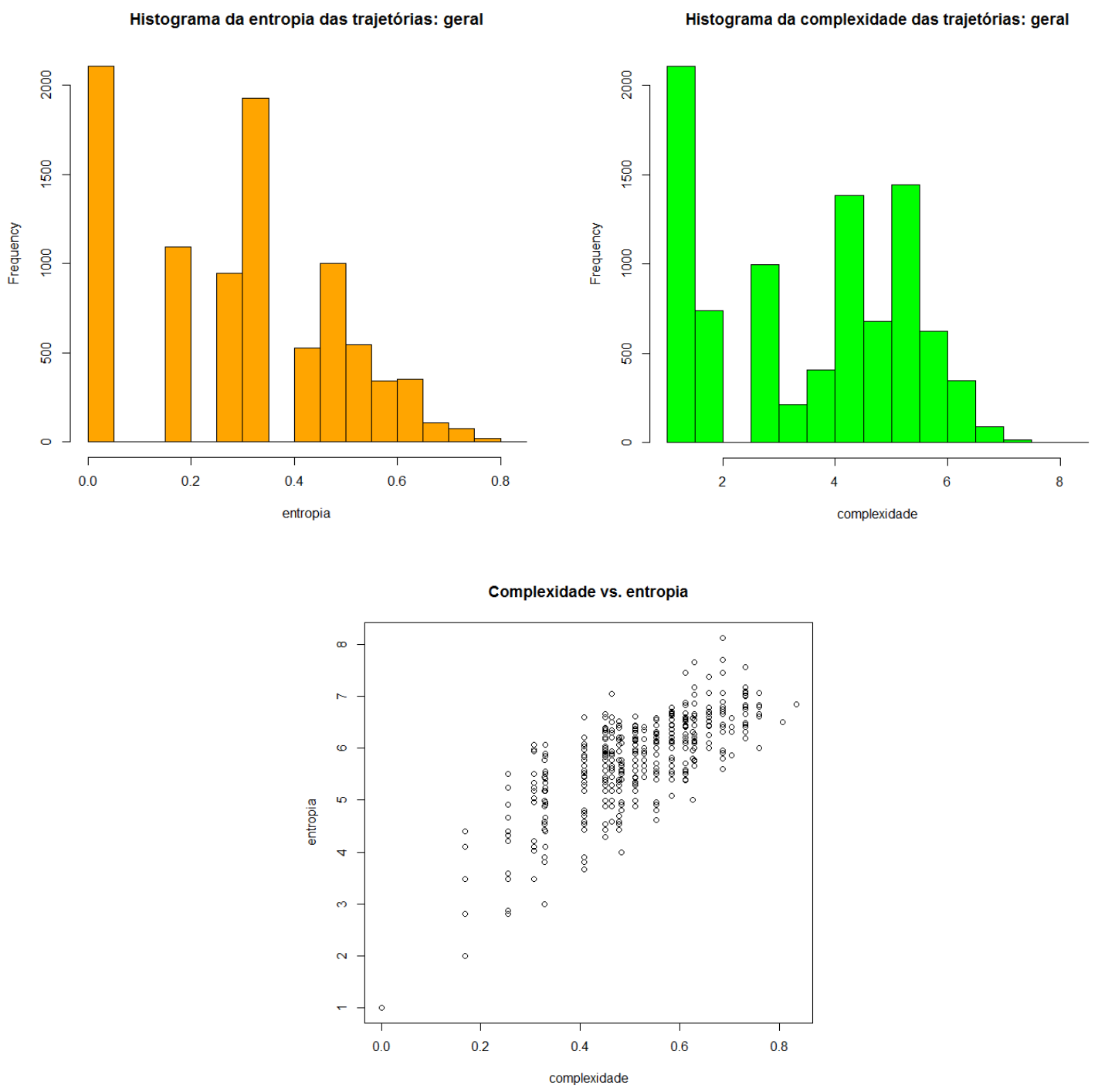

Fonte: elaboração própria a partir da Rais.

A aplicação do Optimal Matching Analysis pressupõe a arbitragem de custos para as transições de estado. Ainda que os fora da Rais sejam tratados como um estado (e não como missings), a aplicação do OMA no pacote TraMiner exige a arbitragem de um custo indel para referência. Estes custos foram arbitrados como 1, o que significa que o custo de substituição (adição seguida de remoção ou vice-versa) seria, teoricamente, igual a 2.

Este custo de substituição é o custo máximo. Seguindo o padrão da literatura, os custos de transição entre os estados foram calibrados com base nas frequências observadas destas transições, partindo do pressuposto de que as transições mais frequentes são menos custosas, e vice-versa, conforme a equação (4) na seção anterior.

A matriz com os custos de transição para a aplicação do OMA se encontra a seguir. Nota-se que a transição dos estados entre eles, por definição, é zero. As transições mais 
raras são a passagem de uma área não-correlata à engenharia em nível de gestão para uma área correlata à engenharia em nível profissional (ou vice-versa, com custo de 1,977), ou em nível técnico (custo de 1,975). Já as passagens de engenheiro típico para o fora da Rais são as mais comuns (custo de 1,880), mas cabe notar que a passagem de engenheiro típico para área correlata à engenharia em nível técnico é comum também (custo de 1,886). Interessantemente, a transição da gestão em não-engenharia para engenharia (ou vice-versa) não é tão rara (custo de 1,905).

Cabe notar que a aplicação que envolve a distância dinâmica de Hamming utiliza uma matriz de transição como a da Tabela 17 para cada ano.

Tabela 17 - Matriz com os custos de transição entre os estados

\begin{tabular}{|c|c|c|c|c|c|c|c|c|c|c|}
\hline & \begin{tabular}{|c|} 
Freq \\
. Em \\
2012
\end{tabular} & $\begin{array}{ll}\% & \text { do } \\
\text { total } & \end{array}$ & $\begin{array}{l}\text { Corr. } \\
\text { Enga } \text { : } \\
\text { gestão }\end{array}$ & $\begin{array}{l}\text { Corr. } \\
\text { Enga: } \\
\text { prof. }\end{array}$ & Eng ${ }^{\circ}$ & $\begin{array}{l}\text { Corr. } \\
\text { Enga: } \\
\text { téc. }\end{array}$ & \begin{tabular}{|l|} 
Fora \\
da \\
Rais
\end{tabular} & $\begin{array}{l}\text { Não- } \\
\text { Enga } \\
\text { gestão }\end{array}$ & $\begin{array}{l}\text { Não- } \\
\text { Enga: } \\
\text { prof. }\end{array}$ & $\begin{array}{l}\text { Não- } \\
\text { Enga } \\
\text { téc. }\end{array}$ \\
\hline $\begin{array}{l}\text { Corr. } \\
\text { gestão }\end{array}$ & 850 & $9,40 \%$ & 0 & & & & & & & \\
\hline $\begin{array}{l}\text { Corr. Eng }{ }^{\mathrm{a}} \text { : } \\
\text { profissional }\end{array}$ & 297 & $3,30 \%$ & 1,970 & 0 & & & & & & \\
\hline Engenheiro & 2993 & $33,10 \%$ & 1,916 & 1,914 & 0 & & & & & \\
\hline 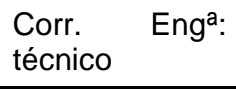 & 787 & $8,70 \%$ & 1,943 & 1,958 & 1,886 & 0 & & & & \\
\hline Fora da Rais & 1897 & $21,00 \%$ & 1,947 & 1,939 & 1,880 & 1,925 & 0 & & & \\
\hline $\begin{array}{l}\text { Não-Enga: } \\
\text { gestão }\end{array}$ & 683 & $7,60 \%$ & 1,905 & 1,977 & 1,946 & 1,975 & 1,940 & 0 & & \\
\hline $\begin{array}{l}\text { Não-Eng }{ }^{\mathrm{a}} \text { : } \\
\text { profissional }\end{array}$ & 693 & $7,70 \%$ & 1,966 & 1,937 & \begin{tabular}{|l|}
1,922 \\
\end{tabular} & 1,956 & 1,935 & 1,929 & 0 & \\
\hline $\begin{array}{l}\text { Não-Enga : } \\
\text { técnico }\end{array}$ & 841 & $9,30 \%$ & 1,956 & 1,961 & 1,913 & 1,901 & 1,902 & 1,905 & 1,895 & 0 \\
\hline Total & 9041 & $100,00 \%$ & & & & & & & & \\
\hline
\end{tabular}

Fonte: elaboração própria a partir da Rais.

Finalmente, o método de agrupamento utilizado foi o cluster, que é padrão na literatura. A escolha do número de clusters envolveu a análise da medida silhouette, disponível no pacote Cluster do R, e a inspeção visual do dendograma.

De acordo com a medida silhouette (ROUSSEEUW, 1987), o melhor ajuste do número de clusters é o que maximiza a medida silhouette média. Intuitivamente, a medida calcula a distância média de uma determinada observação em relação às outras observações do cluster ao qual este ponto pertence (denotada por $a(i)$ ), e compara esta distância à menor distância média entre esta observação e as observações dos clusters ao qual ela não pertence $(b(i))$. Assim, a medida silhouette é dada por

$$
s(i)=\frac{b(i)-a(i)}{\max (a(i), b(i))}
$$


Onde a medida varia entre -1 (situação em que a observação está mal alocada em seu cluster, pois a distância média dela em relação a um outro cluster é menor do que a distância média em relação às observações do próprio cluster) e +1 (situação oposta). Assim, para cada cluster há um silhouette médio, bem como para o conjunto dos clusters.

Deste modo, o Gráfico 12 abaixo mostra a evolução do silhouette médio e mediano com respeito ao número de clusters. O número de clusters que maximiza tanto a média quanto a mediana da medida é 8 .

\section{Gráfico 12 - Silhouette médio e mediano e número de clusters: OMA, 2004-2012}

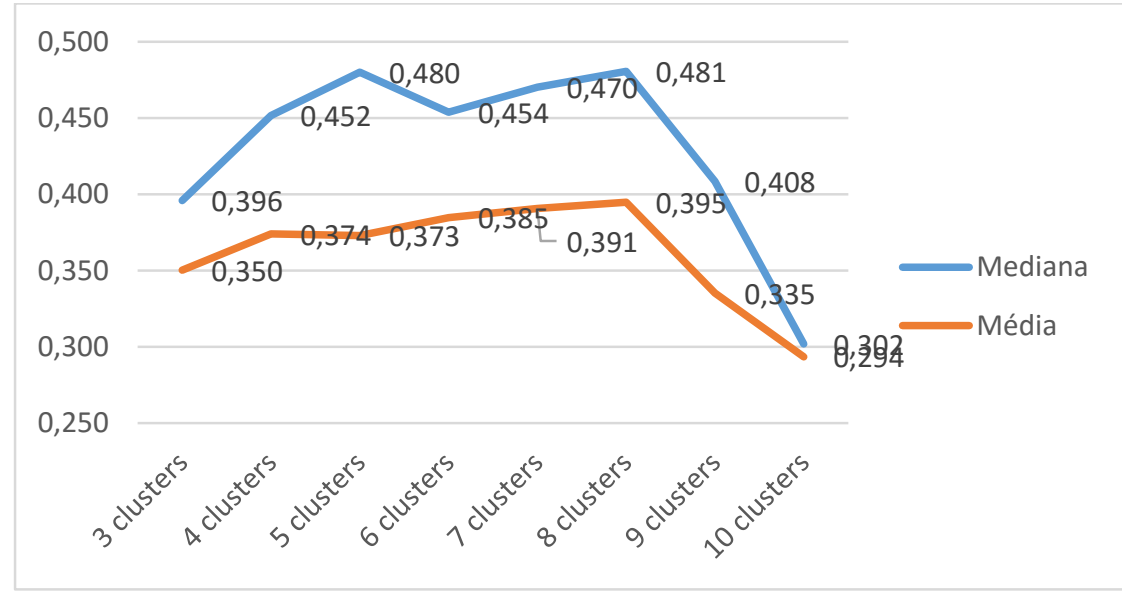

Fonte: elaboração própria a partir da Rais.

O gráfico silhouette (Gráfico 13) é uma espécie de histograma das medidas silhouette das observações em cada cluster. Quanto mais observações com silhouette maior que 0 e, entre estas observações, quanto mais próximo de 1 for o silhouette, melhor. Percebe-se que o cluster de maior silhouette médio é justamente o primeiro e mais numeroso. $\mathrm{O}$ silhouette máximo, atingido pela solução de 8 clusters, foi de 0,39 .

A linha vermelha no dendograma (Gráfico 14) indica o corte em 8 clusters, pois o número de grupos a formar é igual ao número de vezes que a linha cruza o dendograma. Percebe-se que se a linha vermelha cruzasse o dendograma um pouco acima, haveria 6 clusters, e um pouco mais abaixo, 9 clusters. Em comparação à solução de 8 clusters, a solução com 6 agrega os gestores em áreas correlatas à engenharia aos gestores em áreas não-correlatas, e também os profissionais em áreas correlatas aos de áreas não-correlatas. Já a solução de 9 clusters desagrega o grupo dos engenheiros típicos em um grupo que permanece como tal e outro que realiza transições para outros estados no final do período.

Tudo isso considerado, a solução preferida para o caso-base é a de 8 clusters, que provê os 8 padrões de trajetórias analisados no próximo capítulo. 
Gráfico 13 - Gráfico Silhouette por cluster: OMA, 2004-2012

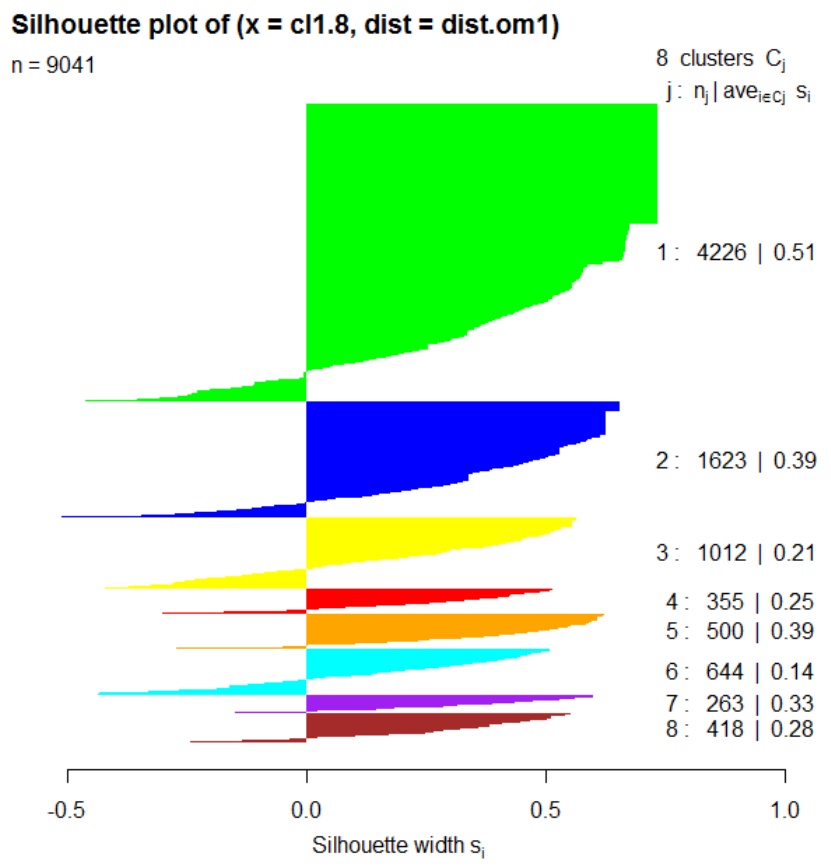

Average silhouette width : 0.39

Fonte: elaboração própria a partir da Rais.

Gráfico 14 - Dendograma para análise de cluster, 2004-2012

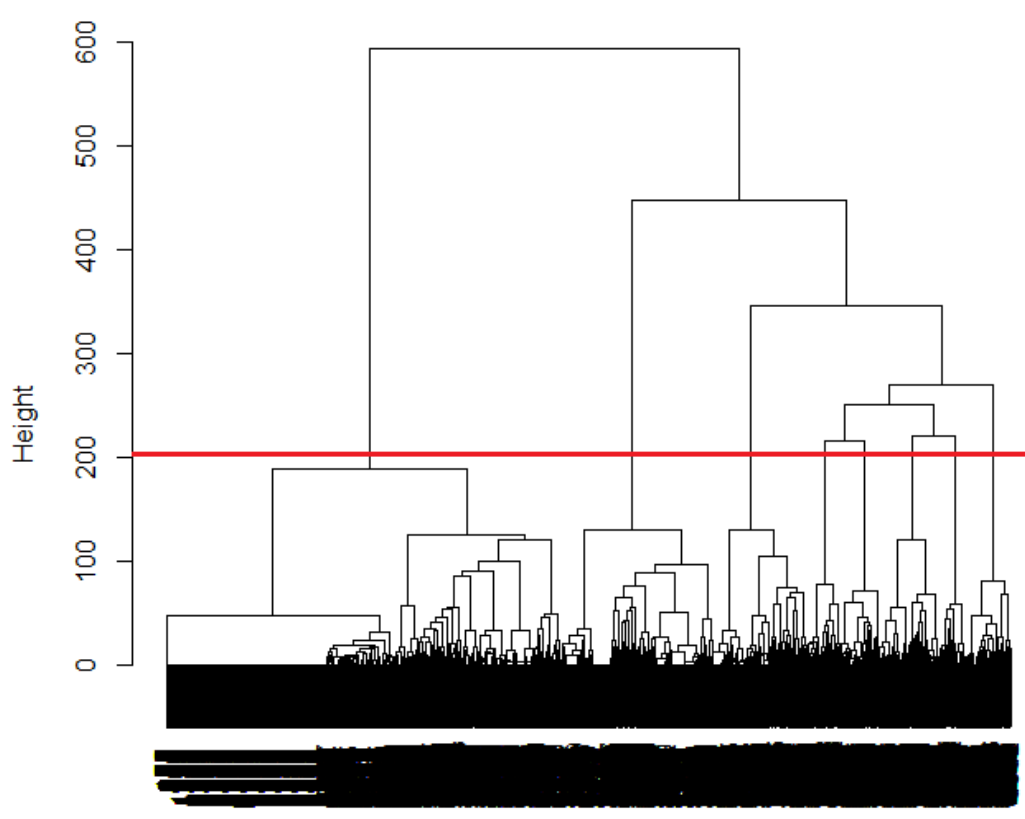

dist.om1

Agglomerative Coefficient $=1$

Fonte: elaboração própria a partir da Rais. 


\section{O CASO-BASE: ENGENHEIROS JOVENS, 2003-2012}

Este capítulo tem por objetivo responder às 4 primeiras perguntas de pesquisa presentes na introdução, quais sejam:

1. Quais são os grandes padrões de trajetórias de ocupações dos jovens engenheiros entre 2003 e 2012 ?

2. Quais são as sequências de ocupações mais comuns em cada trajetória?

3. Em que momento do tempo ocorre a definição destes padrões?

4. Quais são as características de remuneração e estabilidade no emprego referente a cada trajetória no final do período analisado? Em outras palavras, quais são os resultados de mercado de trabalho (labor market outcomes) de cada trajetória?

Os 8 padrões de trajetórias ocupacionais dos jovens engenheiros entre 2003 e 2012 estão identificados nos tempogramas a seguir (Gráfico 15). Ainda, o Gráfico 16 traz as sequências mais comuns por tipo de trajetória, o que além de ajudar a caracterizar os padrões permite também visualizar os momentos de transição entre ocupações.

Os 8 tipos de trajetória podem ser descritos da seguinte forma:

1. Engenheiros típicos ( $\mathrm{N}=4226)$ : São aqueles engenheiros que, majoritariamente, seguem em ocupações típicas da engenharia ao longo do período. Entretanto, nos últimos anos, é possível notar uma migração para outras categorias ocupacionais. Estes profissionais representam quase metade das 9.041 trajetórias;

2. Fora da Rais ( $\mathrm{N}=1623)$ : Categoria composta em sua maioria pelos engenheiros que, aproximadamente até 3 anos depois em ocupações típicas, saem da Rais. Como visto na seção anterior, supõe-se que mais de $70 \%$ destes trabalhadores continuam a trabalhar, seja como conta-própria, como empregadores ou mesmo informais;

3. Engenheiros técnicos em áreas correlatas à engenharia $(\mathrm{N}=1012)$ : São os engenheiros que já nos primeiros anos sob análise passam a exercer ocupações de nível técnico, mas em áreas correlatas à engenharia;

4. Engenheiros gestores em outras áreas $(\mathrm{N}=355)$ : Categoria composta por aqueles que, geralmente após 3 anos, assumem algum cargo gerencial ou de direção em área não-correlatas à engenharia (p. ex. $\mathrm{RH})$;

5. Engenheiros técnicos em outras áreas $(\mathrm{N}=500)$ : A exemplo do tipo 4, são os engenheiros que passam a exercer ocupações de nível técnico, mas desta vez em áreas não-correlatas à engenharia. Esta transição costuma ocorrer mais cedo que as outras categorias. Esta categoria é a de menor remuneração média;

6. Engenheiros profissionais em outras áreas ( $\mathrm{N}=644)$ : Engenheiros que terminam por exercer outras ocupações de nível superior, em áreas não-correlatas à engenharia;

7. Engenheiros profissionais em áreas correlatas à engenharia (N=263): Analogamente, são os profissionais que migram para ocupações de nível superior 
em áreas correlatas à engenharia. Ao final do período sob análise, em alguns casos parece haver uma nova transição para outras ocupações;

8. Engenheiros gestores em engenharia $(\mathrm{N}=418)$ : Estes engenheiros assumem ao longo do tempo um cargo de gestão em engenharia, como gerente de produção, por exemplo.

As 10 sequências mais comuns por padrão presentes no Gráfico 16 nunca representam menos que $20 \%$ das sequências possíveis - lembrando que, ao todo, foram identificadas 3.610 trajetórias ocupacionais distintas. A partir de sua análise, conclui-se que a definição de um padrão de trajetória ocupacional nestas sequências se dá, majoritariamente, até 3 anos após a entrada no mercado de trabalho.

Gráfico 15 - Tipos de trajetórias ocupacionais, 2004-2012

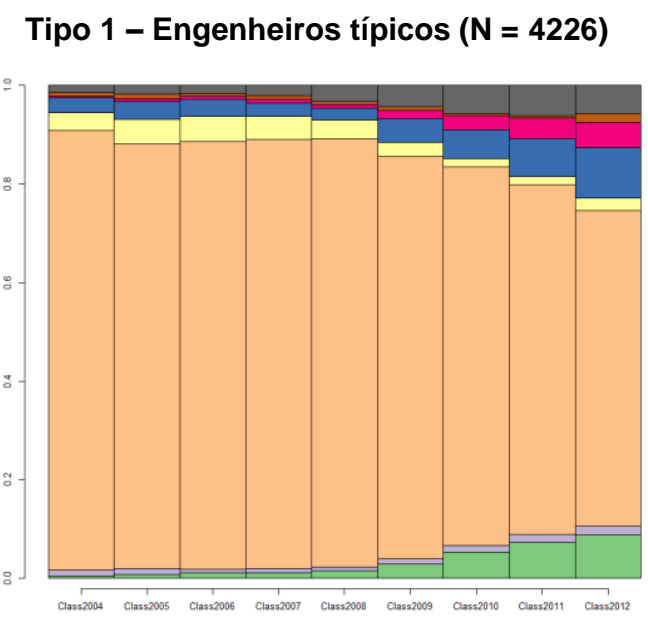

Tipo 3 - Técnicos em engenharia ( $N=1012)$

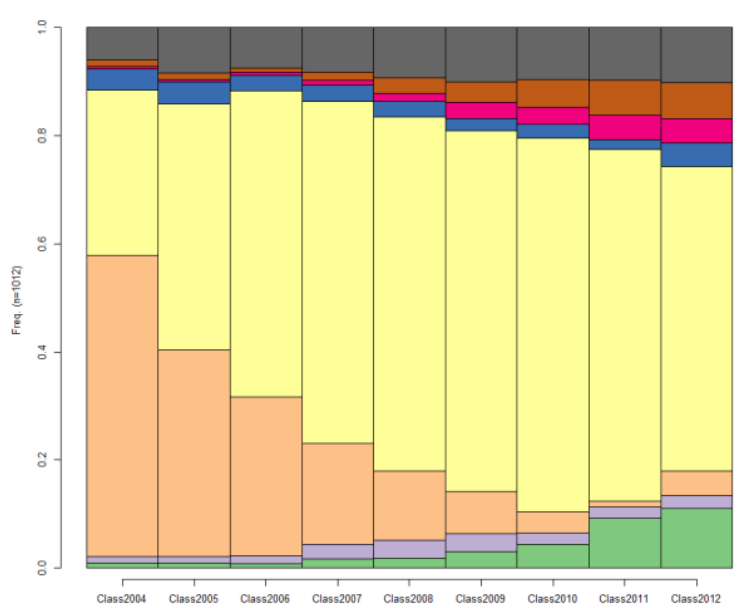

Tipo 2 - Fora da Rais $(\mathbf{N}=1623)$

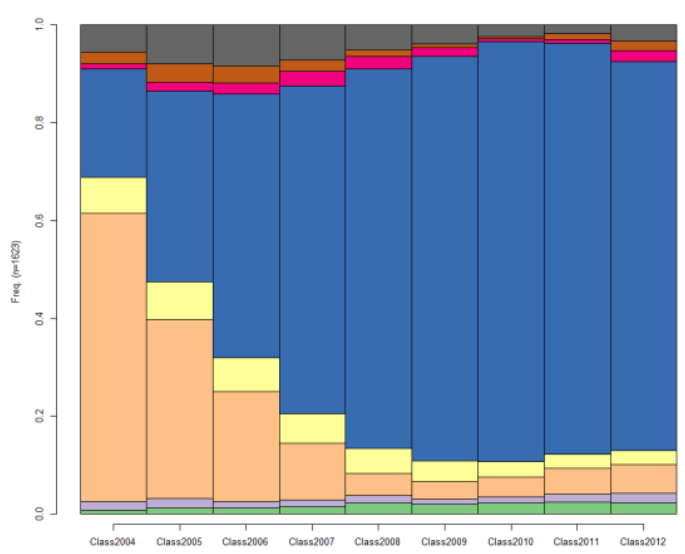

Tipo 4 - Gestores em outras áreas $(\mathrm{N}=355)$

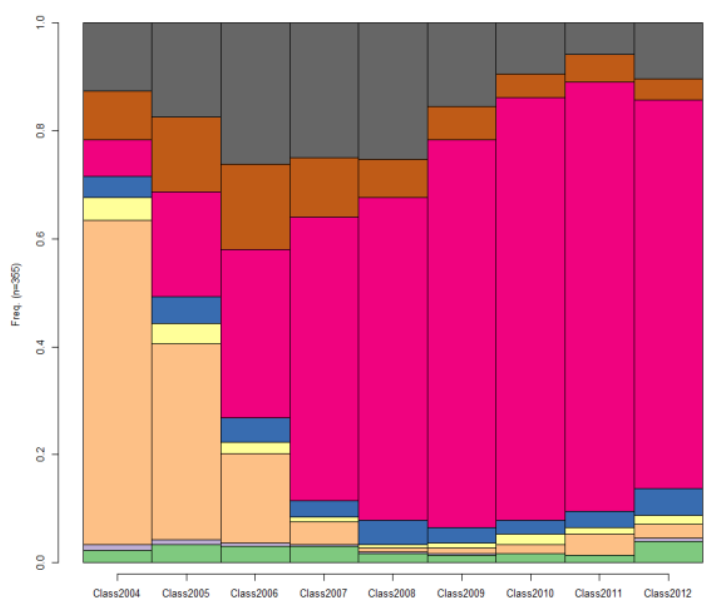


Tipo 5 - Técnicos em outras áreas $(\mathrm{N}=500)$

Tipo 6 - Prof. em outras áreas ( $N=644)$
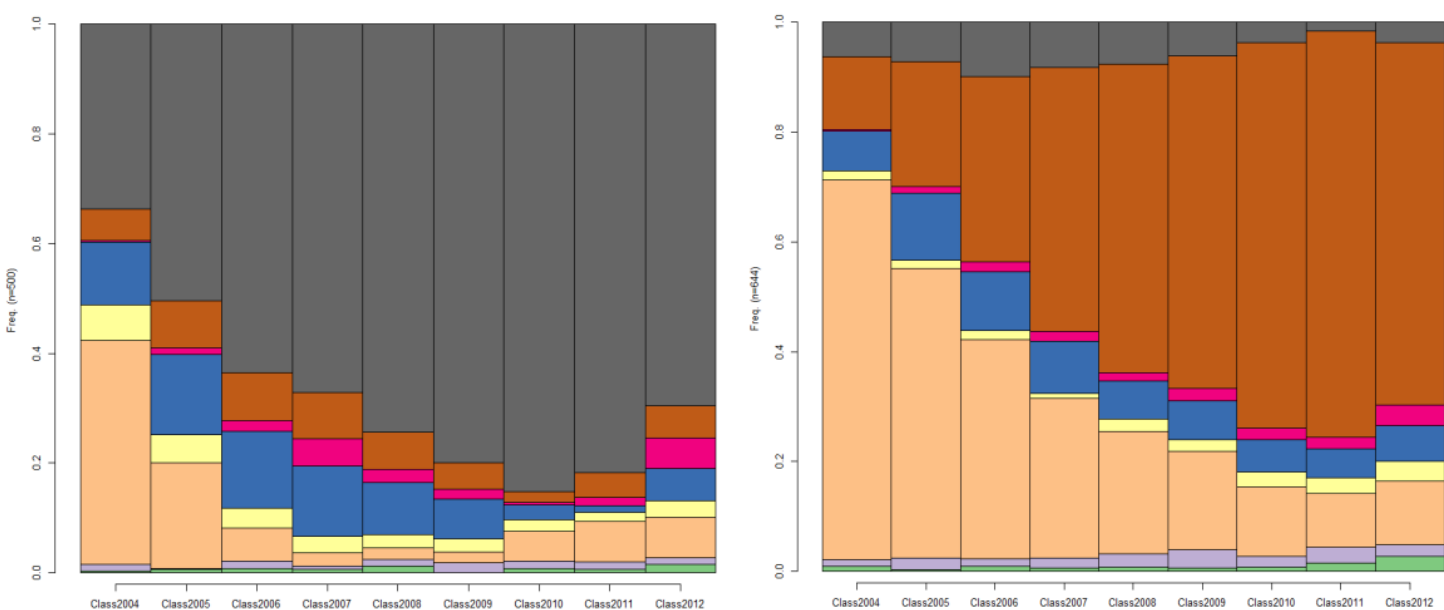

Tipo 7 - Prof. em áreas correlatas à eng ${ }^{\mathrm{a}}(\mathrm{N}=263)$

Tipo 8 - Gestores em engenharia ( $N=418)$
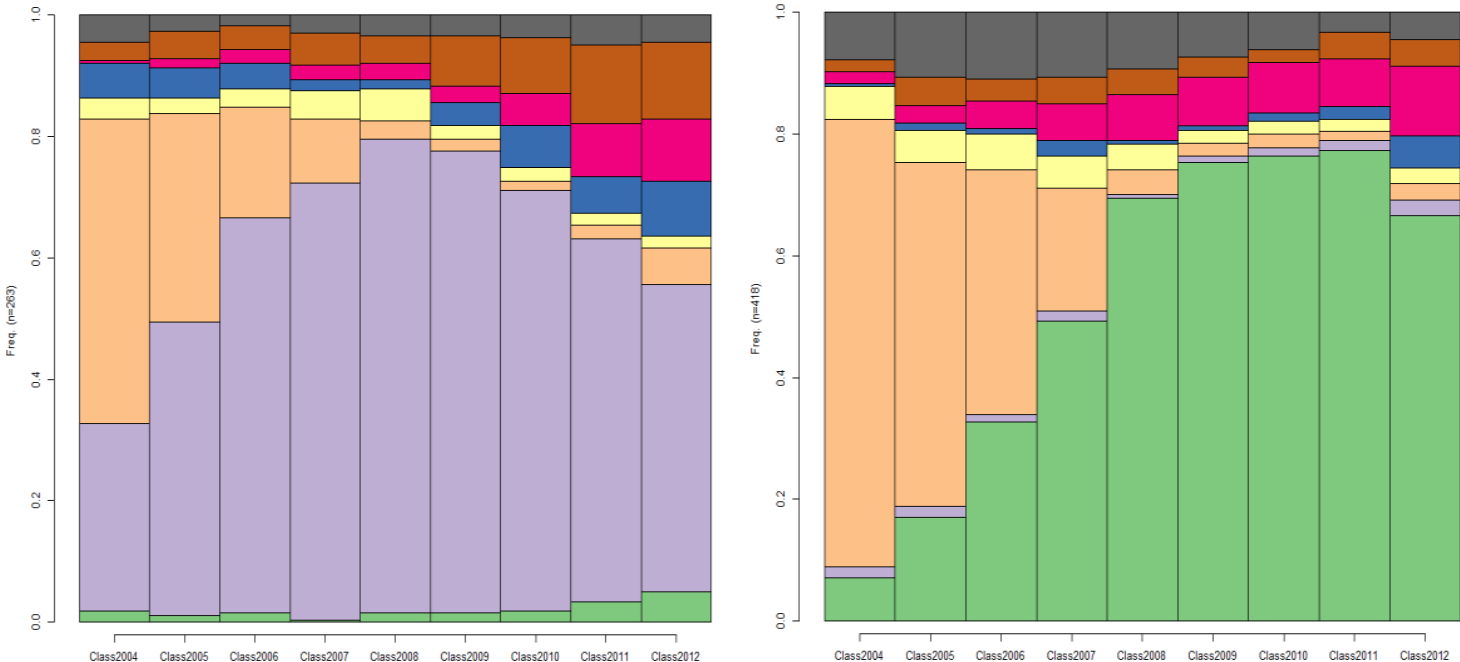

Corr. Enga: Gestão

$\square$ Corr. Enga: Profissional

Engenheiro

Corr. Enga: Técnico

- Fora da Rais

- Não-Enga: Gestão

- Não-Enga: Profissional

- Não-Enga: Técnico

Fonte: Elaboração própria, a partir da Rais. 
Gráfico 16 - Trajetórias mais frequentes por tipo de trajetória ocupacional, 2004-2012
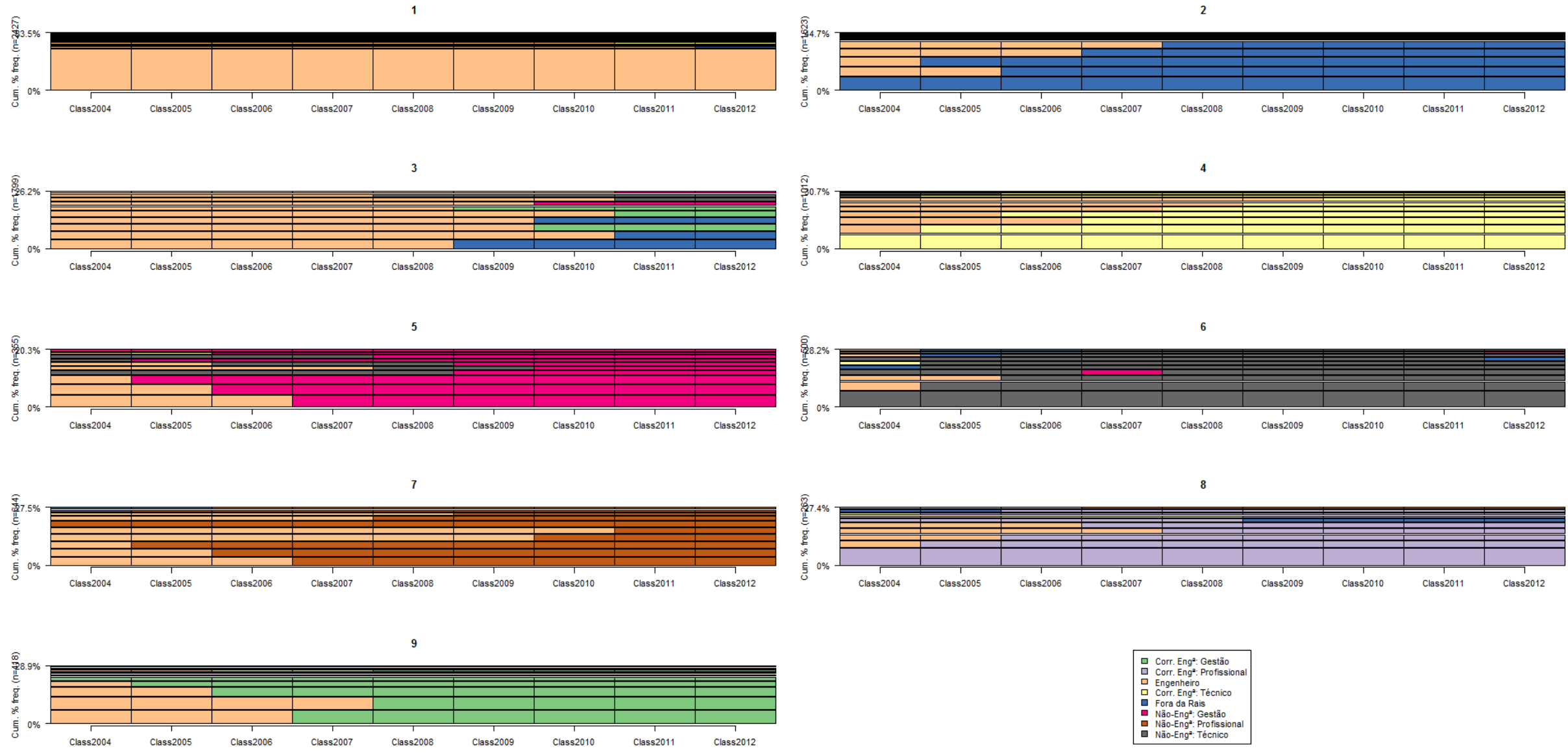

Fonte: elaboração própria a partir da Rais. 


\subsection{Comparação entre os algoritmos de alinhamento de sequências}

Esta subseção tem por objetivo comparar os algoritmos de alinhamento: OMA com o fora da Rais como um estado (caso-base), distância dinâmica de Hamming e OMA com os fora da Rais como missing. O anexo 2 traz os dendogramas, tempogramas e as sequências mais comuns das duas últimas aplicações.

A diferença entre os dois primeiros algoritmos é que o primeiro utiliza uma matriz de transição entre os estados constante, enquanto o segundo varia esta matriz de transição ao longo dos períodos. Ambos algoritmos tratam o fora da Rais como um estado, e não como operações de inserção e eliminação (indel).

A medida silhouette sugeriu soluções de 8 clusters em ambos os casos. Entretanto, no caso da aplicação de Hamming, a medida silhouette da solução de 10 clusters é bem próxima à de 8 . De fato, a inspeção do dendograma indica que a solução de 10 clusters em Hamming poderia gerar subdivisões interessantes. Porém, manter o número de clusters em 8 facilita a comparação, e esta solução de fato maximiza o silhouette médio.

No geral, a solução que emprega a distância dinâmica de Hamming é bem parecida com a do caso-base. Entretanto, o algoritmo de Hamming, por definição, é mais sensível a variações de estado no tempo. Isto fez com que o cluster referente aos gestores em engenharia desse lugar a um cluster que agrupou trajetórias mais mistas, sendo este cluster misto relativamente numeroso, e com alta heterogeneidade (Tabela 18). Fenômeno semelhante foi documentado em Aisenbrey e Fasang (2010), quando da comparação entre o OMA e a distância dinâmica de Hamming - sua categoria de "descontinuidade" (padrões mistos) havia crescido sensivelmente. De todo modo, tanto a média quanto a distribuição da medida de complexidade entre os clusters é semelhante, conforme evidenciado no Gráfico 17.

\section{Gráfico 17 - Box plot das medidas de complexidade: OMA (caso-base), distância de Hamming e OMA com fora da Rais como missing}
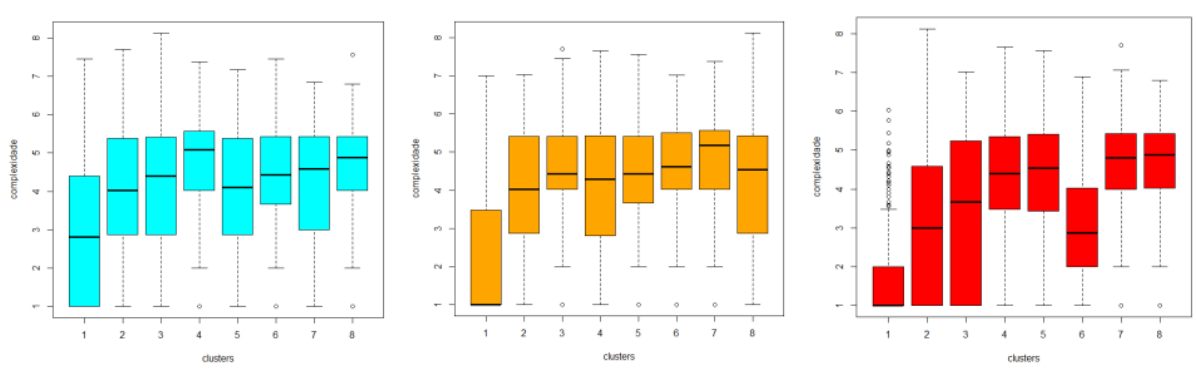

Da esquerda para a direita: OMA (caso-base), distância de Hamming, e OMA com fora da Rais como missing. Fonte: elaboração própria a partir da Rais.

Por sua vez, a diferença entre o caso-base e a aplicação do OMA com o fora da Rais como missing é que é atribuído custo " 2 " para entrar e sair da base de dados (custo equivalente a uma operação de eliminação seguida de inserção, o mais alto possível). Por definição, o padrão "fora da Rais" não existe nesta aplicação. 
Considerando a medida silhouette apenas, a solução preferida neste caso seria a de 7 clusters ( silhouette $=0,3669$ ). Entretanto, a inspeção do dendograma indica que a solução de 8 clusters também é interessante, pois divide a árvore no segundo importante nó da esquerda para a direita. Isto significou, na prática, separar a categoria dos engenheiros típicos em duas, e criar um cluster dos engenheiros típicos em transição. Nesse ponto, esta solução se assemelha ao caso-base com 9 clusters, conforme comentado anteriormente. De todo modo, foi adotada a seleção de 8 clusters para comparação com o caso-base.

Vale lembrar que, nesta aplicação, há sequências incompletas: a inspeção do gráfico das sequências mais frequentes em cada cluster, presente no anexo 2, indica que os clusters 2 e 4 possuem como sequências modais padrões em que o indivíduo sai da Rais e não retorna ao mercado de trabalho com carteira assinada. Já o padrão 3 (padrão misto) tem como sequências mais frequentes indivíduos que saem da Rais e retornam (legendados como missing pelo algoritmo).

De todo modo, a aplicação do OMA com os fora da Rais como missing também resulta em categorias semelhantes à aplicação original, exceção feita à substituição do cluster dos fora da Rais e dos profissionais em áreas correlatas à engenharia por um cluster de padrão misto e outro de engenheiros típicos em transição.

Enfim, considerando: (i) que a grande maioria dos fora da Rais continua trabalhando, o que não justificaria trata-los como operações indel; (ii) que o silhouette médio do casobase é o maior entre as três aplicações; (iii) a clareza na identificação dos padrões encontrados (validade analítica), a solução do OMA com os fora da Rais como um dos estados é a preferida.

Tabela 18 - Medida de complexidade: OMA (caso-base), Distância de Hamming e OMA com fora da Rais como missing

\begin{tabular}{|c|c|c|c|c|}
\hline & & $\begin{array}{l}\text { OMA com } \\
\text { fora da } \\
\text { Rais como } \\
\text { estado } \\
\text { (caso- } \\
\text { base) }\end{array}$ & $\begin{array}{l}\text { Distância } \\
\text { dinâmica } \\
\text { de } \\
\text { Hamming }\end{array}$ & $\begin{array}{l}\text { OMA com } \\
\text { fora da Rais } \\
\text { como } \\
\text { missing }\end{array}$ \\
\hline & Média-geral & 3,52 & 3,52 & 3,15 \\
\hline \multirow{3}{*}{ Engenheiros típicos } & $\mathrm{N}$ & 4.226 & 3.002 & 2.589 \\
\hline & média & 2,82 & 2,17 & 1,55 \\
\hline & desvio-padrão & 1,78 & 1,6 & 0,99 \\
\hline \multirow{3}{*}{ Fora da Rais } & $\mathrm{N}$ & 1.623 & 1.818 & \\
\hline & média & 3,81 & 3,84 & - \\
\hline & desvio-padrão & 1,6 & 1,55 & \\
\hline \multirow{3}{*}{ Técnicos em engenharia } & $N$ & 1.012 & 781 & 550 \\
\hline & média & 4,15 & 3,93 & 2,97 \\
\hline & desvio-padrão & 1,57 & 1,68 & 1,47 \\
\hline \multirow{3}{*}{ Gestores em outras áreas } & $N$ & 355 & 372 & 388 \\
\hline & média & 4,69 & 4,74 & 4,57 \\
\hline & desvio-padrão & 1,24 & 1,23 & 1,31 \\
\hline
\end{tabular}




\begin{tabular}{c|l|c|c|c} 
& $\mathrm{N}$ & 500 & 723 & 909 \\
Técnicos em outras áreas & média & 3,93 & 4,24 & 4,21 \\
& desvio-padrão & 1,58 & 1,46 & 1,53 \\
\hline \multirow{3}{*}{ Profissionais em outras áreas } & $\mathrm{N}$ & 644 & 415 & 1.509 \\
& média & 4,43 & 4,31 & 3,1 \\
& desvio-padrão & 1,37 & 1,53 & 1,83 \\
\hline \multirow{2}{*}{ Profissionais em áreas correlatas à } & $\mathrm{N}$ & 263 & 382 & \\
engenharia & média & 4,16 & 4,51 & - \\
& desvio-padrão & 1,54 & 1,47 & \\
\hline \multirow{2}{*}{ Gestores em engenharia } & $\mathrm{N}$ & 418 & & 491 \\
& média & 4,67 & - & 4,61 \\
& desvio-padrão & 1,25 & & 1,32 \\
\hline \multirow{2}{*}{ Padrão misto } & $\mathrm{N}$ & & 1.548 & 606 \\
& média & - & 4,49 & 3,43 \\
& desvio-padrão & & 1,06 & 1,97 \\
\hline \multirow{2}{*}{ Engenheiros típicos em transição } & $\mathrm{N}$ & & & 1.999 \\
& média & - & - & 4,13 \\
& desvio-padrão & & & 1,5 \\
\hline
\end{tabular}

Fonte: elaboração própria a partir da Rais.

\subsection{Resultados de mercado de trabalho (labor market outcomes) e trajetórias}

Conforme o esperado, as maiores remunerações ao final do período estão entre os gestores, em áreas correlatas à engenharia (tipo 8) ou não (tipo 4). Estes profissionais ganhavam, em média, $\mathrm{R} \$ 13.680$ e $\mathrm{R} \$ 13.443$, respectivamente. Estes grupos também experimentam o maior crescimento da remuneração. Estes grupos são seguido pelos engenheiros típicos ( $\mathrm{R} \$ 10.832)$, pelos engenheiros que migraram para áreas correlatas à engenharia em nível profissional (tipo 6), pelos profissionais em áreas não-correlatas à engenharia (tipo 7) e, finalmente, pelas ocupações de nível médio. Pouco se pode dizer sobre os fora da Rais, pois só se tem informações sobre aqueles que eventualmente retornaram para ocupações de carteira assinada, ou seja, 332 de 1.623).

Os testes ANOVA ${ }^{22}$ indicaram que as médias em conjunto são diferentes de acordo com as categorias, a 1\% de significância, tanto para as remunerações iniciais, finais, crescimento da remuneração e tempo de emprego. Os testes de contrastes $^{23}$, utilizando a

22 Pode-se questionar se não seria o caso para uma MANOVA - a análise multivariada de variância, em que pode se testar a influência de um conjunto de variáveis categóricas (fatores) sobre mais de uma variável dependente. No entanto, Hair et al. (2009) recomenda que as variáveis dependentes sejam correlacionadas. No caso, remuneração em 2012 e tempo de emprego apresentam correlação de 0,07, o que é considerado muito baixo para se aplicar uma MANOVA.

${ }^{23}$ Os testes de contrastes são ajustes em testes $t$ em que se comparam a média de uma categoria contra outra, considerando que os dados são provenientes da mesma base de dados. Em teoria, o fato de os dados virem da mesma base aumenta a probabilidade de um erro tipo I ( i.e., rejeitar a hipótese nula 
técnica de Tukey Honestly Significant Difference (Tukey HSD) mostraram que em 2012 a remuneração entre os gestores em engenharia ou em áreas não correlatas não eram diferentes (99\% de significância), e tampouco eram significativas as diferenças entre os que seguiram trajetória profissional em áreas correlatas ou não (41\% de significância). Fora estas, todas as trajetórias diferiram entre si no que diz respeito à remuneração.

Assim, tomando-se a categoria de menor remuneração por base (tipo $6=100$ ), os gestores, em engenharia ou não, ganhavam em 2012 mais que o dobro do que os técnicos de nível médio em áreas não-correlatas à engenharia, conforme o Gráfico 19. No entanto, este resultado pode ser explicado a partir das maiores responsabilidades intrínsecas a estas ocupações. Mais interessante é notar que em 2012 os engenheiros típicos (terceira trajetória melhor remunerada) ganhavam $70 \%$ a mais do que categoria-base.

Com respeito ao tempo de emprego - variável que apresenta menor dispersão entre as categorias -, o teste de contrastes Tukey HSD mostra que só há diferença estatística de estabilidade no emprego entre os engenheiros típicos e as demais categorias. Sem embargo, esta categoria apresenta o maior "tempo de casa" entre as categorias (70 meses), a segunda colocada é a categoria dos engenheiros gestores em engenharia (58 meses). Os demais - excetuando os conta-própria, pelas razões acima - se situam em torno dos 50 meses. Isto significa que a experiência na firma é relativamente mais valorizada entre aqueles que assumem um cargo de gestão em uma área de engenharia do que entre aqueles gestores em outras áreas.

Esta indicação de que a trajetória de engenheiro típico - seguidas por praticamente metade dos jovens engenheiros - era, ao final do período sob análise, a terceira trajetória mais valorizada em termos de remuneração e a mais estável em termos de tempo de emprego é um resultado importante, principalmente frente ao que ocorreu durante os anos 90.

quando verdadeira), tornando necessário corrigir o nível de significância dos testes de diferença de médias. Analiticamente, não reportaremos os casos de diferença estatística que envolvem os fora da Rais, devido à micronumerosidade. 


\section{Tabela 19 - Características do emprego, por tipo de trajetória, 2003- 2012}

\begin{tabular}{|c|c|c|c|c|c|}
\hline \multicolumn{6}{|c|}{ Remuneração em 2003 (em R $\$$ de 2012) } \\
\hline & $N$ & Média & $\begin{array}{l}\text { Desvio- } \\
\text { padrão }\end{array}$ & Mediana & $\begin{array}{l}\text { Desvio } \\
\text { mediano }\end{array}$ \\
\hline Tipo 1 - engenheiros típicos (N=4226) & 4.226 & $4.178,13$ & $2.228,14$ & $3.813,93$ & $1.431,66$ \\
\hline Tipo 2 - Fora da Rais (N=1623) & 1.623 & $3.516,12$ & $2.874,91$ & $3.315,24$ & $1.729,74$ \\
\hline Tipo 3 - técnicos em engenharia (N=1012) & 1.012 & $3.009,23$ & $1.846,43$ & $2.848,50$ & $1.870,09$ \\
\hline Tipo 4 - gestores em outras áreas (N=355) & 355 & $4.219,15$ & $2.275,77$ & $3.951,66$ & $1.572,04$ \\
\hline Tipo 5 - técnicos em outras áreas $(\mathrm{N}=500)$ & 500 & $2.730,84$ & $2.117,36$ & $2.542,62$ & $1.837,42$ \\
\hline Tipo 6 - profissionais em outras áreas $(\mathrm{N}=644)$ & 644 & $4.014,59$ & $2.002,54$ & $3.747,78$ & $1.470,23$ \\
\hline Tipo 7 - profissionais em engenharia $(\mathrm{N}=263)$ & 263 & $4.083,38$ & $2.365,33$ & $3.719,73$ & $1.662,43$ \\
\hline Tipo 8 - gestores em engenharia $(\mathrm{N}=418)$ & 418 & $4.247,81$ & $1.875,77$ & $3.926,95$ & $1.276,77$ \\
\hline F-ANOVA $=57.78, p=0,000, \theta^{2}=0,042$ & & & & & \\
\hline \multicolumn{6}{|c|}{ Remuneração em 2012 (em R\$ de 2012) } \\
\hline & $N$ & Média & $\begin{array}{l}\text { Desvio- } \\
\text { padrão }\end{array}$ & Mediana & \begin{tabular}{|l} 
Desvio \\
mediano
\end{tabular} \\
\hline Tipo 1 - engenheiros típicos (N=4226) & 3.779 & $10.832,14$ & $5.685,91$ & $10.063,33$ & $4.262,63$ \\
\hline Tipo 2 - Fora da Rais $(\mathrm{N}=1623)$ & 332 & $7.616,14$ & $6.137,49$ & $6.378,92$ & $5.059,35$ \\
\hline Tipo 3 - técnicos em engenharia $(\mathrm{N}=1012)$ & 966 & $7.446,14$ & $5.091,39$ & $6.654,21$ & $4.786,98$ \\
\hline Tipo 4 - gestores em outras áreas $(\mathrm{N}=355)$ & 337 & $13.442,94$ & $7.572,94$ & $12.642,00$ & $6.363,92$ \\
\hline Tipo 5 - técnicos em outras áreas $(\mathrm{N}=500)$ & 468 & $6.366,13$ & $4.718,82$ & $5.848,58$ & $5.461,20$ \\
\hline Tipo 6 - profissionais em outras áreas $(\mathrm{N}=644)$ & 600 & $10.210,64$ & $6.191,39$ & $9.378,04$ & $5.257,16$ \\
\hline Tipo 7 - profissionais em engenharia $(\mathrm{N}=263)$ & 238 & $9.280,49$ & $5.028,64$ & $8.803,47$ & $4.012,86$ \\
\hline Tipo 8 - gestores em engenharia $(\mathrm{N}=418)$ & 395 & $13.680,30$ & $6.916,16$ & $12.539,04$ & $6.110,15$ \\
\hline F-ANOVA $=113,00, p=0,000, \theta^{2}=0,100$ & & & & & \\
\hline \multicolumn{6}{|c|}{ Crescimento da remuneração, 2003-2012 (em R $\$$ de 2012) } \\
\hline & $\mathrm{N}$ & Média & \begin{tabular}{|l} 
Desvio- \\
padrão
\end{tabular} & Mediana & \begin{tabular}{|l} 
Desvio \\
mediano \\
\end{tabular} \\
\hline Tipo 1 - engenheiros típicos (N=4226) & 3.779 & $6.646,91$ & $5.351,20$ & $5.728,77$ & $3.644,62$ \\
\hline Tipo 2 - Fora da Rais $(\mathrm{N}=1623)$ & 332 & $4.340,26$ & $5.341,88$ & $3.258,89$ & $4.055,23$ \\
\hline Tipo 3 - técnicos em engenharia $(\mathrm{N}=1012)$ & 966 & $4.430,30$ & $4.474,60$ & $3.552,15$ & $3.315,35$ \\
\hline Tipo 4 - gestores em outras áreas (N=355) & 337 & $9.229,79$ & $6.754,17$ & $8.420,34$ & $5.705,04$ \\
\hline Tipo 5 - técnicos em outras áreas $(\mathrm{N}=500)$ & 468 & $3.597,40$ & $4.229,61$ & $3.118,66$ & $3.762,59$ \\
\hline Tipo 6 - profissionais em outras áreas $(\mathrm{N}=644)$ & 600 & $6.221,99$ & $5.922,46$ & $5.538,55$ & $4.731,69$ \\
\hline Tipo 7 - profissionais em engenharia $(\mathrm{N}=263)$ & 238 & $5.160,60$ & $5.157,49$ & $4.792,63$ & $3.580,02$ \\
\hline Tipo 8 - gestores em engenharia $(\mathrm{N}=418)$ & 395 & $9.423,05$ & $6.482,67$ & $8.199,37$ & $5.945,07$ \\
\hline F-ANOVA $=77,18, p=0,000, \theta^{2}=0,070$ & & & & & \\
\hline \multicolumn{6}{|c|}{ Tempo de emprego em 2012 (em meses) } \\
\hline & $N$ & Média & \begin{tabular}{|l} 
Desvio- \\
padrão
\end{tabular} & Mediana & \begin{tabular}{|l} 
Desvio \\
mediano
\end{tabular} \\
\hline Tipo 1 - engenheiros típicos ( $N=4226)$ & 3.797 & 62,45 & 45,23 & 57,8 & 59,16 \\
\hline Tipo 2 - Fora da Rais $(\mathrm{N}=1623)$ & 333 & 20,70 & 21,33 & 14,5 & 13,34 \\
\hline
\end{tabular}




\begin{tabular}{l|c|c|c|c|c} 
Tipo 3 - técnicos em engenharia $(\mathrm{N}=1012)$ & 969 & 52,66 & 43,97 & 39,2 & 41,96 \\
\hline Tipo 4 - gestores em outras áreas $(\mathrm{N}=355)$ & 337 & 52,85 & 39,76 & 41,9 & 42,4 \\
\hline Tipo 5 - técnicos em outras áreas $(\mathrm{N}=500)$ & 471 & 50,79 & 41,33 & 39,6 & 42,55 \\
\hline Tipo 6 - profissionais em outras áreas $(\mathrm{N}=644)$ & 602 & 51,19 & 36,95 & 42,55 & 40,4 \\
\hline Tipo 7 - profissionais em engenharia $(\mathrm{N}=263)$ & 239 & 52,26 & 35,53 & 47,9 & 37,06 \\
\hline Tipo 8 - gestores em engenharia $(\mathrm{N}=418)$ & 396 & 58,19 & 46,19 & 47,6 & 50,33 \\
\hline F-ANOVA $=48,12, \mathrm{p}=0,000, \theta^{2}=0,045$ & & & & &
\end{tabular}

Fonte: elaboração própria a partir da Rais.

\section{Gráfico 18 - Remuneração média, crescimento da remuneração e tempo de emprego (em $R \$$ de 2012 e em meses)}

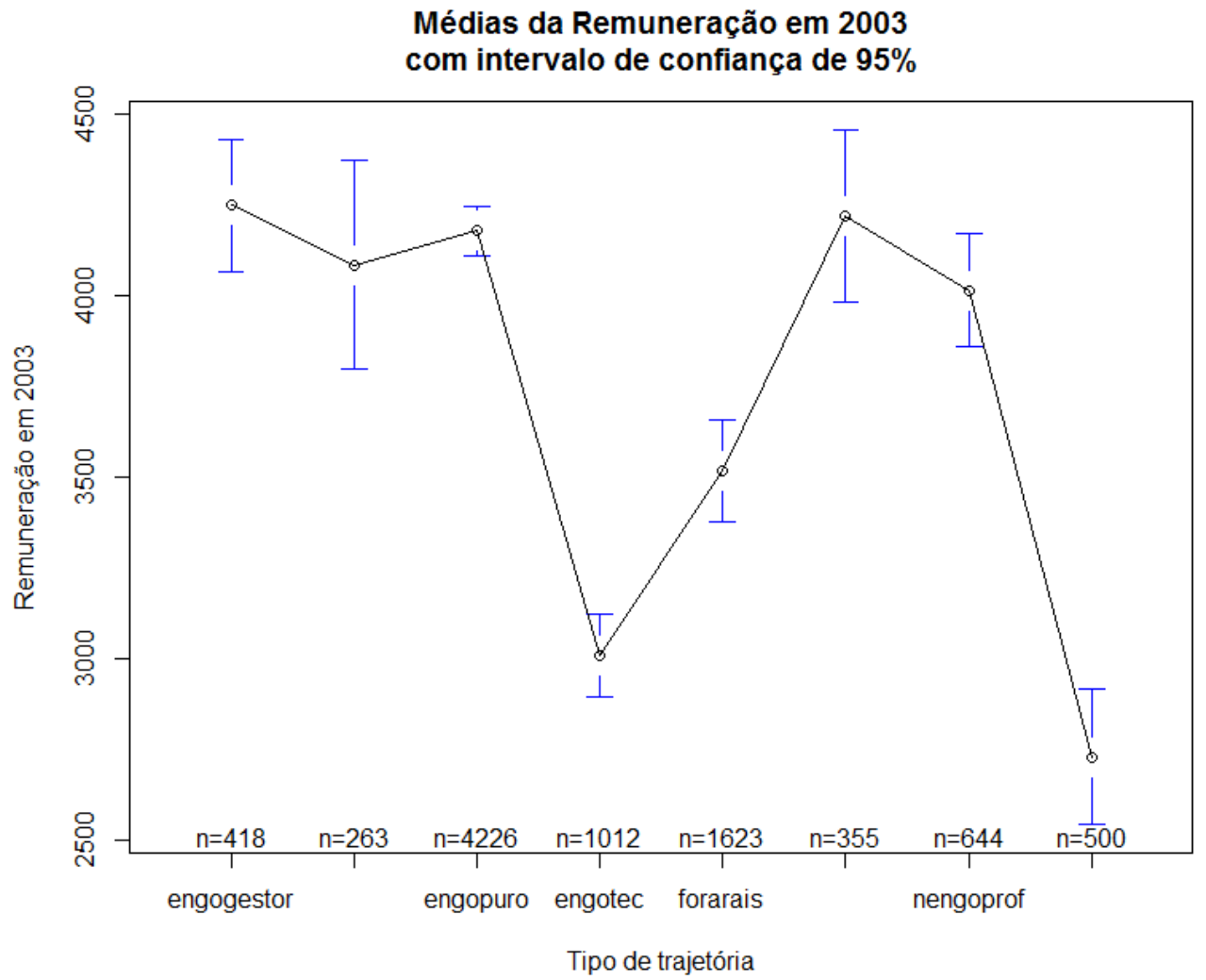


Médias da Remuneração em 2012

com intervalo de confiança de $95 \%$

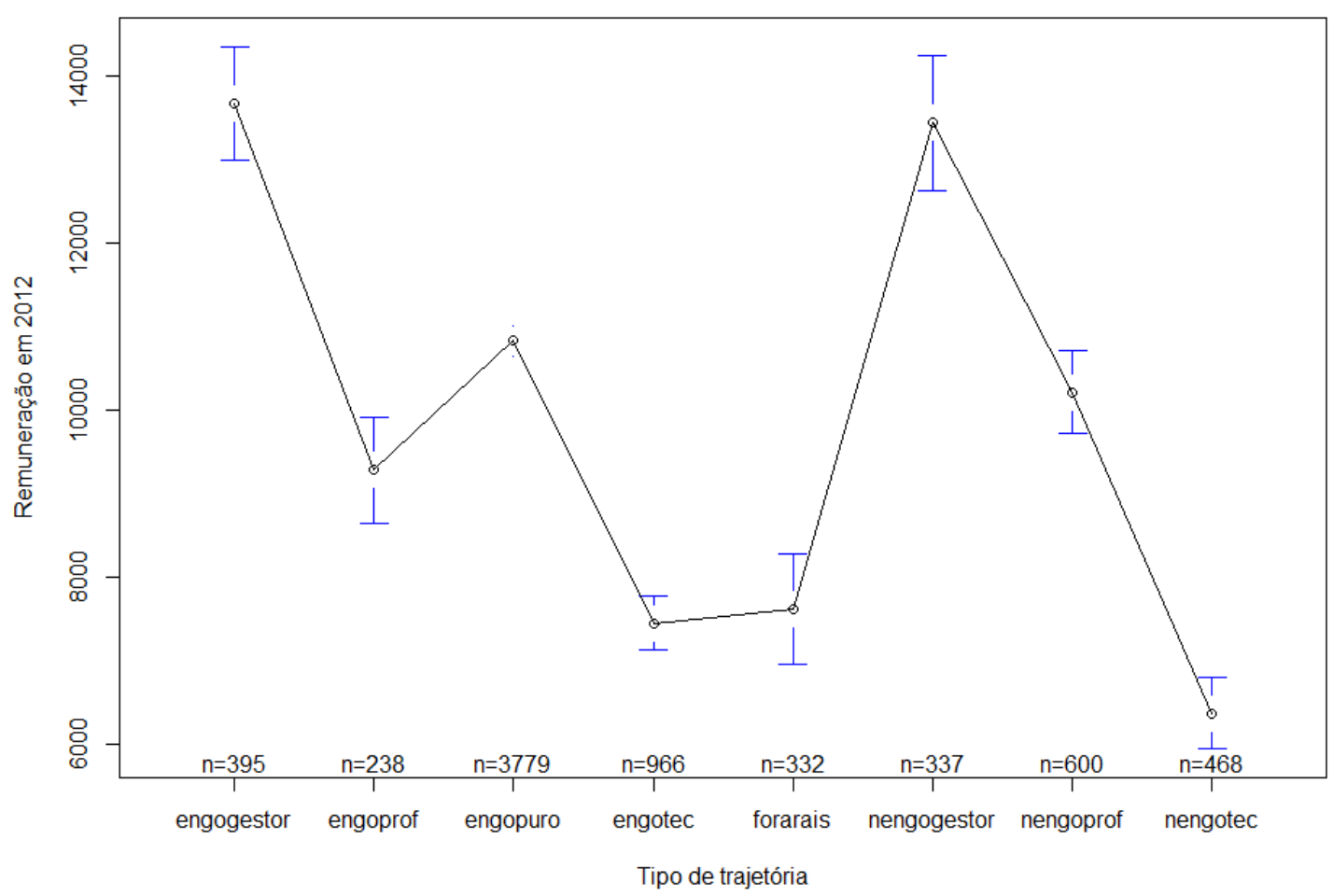

Crescimento da Remuneração entre 2003-2012

com intervalo de confiança de $95 \%$

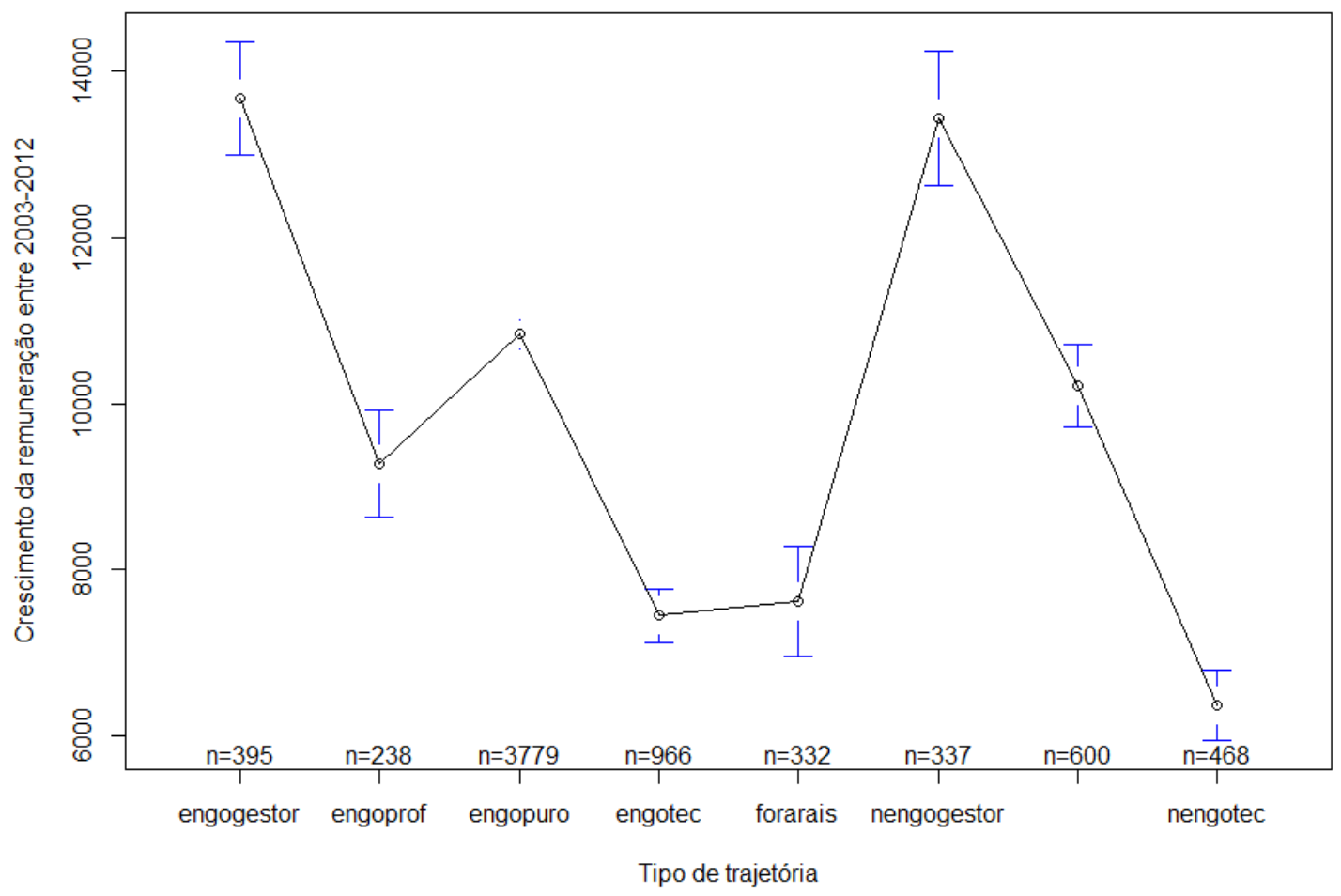


Tempo de emprego em 2012

com intervalo de confiança de $95 \%$

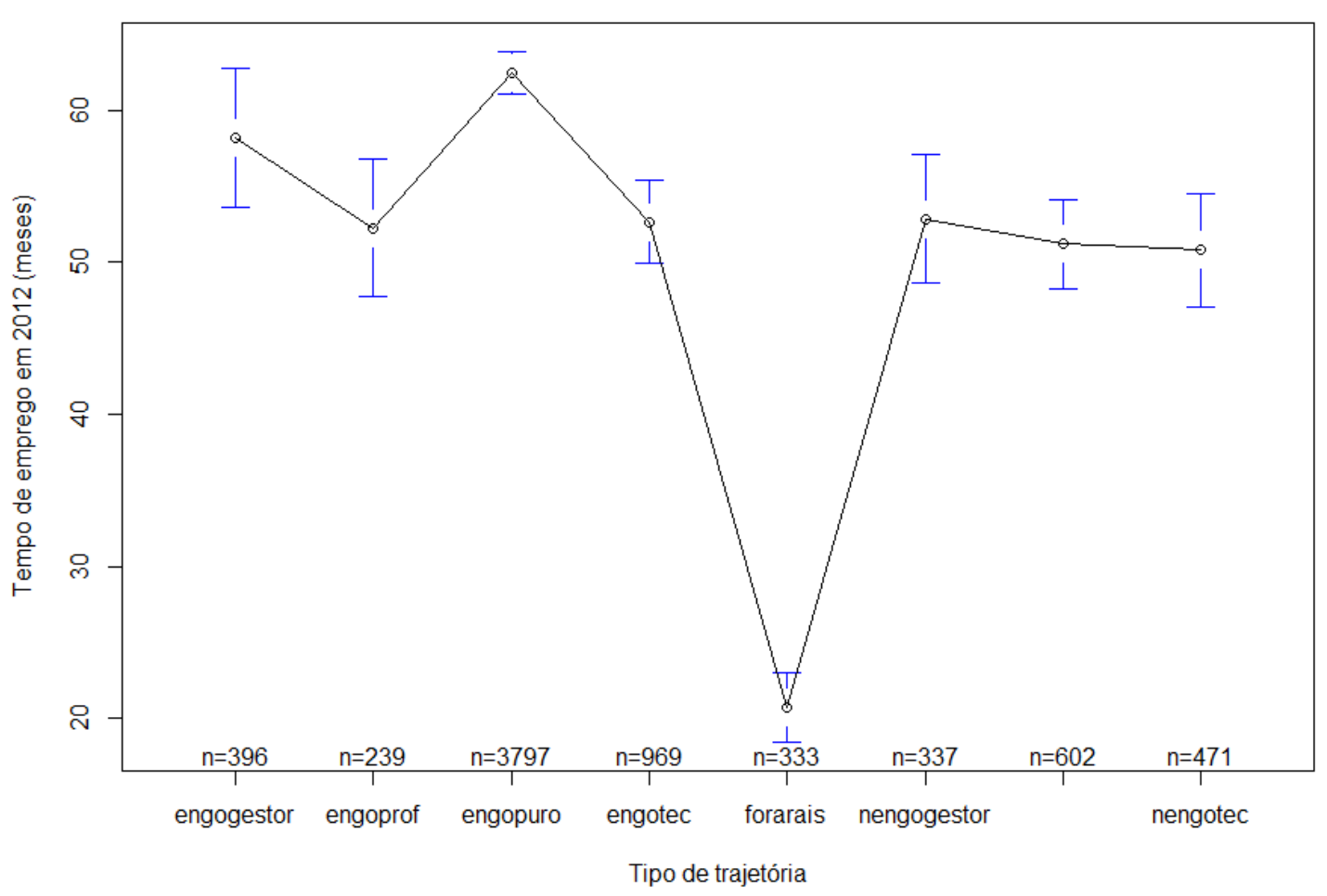

Fonte: elaboração própria a partir da Rais.

\section{Gráfico 19 - Remunerações relativas e crescimento da remuneração, 2003-2012}

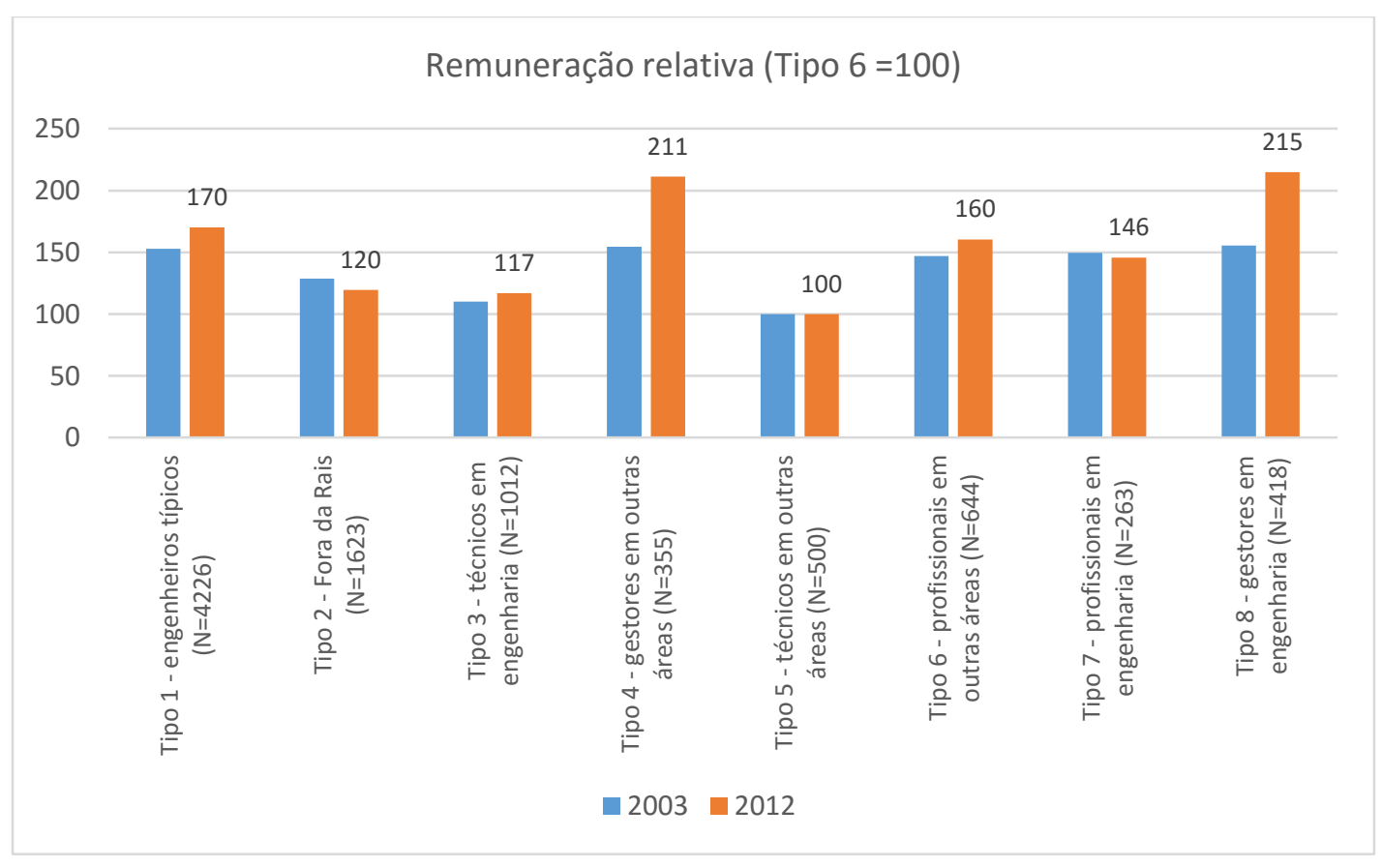




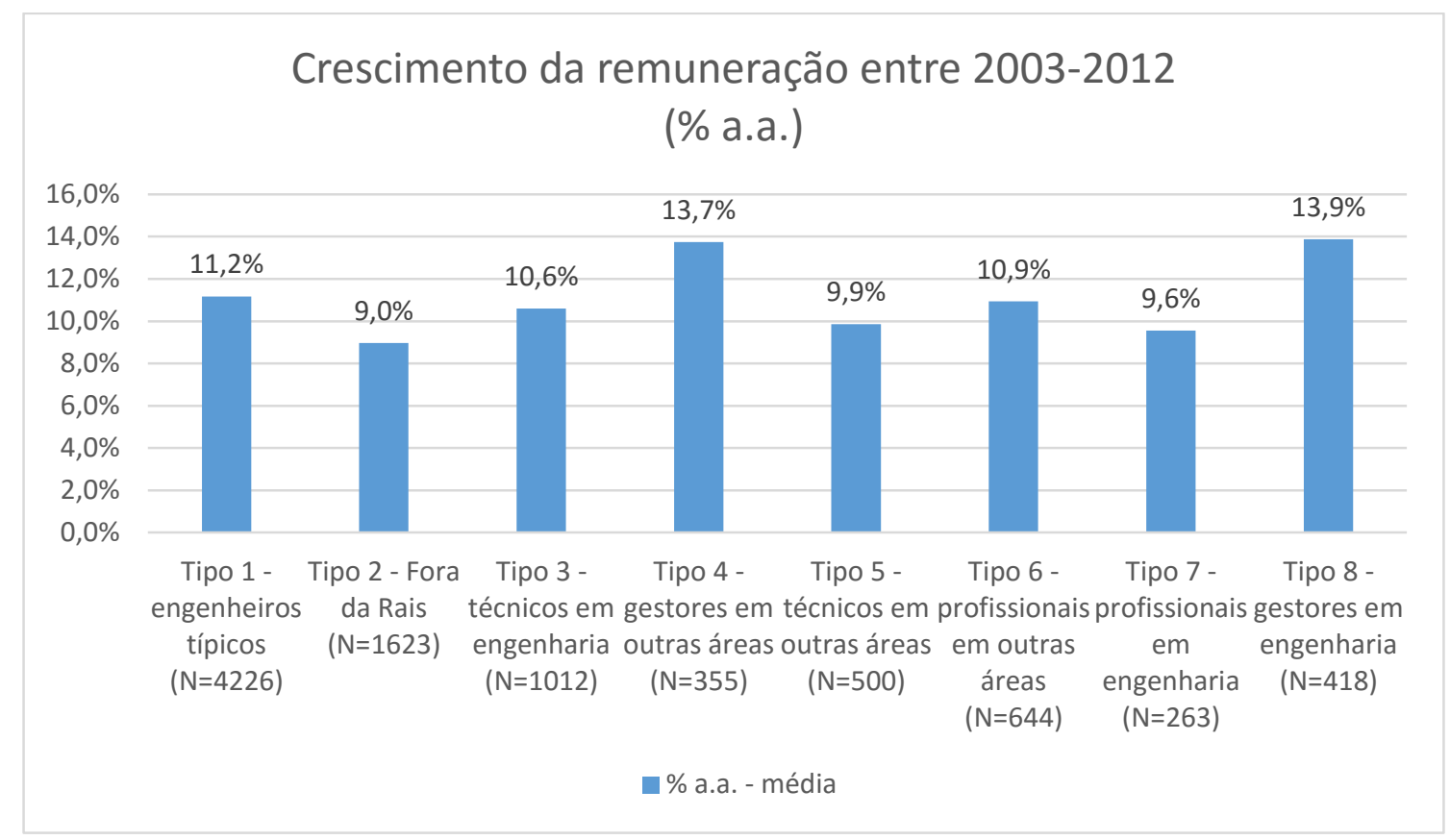

Fonte: elaboração própria a partir da Rais.

O teste ANOVA ainda traz uma interessante medida, chamada eta-quadrado $\left(\theta^{2}\right)$. Quando há apenas uma variável, esta medida é a razão entre a soma dos quadrados explicada pela variável de interesse e a soma total dos quadrados, sendo, portanto, uma medida análoga ao $\mathrm{R}^{2}$ em uma regressão. Quando há mais de uma variável, a medida é modificada e se tem o eta-quadrado parcial, mas a interpretação é a mesma: o quanto da variância total é explicada por uma variável de interesse.

No caso em estudo, o eta-quadrado parcial permite discernir, por exemplo, se as trajetórias ocupacionais são mais importantes para explicar os salários do que o setor de atividade do emprego ou a região, por exemplo. Segundo Cohen (1988), em ANOVA um efeito pequeno se situa em torno de 0,01 , um efeito médio em torno de 0,06 e um efeito grande em torno de 0,14 .

Quando avaliada individualmente, as trajetórias ocupacionais têm um efeito médio sobre a remuneração em $2003\left(\theta^{2}\right.$ em torno de 0,04$)$, sobre o crescimento da remuneração $\left(\theta^{2}\right.$ em torno de 0,07$)$, sobre o tempo de emprego $\left(\theta^{2}\right.$ em torno de 0,04$)$ e um efeito médioalto sobre a remuneração em $2012\left(\theta^{2}\right.$ em torno de 0,10$)$, segundo a Tabela 20. Porém, o mais interessante é avaliar esta estatística comparativamente a outras variáveis. A especificação linear testada inclui, portanto, as trajetórias, o macrossetor, o gênero, o porte da empresa, a região e os efeitos de interação.

Com efeito, as trajetórias ocupacionais são as variáveis com efeito individual mais alto sobre a remuneração, sobre seu crescimento e sobre o tempo de emprego. Também é interessante notar, além do efeito individual relativamente pequeno das outras variáveis, que as interações entre trajetória, macrossetor, gênero, porte da empresa e sua região, mesmo quando significativas, não se mostraram muito importantes para as variáveis dependentes, pois o $\theta^{2}$ destas interações é muito baixo. 
Tabela 20 - Eta-quadrado das trajetórias e fatores sobre as características do emprego, 2003-2012

\begin{tabular}{|c|c|c|c|c|}
\hline & $\begin{array}{c}\text { Remuneração } \\
\text { em } 2003\end{array}$ & $\begin{array}{c}\text { Remuneração } \\
\text { em } 2012\end{array}$ & $\begin{array}{l}\text { Crescimento } \\
\text { da } \\
\text { remuneração, } \\
2003-2012\end{array}$ & $\begin{array}{l}\text { Tempo de } \\
\text { emprego } \\
\text { em } 2012\end{array}$ \\
\hline Trajetória & $0,043^{* * *}$ & $0,103^{\star * *}$ & $0,072^{* * *}$ & $0,043^{* * *}$ \\
\hline Gênero & $0,004^{* * *}$ & $0,014^{* * *}$ & $0,012^{* * *}$ & 0,000 \\
\hline Porte & $0,030^{* * *}$ & $0,014^{\star \star \star}$ & $0,008^{* * *}$ & $0,008^{\star * \star}$ \\
\hline Região & $0,023^{* * *}$ & $0,052^{* * *}$ & $0,045^{* * *}$ & $0,002^{* * *}$ \\
\hline Macrossetor & $0,008^{* * *}$ & $0,009^{* * *}$ & $0,008^{* * *}$ & $0,022^{* * *}$ \\
\hline Trajetória*gênero & $0,003^{* * *}$ & 0,001 & 0,001 & 0,002 \\
\hline Trajetória*porte & $0,003^{\star * \star}$ & 0,001 & 0,002 & 0,001 \\
\hline Gênero*porte & $0,001^{* *}$ & 0,000 & 0,000 & 0,000 \\
\hline Trajetória*região & $0,006^{* * *}$ & $0,029^{\star * *}$ & $0,023^{* * *}$ & 0,005 \\
\hline Gênero*região & 0,001 & 0,001 & 0,001 & 0,000 \\
\hline Porte*região & $0,004^{* * *}$ & $0,004^{* * *}$ & $0,004^{* * *}$ & 0,001 \\
\hline Trajetória*macrossetor & $0,004^{\star *}$ & $0,005^{\star * *}$ & $0,006^{\star * *}$ & 0,004 \\
\hline Gênero*macrossetor & $0,001^{* *}$ & 0,001 & 0,001 & 0,000 \\
\hline Porte*macrossetor & $0,004^{* * *}$ & $0,002^{\star * *}$ & $0,001^{* *}$ & $0,003^{* * *}$ \\
\hline Região*macrossetor & $0,007^{* * *}$ & 0,002 & 0,002 & $0,004^{* *}$ \\
\hline Trajetória*gênero*porte & 0,001 & 0,001 & 0,001 & 0,002 \\
\hline Trajetória*gênero*região & $0,007^{\star \star \star}$ & 0,004 & 0,004 & 0,004 \\
\hline Trajetória*porte*região & 0,004 & 0,005 & $0,006^{*}$ & 0,003 \\
\hline Gênero*porte*região & 0,000 & 0,001 & 0,001 & 0,001 \\
\hline Trajetória*gênero*macrossetor & 0,002 & 0,002 & 0,002 & 0,003 \\
\hline Trajetória*porte*macrossetor & 0,002 & 0,003 & 0,003 & 0,001 \\
\hline Gênero*porte*macrossetor & 0,000 & $0,001^{* * *}$ & $0,001^{* *}$ & 0,001 \\
\hline Trajetória*região*macrossetor & $0,014^{* *}$ & $0,017^{* * *}$ & $0,015^{\star *}$ & 0,013 \\
\hline Gênero*região*macrossetor & $0,002^{* \star *}$ & 0,003 & 0,003 & 0,001 \\
\hline Porte*região*macrossetor & 0,007 & $0,006^{\star * *}$ & $0,006^{\star * *}$ & $0,005^{\star * \star}$ \\
\hline Trajetória*gênero*porte*região & 0,003 & 0,003 & 0,002 & 0,003 \\
\hline Trajetória*gênero*porte*macrossetor & 0,002 & 0,003 & 0,004 & 0,001 \\
\hline Trajetória*gênero*região*macrossetor & 0,006 & 0,004 & 0,004 & 0,005 \\
\hline Trajetória*porte*região*macrossetor & 0,010 & 0,007 & 0,006 & 0,007 \\
\hline Gênero*porte*região*macrossetor & 0,001 & 0,001 & 0,002 & 0,002 \\
\hline Trajetória*gênero*porte*região*macrossetor & 0,004 & 0,001 & 0,001 & 0,001 \\
\hline
\end{tabular}

Fonte: Elaboração própria a partir da Rais. *** - significante a 1\%, ** - significante a 5\%, *- significante a $10 \%$, n.s. - não significante.

Este é um resultado muito importante, pois lança luz sobre se vale a pena fazer uma classificação polidimensional, em que se considere não apenas a ocupação como também algumas características do empregador, como em Blair-Loy (1999).

Com efeito, combinando as 7 categorias de $\mathrm{CBO}$ com os 4 macrossetores, por exemplo, são 29 possibilidades ( 4 x $7+1$ categoria dos fora da Rais, pois, por definição, estes não podem ser combinados com os macrossetores). Esta aplicação está no anexo 3. 
Neste caso, a solução que maximizou o silhouette médio foi a de 8 clusters, dois quais 3 eram formados por engenheiros típicos, seja na indústria (tipo 1), na construção (tipo 4) ou em prestadoras de serviços a empresas (tipo 5). Cabe notar que:

- Os $\theta^{2}$ desta classificação bidimensional sobre as variáveis de remuneração e de tempo de emprego foram bem baixos, variando de 0,223 (crescimento da remuneração) a 0,0335 (tempo de emprego), indicado baixa força discriminatória;

- Os contrastes Tukey HSD entre os engenheiros típicos entre os três clusters indicam que, apesar das diferenças na remuneração em 2003 serem significantes, em 2012 elas já não o eram. Em outras palavras, isto sinaliza que mais importante para a remuneração é a escolha da ocupação, independentemente do setor de atuação. Fenômeno semelhante ocorre quando se considera o porte (disponível sob demanda).

Diante destes resultados, o caso-base considerará apenas a ocupação para a definição dos padrões de trajetória ocupacional.

\subsection{Gênero, características do emprego e trajetórias}

Nesta seção avalia-se como o gênero e as características do primeiro e do último emprego dos jovens engenheiros se relacionam com as trajetórias ocupacionais (questão de pesquisa número 5 da introdução). Serão aplicados dois tipos de análise. O primeiro, mais descritivo, utiliza gráficos-mosaico de tabulações cruzadas, os quais visam detectar sobre ou subrepresentação nos cruzamentos ${ }^{24}$. O segundo é um modelo multinomial logístico de predição das probabilidades de um indivíduo se situar em cada categoria de trajetórias em função das características do emprego e gênero. O objetivo é comparar as conclusões das duas estratégias. ${ }^{25}$

${ }^{24}$ Quando se faz uma tabulação cruzada, o valor esperado de uma determinada célula deste cruzamento é dado pela proporção na linha vezes a proporção na coluna - o produto das probabilidades marginais. Uma sobre ou subrepresentação ocorre quando o valor observado é significantemente maior ou menor do que o esperado, de acordo com critérios estatísticos. Para efeitos do estudo, consideramos forte sobre ou subrepresentação quando o coeficiente de Pearson é maior que 4 em módulo, e leve sobre ou subrepresentação quando ele é maior que 2 em módulo. Assim, o gráfico-mosaico mostra exatamente isso: quais as células apresentam sobre ou sub-representação. Adicionalmente, a largura e o tamanho dos retângulos são diretamente proporcionais à participação daquela coluna ou linha, respectivamente, nos totais.

${ }^{25}$ Tentou-se também uma análise de correspondência entre as trajetórias e estas características. Entretanto, a redução dimensional que a aplicação da técnica implica não se mostrou adequada: por um lado, mesmo comparando apenas duas variáveis por vez, cada dimensão explicava em torno de 10 a $15 \%$ da variância total; por outro lado análises de correspondência que envolvem mais de 3 dimensões são pouco convenientes, pois perdem o apelo gráfico. Detalhes sobre análise de correspondência podem ser encontrados em Hair et al. (2009, cap. 9). 


\subsubsection{Gráficos-mosaico}

Em relação ao gênero (Gráfico 20), as mulheres estão mais fortemente sobrerrepresentadas na trajetória de ocupações técnicas fora da engenharia (o padrão de menor remuneração). Outras trajetórias onde há uma sobrerrepresentação feminina, ainda que mais leve, são entre os fora da Rais e entre os profissionais fora da engenharia. A hipótese de que as mulheres pudessem estar sobrerrepresentadas entre os fora da Rais devido aos filhos foi avaliada. Como discutido no anexo 1, não é possível concluir definitivamente que o viés feminino em estar fora do mercado de trabalho esteja relacionado ao número de filhos.

Inversamente, as mulheres tendem a estar subrepresentadas entre os técnicos em engenharia e entre os engenheiros típicos.

\section{Gráfico 20 - Gráfico-mosaico da distribuição do gênero por tipo de trajetória}

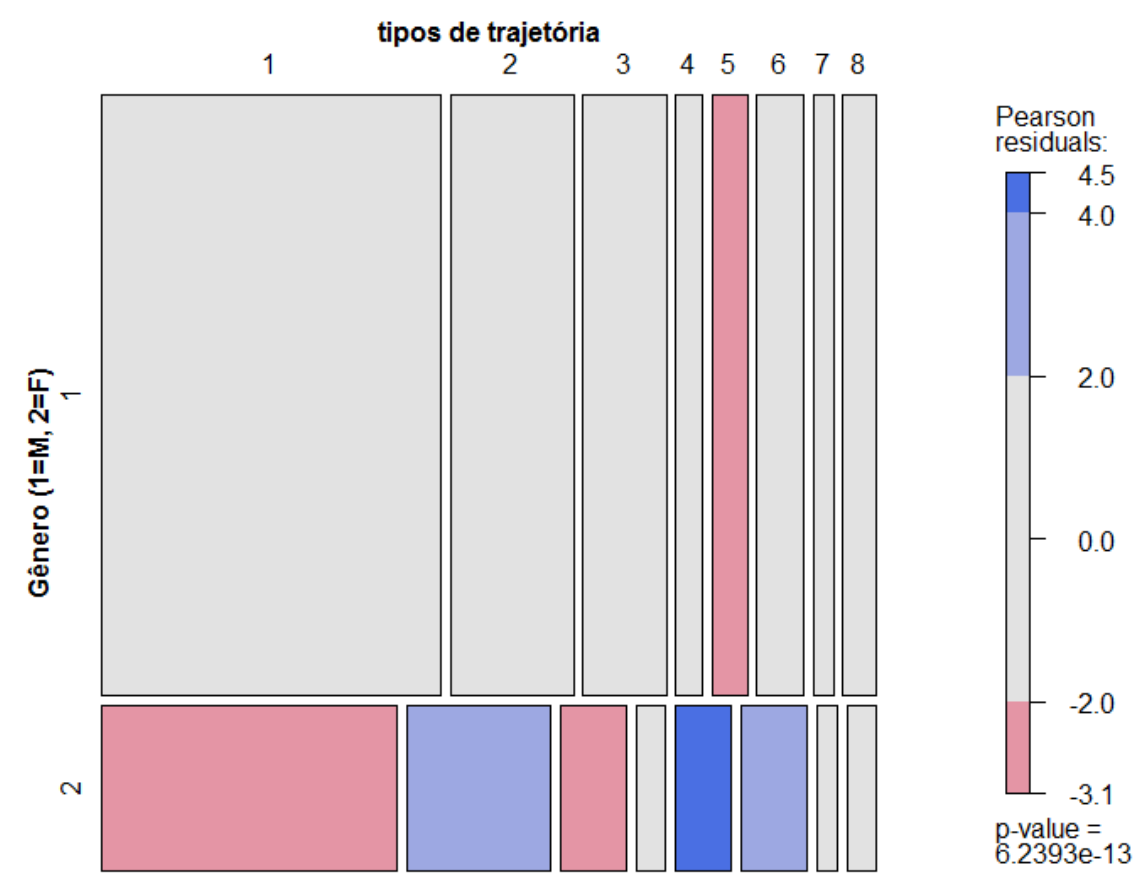

Fonte: elaboração própria a partir da Rais.

Quando se separa as categorias de tamanho somente entre porte grande (mais de 1.000 empregados) e pequeno (Gráfico 21), vê-se que todas as categorias, exceto os gestores em outras áreas (tipo 4) e os técnicos em outras áreas (tipo 5) e, naturalmente, os fora da Rais (tipo 2), estão sobrerrepresentadas na faixa das empresas de grande porte em 
2012. Engenheiros típicos e gestores em engenharia tendem a também começar suas trajetórias em empresas de grande porte. $\mathrm{O}$ gráfico também mostra que os profissionais que saem da Rais ao longo do período tendem a começar suas carreiras em empresas de pequeno porte.

\section{Gráfico 21 - Gráfico-mosaico da distribuição do porte por tipo de trajetória}
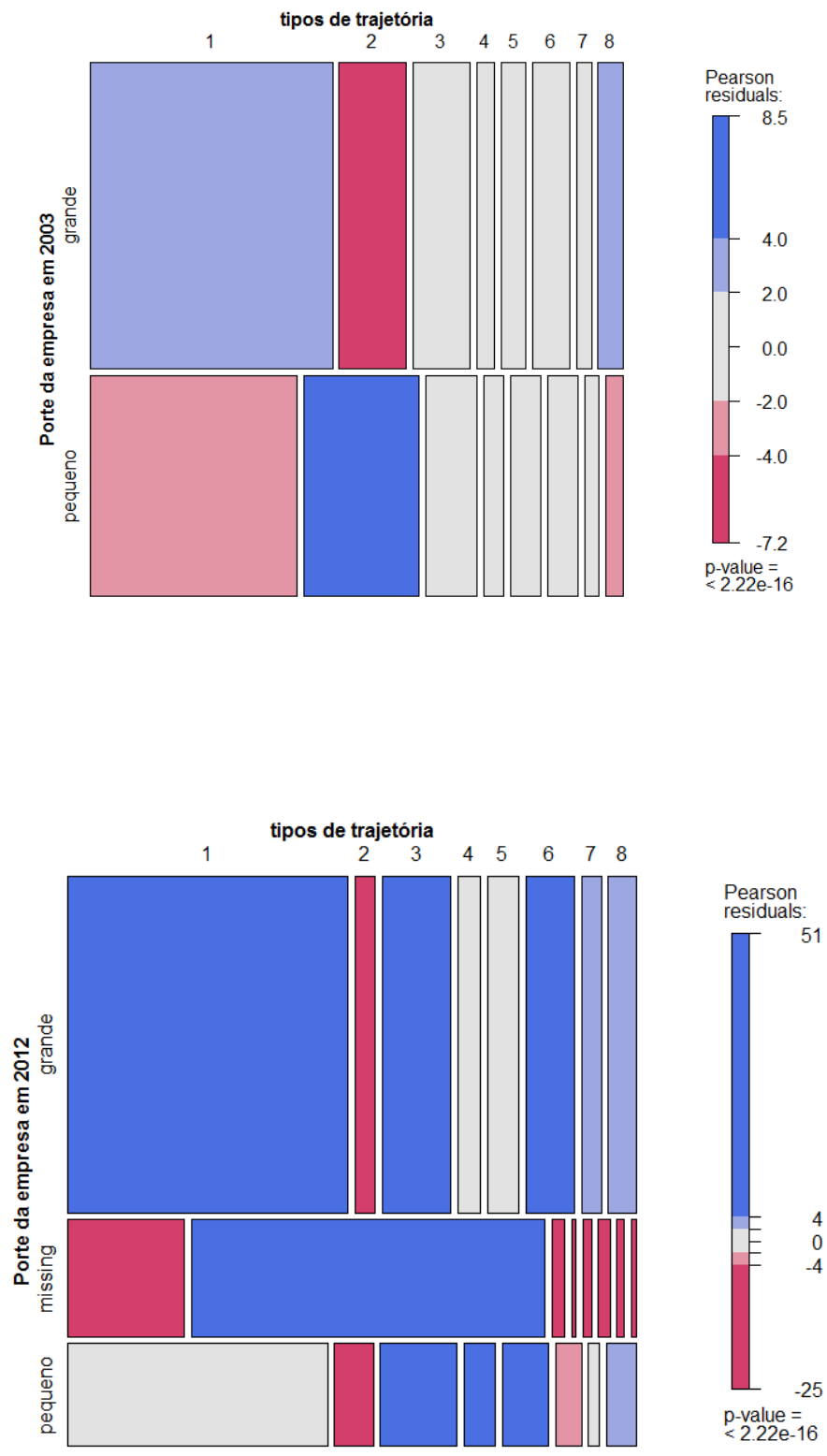

Fonte: elaboração própria a partir da Rais.

De uma forma geral, não há vieses regionais muito fortes (Gráfico 22). Entretanto, os profissionais em áreas correlatas à engenharia e aqueles que viram gestores em 
engenharia tendem a começar mais que proporcionalmente suas trajetórias na região SE (fora SP), e aqueles que viram gestores fora da engenharia tendem a começar em SP. Ademais, aqueles que eventualmente saem da Rais ao longo do período tendem a iniciar mais que proporcionalmente suas trajetórias nas regiões Centro-Oeste e Sul. Este não é um panorama que se altera significantemente ao longo do tempo, pois, como discutido no capítulo 3, sabe-se que a mobilidade dos engenheiros não é tão grande.

Gráfico 22 - Gráfico-mosaico da distribuição da Região, em 2003 e 2012, por tipo de trajetória
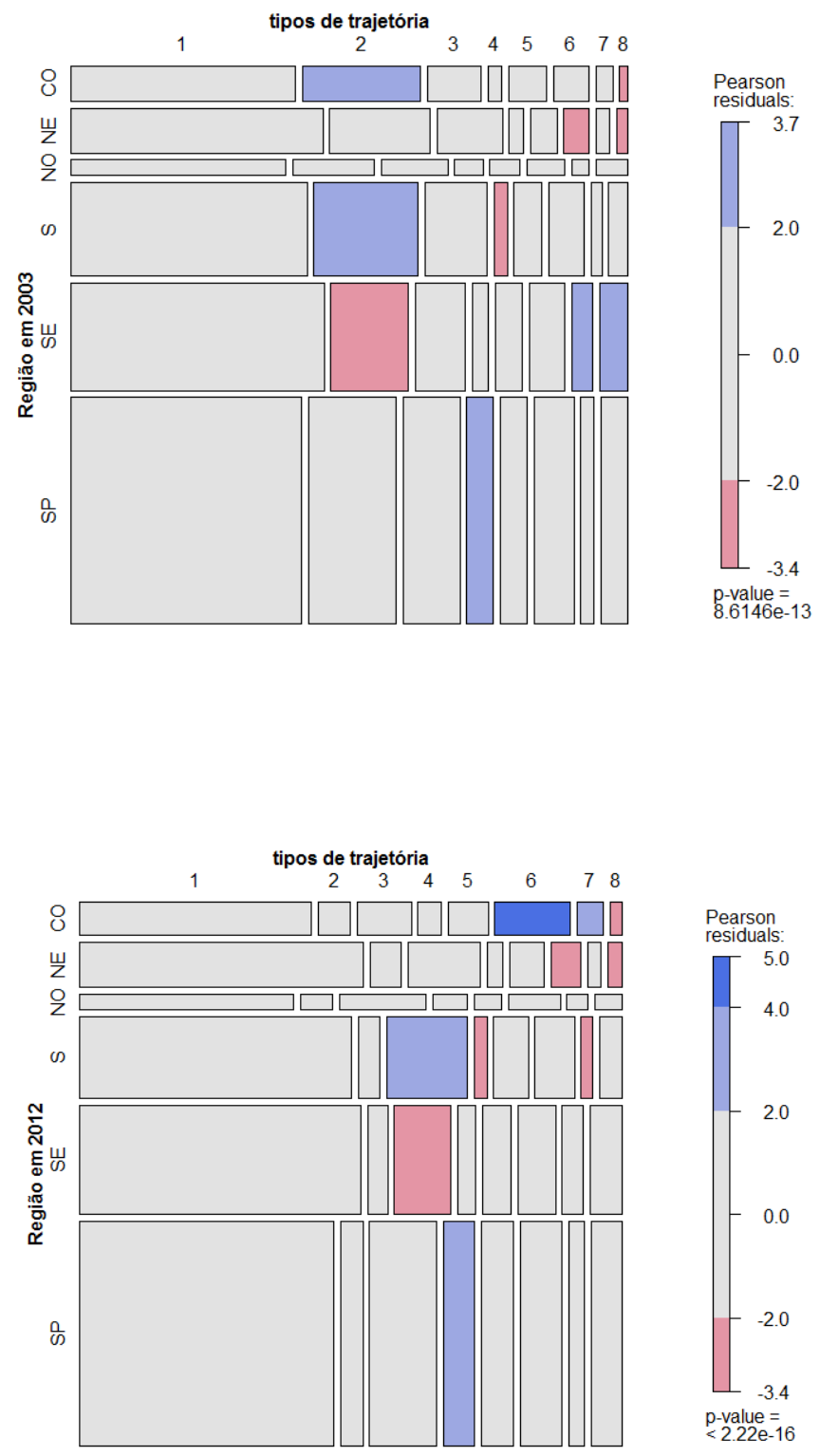

Fonte: elaboração própria a partir da Rais. 
Do ponto de vista setorial, de acordo com o Gráfico 23 tem-se que:

- Os engenheiros típicos tendem a começar na construção e na indústria, e, ao longo do tempo, tendem a migrar também para as prestadoras de serviços (categoria "empresas");

- Aqueles que saem da Rais (tipo 2) tendem a iniciar suas trajetórias nas empresas de serviços e tendem a começar menos que proporcionalmente na indústria;

- Os técnicos em áreas correlatas à engenharia (tipo 3) tendem a começar na indústria;

- Os tipos 4, 5, 6 e 7 (gestores, profissionais e técnicos em outras áreas e os profissionais em áreas correlatas à engenharia) tendem a começar suas trajetórias em empresas de serviços, tendência reforçada até 2012;

- Os gestores em engenharia (tipo 8) estão sobrerrepresentados na indústria, tanto em 2003 quanto em 2012.

\section{Gráfico 23 - Gráfico-mosaico da distribuição macrossetorial, em 2003 e 2012, por tipo de trajetória}

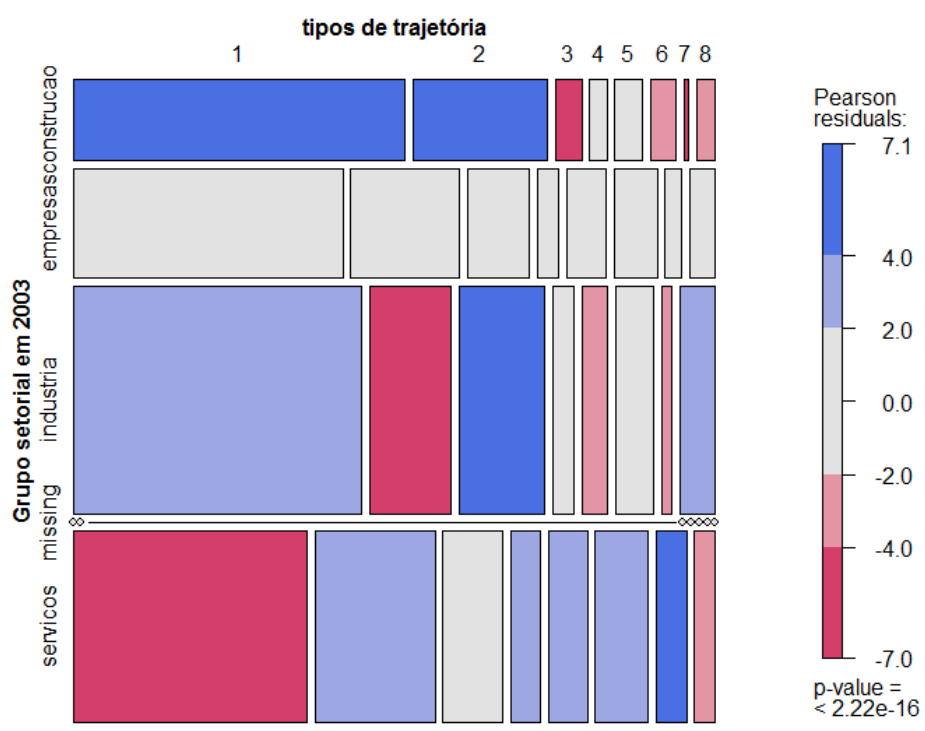




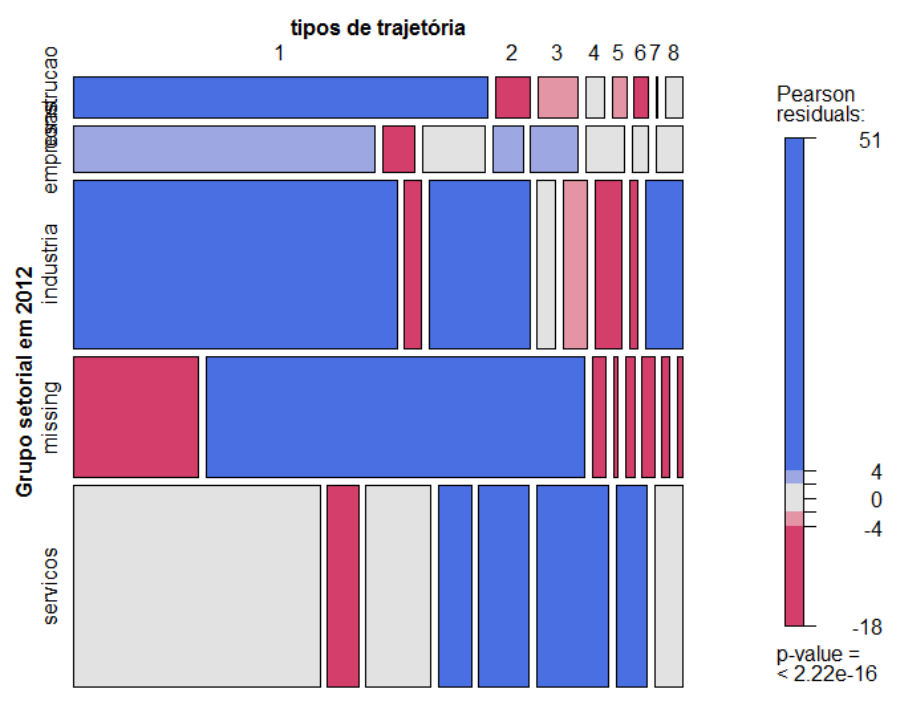

Fonte: elaboração própria a partir da Rais.

As CBOs de engenharia daquele que é possivelmente o primeiro emprego desses jovens foram agrupadas em 8 categorias para a confecção do Gráfico 24. Deste modo, em termos de ocupações em 2003:

- Os que começam como engenheiros agrimensores e cartográficos (CBO 2148), os agrossilvipecuários (CBO 2221) e os de alimentos (CBO 2222) - grupo "agrônomo" - estão sobrerrepresentados entre os fora da Rais (tipo 2) e os profissionais em outras áreas (tipo 5). Estes profissionais também estão subrepresentados entre os engenheiros típicos (tipo 1);

- Os engenheiros civis (CBO 2142) estão sobrerrepresentados no tipo 1 (engenheiros típicos) e subrepresentados entre os técnicos em áreas correlatas à engenharia (tipo 3);

- A sobrerrepresentação entre os engenheiros típicos também é característica dos que iniciam suas trajetórias como engenheiros mecânicos (CBO 2144). Estes estão fortemente subrepresentados entre os fora da Rais (tipo 2) e os profissionais em áreas correlatas à engenharia (tipo 7);

- Por sua vez, os engenheiros do grupo elétrico (engenheiros de controle e automação e mecatrônicos - CBO 2021, eletricistas e eletrônicos - CBO 2143 e de computação - CBO 2122) estão sobrerrepresentados entre os profissionais, em áreas correlatas à engenharia (tipo 7) ou não (tipo 6);

- Os jovens engenheiros do grupo metal-químico em 2003 (metalúrgicos - CBO 2146, químicos - CBO 2145, de minas - CBO 2147 e profissionais da metrologia - CBO 2012) apresentam uma leve sobrerrepresentação entre os técnicos em áreas correlatas à engenharia (tipo 3) e os gestores em engenharia (tipo 8), e uma leve sub-representação entre os fora da Rais (tipo 2); 
- Os jovens pesquisadores em 2003 (CBOs 2031, 2032 e 2034, pesquisadores em ciências naturais, em engenharia e tecnologia e agricultura, respectivamente) estão sobrerrepresentados como técnicos, em áreas correlatas à engenharia (tipo 3) ou não (tipo 5), e subrepresentados no grupo dos engenheiros típicos (tipo 1);

- Por fim, aqueles que iniciam suas trajetórias como engenheiros de produção (CBO 2149) estão sobrerrepresentados nas trajetórias de técnicos em engenharia (tipo 3) e gestores em engenharia (tipo 8). Neste caso, há de se lembrar que a descrição completa da CBO 2149 é engenharia de produção, qualidade, segurança e afins, o que pode ajudara compreender a associação desta CBO ao tipo 3 .

\section{Gráfico 24 - Gráfico-mosaico das CBOs do primeiro emprego (2003) por tipo de trajetória}

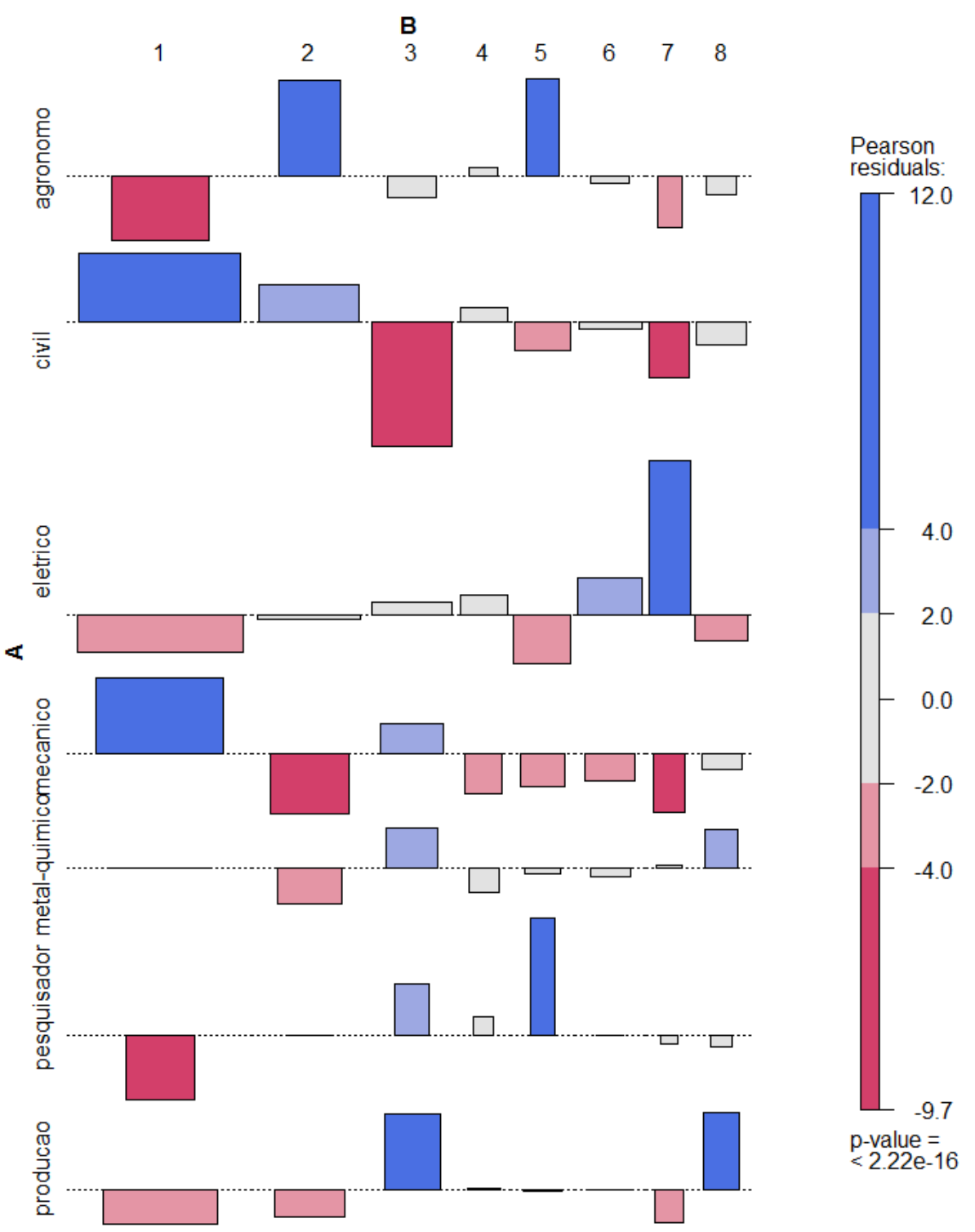

Fonte: elaboração própria a partir da Rais. 
Em resumo, estes gráficos-mosaico mostram que há uma subrepresentação feminina na trajetória associada aos engenheiros típicos (tipo 1) e uma sobrerrepresentação entre as trajetórias de ocupações técnicas fora da engenharia - tipo 5, justamente o padrão de menor remuneração -, entre os fora da Rais (tipo 2) e os profissionais fora da engenharia (tipo 6). Ao longo do tempo, os profissionais de todas as trajetórias parecem migrar para empresas maiores, e aqueles que eventualmente saem da Rais tendem a iniciar suas trajetórias em empresas de menor porte. Os engenheiros típicos (tipo 1) e os gestores em engenharia (tipo 8) tendem a iniciar suas trajetórias em empresas com mais de 1.000 empregados. Não foram percebidos vieses regionais importantes com respeito às trajetórias ocupacionais. Finalmente, com respeito à ocupação do primeiro emprego, pode-se afirmar que aqueles que iniciam suas trajetórias como engenheiro civil ou mecânico estão relativamente mais propensos a seguir trajetória como engenheiros típicos, os do grupo elétrico estão relativamente mais associados aos profissionais em áreas correlatas à engenharia e os de produção estão associados a trajetórias técnicas em engenharia e gestão em engenharia.

A seguir, o uso de um modelo logístico multinomial ajudará a clarificar estas relações de dependência das trajetórias ocupacionais do gênero e das características do primeiro emprego.

\subsubsection{Modelo multinomial logístico}

O uso de um modelo multinomial logístico permite realizar testes de hipóteses de maneira sistemática sobre a dependência das 8 trajetórias ocupacionais com respeito aos fatores gênero, porte, região, macrossetor e ocupação em 2003, e isolar os efeitos destes fatores mantendo os outros constantes. Um modelo multinomial logístico se assemelha a um modelo logístico comum (logit), com a peculiaridade que a variável dependente tem mais de dois níveis. Assim, há uma categoria de referência para a variável dependente e o modelo é estimado a partir da razão de chance de uma determinada categoria em relação à categoria de referência. Na prática, isto quer dizer que cada coluna na Tabela 22 pode ser interpretada como um logit. ${ }^{26}$

Primeiramente, cabe analisar a relevância explicativa de cada fator. Em verdade, este é um teste de máxima verossimilhança, em que se compara o poder explicativo do modelo completo com o do modelo restrito (sem aquele fator). Assim, avalia-se o quanto a medida -2Log Likelihood é alterada pela inclusão do fator e testam-se hipóteses com base na distribuição qui-quadrado, com número de graus de liberdade igual a $k-1$ variáveis associadas ao fator vezes o número de modelos estimados. A hipótese nula dos testes é de que o fator não é relevante para explicar a distribuição de probabilidade das categorias.

${ }^{26}$ Ainda que o software utilizado na análise tenha sido o $\mathrm{R}$, o leitor interessado sobre nas especificidades do modelo multinomial tem em Cameron e Trivedi (2009) uma excelente referência. 
Assim, a Tabela 21 mostra que todas os fatores foram importantes para distinguir as probabilidades relativas das categorias de trajetórias ocupacionais, pois a probabilidade de erro tipo II ( $p$-score, ou probabilidade de rejeitar a hipótese nula ela sendo verdadeira) é extremamente baixa (sempre menor que $1 \%$ ).

\section{Tabela 21 - Teste LR dos fatores no modelo multinomial logístico, 2003-2012}

\begin{tabular}{|c|c|c|c|c|}
\hline $\begin{array}{l}\text { Grupos de } \\
\text { variáveis }\end{array}$ & $\begin{array}{l}\text {-2Log } \\
\text { Likelihood: } \\
\text { modelo } \\
\text { restrito }\end{array}$ & $\begin{array}{l}\text { Qui- } \\
\text { quadrado } \\
\text { observado }\end{array}$ & G.I. & $\begin{array}{l}\text { Prob > qui-quadrado } \\
\text { (g.l.) }\end{array}$ \\
\hline Gênero & $14.136,07$ & 29,91 & 7 & $9,8718 E-05$ \\
\hline Porte & $14.158,18$ & 52,02 & 7 & 5,7862E-09 \\
\hline Região & $14.169,05$ & 62,89 & 35 & 2,6218E-03 \\
\hline Macrossetor & $14.171,05$ & 64,90 & 21 & $2,2572 E-06$ \\
\hline Grupo CBO & $14.373,58$ & 267,42 & 42 & $0,0000 E+00$ \\
\hline
\end{tabular}

A Tabela 22 mostra os modelos multinomiais tendo por categoria base a dos engenheiros típicos (tipo 1). As células trazem, além dos coeficientes e do erro-padrão, a razão de chance associada àquela variável, ou seja, o quanto as chances entre duas categorias se alteram devido a uma determinada variável. Por exemplo, a razão de chance associada ao gênero masculino e a categoria fora da Rais significa que homens tem 0,74 das chances de uma mulher de pertencer à categoria fora da Rais (em relação à categoria base), ou seja, $26 \%$ a menos de chances de pertencer à esta categoria. Coeficientes acima de zero fazem com que a razão de chance seja maior que 1 (o que significa que as chances a participar daquela categoria em relação à categoria base aumentam), e vice-versa. Para facilitar a interpretação, as razões de chance cujos coeficientes são significantes a $1 \%$ estão em negrito. ${ }^{27}$

Tabela 22 - Modelo multinomial logístico de previsão das trajetórias ocupacionais, 2003-2012

\begin{tabular}{|c|c|c|c|c|c|c|c|}
\hline & $\begin{array}{c}\text { Enga }{ }^{\text {a. }} \\
\text { gestão }\end{array}$ & $\begin{array}{l}\text { Eng }{ }^{\mathrm{a}} \text { : } \\
\text { profissional }\end{array}$ & $\begin{array}{l}\text { Eng }{ }^{\mathrm{a}} \text { : } \\
\text { técnico }\end{array}$ & $\begin{array}{c}\text { Fora da } \\
\text { Rais }\end{array}$ & $\begin{array}{c}\text { Não- } \\
\text { enga } \\
\text { gestão }\end{array}$ & $\begin{array}{l}\text { Não-eng }{ }^{\mathrm{a}} \text { : } \\
\text { profissional }\end{array}$ & $\begin{array}{c}\text { Não- } \\
\text { eng } \\
\text { técnico } \\
\end{array}$ \\
\hline Intercepto & $-3,475$ & $-5,204$ & $-1,967$ & $-0,253$ & $-3,154$ & $-2,076$ & $-0,816$ \\
\hline Erro-padrão & $0,440^{* * *}$ & $0,660^{* * *}$ & $0,270^{* * *}$ & $0,182^{\text {n.s. }}$ & $0,385^{* * *}$ & $0,290^{* * *}$ & $0,288^{* * *}$ \\
\hline $\begin{array}{l}\text { Gênero: } \\
\text { masculino }\end{array}$ & 0,125 & $-0,265$ & 0,114 & $-0,299$ & $-0,193$ & $-0,467$ & $-0,529$ \\
\hline Erro-padrão & $0,133^{\text {n.s. }}$ & $0,158^{*}$ & $0,094^{\text {n.s. }}$ & $0,072^{* \star *}$ & $0,135^{\text {n.s. }}$ & $0,099^{* * *}$ & $0,109^{* * *}$ \\
\hline Razão de chance & 1,133 & 0,767 & 1,121 & 0,742 & 0,824 & 0,627 & 0,589 \\
\hline $\begin{array}{l}\text { Porte em 2003: } \\
\text { pequeno }\end{array}$ & 0,040 & 0,138 & 0,314 & 0,602 & 0,278 & $-0,031$ & 0,326 \\
\hline Erro-padrão & $0,116^{\text {n.s. }}$ & $0,136^{\text {n.s. }}$ & $0,078^{* \star *}$ & $0,064^{\star * *}$ & $0,118^{* *}$ & $0,093^{\text {n.s. }}$ & $0,103^{* * *}$ \\
\hline Razão de chance & 1,041 & 1,148 & 1,369 & 1,826 & 1,320 & 0,969 & 1,385 \\
\hline
\end{tabular}

${ }^{27}$ Formalmente, basta lembrar que o modelo é ajustado sobre $\frac{\operatorname{Pr}\left(y_{i}=j\right)}{\operatorname{Pr}\left(y_{i}=1\right)}=\exp \left(X^{\prime} \beta\right)$, ou seja, sobre a probabilidade relativa de se estar em uma determinada categoria com respeito à categoria-base - a razão de chance). 


\begin{tabular}{|c|c|c|c|c|c|c|c|}
\hline $\begin{array}{l}\text { Região em 2003: } \\
\text { NE }\end{array}$ & 0,149 & $-0,304$ & 0,072 & $-0,111$ & 0,024 & $-0,413$ & $-0,221$ \\
\hline Erro-padrão & $0,408^{\text {n.s. }}$ & $0,326^{\text {n.s. }}$ & $0,185^{\text {n.s. }}$ & $0,145^{\text {n.s. }}$ & $0,335^{\text {n.s. }}$ & $0,240^{*}$ & $0,238^{\text {n.s. }}$ \\
\hline Razão de chance & 1,161 & 0,738 & 1,075 & 0,895 & 1,024 & 0,662 & 0,802 \\
\hline $\begin{array}{l}\text { Região em 2003: } \\
\text { NO }\end{array}$ & 1,211 & 0,259 & 0,106 & $-0,197$ & 0,801 & 0,138 & $-0,107$ \\
\hline Erro-padrão & $0,417^{\star \star \star}$ & $0,427^{\text {n.s. }}$ & $0,245^{\text {n.s. }}$ & $0,211^{\text {n.s. }}$ & $0,375^{\star \star}$ & $0,297^{\text {n.s. }}$ & $0,320^{\text {n.s. }}$ \\
\hline Razão de chance & 3,357 & 1,296 & 1,112 & 0,821 & 2,228 & 1,148 & 0,899 \\
\hline $\begin{array}{l}\text { Região em 2003: } \\
\text { S }\end{array}$ & 0,606 & $-0,239$ & $-0,211$ & $-0,012$ & $-0,033$ & 0,024 & $-0,315$ \\
\hline Erro-padrão & $0,352^{*}$ & $0,302^{\text {n.s. }}$ & $0,169^{\text {n.s. }}$ & $0,128^{\text {n.s. }}$ & $0,300^{\text {n.s. }}$ & $0,199^{\text {n.s. }}$ & $0,206^{\text {n.s. }}$ \\
\hline Razão de chance & 1,833 & 0,787 & 0,810 & 0,988 & 0,968 & 1,024 & 0,730 \\
\hline $\begin{array}{l}\text { Região em 2003: } \\
\text { SE }\end{array}$ & 1,009 & $-0,011$ & $-0,431$ & $-0,300$ & 0,173 & $-0,151$ & $-0,297$ \\
\hline Erro-padrão & $0,343^{\star \star *}$ & $0,270^{\text {n.s. }}$ & $0,169^{\star *}$ & $0,130^{\star *}$ & $0,289^{\text {n.s. }}$ & $0,196^{\text {n.s. }}$ & $0,203^{\text {n.s. }}$ \\
\hline Razão de chance & 2,743 & 0,989 & 0,650 & 0,741 & 1,189 & 0,860 & 0,743 \\
\hline $\begin{array}{l}\text { Região em 2003: } \\
\text { SP }\end{array}$ & 0,986 & $-0,155$ & $-0,273$ & 0,031 & 0,790 & 0,157 & $-0,047$ \\
\hline Erro-padrão & $0,337^{* * *}$ & $0,263^{\text {n.s. }}$ & $0,159^{*}$ & $0,121^{\text {n.s. }}$ & $0,269^{* * *}$ & $0,185^{\text {n.s. }}$ & $0,191^{\text {n.s. }}$ \\
\hline Razão de chance & 2,680 & 0,856 & 0,761 & 1,031 & 2,203 & 1,170 & 0,954 \\
\hline $\begin{array}{l}\text { Macrossetor em } \\
\text { 2003: } \\
\text { prestadoras }\end{array}$ & 0,319 & 0,845 & 0,484 & $-0,046$ & 0,470 & 0,631 & 0,114 \\
\hline Erro-padrão & $0,230^{\text {n.s. }}$ & $0,365^{\star *}$ & $0,187^{\star * *}$ & $0,113^{\text {n.s. }}$ & $0,238^{\star *}$ & $0,189^{* * *}$ & $0,202^{\text {n.s. }}$ \\
\hline Razão de chance & 1,376 & 2,328 & 1,623 & 0,955 & 1,600 & 1,879 & 1,121 \\
\hline $\begin{array}{l}\text { Macrossetor em } \\
\text { 2003: indústria }\end{array}$ & 0,464 & 0,434 & 0,590 & $-0,297$ & 0,502 & 0,442 & $-0,258$ \\
\hline Erro-padrão & $0,228^{\star *}$ & $0,371^{\text {n.s. }}$ & $0,184^{\star \star \star}$ & $0,117^{\star *}$ & $0,240^{\star *}$ & $0,193^{* *}$ & $0,210^{\text {n.s. }}$ \\
\hline Razão de chance & 1,590 & 1,543 & 1,804 & 0,743 & 1,652 & 1,556 & 0,773 \\
\hline $\begin{array}{l}\text { Macrossetor em } \\
\text { 2003: serviços }\end{array}$ & 0,310 & 1,374 & 0,534 & 0,043 & 0,917 & 0,946 & 0,203 \\
\hline Erro-padrão & $0,225^{\text {n.s. }}$ & $0,347^{* * *}$ & $0,182^{* \star *}$ & $0,108^{\text {n.s. }}$ & $0,221^{* * *}$ & $0,180^{\star * *}$ & $0,195^{\text {n.s. }}$ \\
\hline Razão de chance & 1,363 & 3,951 & 1,706 & 1,044 & 2,502 & 2,575 & 1,225 \\
\hline Grupo CBO: civil & $-0,281$ & 1,095 & $-0,957$ & $-0,788$ & $-0,185$ & $-0,103$ & $-1,396$ \\
\hline Erro-padrão & $0,249^{\text {n.s. }}$ & $0,548^{\star *}$ & $0,188^{* \star *}$ & $0,122^{* * *}$ & $0,228^{\text {n.s. }}$ & $0,188^{\text {n.s. }}$ & $0,189^{* * *}$ \\
\hline Razão de cha & 0,755 & 2,989 & 0,384 & 0,455 & 0,831 & 0,902 & 0,248 \\
\hline $\begin{array}{l}\text { Grupo CBO: } \\
\text { elétrico }\end{array}$ & $-0,285$ & 2,672 & 0,156 & $-0,515$ & $-0,191$ & 0,160 & $-1,233$ \\
\hline Erro-padrão & $0,234^{\text {n.s. }}$ & $0,513^{\star * *}$ & $0,152^{\text {n.s. }}$ & $0,111^{* * *}$ & $0,214^{\text {n.s. }}$ & $0,174^{\text {n.s. }}$ & $0,171^{* \star *}$ \\
\hline Razão de chance & 0,752 & 14,469 & 1,169 & 0,598 & 0,826 & 1,174 & 0,291 \\
\hline $\begin{array}{l}\text { Grupo CBO: } \\
\text { mecânico }\end{array}$ & $-0,661$ & 0,598 & 0,038 & $-0,925$ & $-1,040$ & $-0,427$ & $-1,241$ \\
\hline Erro-padrão & $0,263^{\star *}$ & $0,598^{\text {n.s. }}$ & $0,169^{\text {n.s. }}$ & $0,136^{\star * *}$ & $0,278^{* * *}$ & $0,209^{* *}$ & $0,207^{\star * *}$ \\
\hline Razão de chance & 0,516 & 1,818 & 1,039 & 0,397 & 0,353 & 0,652 & 0,289 \\
\hline $\begin{array}{l}\text { Grupo CBO: } \\
\text { metal-químico }\end{array}$ & 0,172 & 1,966 & 0,334 & $-0,705$ & $-0,665$ & $-0,179$ & $-0,897$ \\
\hline Erro-padrão & $0,257^{\text {n.s. }}$ & $0,548^{* * *}$ & $0,176^{*}$ & $0,145^{\star * *}$ & $0,289^{* *}$ & $0,216^{\text {n.s. }}$ & $0,210^{\star * *}$ \\
\hline Razão de chance & 1,188 & 7,142 & 1,397 & 0,494 & 0,514 & 0,836 & 0,408 \\
\hline $\begin{array}{l}\text { Grupo CBO: } \\
\text { pesquisador }\end{array}$ & 0,007 & 2,073 & 1,016 & $-0,098$ & 0,424 & 0,273 & 0,613 \\
\hline Erro-padrão & $0,357^{\text {n.s. }}$ & $0,619^{* * *}$ & $0,210^{\star * *}$ & $0,184^{\text {n.s. }}$ & $0,312^{\text {n.s. }}$ & $0,269^{\text {n.s. }}$ & $0,214^{\star * \star}$ \\
\hline Razão de chance & 1,007 & 7,949 & 2,762 & 0,907 & 1,528 & 1,314 & 1,846 \\
\hline $\begin{array}{l}\text { Grupo CBO: } \\
\text { produção }\end{array}$ & 0,470 & 1,601 & 0,613 & $-0,420$ & $-0,195$ & 0,093 & $-0,613$ \\
\hline
\end{tabular}




\begin{tabular}{|c|c|c|c|c|c|c|c|}
\hline Erro-padrão & $0,251^{*}$ & $0,573^{\star \star \star}$ & $0,173^{\star \star *}$ & $0,141^{* * *}$ & $0,265^{\text {n.s. }}$ & $0,212^{\text {n.s. }}$ & $0,206^{\star \star \star}$ \\
\hline Razão de chance & 1,600 & 4,958 & 1,846 & 0,657 & 0,823 & 1,097 & 0,542 \\
\hline \multicolumn{8}{|c|}{ Estatísticas de diagnóstico } \\
\hline \multicolumn{8}{|c|}{-2 Log Likelihood (modelo só com intercepto) = 18.798,15 } \\
\hline \multicolumn{8}{|c|}{-2 Log Likelihood (modelo completo) = 14.106,16 } \\
\hline \multicolumn{8}{|c|}{ Qui-quadrado observado $=4.691,99$} \\
\hline \multicolumn{8}{|c|}{ Prob $>$ qui-quadrado (112 g.I. $)=<0,00000$} \\
\hline \multicolumn{8}{|c|}{ Pseudo $R^{2}=0,2496$} \\
\hline
\end{tabular}

Fonte: elaboração própria a partir da Rais. *** - significante a 1\%, ** - significante a 5\%, *significante a $10 \%$, n.s. - não significante. As categorias base para as variáveis utilizadas no modelo são: gênero - feminino; porte - grande; região - CO; macrossetor - construção; grupo CBO agrônomo. Assim, o intercepto se refere a uma jovem agrônoma trabalhando em uma grande empresa do ramo da construção na região Centro-Oeste. As categorias foram escolhidas pelo software R por ordem numérica ou alfabética.

Assim, tem-se que:

- Ser homem está negativamente associado a pertencer às trajetórias fora da Rais, profissional ou técnico em outras áreas;

- Iniciar em empresas de pequeno porte está associado a sair da Rais e a seguir as trajetórias técnicas, em engenharia ou em outras áreas. Mas também está positivamente ligado às trajetórias de gestão em outras áreas;

- Começar a trajetória profissional em SP está positivamente associado às trajetórias de gestão, em engenharia ou não. Começar na região Norte também está associado à trajetória de gestão em engenharia;

- Ter o primeiro emprego em prestadoras de serviços a empresas aumenta a chance relativa de seguir uma trajetória como técnico em engenharia, ou profissional em outras áreas, em relação a começar na construção (categoriabase). Começar na indústria também está associado a uma trajetória como técnico em engenharia. Por sua vez, começar no setor de serviços está associado aos níveis profissional e técnico em engenharia, e gestão e profissional em outras áreas, pelo menos em relação aos jovens engenheiros típicos na construção.

- Com respeito à primeira $\mathrm{CBO}$ (em 2003):

- Começar como engenheiro civil reduz as chances de seguir a trajetória de técnico, em engenharia ou não, e de sair da Rais;

- Começar como elétrico ou como metal-químico aumenta sobremaneira a chance relativa (14,5 e 7 vezes, respectivamente) de seguir o padrão profissional em áreas correlatas à engenharia, e também reduz as chances de sair da Rais ou seguir uma trajetória como técnico em outras áreas;

- Os engenheiros mecânicos também apresentam menor chance de sair da Rais relativamente aos agrônomos (categoria-base), bem como de seguir trajetória como técnico ou gestores em outras áreas; 
- Os pesquisadores têm mais chances relativas de seguir uma trajetória como profissional em áreas correlatas à engenharia, mas também apresentam maior chance relativa de sair da Rais ou de seguir como técnico em outras áreas;

- Os engenheiros de produção apresentam maiores chances relativas de seguir o padrão de profissionais e técnicos em áreas correlatas em engenharia, e menores chances relativas de sair da Rais ou de seguir como técnico em outras áreas. Em comparação com o gráfico mosaico, que apontou que os engenheiros de produção estavam sobrerrepresentados também entre os gestores em engenharia, cabe notar que o coeficiente é positivo e significante, mas somente a $10 \%$.

De uma forma geral, os resultados do modelo multinomial são coerentes com os gráficos-mosaico, com a vantagem de uma interpretação mais direta, baseada em testes estatísticos relativamente conhecidos e do isolamento dos efeitos condicionais, isto é, o modelo calcula os efeitos marginais das variáveis mantendo tudo mais constante. 


\section{OS ENGENHEIROS JOVENS ENTRE 1995 E 2002: A GERAÇÃO 90 EM 90}

Esta subseção visa responder à sexta pergunta de pesquisa, qual seja, "Como comparar estes padrões de trajetórias, suas características e determinantes com os de uma geração anterior de engenheiros jovens (1995-2002)?”.

Como no capítulo anterior, o OMA com custos de transição baseados nas transições observadas, para posterior análise de cluster, foi aplicado sobre as trajetórias ocupacionais no período 1996-2002. ${ }^{28}$ A mesma estrutura de codificação foi aplicada à CBO 1994. A estrutura das sequências mais frequentes e do tempograma é bastante semelhante à observada para o caso-base, como se pode ver no Gráfico 25 e no Gráfico 26. Porém, cabe notar que o número de engenheiros ingressantes no mercado de trabalho em 1995 foi bem menor (5.625).

Gráfico 25 - Sequências mais frequentes, 1996-2002

Sequências mais frequentes

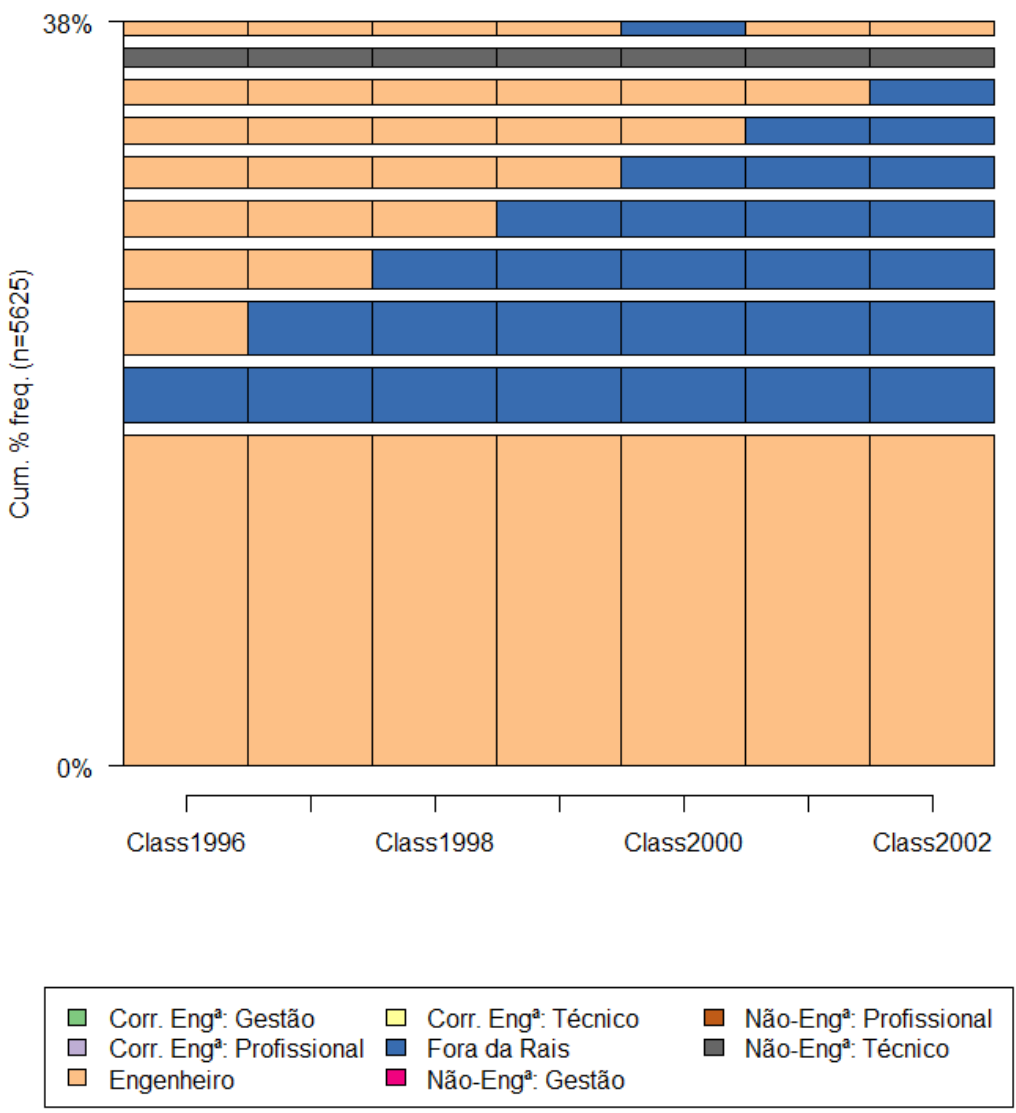

Fonte: elaboração própria a partir da Rais.

${ }^{28}$ Lembrando que, em 1995, por definição, todos os jovens eram engenheiros típicos. 


\section{Gráfico 26 - Distribuição dos estados, 1996-2002}

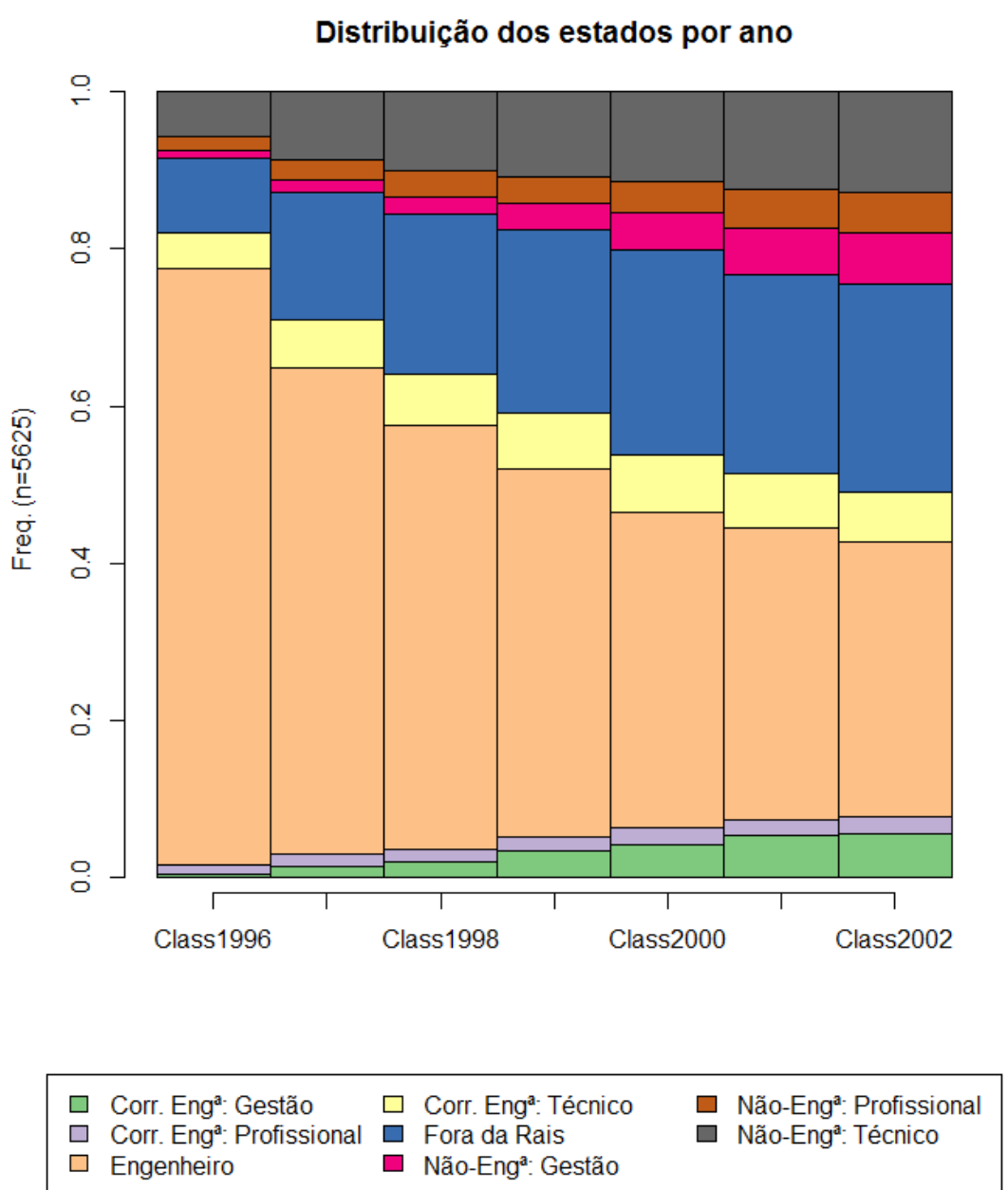

Fonte: elaboração própria a partir da Rais.

Como anteriormente, com base na medida silhouette (máximo de 0,42 ) e na inspeção do dendograma (Gráfico 27), foram mapeados 7 padrões de trajetória, que guardam bastante equivalência aos anteriores - a única diferença é que a categoria dos profissionais em áreas correlatas à engenharia não chega a formar um padrão, talvez pelo menor número de trajetórias sob análise. Sem embargo, foi considerada também uma solução de 8 clusters, mas esta solução dividiu os engenheiros típicos em 2 padrões, um deles com a saída da Rais de vários indivíduos nos anos 2000. Os tempogramas e sequências mais frequentes por padrão estão a seguir, no Gráfico 28 e Gráfico 29. 


\section{Gráfico 27 - Dendograma para análise de cluster, 1996-2002}

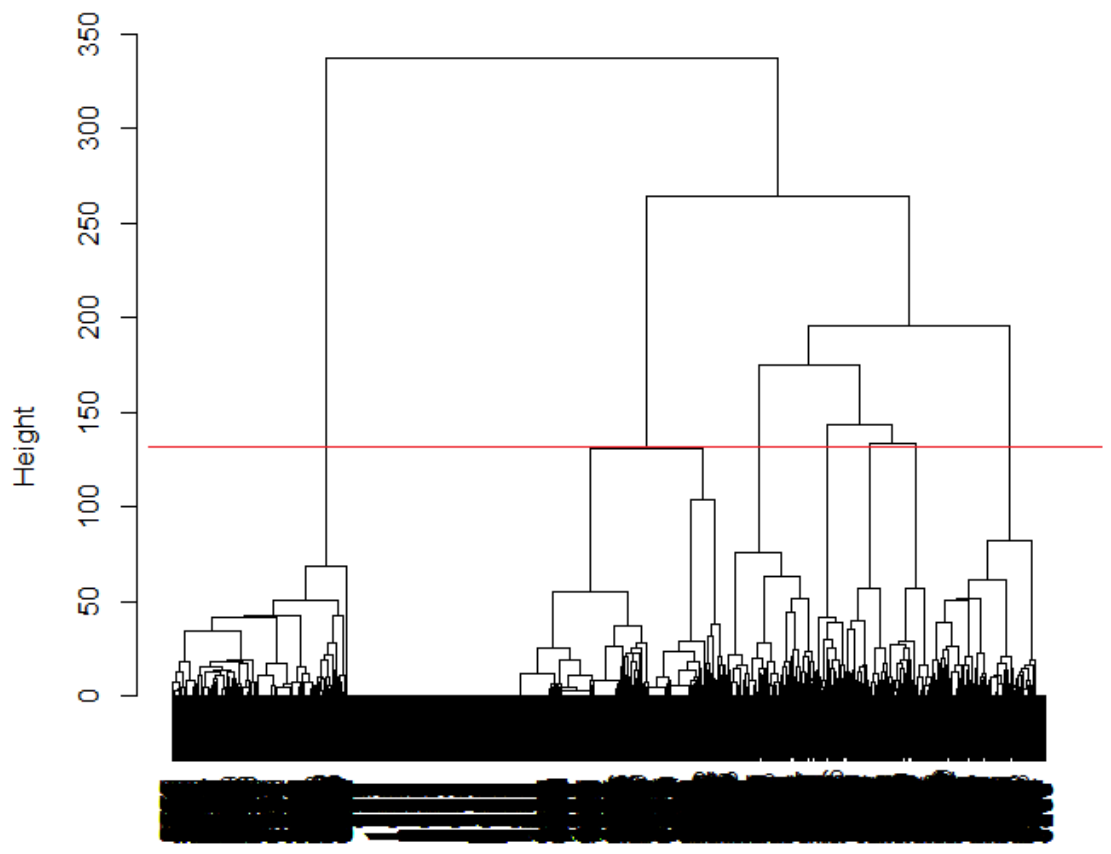

dist.om1

Agglomerative Coefficient $=1$

Fonte: elaboração própria a partir da Rais.

Entretanto, os resultados em termos de remuneração são bastante diferentes dos observados para o período 2003-2012. Fora os gestores em engenharia ou em áreas nãocorrelatas (e os conta-própria, por razões explicadas anteriormente), todas as outras trajetórias parecem apresentar a mesma remuneração. Não há a valorização em termos de remuneração da trajetória dos engenheiros típicos observada no caso-base do capítulo anterior. Os contrastes Tukey HSD indicam que, em 2002, a remuneração dos engenheiros típicos não era estatisticamente diferente a $10 \%$ de significância daquela dos que optaram por uma trajetória técnica em engenharia ou não e dos profissionais em outras áreas - os tipos 3,4 e 5, ou os padrões que não envolvem gestão; o mesmo acontece com o crescimento da remuneração entre 1995 e 2002. Aliás, mesmo que não significante, nota-se a partir da Tabela 23 e do Gráfico 30 que a remuneração em 2002 dos engenheiros típicos era a menor entre os padrões, exceção feita àqueles que saem da Rais.

Sem prejuízo a futuras análises, estes resultados sinalizam um importante efeito que um cenário de estagnação econômica pode ter sobre a evolução profissional dos engenheiros - em outras palavras, os resultados sugerem um importante efeito período. 
Gráfico 28 - Tipos de trajetórias ocupacionais, 1996-2002
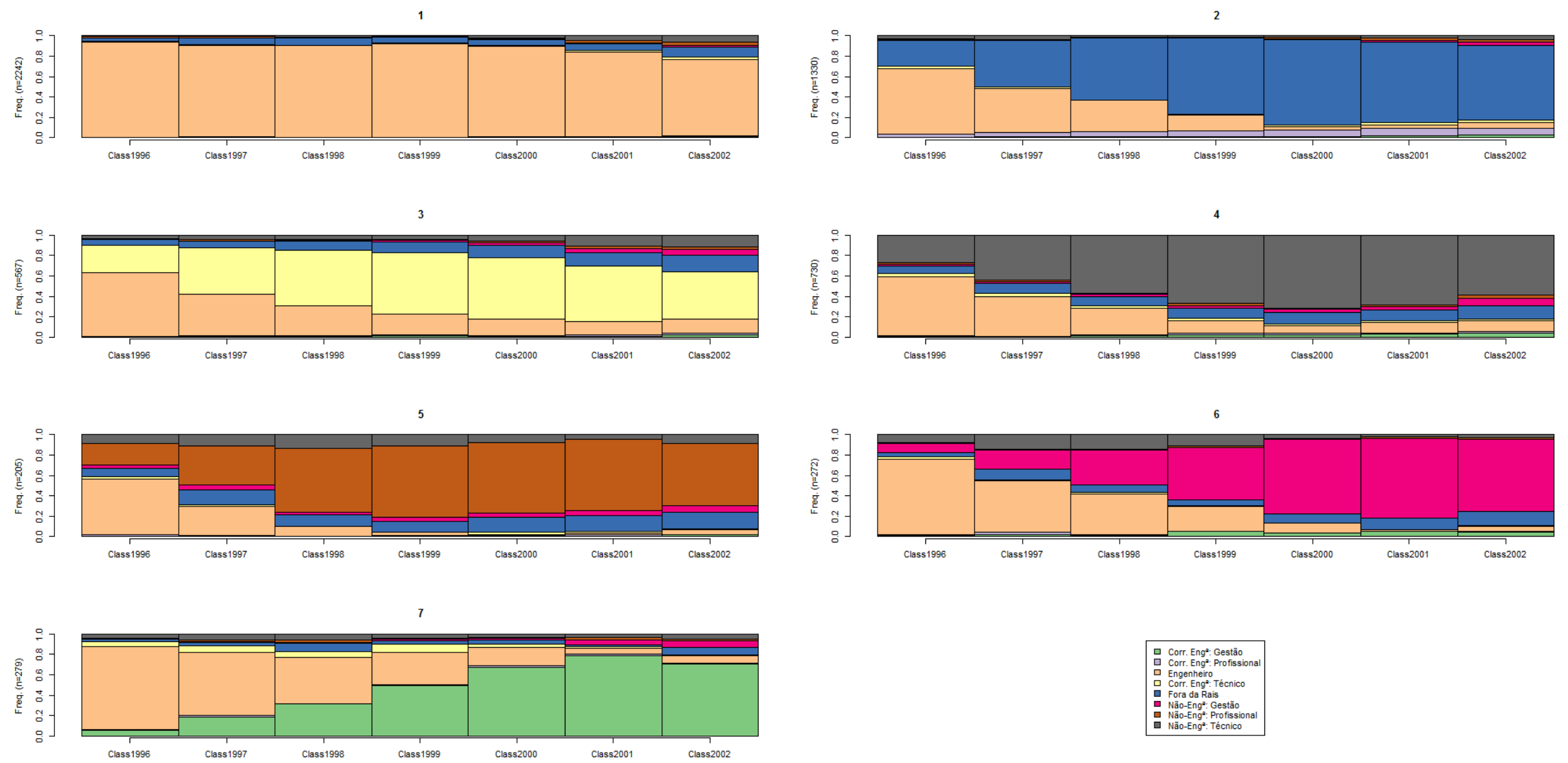

Fonte: Elaboração própria a partir da Rais. 
Gráfico 29 - Trajetórias mais frequentes por tipo de trajetória ocupacional, 1996-2002
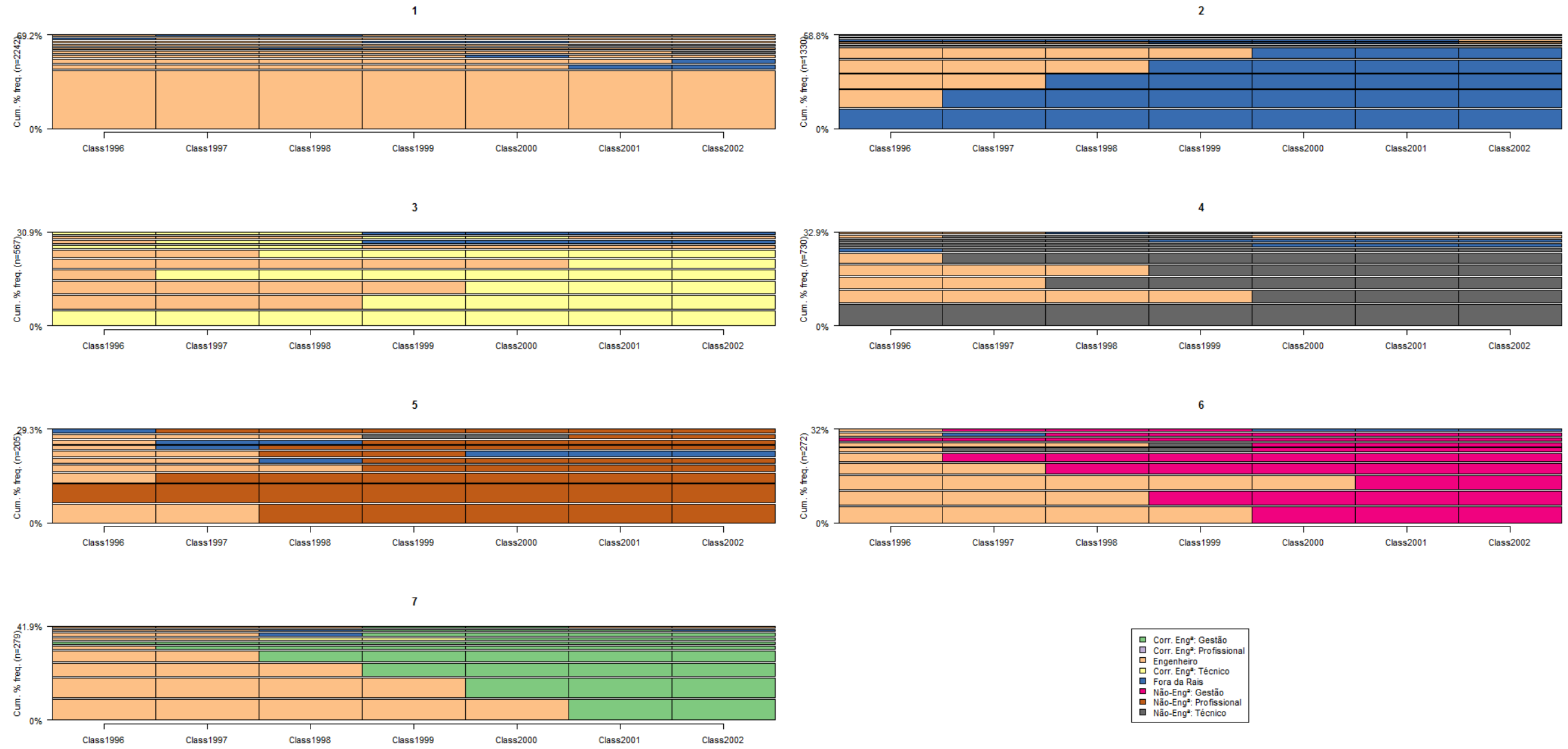

Fonte: Elaboração própria a partir da Rais. 
Tabela 23 - Características do emprego, por tipo de trajetória, 1995-2002

\begin{tabular}{l|l|l|l|l|l}
\hline \multicolumn{7}{c}{ Remuneração em 1995 (em $\mathrm{R} \$$ de 2012) } \\
\hline Tipo 1 - engenheiros típicos $(\mathrm{N}=2242)$ & $\mathrm{N}$ & Média & $\begin{array}{l}\text { Desvio- } \\
\text { padrão }\end{array}$ & Mediana & $\begin{array}{l}\text { Desvio } \\
\text { mediano }\end{array}$ \\
\hline Tipo 2 - Fora da Rais $(\mathrm{N}=1330)$ & 2.242 & $3.768,73$ & $1.714,68$ & $3.505,39$ & $1.431,24$ \\
\hline Tipo 3 - técnicos em engenharia $(\mathrm{N}=567)$ & 1.330 & $3.498,58$ & $1.853,51$ & $3.172,51$ & $1.454,84$ \\
\hline Tipo 4 - técnicos em outras áreas $(\mathrm{N}=730)$ & 567 & $3.664,17$ & $1.569,21$ & $3.473,55$ & $1.334,68$ \\
\hline Tipo 5 - profissionais em outras áreas $(\mathrm{N}=205)$ & 205 & $3.747,60$ & $1.862,85$ & $3.346,19$ & $1.738,09$ \\
\hline Tipo 6 - gestores em outras áreas $(\mathrm{N}=272)$ & 272 & $4.055,41$ & $1.743,57$ & $3.839,72$ & $1.570,72$ \\
\hline Tipo 7 - gestores em engenharia $(\mathrm{N}=269)$ & 279 & $4.754,05$ & $2.616,98$ & $4.359,31$ & $1.424,80$ \\
\hline F-ANOVA = 20,28, $\mathrm{p}=0,000, \theta^{2}=0,021$ & & & & & \\
\hline
\end{tabular}

\section{Remuneração em 2002 (em R $\$$ de 2012)}

\begin{tabular}{l|l|l|l|l|l}
\hline & $\mathrm{N}$ & Média & $\begin{array}{l}\text { Desvio- } \\
\text { padrão }\end{array}$ & Mediana & $\begin{array}{l}\text { Desvio } \\
\text { mediano }\end{array}$ \\
\hline Tipo 1 - engenheiros típicos $(\mathrm{N}=2242)$ & 2.014 & $8.175,57$ & $5.156,75$ & $7.334,10$ & $3.795,62$ \\
\hline Tipo 2 - Fora da Rais $(\mathrm{N}=1330)$ & 348 & $6.930,23$ & $6.036,63$ & $5.307,28$ & $4.434,33$ \\
\hline Tipo 3 - técnicos em engenharia $(\mathrm{N}=567)$ & 474 & $8.385,67$ & $5.287,69$ & $7.715,13$ & $3.678,62$ \\
\hline Tipo 4 - técnicos em outras áreas $(\mathrm{N}=730)$ & 635 & $8.682,01$ & $5.822,22$ & $8.017,88$ & $5.051,00$ \\
\hline Tipo 5 - profissionais em outras áreas $(\mathrm{N}=205)$ & 171 & $8.390,44$ & $6.028,24$ & $7.130,50$ & $5.314,32$ \\
\hline Tipo 6 - gestores em outras áreas $(\mathrm{N}=272)$ & 233 & $13.338,89$ & $8.115,34$ & $12.754,32$ & $5.888,38$ \\
\hline Tipo 7 - gestores em engenharia $(\mathrm{N}=269)$ & 258 & $12.785,39$ & $6.813,07$ & $11.769,53$ & $4.497,27$ \\
\hline F-ANOVA = 56,4, $\mathrm{p}=0,000, \theta^{2}=0,076$ & & & & & \\
\hline
\end{tabular}

Crescimento da remuneração, 1995-2002 (em R\$ de 2012)

\begin{tabular}{l|l|l|l|l|l}
\hline & $\mathrm{N}$ & Média & $\begin{array}{l}\text { Desvio- } \\
\text { padrão }\end{array}$ & Mediana & $\begin{array}{l}\text { Desvio } \\
\text { mediano }\end{array}$ \\
\hline Tipo 1 - engenheiros típicos $(\mathrm{N}=2242)$ & 2.014 & $4.391,23$ & $4.845,25$ & $3.508,14$ & $2.950,82$ \\
\hline Tipo 2 - Fora da Rais $(\mathrm{N}=1330)$ & 348 & $3.295,31$ & $5.720,34$ & $2.172,75$ & $3.987,31$ \\
\hline Tipo 3 - técnicos em engenharia $(\mathrm{N}=567)$ & 474 & $4.739,48$ & $4.852,81$ & $3.850,39$ & $3.135,10$ \\
\hline Tipo 4 - técnicos em outras áreas $(\mathrm{N}=730)$ & 635 & $4.964,36$ & $5.620,56$ & $4.333,49$ & $4.083,08$ \\
\hline Tipo 5 - profissionais em outras áreas $(\mathrm{N}=205)$ & 171 & $4.583,26$ & $5.621,69$ & $3.408,83$ & $4.458,60$ \\
\hline Tipo 6 - gestores em outras áreas $(\mathrm{N}=272)$ & 233 & $9.266,12$ & $7.712,12$ & $8.129,25$ & $5.212,27$ \\
\hline Tipo 7 - gestores em engenharia $(\mathrm{N}=269)$ & 258 & $8.047,20$ & $6.590,09$ & $7.113,17$ & $4.323,33$ \\
\hline F-ANOVA $=48,32, \mathrm{p}=0,000, \theta^{2}=0,065$ & & & & & \\
\hline
\end{tabular}

Tempo de emprego em 2002 (em meses)

\begin{tabular}{l|c|c|c|c|c}
\hline & $\mathrm{N}$ & Média & $\begin{array}{l}\text { Desvio- } \\
\text { padrão }\end{array}$ & Mediana & $\begin{array}{l}\text { Desvio } \\
\text { mediano }\end{array}$ \\
\hline Tipo 1 - engenheiros típicos (N=2242) & 2.020 & 53,53 & 37,86 & 45,90 & 48,85 \\
\hline Tipo 2 - Fora da Rais $(\mathrm{N}=1330)$ & 350 & 26,10 & 26,06 & 16,90 & 16,98 \\
\hline Tipo 3 - técnicos em engenharia (N=567) & 475 & 45,68 & 31,61 & 38,80 & 33,66 \\
\hline Tipo 4 - técnicos em outras áreas (N=730) & 635 & 45,25 & 32,97 & 37,60 & 36,18 \\
\hline Tipo 5 - profissionais em outras áreas $(\mathrm{N}=205)$ & 172 & 45,40 & 31,03 & 45,45 & 38,18 \\
\hline
\end{tabular}




\begin{tabular}{l|l|l|l|l|l}
\hline Tipo 6 - gestores em outras áreas $(\mathrm{N}=272)$ & 234 & 45,00 & 30,45 & 36,70 & 31,36 \\
\hline Tipo 7 - gestores em engenharia $(\mathrm{N}=269)$ & 258 & 45,59 & 35,33 & 35,25 & 36,10 \\
\hline F-ANOVA $=33,33, p=0,000, \theta^{2}=0,046$ & & & & & \\
\hline
\end{tabular}

Fonte: Elaboração própria a partir da Rais.

\section{Gráfico 30 - Remunerações relativas, 1995-2002}

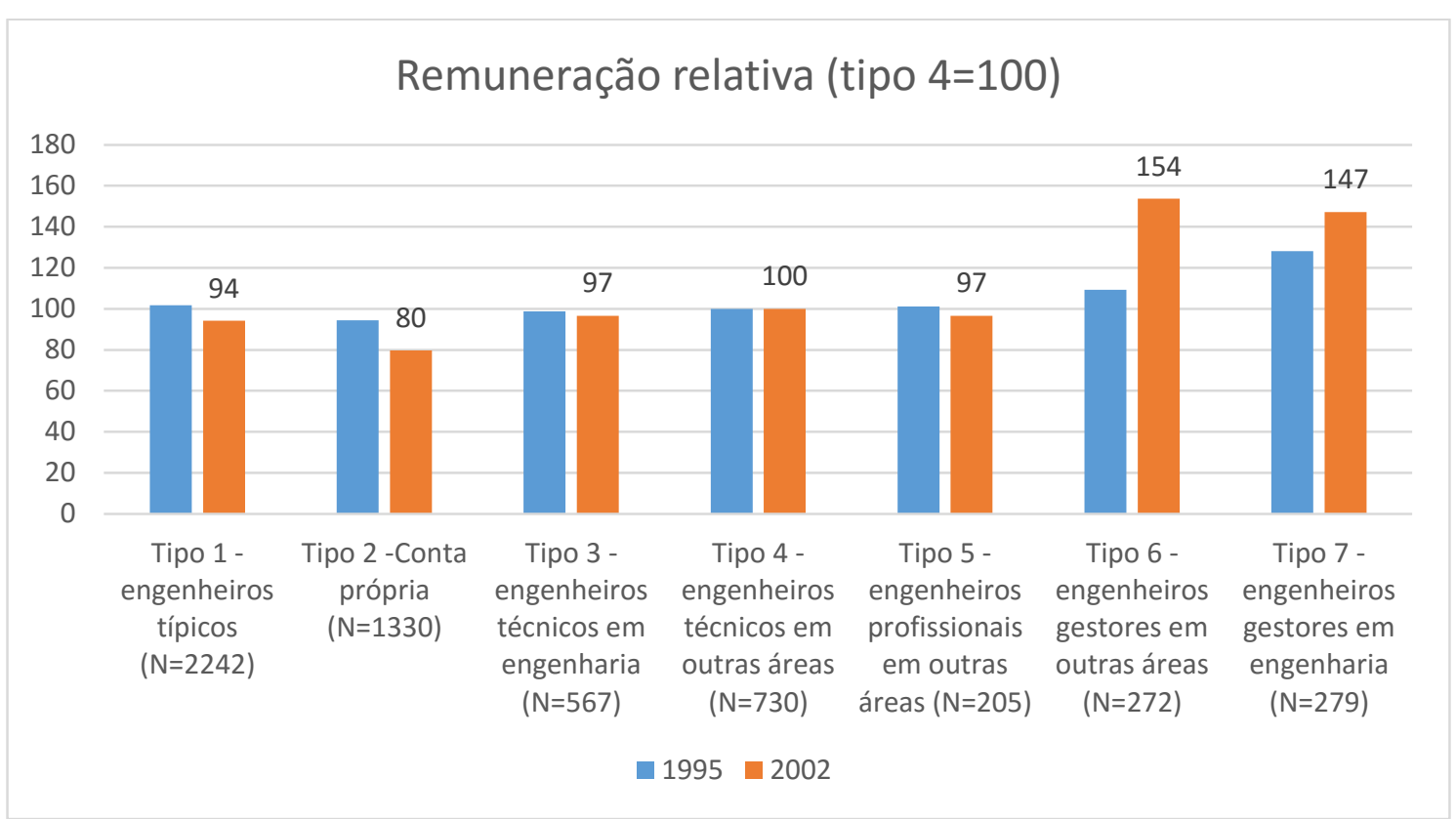

Fonte: Elaboração própria a partir da Rais.

A exemplo do que foi feito no caso-base, foram calculados os eta-quadrado para os fatores e suas interações, expostos na Tabela 24. De uma forma geral, o tamanho dos efeitos foi menor do que no caso-base, mas o padrão é o mesmo: as trajetórias são o componente mais importante para explicar a remuneração em 2002 e o tempo de emprego em 2002, e as interações, mesmo quando significantes, têm efeito muito pequeno.

Tabela 24 - Eta-quadrado das trajetórias e fatores sobre as características do emprego, 1995-2002

\begin{tabular}{|c|c|c|c|c|}
\hline & $\begin{array}{l}\text { Remuneração } \\
\text { em } 1995\end{array}$ & $\begin{array}{l}\text { Remuneração } \\
\text { em } 2002\end{array}$ & $\begin{array}{c}\text { Crescimento } \\
\text { da } \\
\text { remuneração, } \\
1995-2002\end{array}$ & $\begin{array}{l}\text { Tempo de } \\
\text { emprego } \\
\text { em } 2002\end{array}$ \\
\hline Trajetória & $0,014^{* \star *}$ & $0,076^{\star \star \star}$ & $0,066^{\star \star \star}$ & $0,042^{* * *}$ \\
\hline Gênero & $0,008^{\star \star \star}$ & $0,011^{* \star \star}$ & $0,006^{* \star *}$ & 0,000 \\
\hline Porte & $0,015^{\star \star \star}$ & $0,007^{* \star \star}$ & $0,004^{* \star *}$ & $0,003^{* * *}$ \\
\hline Região & $0,058^{\star \star \star}$ & $0,048^{\star \star \star}$ & $0,027^{\star \star \star}$ & $0,004^{* \star *}$ \\
\hline Macrossetor & $0,045^{\star * \star}$ & $0,012^{\star \star \star}$ & $0,008^{\star \star *}$ & $0,004^{\star \star *}$ \\
\hline Trajetória*gênero & 0,001 & 0,002 & 0,002 & 0,001 \\
\hline Trajetória*porte & 0,001 & 0,002 & 0,002 & 0,001 \\
\hline Gênero*porte & $0,001^{*}$ & 0,000 & 0,000 & 0,000 \\
\hline
\end{tabular}




\begin{tabular}{|c|c|c|c|c|}
\hline Trajetória*região & $0,012^{* * *}$ & $0,010^{* \star *}$ & $0,010^{* *}$ & $0,011^{*}$ \\
\hline Gênero*região & $0,002^{\star *}$ & 0,000 & 0,000 & 0,002 \\
\hline Porte*região & 0,001 & $0,001^{* *}$ & $0,001^{*}$ & 0,000 \\
\hline Trajetória*macrossetor & $0,007^{* * *}$ & $0,010^{* * *}$ & $0,008^{*}$ & 0,006 \\
\hline Gênero*macrossetor & 0,000 & $0,002^{*}$ & $0,002^{*}$ & $0,002^{*}$ \\
\hline Porte*macrossetor & $0,003^{\star * \star}$ & 0,002 & 0,002 & $0,003^{* *}$ \\
\hline Região*macrossetor & $0,009^{* * *}$ & $0,013^{* \star *}$ & $0,011^{* \star *}$ & $0,009^{* * *}$ \\
\hline Trajetória*gênero*porte & 0,001 & 0,001 & 0,001 & 0,002 \\
\hline Trajetória*gênero*região & 0,004 & 0,005 & 0,005 & 0,009 \\
\hline Trajetória*porte*região & $0,011^{* \star *}$ & $0,013^{\star \star \star}$ & $0,013^{\star \star \star}$ & 0,007 \\
\hline Gênero*porte*região & 0,001 & 0,003 & 0,002 & 0,002 \\
\hline Trajetória*gênero*macrossetor & $0,014^{* * *}$ & $0,004^{*}$ & 0,004 & $0,006^{*}$ \\
\hline Trajetória*porte*macrossetor & 0,003 & $0,012^{* *}$ & $0,009^{*}$ & 0,003 \\
\hline Gênero*porte*macrossetor & 0,001 & 0,001 & 0,001 & 0,001 \\
\hline Trajetória*região*macrossetor & $0,021^{\star *}$ & 0,013 & 0,015 & 0,015 \\
\hline Gênero*região*macrossetor & 0,003 & 0,005 & 0,004 & 0,003 \\
\hline Porte*região*macrossetor & 0,003 & $0,007^{\star \star}$ & $0,006^{\star *}$ & $0,010^{* * *}$ \\
\hline Trajetória*gênero*porte*região & 0,004 & 0,004 & 0,005 & 0,002 \\
\hline Trajetória*gênero*porte*macrossetor & 0,001 & 0,004 & 0,005 & 0,003 \\
\hline Trajetória*gênero*região*macrossetor & 0,004 & 0,005 & 0,004 & 0,003 \\
\hline Trajetória*porte*região*macrossetor & $0,018^{* *}$ & 0,005 & 0,006 & 0,005 \\
\hline Gênero*porte*região*macrossetor & 0,003 & 0,002 & 0,002 & 0,002 \\
\hline Trajetória*gênero*porte*região*macrossetor & 0,002 & 0,001 & 0,001 & 0,001 \\
\hline
\end{tabular}

a $10 \%$, n.s. - não significante.

As tabelas a seguir trazem o modelo multinomial logístico de previsão das trajetórias ocupacionais entre 1995 e 2002 . A Tabela 25 indica que, nesta aplicação, a região não é uma variável relevante para explicar as probabilidades relativas das categorias de trajetórias ocupacionais em relação à categoria-base. Entretanto, este fator foi deixado no modelo para comparabilidade com o multinomial anterior.

Tabela 25 - Teste LR dos fatores no modelo multinomial logístico, 19952002

\begin{tabular}{|c|c|c|c|c|}
\hline $\begin{array}{l}\text { Grupos de } \\
\text { variáveis }\end{array}$ & $\begin{array}{l}\text { Log } \\
\text { Likelihood: } \\
\text { modelo } \\
\text { restrito }\end{array}$ & $\begin{array}{l}\text { Qui- } \\
\text { quadrado } \\
\text { observado }\end{array}$ & G.I. & $\begin{array}{l}\text { Prob > qui-quadrado } \\
\text { (g.l.) }\end{array}$ \\
\hline Gênero & 8822,33 & 21,94 & 6 & 1,2412E-03 \\
\hline Porte & 8826,09 & 25,69 & 6 & 2,5385E-04 \\
\hline Região & 8823,04 & 22,65 & 30 & 8,2935E-01 \\
\hline Macrossetores & 8852,57 & 52,17 & 18 & 3,5171E-05 \\
\hline Grupo CBO & 8857,84 & 57,45 & 36 & 1,3032E-02 \\
\hline
\end{tabular}

Fonte: Elaboração própria a partir da Rais. 
Tabela 26 - Modelo multinomial logístico de previsão das trajetórias ocupacionais, 1995-2002

\begin{tabular}{|c|c|c|c|c|c|c|}
\hline & $\begin{array}{l}\text { Eng }{ }^{\text {a. }} \\
\text { gestão }\end{array}$ & $\begin{array}{l}\text { Eng } \\
\text { técnico }\end{array}$ & $\begin{array}{c}\text { Fora da } \\
\text { Rais } \\
\end{array}$ & $\begin{array}{l}\text { Não-enga }{ }^{\text {a }} \\
\text { gestão }\end{array}$ & $\begin{array}{l}\text { Não-eng }{ }^{\text {a: }} \\
\text { profissional }\end{array}$ & $\begin{array}{l}\text { Não-eng }{ }^{\text {a. }} \\
\text { técnico }\end{array}$ \\
\hline Intercepto & $-4,492$ & $-2,158$ & 0,025 & $-1,890$ & $-1,823$ & $-0,579$ \\
\hline Erro-padrão & $0,634^{\star * *}$ & $0,359^{\star * *}$ & $0,217^{\text {n.s. }}$ & $0,404^{* * *}$ & $0,476^{\star * *}$ & $0,283^{* *}$ \\
\hline $\begin{array}{l}\text { Gênero: } \\
\text { masculino }\end{array}$ & 0,479 & $-0,014$ & $-0,282$ & 0,162 & $-0,476$ & $-0,450$ \\
\hline Erro-padrão & $0,194^{\star *}$ & $0,126^{\text {n.s. }}$ & $0,087^{* * *}$. & $0,179^{\text {n.s. }}$ & $0,170^{\star * *}$ & $0,105^{\star * *}$ \\
\hline Razão de chance & 1,614 & 0,986 & 0,755 & 1,176 & 0,621 & 0,638 \\
\hline $\begin{array}{l}\text { Porte em 1995: } \\
\text { pequeno }\end{array}$ & $-0,353$ & 0,116 & 0,445 & 0,210 & $-0,029$ & 0,275 \\
\hline Erro-padrão & $0,161^{* *}$ & $0,107^{\text {n.s. }}$ & $0,075^{\star * *}$ & $0,139^{\text {n.s. }}$ & $0,161^{\text {n.s. }}$ & $0,094^{\star \star \star}$ \\
\hline Razão de chance & 0,702 & 1,123 & 1,561 & 1,234 & 0,971 & 1,316 \\
\hline $\begin{array}{l}\text { Região em 1995: } \\
\text { NE }\end{array}$ & 0,770 & $-0,005$ & $-0,089$ & $-0,327$ & $-0,009$ & $-0,211$ \\
\hline Erro-padrão & $0,518^{\text {n.s. }}$ & $0,302^{\text {n.s. }}$ & $0,179^{\text {n.s. }}$ & $0,335^{\text {n.s. }}$ & $0,391^{\text {n.s. }}$ & $0,260^{\text {n.s. }}$ \\
\hline Razão de chance & 2,159 & 0,995 & 0,915 & 0,721 & 0,991 & 0,810 \\
\hline $\begin{array}{l}\text { Região em 1995: } \\
\text { NO }\end{array}$ & $-1,068$ & 0,512 & 0,067 & $-0,734$ & 0,445 & 0,290 \\
\hline Erro-padrão & $1,115^{\text {n.s. }}$ & $0,388^{\text {n.s. }}$ & $0,268^{\text {n.s. }}$ & $0,579^{\text {n.s. }}$ & $0,512^{\text {n.s. }}$ & $0,355^{\text {n.s. }}$ \\
\hline Razão de chance & 0,344 & 1,668 & 1,069 & 0,480 & 1,560 & 1,337 \\
\hline $\begin{array}{l}\text { Região em 1995: } \\
\text { S }\end{array}$ & 0,297 & $-0,126$ & $-0,476$ & $-0,918$ & $-0,499$ & $-0,140$ \\
\hline Erro-padrão & $0,490^{\text {n.s. }}$ & $0,269^{\text {n.s. }}$ & $0,163^{* * *}$ & $0,300^{\star \star \star}$ & $0,365^{\text {n.s. }}$ & $0,220^{\text {n.s. }}$ \\
\hline Razão de chance & 1,346 & 0,881 & 0,621 & 0,399 & 0,607 & 0,870 \\
\hline $\begin{array}{l}\text { Região em 1995: } \\
\text { SE }\end{array}$ & 0,590 & 0,032 & $-0,246$ & $-0,342$ & $-0,110$ & $-0,142$ \\
\hline Erro-padrão & $0,489^{\text {n.s. }}$ & $0,269^{\text {n.s. }}$ & $0,161^{\text {n.s. }}$ & $0,287^{\text {n.s. }}$ & $0,351^{\text {n.s. }}$ & $0,226^{\text {n.s. }}$ \\
\hline Razão de chance & 1,804 & 1,032 & 0,782 & 0,711 & 0,896 & 0,868 \\
\hline $\begin{array}{l}\text { Região em 1995: } \\
\text { SP }\end{array}$ & 0,490 & 0,042 & $-0,248$ & $-0,421$ & $-0,329$ & 0,048 \\
\hline Erro-padrão & $0,476^{\text {n.s. }}$ & $0,255^{\text {n.s. }}$ & $0,150^{\star}$ & $0,266^{\text {n.s. }}$ & $0,335^{\text {n.s. }}$ & $0,209^{\text {n.s. }}$ \\
\hline Razão de chance & 1,632 & 1,043 & 0,781 & 0,657 & 0,719 & 1,049 \\
\hline $\begin{array}{l}\text { Macrossetor em } \\
\text { 1995: prestadoras }\end{array}$ & 0,858 & 0,307 & 0,056 & $-0,102$ & 0,198 & 0,471 \\
\hline Erro-padrão & $0,350^{\star *}$ & $0,209^{\text {n.s. }}$ & $0,128^{\text {n.s. }}$ & $0,283^{\text {n.s. }}$ & $0,275^{\text {n.s. }}$ & $0,172^{\star \star \star}$ \\
\hline Razão de chance & 2,358 & 1,360 & 1,058 & 0,903 & 1,219 & 1,601 \\
\hline $\begin{array}{l}\text { Macrossetor em } \\
\text { 1995: indústria }\end{array}$ & 1,661 & 0,976 & $-0,010$ & 0,398 & 0,119 & 0,601 \\
\hline Erro-padrão & $0,304^{* * *}$ & $0,179^{\star \star *}$ & $0,118^{\text {n.s. }}$ & $0,230^{*}$ & $0,255^{\text {n.s. }}$ & $0,159^{\star \star \star}$ \\
\hline Razão de chance & 5,264 & 2,654 & 0,990 & 1,489 & 1,126 & 1,824 \\
\hline $\begin{array}{l}\text { Macrossetor em } \\
\text { 1995: serviços }\end{array}$ & 0,953 & 0,287 & 0,081 & 0,376 & 0,115 & 0,282 \\
\hline Erro-padrão & $0,322^{* * *}$ & $0,192^{\text {n.s. }}$ & $0,117^{\text {n.s. }}$ & $0,232^{\text {n.s. }}$ & $0,258^{\text {n.s. }}$ & $0,164^{*}$ \\
\hline
\end{tabular}




\begin{tabular}{|c|c|c|c|c|c|c|}
\hline Razão de chance & 2,593 & 1,333 & 1,084 & 1,456 & 1,122 & 1,326 \\
\hline Grupo CBO: civil & 0,266 & 0,077 & $-0,155$ & $-0,540$ & $-0,176$ & $-0,832$ \\
\hline Erro-padrão & $0,360^{\text {n.s. }}$ & $0,237^{\text {n.s. }}$ & $0,148^{\text {n.s. }}$ & $0,283^{*}$ & $0,338^{\text {n.s. }}$ & $0,179^{* \star *}$ \\
\hline Razão de chance & 1,304 & 1,080 & 0,856 & 0,583 & 0,839 & 0,435 \\
\hline $\begin{array}{l}\text { Grupo CBO: } \\
\text { elétrico }\end{array}$ & 0,518 & 0,067 & $-0,442$ & 0,024 & $-0,337$ & $-0,946$ \\
\hline Erro-padrão & $0,321^{\text {n.s. }}$ & $0,217^{\text {n.s. }}$ & $0,142^{* * *}$ & $0,242^{\text {n.s. }}$ & $0,326^{\text {n.s. }}$ & $0,165^{\star \star *}$ \\
\hline Razão de chance & 1,678 & 1,069 & 0,643 & 1,024 & 0,714 & 0,388 \\
\hline $\begin{array}{l}\text { Grupo CBO: } \\
\text { mecânico }\end{array}$ & $-0,004$ & 0,235 & $-0,421$ & $-0,550$ & $-0,018$ & $-0,728$ \\
\hline Erro-padrão & 0,355 & 0,232 & $0,164^{\star *}$ & $0,299^{\star *}$ & 0,355 & $0,184^{\star \star \star}$ \\
\hline Razão de chance & 0,996 & 1,265 & 0,657 & 0,577 & 0,982 & 0,483 \\
\hline $\begin{array}{l}\text { Grupo CBO: } \\
\text { metal-químico }\end{array}$ & 0,934 & 0,510 & $-0,406$ & 0,028 & 0,254 & $-0,363$ \\
\hline Erro-padrão & $0,349^{\star \star *}$ & $0,246^{\star *}$ & $0,185^{\star \star}$ & 0,307 & 0,370 & $0,196^{*}$ \\
\hline Razão de chance & 2,544 & 1,665 & 0,666 & 1,028 & 1,290 & 0,696 \\
\hline $\begin{array}{l}\text { Grupo CBO: } \\
\text { pesquisador }\end{array}$ & 0,718 & 0,061 & $-0,384$ & $-0,140$ & 0,429 & $-0,663$ \\
\hline Erro-padrão & $0,349^{\star *}$ & 0,253 & $0,171^{* *}$ & 0,298 & 0,342 & $0,194^{\star \star \star}$ \\
\hline Razão de chance & 2,050 & 1,063 & 0,681 & 0,869 & 1,535 & 0,516 \\
\hline $\begin{array}{l}\text { Grupo CBO: } \\
\text { produção }\end{array}$ & 0,393 & 0,246 & $-0,496$ & $-0,503$ & 0,098 & $-0,499$ \\
\hline Erro-padrão & 0,378 & 0,261 & $0,196^{* *}$ & 0,357 & 0,394 & $0,207^{* *}$ \\
\hline Razão de chance & 1,482 & 1,279 & 0,609 & 0,605 & 1,103 & 0,607 \\
\hline
\end{tabular}

\section{Estatísticas de diagnóstico}

-2 Log Likelihood (modelo só com intercepto) = 10.900,99

-2 Log Likelihood (modelo completo) $=8.800,39$

Qui-quadrado observado $=2.100,60$

Prob $>$ qui-quadrado (96 g.l.) $=<0,00000$

Pseudo $R^{2}=0,193$

Fonte: elaboração própria a partir da Rais. *** - significante a 1\%, ** - significante a 5\%, *significante a $10 \%$, n.s. - não significante. As categorias base para as variáveis utilizadas no modelo são: gênero - feminino; porte - grande; região - CO; macrossetor - construção; grupo CBO agrônomo. Assim, o intercepto se refere a uma jovem agrônoma trabalhando em uma grande empresa do ramo da construção na região Centro-Oeste. As categorias foram escolhidas pelo software R por ordem numérica ou alfabética.

Assim, tem-se que:

- Assim como no caso-base, ser homem está negativamente associado a pertencer às trajetórias fora da Rais, e profissional técnico em outras áreas. No entanto, nesta aplicação, ser homem também está associado positivamente a seguir uma trajetória de gestão em engenharia: os homens têm $61 \%$ a mais de chances do que mulheres; 
- Começar a trabalhar em empresas pequenas está positivamente associado a sair da Rais ou seguir um padrão como técnico em outras áreas;

- Ter o primeiro emprego em prestadoras de serviços a empresas aumenta a chance relativa de seguir uma trajetória como técnico em outras áreas, em relação a começar na construção. Assim como no caso-base, começar na indústria está associado a uma trajetória como técnico em engenharia, mas também está associado à gestão em engenharia (mais de 5 vezes mais chances do que começar na construção0 e a uma trajetória técnica em outras áreas. $\mathrm{O}$ setor de serviços também está associado à trajetória de gestão em engenharia em relação aos jovens engenheiros típicos na construção.

- Com respeito à $\mathrm{CBO}$ :

- Começar como engenheiro civil reduz as chances de seguir a trajetória de técnico em outras áreas, assim como começar como mecânico;

- Além de reduzir a chance de seguir a trajetória como técnico em outras áreas, começar como elétrico reduz a chance de sair da Rais;

- Começar como metal-químico aumenta a chance relativa $(2,5)$ de seguir o padrão de gestão em engenharia;

- Os pesquisadores têm mais chances relativas de seguir uma trajetória como profissional em áreas correlatas à engenharia, mas também apresentam maior chance relativa de sair da Rais ou de seguir como técnico em outras áreas;

- Os engenheiros de produção apresentam menores chances, relativamente aos agrônomos, de seguir como técnico em outras áreas. 


\section{A GERAÇÃO 90 EM 2003-2012}

Por fim, resta a sétima e última questão de pesquisa, "Como as trajetórias ocupacionais desta geração anterior de engenheiros jovens se comportaram durante os anos 2000? Em que medida isto se relaciona aos aspectos demográficos dos engenheiros apontados em outros estudos?”.

Tecnicamente, há três formas de se fazer isso. A primeira é promover um novo alinhamento das sequências entre 2003 e 2012 para a geração 90. A outra é simplesmente estender o painel 1995-2002 até 2012 e utilizar as categorias de trajetórias da última subseção. A terceira forma consiste em alinhar as sequências utilizando toda a informação possível, de 1995 a 2012.

Neste capítulo, prefere-se a primeira forma. As razões são que: (i) a comparação com a geração 2000 em 2000 é direta, uma vez que o período é o mesmo; e (ii) os indivíduos podem mudar de tipo de trajetória entre 1995-2002 e 2003-2012, e padrões interessantes podem emergir - como promoções, por exemplo. Entretanto, as outras duas formas estão caracterizadas no anexo 4, e vale notar que os resultados de mercado de trabalho que emergem das três categorizações são bastante semelhantes. ${ }^{29}$

Assim, o alinhamento das sequências ocupacionais dos jovens engenheiros em 1995 durante o período 2003-2012 revela uma estrutura bem mais estática do que os casos anteriores, indicando poucas transições por parte da geração 90 nos anos 2000. Isto pode ser observado principalmente pelo tempograma (Gráfico 32) destas sequências. Entretanto, há uma outra medida chamada turbulência, ou complexidade. Como visto no capítulo 2, esta medida se refere não à similaridade/diferença entre estados, mas ao número de estados, ordem e duração dentro de uma mesma sequência, para um determinado indivíduo. Recorrendo a uma (grosseira) analogia, a medida de complexidade está para as sequências assim como as medidas de dispersão (desviopadrão) estão para as medidas de tendência central (média, mediana etc). Logo, quanto menores estas medidas, mais simples é a sequência, no sentido de número de estados e/ou na maior duração em um estado em particular. A complexidade é calculada para cada observação.

O Gráfico 33 mostra que a distribuição da complexidade das trajetórias da geração 90 nos anos 2000 está mais à esquerda do que as outras, com maior participação relativa da complexidade zero e a ausência de picos à direita no histograma. Isto indica que, de fato, as sequências da geração 90 nos anos 2000 são mais estáveis, com relativamente menos mudanças de estado por parte dos já não tão jovens engenheiros. Esta pouca

${ }^{29}$ Com efeito, a comunalidade entre as classificações entre a classificação 1995-2002 e a classificação 1995-2012 é de 48,7\% - mas há de se lembrar que a 1995-2002 tem uma categoria a menos. Já a comunalidade entre o realinhamento para 2003-2012 e a sequência longa 1995-2012 é de 82,5\%. A comunalidade entre a classificação 1995-2002 e o realinhamento para 2003-2012 está na Tabela 27. 
mobilidade revela que é difícil trazer aqueles formados em engenharia que seguiram outra trajetória ocupacional de volta para a engenharia.

\section{Gráfico 31 - Sequências mais frequentes, geração 90 em 2003-2012}

\section{Sequências mais frequentes}

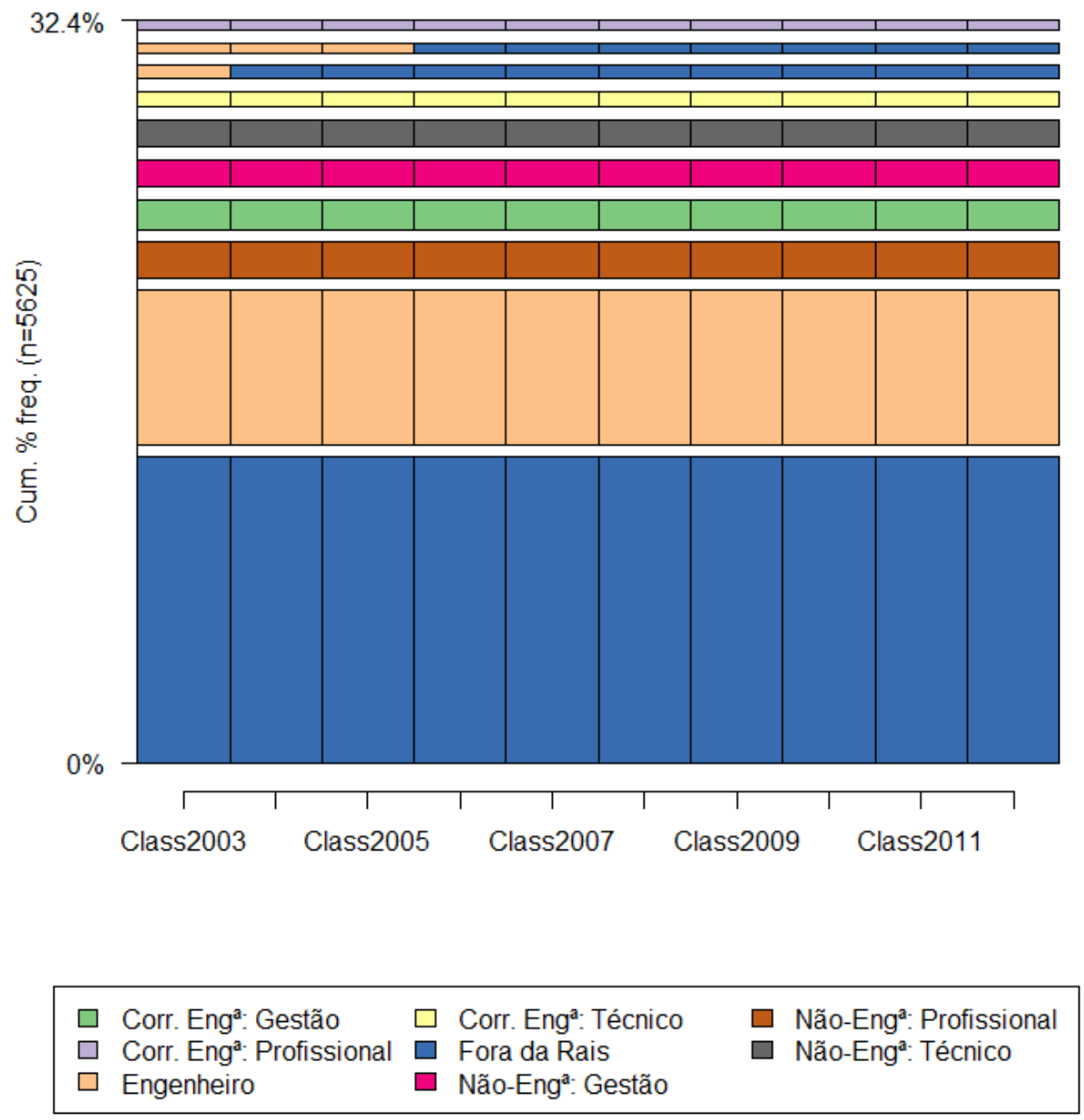

Fonte: elaboração própria a partir da Rais. 
Gráfico 32 - Distribuição dos estados, geração 90 em 2003-2012

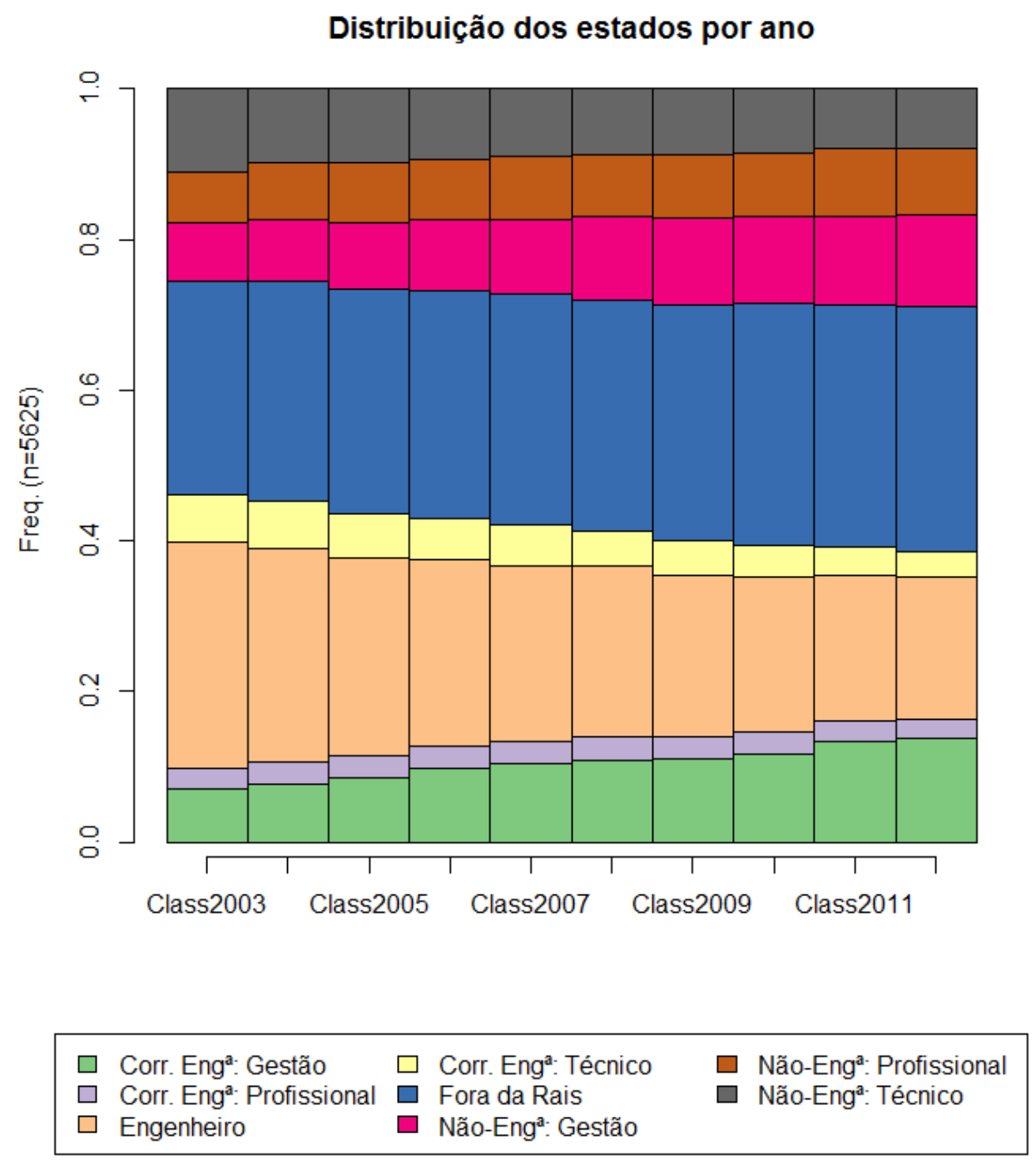

Fonte: elaboração própria a partir da Rais. 


\section{Gráfico 33 - Complexidade das trajetórias: geração 90 em 2003-2012, 1995-2002 e caso-base (2003-2012)}
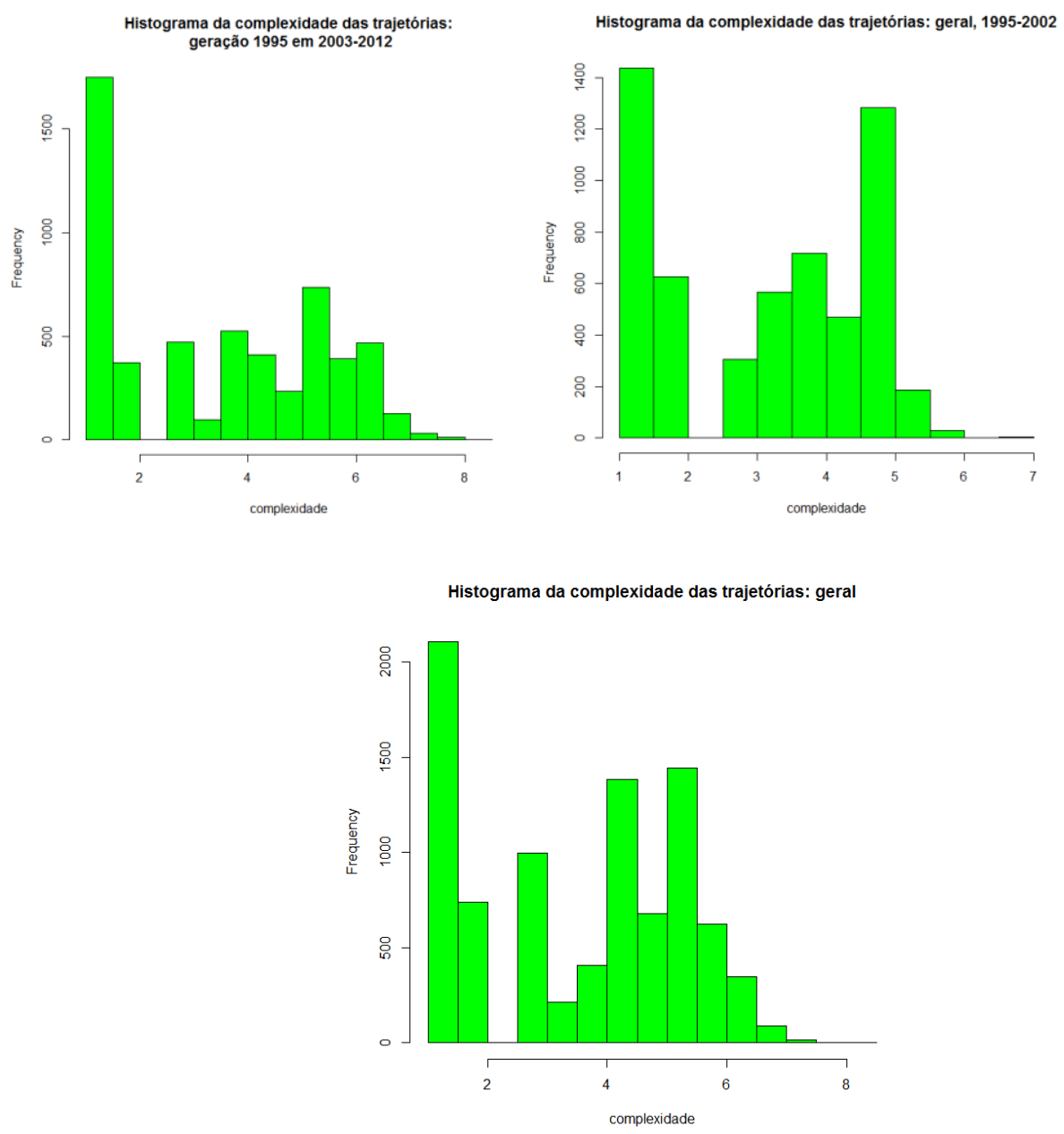

Fonte: elaboração própria a partir da Rais.

O silhouette (máximo de 0,45) e o dendograma indicam uma solução de 8 clusters, cada um correspondente a um estado possível, tal qual no caso-base. Interessantemente, a categoria mais numerosa (1.706 indivíduos) é a dos engenheiros típicos, como na geração 90 em 90, ainda que os fora da Rais também sejam bastante numerosos, até mesmo por conta do longo período em tela. O passo seguinte é, então, calcular a matriz de transição entre a classificação da geração 90 em 90 - feita no capítulo anterior - e a que emerge do realinhamento das sequências.

Isto é feito na Tabela 27. Esta tabela mostra que a retenção nas categorias é de 43\%, que pode ser considerada alta pois (i) não há nada que ligue necessariamente uma classificação à outra, (ii) a classificação da geração 90 em 2003-2012 apresenta uma categoria a mais, o que por si só já abaixa a taxa de retenção. Mas há outras observações interessantes além desta taxa de retenção. 


\section{Gráfico 34 - Dendograma para análise de cluster, geração 90 em 2003-2012}

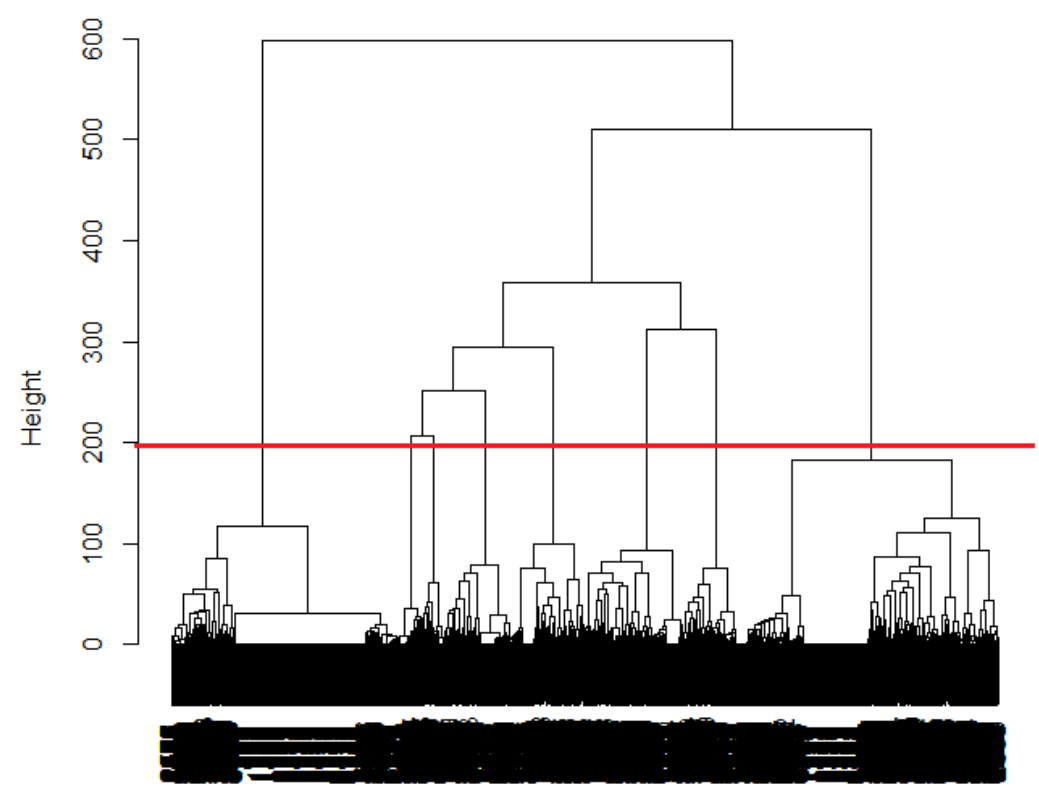

dist.om1

Agglomerative Coefficient $=1$

Fonte: elaboração própria a partir da Rais.

Tabela 27 - Matriz de transição entre as classificações: 1995-2002 vs. Geração 90 em 2003-2012

\begin{tabular}{|c|c|c|c|c|c|c|c|c|c|}
\hline \multirow[b]{2}{*}{$\begin{array}{l}\text { Classificação 1995- } \\
2002\end{array}$} & \multicolumn{9}{|c|}{ Classificação da geração 90 em 2003-2012 } \\
\hline & $\begin{array}{l}\text { Eng } \\
\text { gestão }\end{array}$ & $\begin{array}{l}\text { Enga: } \\
\text { prof. }\end{array}$ & $\begin{array}{c}\text { Engo } \\
\text { típico }\end{array}$ & $\begin{array}{l}\text { Eng }{ }^{\mathrm{a}} \text { : } \\
\text { técnico }\end{array}$ & $\begin{array}{c}\text { Fora } \\
\text { da } \\
\text { Rais }\end{array}$ & $\begin{array}{c}\text { Não- } \\
\text { eng } \\
\text { gestão }\end{array}$ & $\begin{array}{l}\text { Não- } \\
\text { enga } \\
\text { prof. }\end{array}$ & $\begin{array}{l}\text { Não- } \\
\text { enga : } \\
\text { técnico }\end{array}$ & $\begin{array}{l}\text { Total } \\
\text { Geral }\end{array}$ \\
\hline $\begin{array}{l}\text { Gestor em } \\
\text { engenharia }\end{array}$ & 114 & 3 & 39 & 3 & 40 & 51 & 15 & 14 & 279 \\
\hline Engenheiro típico & 254 & 42 & 1.164 & 45 & 382 & 116 & 104 & 135 & 2.242 \\
\hline $\begin{array}{l}\text { Técnico em } \\
\text { engenharia }\end{array}$ & 94 & 19 & 132 & 73 & 108 & 44 & 35 & 62 & 567 \\
\hline Fora da Rais & 55 & 70 & 196 & 14 & 749 & 47 & 100 & 99 & 1.330 \\
\hline $\begin{array}{l}\text { Gestor em outras } \\
\text { áreas }\end{array}$ & 44 & 4 & 34 & 2 & 73 & 61 & 34 & 20 & 272 \\
\hline $\begin{array}{l}\text { Profissional em outras } \\
\text { áreas }\end{array}$ & 16 & 6 & 20 & 1 & 41 & 22 & 85 & 14 & 205 \\
\hline $\begin{array}{l}\text { Técnico em outras } \\
\text { áreas }\end{array}$ & 99 & 17 & 121 & 11 & 160 & 98 & 63 & 161 & 730 \\
\hline Total Geral & 676 & 161 & 1.706 & 149 & 1.553 & 439 & 436 & 505 & 5.625 \\
\hline
\end{tabular}

Fonte: elaboração própria a partir da Rais. 
Gráfico 35 - Tipos de trajetórias ocupacionais, geração 90 em 2003-2012
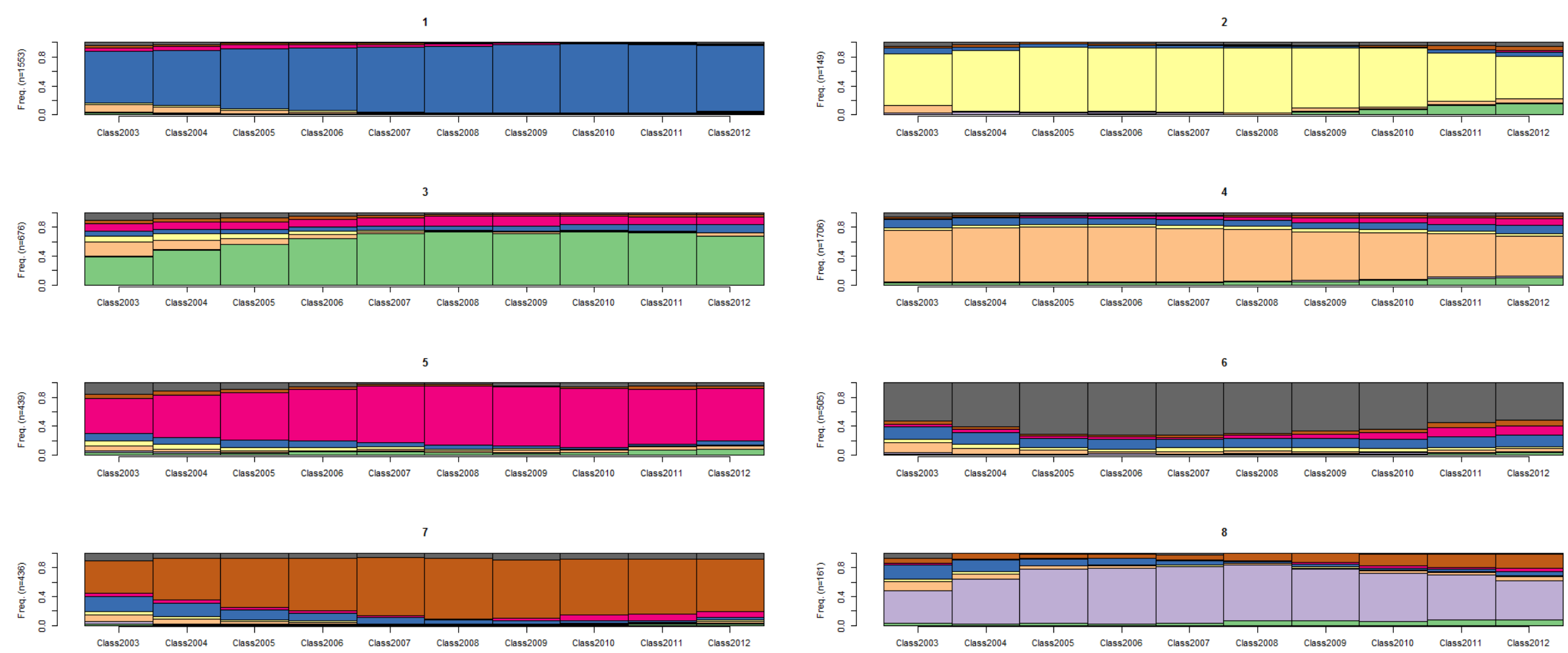

\begin{tabular}{|c|c|c|c|c|c|}
\hline $\begin{array}{l}\square \\
\square\end{array}$ & $\begin{array}{l}\text { Corr. Enga: Gestâto } \\
\text { Corr. Enga: Profissional } \\
\text { Engenheiro }\end{array}$ & 口 & 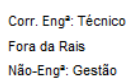 & 吕 & $\begin{array}{l}\text { Näa-Enga": Profifssional } \\
\text { Năo-Eng": Técnicos }\end{array}$ \\
\hline
\end{tabular}

Fonte: elaboração própria a partir da Rais. 
Gráfico 36 - Trajetórias mais frequentes por tipo de trajetória ocupacional, geração 90 em 2003-2012
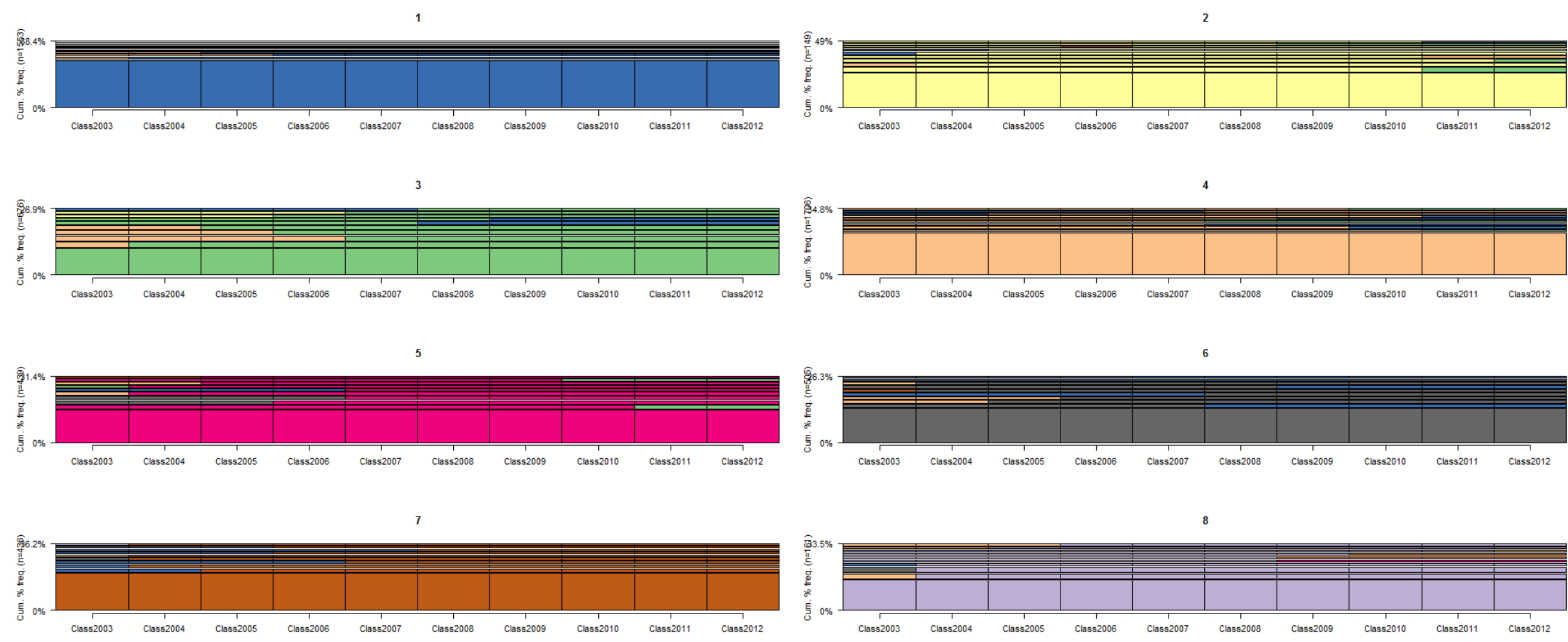

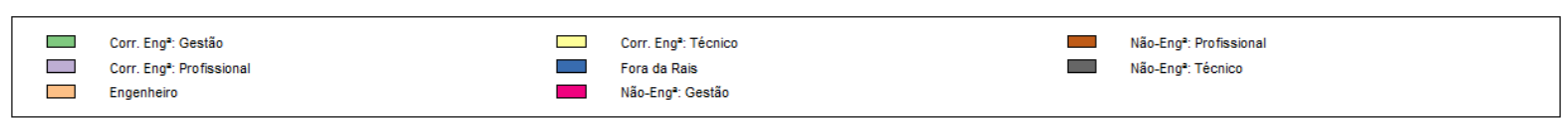

Fonte: elaboração própria a partir da Rais. 
A primeira é que o número de gestores em engenharia mais que dobra entre uma classificação e a outra, e este aumento veio da promoção dos engenheiros típicos: dos 676 gestores na nova classificação, 254 vieram dos engenheiros típicos da classificação antiga. Fenômeno semelhante acontece com os gestores em outras áreas. A categoria aumenta em $60 \%$, e a maior parte desse aumento parece vir da promoção dos engenheiros típicos. De todo modo, cabe notar que a maior parte dos gestores, tanto em engenharia quanto em outras áreas, permanece como tal no período seguinte.

A segunda observação é que, somando ao número original (1995-2002) os engenheiros típicos que foram promovidos em 2003-2012, a retenção é de 68\%. Isto é, caso se considere a ascensão a cargos de gestão como parte da trajetória ocupacional de engenheiros, a retenção é relativamente alta.

Estas duas observações parecem mostrar que há dois momentos de definição das trajetórias ocupacionais dos engenheiros jovens. Um primeiro momento, evidenciado nos casos da geração 2000 em 2000 e da geração 90 em 90, se dá até em torno de 3 anos após o primeiro emprego. Um segundo momento, evidenciado pela observação da geração 90 em 2000, diz respeito às possibilidades de ascensão aos cargos de gestão: quando esta ascensão não ocorre logo dentro dos 3 anos, há momento posterior de valorização da experiência profissional. Porém, neste último caso, não há como observar ainda o comportamento da geração 2000, por exemplo, na década posterior, a fim de comprovar ou refutar esta hipótese.

A terceira observação diz respeito à origem dos indivíduos na nova categoria dos profissionais em áreas correlatas à engenharia. Segundo a Tabela 27, a quase totalidade destes profissionais é oriunda dos engenheiros típicos e, principalmente, daqueles que estavam na categoria fora da Rais anteriormente.

Comparando os resultados de mercado de trabalho (Tabela 28) tem-se que, como esperado, as trajetórias associadas à gestão são as que oferecem melhor remuneração. De fato, os gestores (em engenharia ou não) de uma geração anterior ganhavam, em 2012, aproximadamente $50 \%$ a mais do que seus colegas da geração 2000. Todavia, aqueles engenheiros típicos da geração 90 que permaneceram como tais durante o período 20032012 ganhavam somente $14 \%$ a mais que seus colegas mais jovens.

No caso do tempo de emprego, há bastante diferença nos técnicos em engenharia e nos profissionais em outras áreas (neste último caso, deve haver alguma influência das carreiras no serviço público), mas as demais categorias apresentam números relativamente próximos. Cabe notar que a média total de tempo de emprego da geração 90 em 2003-2012 é bastante alta (80 meses). Isto parece indicar que estes profissionais não apenas apresentam pouca mobilidade ocupacional, mas também pouca mobilidade entre empresas. 


\section{Tabela 28 - Características do emprego, geração 90 em 2000, por tipo de trajetória, 2003-2012}

\begin{tabular}{|c|c|c|c|c|c|}
\hline \multicolumn{6}{|c|}{ Remuneração em 2003 (em R\$ de 2012) } \\
\hline & $\mathrm{N}$ & Média & $\begin{array}{l}\text { Desvio- } \\
\text { padrão }\end{array}$ & Mediana & $\begin{array}{l}\text { Desvio } \\
\text { mediano }\end{array}$ \\
\hline Tipo 1 - fora da Rais $(\mathrm{N}=1553)$ & 453 & $8.241,71$ & $6.980,51$ & $6.785,20$ & $5.369,95$ \\
\hline Tipo 2 - técnicos em engenharia $(\mathrm{N}=149)$ & 137 & $5.981,95$ & $3.281,12$ & $5.962,82$ & $2.924,15$ \\
\hline Tipo 3 - gestores em engenharia $(\mathrm{N}=676)$ & 627 & $12.137,67$ & $6.481,83$ & $10.874,45$ & $4.272,24$ \\
\hline Tipo 4 - engenheiros típicos (N=1706) & 1.518 & $7.505,45$ & $4.545,09$ & $7.009,06$ & $3.708,48$ \\
\hline Tipo 5 - gestores em outras áreas (N=439) & 396 & $11.446,46$ & $5.853,49$ & $11.049,82$ & $5.353,00$ \\
\hline Tipo 6 - técnicos em outras áreas $(\mathrm{N}=505)$ & 419 & $6.967,70$ & $4.839,88$ & $6.598,47$ & $4.423,86$ \\
\hline Tipo 7 - profissionais em outras áreas $(\mathrm{N}=436)$ & 347 & $8.048,41$ & $5.588,62$ & 7.446,77 & $4.928,24$ \\
\hline Tipo 8 - profissionais em engenharia $(\mathrm{N}=161)$ & 130 & $7.216,19$ & $5.496,06$ & $6.456,97$ & $3.999,26$ \\
\hline F-ANOVA $=73.91, p=0,000, \theta^{2}=0,114$ & & & & & \\
\hline \multicolumn{6}{|c|}{ Remuneração em 2012 (em R\$ de 2012) } \\
\hline & $N$ & Média & \begin{tabular}{|l|}
$\begin{array}{l}\text { Desvio- } \\
\text { padrão }\end{array}$ \\
\end{tabular} & Mediana & \begin{tabular}{|l|} 
Desvio \\
mediano \\
\end{tabular} \\
\hline Tipo 1 - fora da Rais $(\mathrm{N}=1553)$ & 142 & $11.590,54$ & $12.032,45$ & $7.595,37$ & $9.046,05$ \\
\hline Tipo 2 - técnicos em engenharia $(\mathrm{N}=149)$ & 137 & $9.077,83$ & $5.961,11$ & $8.525,81$ & $5.977,92$ \\
\hline Tipo 3 - gestores em engenharia $(\mathrm{N}=676)$ & 597 & $21.292,75$ & $11.762,61$ & $18.922,75$ & $9.006,30$ \\
\hline Tipo 4 - engenheiros típicos (N=1706) & 1.506 & $12.342,73$ & $7.380,01$ & $11.154,55$ & $6.126,15$ \\
\hline Tipo 5 - gestores em outras áreas (N=439) & 405 & $19.487,02$ & $11.382,23$ & $17.542,83$ & $9.814,46$ \\
\hline Tipo 6 - técnicos em outras áreas $(\mathrm{N}=505)$ & 422 & $10.410,50$ & $8.098,85$ & $9.275,52$ & 7.306,82 \\
\hline Tipo 7 - profissionais em outras áreas $(\mathrm{N}=436)$ & 416 & $13.430,88$ & $9.809,66$ & $12.014,63$ & $9.856,87$ \\
\hline Tipo 8 - profissionais em engenharia $(\mathrm{N}=161)$ & 150 & $9.730,11$ & $5.794,61$ & $9.148,02$ & $5.451,90$ \\
\hline F-ANOVA $=103,30, p=0,000, \theta^{2}=0,161$ & & & & & \\
\hline \multicolumn{6}{|c|}{ Crescimento da remuneração, 2003-2012 (em R $\$$ de 2012) } \\
\hline & $N$ & Média & $\begin{array}{l}\text { Desvio- } \\
\text { padrão }\end{array}$ & Mediana & \begin{tabular}{|l} 
Desvio \\
mediano \\
\end{tabular} \\
\hline Tipo 1 - fora da Rais $(\mathrm{N}=1553)$ & 50 & $3.520,85$ & $11.647,76$ & 787,74 & $9.895,39$ \\
\hline Tipo 2 - técnicos em engenharia $(\mathrm{N}=149)$ & 126 & $3.301,78$ & $4.320,74$ & $2.517,06$ & $2.983,20$ \\
\hline Tipo 3 - gestores em engenharia $(\mathrm{N}=676)$ & 553 & $9.209,62$ & $9.743,90$ & $7.637,07$ & $7.368,51$ \\
\hline Tipo 4 - engenheiros típicos (N=1706) & 1.344 & $5.065,56$ & $6.581,71$ & $3.978,17$ & $4.618,94$ \\
\hline Tipo 5 - gestores em outras áreas $(\mathrm{N}=439)$ & 367 & $8.655,21$ & $9.139,86$ & $6.663,95$ & $6.696,48$ \\
\hline Tipo 6 - técnicos em outras áreas (N=505) & 347 & $4.194,41$ & $5.784,47$ & $3.236,98$ & $3.982,96$ \\
\hline Tipo 7 - profissionais em outras áreas $(\mathrm{N}=436)$ & 331 & $5.925,91$ & $8.133,29$ & $5.067,53$ & $6.235,81$ \\
\hline Tipo 8 - profissionais em engenharia $(\mathrm{N}=161)$ & 123 & $2.631,91$ & $6.694,66$ & $2.602,24$ & $4.282,03$ \\
\hline F-ANOVA $=32,28, p=0,000, \theta^{2}=0,065$ & & & & & \\
\hline \multicolumn{6}{|c|}{ Tempo de emprego em 2012 (em meses) } \\
\hline & $N$ & Média & $\begin{array}{l}\text { Desvio- } \\
\text { padrão }\end{array}$ & Mediana & \begin{tabular}{|l} 
Desvio \\
mediano
\end{tabular} \\
\hline Tipo 1 - fora da Rais $(\mathrm{N}=1553)$ & 142 & 22,43 & 42,26 & 10,35 & 10,53 \\
\hline Tipo 2 - técnicos em engenharia $(\mathrm{N}=149)$ & 139 & 95,14 & 79,58 & 68,90 & 87,47 \\
\hline Tipo 3 - gestores em engenharia $(\mathrm{N}=676)$ & 600 & 82,51 & 75,76 & 54,05 & 62,49 \\
\hline
\end{tabular}




\begin{tabular}{l|c|c|c|c|c}
\hline Tipo 4 - engenheiros típicos $(\mathrm{N}=1706)$ & 1510 & 80,71 & 70,46 & 56,90 & 62,79 \\
\hline Tipo 5 - gestores em outras áreas $(\mathrm{N}=439)$ & 413 & 76,64 & 66,37 & 53,70 & 57,82 \\
\hline Tipo 6 - técnicos em outras áreas (N=505) & 424 & 77,89 & 65,76 & 54,40 & 60,19 \\
\hline Tipo 7 - profissionais em outras áreas (N=436) & 421 & 94,50 & 64,44 & 80,90 & 71,16 \\
\hline Tipo 8 - profissionais em engenharia $(\mathrm{N}=161)$ & 151 & 77,68 & 61,09 & 60,50 & 58,41 \\
\hline F-ANOVA $=18,14, p=0,000, \theta^{2}=0,032$ & & & & & \\
\hline
\end{tabular}

Fonte: elaboração própria a partir da Rais. 


\section{CONCLUSÃO}

Este capítulo final se inicia com um resumo dos principais resultados desta tese, estruturados de acordo com as perguntas da introdução que nortearam esta pesquisa e suas respectivas respostas:

1. Quais são os grandes padrões de trajetórias de ocupações dos jovens engenheiros entre 2003 e 2012 ?

Levando em consideração que os engenheiros formados não necessariamente exercem ocupações ligadas à engenharia, os 8 grandes padrões de trajetórias são os seguintes, em ordem de tamanho: (i) engenheiro típico ( $\mathrm{N}=4.226$ ); (ii) fora da Rais ( $\mathrm{N}=1.623)$; (iii) técnicos em engenharia $(\mathrm{N}=1.012)$; (iv) profissionais em outras áreas $(\mathrm{N}=644)$; (v) técnicos em outras áreas $(\mathrm{N}=500)$; (vi) gestores em engenharia ( $\mathrm{N}=418)$; (vii) gestores em outras áreas ( $\mathrm{N}=355)$; (viii) profissionais em engenharia ( $\mathrm{N}=263)$. Portanto, percebe-se que aproximadamente metade das 9.041 trajetórias ocupacionais analisadas compõe o padrão dos engenheiros típicos.

2. Quais são as sequências de ocupações mais comuns em cada trajetória?

As sequências de ocupações mais comuns são justamente aquelas que batizam as categorias. Estas sequências mais comuns estão no Gráfico 16 do capítulo 4.

3. Em que momento do tempo ocorre a definição destes padrões?

Quando o horizonte temporal é de 8 a 10 anos, o padrão de trajetória ocupacional é definido em torno de 3 anos após o primeiro emprego.

4. Quais são as características de remuneração e estabilidade no emprego referente a cada trajetória no final do período analisado? Em outras palavras, quais são os resultados de mercado de trabalho (labor market outcomes) de cada trajetória?

Conforme esperado, as trajetórias associadas à gestão (em engenharia ou não) são as que oferecem melhor remuneração. Contudo, é digno de nota que nos anos 2000 a terceira trajetória a oferecer maior remuneração era permanecer como engenheiro típico. De uma forma geral, os empregos dos engenheiros são bastante estáveis, com os profissionais tendo permanecido na mesma firma em torno de 50 meses em 2012 (62 meses no caso dos engenheiros típicos).

5. Como gênero e características do primeiro emprego (ocupação, região, tamanho do estabelecimento empregador, setor de atividade) se relacionam com as trajetórias subsequentes? Em que medida estas características determinam estas trajetórias?

De uma maneira geral, relativamente aos homens, as mulheres tendem às trajetórias de ocupações técnicas fora da engenharia (o padrão de menor remuneração), como também a sair do trabalho de carteira assinada e às trajetórias ocupacionais fora da engenharia. Ao longo do tempo, os profissionais de todas as 
trajetórias parecem migrar para empresas maiores, e aqueles que eventualmente saem da Rais tendem a iniciar suas trajetórias em empresas de menor porte. Os engenheiros típicos e os gestores em engenharia tendem a iniciar suas trajetórias em empresas com mais de 1.000 empregados. Não foram percebidos vieses regionais importantes com respeito às trajetórias ocupacionais. Finalmente, com respeito à ocupação do primeiro emprego, pode-se afirmar que aqueles que iniciam suas trajetórias como engenheiro civil ou mecânico estão relativamente mais propensos a seguir trajetória como engenheiros típicos, os do grupo elétrico estão relativamente mais associados aos profissionais em áreas correlatas à engenharia, e os engenheiros de produção estão associados a trajetórias técnicas em engenharia e gestão em engenharia.

6. Como comparar estes padrões de trajetórias, suas características e determinantes com os de uma geração anterior de engenheiros jovens (1995-2002)?

Aplicando-se a mesma metodologia do caso-base, tem-se que os 5.625 engenheiros jovens que ingressaram no mercado de trabalho em 1995 se dividem em 7 padrões: (i) engenheiros típicos ( $\mathrm{N}=2.242)$; (ii) fora da Rais $(\mathrm{N}=1.330)$, (iii) técnicos em outras áreas ( $\mathrm{N}=730)$; (iv) técnicos em engenharia $(\mathrm{N}=567)$; (v) gestores em outras áreas ( $\mathrm{N}=272)$; (vi) gestores em engenharia $(\mathrm{N}=269)$; (vii) profissionais em outras áreas $(\mathrm{N}=205)$.

Novamente, conforme esperado, as trajetórias associadas à gestão são as que oferecem melhor remuneração. Porém, diferentemente do que ocorre no período 2003-2012, todas as outras trajetórias terminam 2002 oferecendo a mesma remuneração, indicando que a trajetória de engenheiro típico não se diferenciou das demais neste quesito.

Com respeito aos determinantes das trajetórias, não houve diferenças importantes com respeito ao verificado no período 2003-2012.

7. Como as trajetórias ocupacionais desta geração anterior de engenheiros jovens se comportaram durante os anos 2000? Em que medida isto se relaciona aos aspectos demográficos dos engenheiros apontados em outros estudos?

Em primeiro lugar, a geração 90 em 2000 apresenta baixa mobilidade ocupacional - os padrões de trajetória identificados são mais estáveis do que os da geração 90 em 90 e da geração 2000 em 2000.

Em segundo lugar, a análise das trajetórias da geração 90 dos anos 2000 sugere a existência de um outro momento de transição na trajetória ocupacional: vários engenheiros típicos durante os anos 90 chegam a cargos de gestão na década seguinte. Os resultados de mercado de trabalho destas transições serão discutidos adiante.

Por fim, aliada à baixa mobilidade ocupacional está a baixa mobilidade de empregador, pois a geração 90 em 2000 apresenta tempo de empresa médio em torno de 80 meses. 
Além destas questões de pesquisa, cabe retomar a ideia do desenho metodológico exposto no capítulo 3, a fim de identificar os efeitos de idade e período. A Tabela 29 compara a remuneração média entre os três conjuntos de dados.

Tabela 29 - Remuneração média por diferentes tipos de trajetória: geração 90 em 90, geração 2000 em 2000 e geração 90 em 2000 (em R\$ de 2012)

\begin{tabular}{l|c|c|c|c|c|c}
\hline & \multicolumn{2}{|c|}{ geração $\mathbf{9 0}$ em 90 } & \multicolumn{2}{c|}{ geração 2000 em 2000 } & \multicolumn{2}{c}{ geração 90 nos anos } \\
\hline & 1995 & 2002 & 2003 & 2012 & 2003 & 2012 \\
\hline Gestores em engenharia & $4.754,05$ & $12.785,39$ & $4.247,81$ & $13.680,30$ & $12.137,67$ & $21.292,75$ \\
\hline Profissionais em engenharia & - & - & $4.083,38$ & $9.280,49$ & $7.216,19$ & $9.730,11$ \\
\hline Engenheiros típicos & $3.768,73$ & $8.175,57$ & $4.178,13$ & $10.832,14$ & $7.505,45$ & $12.342,73$ \\
\hline Fora da Rais & $3.498,58$ & $6.930,23$ & $3.516,12$ & $7.616,14$ & $5.981,95$ & $9.077,83$ \\
\hline Técnicos em engenharia & $3.664,17$ & $8.385,67$ & $3.009,23$ & $7.446,14$ & $8.241,71$ & $11.590,54$ \\
\hline Gestores em outras áreas & $4.055,41$ & $13.338,89$ & $4.219,15$ & $13.442,94$ & $11.446,46$ & $19.487,02$ \\
\hline Profissionais em outras áreas & $3.747,60$ & $8.390,44$ & $4.014,59$ & $10.210,64$ & $8.048,41$ & $13.430,88$ \\
\hline Técnicos em outras áreas & $3.707,67$ & $8.682,01$ & $2.730,84$ & $6.366,13$ & $6.967,70$ & $10.410,50$ \\
\hline
\end{tabular}

Fonte: elaboração própria a partir da Rais.

Nota-se, primeiramente, que sempre vale a pena em termos de remuneração, seguir uma trajetória associada à gestão, seja em áreas correlatas à engenharia ou fora dela. No entanto, nos anos 2000 valeu a pena seguir uma trajetória de engenheiro típico. Esta trajetória foi relativamente valorizada, em termos de remuneração, frente às alternativas. Os engenheiros típicos da geração 2000 chegaram ao final do período ganhando apenas $26 \%$ a menos do que os gestores em engenharia (maior remuneração).

Entretanto, esta é uma realidade totalmente distinta dos anos 90. Todas as trajetórias profissionais dos engenheiros jovens pareciam remunerar de modo muito semelhante inclusive, a trajetória dos engenheiros típicos era a de pior remuneração, ainda que esta não fosse estatisticamente diferente das trajetórias que não as de gestão. Além disso, o "salário de entrada" dos engenheiros jovens subiu $24 \%$ em termos reais na comparação entre 1995 e 2003.

Em consonância com estudos anteriores, bem como com o aumento expressivo de jovens engenheiros entrando no mercado de trabalho nos anos 2000 em comparação com os anos $90(+60 \%)$, estes resultados indicam que houve uma revalorização das carreiras em engenharia na última década. Isto indica um forte efeito período sobre a demanda de engenheiros, implicando tanto em maior valorização dos jovens profissionais quanto no aumento da oferta dos mesmos, resultado do crescimento nas inscrições de cursos de engenharia.

Parte do efeito idade é capturado pela comparação da geração 2000 em 2000 com a geração 90 em 2000. Naturalmente, a remuneração da geração mais experiente é maior. No entanto, vale notar que os jovens engenheiros de 1995 que permaneceram como engenheiros típicos durante os anos 2000 chegaram a 2012 ganhando apenas $14 \%$ a mais do que os jovens engenheiros de 2003 (com 8 anos a menos de experiência); para comparação, os gestores da geração 90 ganhavam em torno de $50 \%$ a mais do que os da 
geração 2000. Isto significa que a valorização da experiência varia de acordo com a trajetória escolhida. Em verdade, este resultado não é tão surpreendente, visto que uma análise de transição entre os padrões mostrou que os gestores são escolhidos entre os engenheiros típicos (promoção). Portanto, uma interpretação possível é que os engenheiros típicos que permanecem como tal após 17 anos não conseguiram (ou não tentaram) estas promoções.

Ademais, outro resultado importante diz respeito à identificação de dois momentos de definição de trajetórias. O primeiro ocorre até 3 anos após o primeiro emprego, e é identificado a partir da análise da geração 90 em 90 e da geração 2000 em 2000. Estes padrões guardam alguma relação com características do primeiro emprego, como porte da empresa, região, setor e ocupação, bem como com o gênero. Outro momento se relaciona às possibilidades de promoção devido à experiência, e é identificado na análise da geração 90 em 2000.

Estes resultados indicam que, se por um lado houve uma revalorização das carreiras em engenharia na última década, por outro essa revalorização não trouxe engenheiros anteriormente formados a trajetórias típicas em engenharia. Isto, em conjunto com a baixa demanda pelos cursos de engenharia durante os anos 80 e 90, corrobora a hipótese de um hiato geracional, pois além do déficit de formação de engenheiros, mostra que é difícil trazer aqueles formados que seguiram outra trajetória ocupacional de volta para a engenharia.

Esta tese apresenta a limitação de se referir apenas ao trabalho com carteira assinada, não conseguindo retratar trajetórias dos jovens engenheiros como conta-própria, empregadores, informais ou os fora do mercado de trabalho (voluntariamente ou não). Contudo, esta é uma limitação inerente à base de dados utilizada, qual seja, a Rais.

Outro aspecto que não pôde ser capturado é a influência da instituição de ensino sobre as trajetórias ocupacionais. É razoável supor que a instituição de ensino exerça grande influência sobre o padrão a ser seguido, abrindo ou fechando portas em processos seletivos e promoções; porém, novamente, há a limitação pelos dados. Esta barreira poderia ser transposta, por exemplo, pela concatenação dos dados do Censo Escolar com a Rais, ou mesmo por pesquisas de campo e/ou qualitativas. É possível e desejável que estudos futuros, utilizando outras técnicas de pesquisa, metodologias e bases de dados, venham a preencher estas lacunas.

No mais, as técnicas de análise de sequências aqui aplicadas podem ser replicadas em outros campos profissionais (por exemplo, trajetórias de médicos, professores etc), feitas, naturalmente, as devidas adaptações ao problema de pesquisa. 


\section{REFERÊNCIAS BIBLIOGRÁFICAS}

AASSVE, A.; BILLARI, F. C.; PICCARRETA, R. Strings of Adulthood: A Sequence Analysis of Young British Women's Work-Family Trajectories (Parcours de la vie adulte: Une analyse par séquence des trajectoires travail-famille des jeunes femmes britanniques). European Journal of Population / Revue Européenne de Démographie, v. 23 , n. $3 / 4$, p. 369-388, 1 out. 2007.

ABBOTT, A. A Primer on Sequence Methods. Organization Science, 1 nov. 1990.

ABBOTT, A.; FORREST, J. Optimal Matching Methods for Historical Sequences. The Journal of Interdisciplinary History, v. 16, n. 3, p. 471-494, 1 jan. 1986.

ABBOTT, A.; HRYCAK, A. Measuring Resemblance in Sequence Data - an Optimal Matching Analysis of Musicians Careers. American Journal of Sociology, v. 96, n. 1, p. 144-185, jul. 1990.

ABBOTT, A.; TSAY, A. Sequence Analysis and Optimal Matching Methods in Sociology Review and Prospect. Sociological Methods \& Research, v. 29, n. 1, p. 3-33, 8 jan. 2000.

AISENBREY, S.; FASANG, A. E. New Life for Old Ideas: The "Second Wave" of Sequence Analysis Bringing the "Course" Back Into the Life Course. Sociological Methods \& Research, v. 38, n. 3, p. 420-462, 2 jan. 2010.

BIEMANN, T. A Transition-Oriented Approach to Optimal Matching. Sociological Methodology, v. 41, n. 1, p. 195-221, 1 ago. 2011.

BIEMANN, T.; FASANG, A. E.; GRUNOW, D. Do Economic Globalization and Industry Growth Destabilize Careers? An Analysis of Career Complexity and Career Patterns Over Time. Organization Studies, v. 32, n. 12, p. 1639-1663, 1 dez. 2011.

BIEMANN, T.; WOLF, J. Career patterns of top management team members in five countries: an optimal matching analysis. The International Journal of Human Resource Management, 28 maio 2009.

BIEMANN, T.; ZACHER, H.; FELDMAN, D. C. Career patterns: A twenty-year panel study. Journal of Vocational Behavior, Fresh Perspectives on the New Career. v. 81, n. 2, p. 159-170, out. 2012.

BLAIR-LOY, M. Career Patterns of Executive Women in Finance: An Optimal Matching Analysis. American Journal of Sociology, v. 104, n. 5, p. 1346-1397, 1 mar. 1999.

BRZINSKY-FAY, C.; KOHLER, U. New Developments in Sequence Analysis. Sociological Methods \& Research, v. 38, n. 3, p. 359-364, 2 jan. 2010.

CHAN, T. W. Optimal Matching Analysis: A Methodological Note on Studying Career Mobility. Work and Occupations, v. 22, n. 4, p. 467-490, 11 jan. 1995.

COHEN, J. Statistical power analysis for the behavioral sciences. [s.1.] Lawrence Erlbaum Associates, Hillsdale, New Jersey, 1988. 
CONFEDERAÇÃO NACIONAL DA INDÚSTRIA. Recursos humanos para inovação: engenheiros e tecnólogos. Brasília: CNI, 2014.

DIJKSTRA, W.; TARIS, T. Measuring the Agreement between Sequences. Sociological Methods \& Research, v. 24, n. 2, p. 214-231, 11 jan. 1995.

ELZINGA, C. H. Sequence Similarity A Nonaligning Technique. Sociological Methods \& Research, v. 32, n. 1, p. 3-29, 8 jan. 2003.

Complexity of Categorical Time Series. Sociological Methods \& Research, v. 38, n. 3, p. 463-481, 2 jan. 2010.

FELDMAN, D. C.; NG, T. W. H. Careers: Mobility, Embeddedness, and Success. Journal of Management, v. 33, n. 3, p. 350-377, 6 jan. 2007.

FROST, W. H. The Age Selection of Mortality from Tuberculosis in Successive Decades. The Milbank Memorial Fund Quarterly, v. 18, n. 1, p. 61-66, 1 jan. 1940.

GABADINHO, A. et al. Analyzing and Visualizing State Sequences in R with TraMineR. Journal of Statistical Software, v. 40, n. 4, p. 1-37, 2011.

GUIMARÃES, R. R. DE M.; RIOS-NETO, E. L. G. Comparação entre metodologias de idade-período-coorte para o estudo de uma medida da progressão escolar no Brasil. Revista Brasileira de Estudos de População, v. 28, n. 2, p. 349-367, dez. 2011.

GUSSO, D. A.; NASCIMENTO, P. A. M. M. A formação de engenheiros e pessoal técnico-científico no Brasil entre 2001 e 2011. Brasilia: Mimeo, 2014.

HAIR, J. F. et al. Análise multivariada de dados - 6ed. [s.1.] Bookman, 2009.

HALPIN, B.; CHAN, T. W. Class Careers as Sequences: An Optimal Matching Analysis of Work-Life Histories. European Sociological Review, v. 14, n. 2, p. 111-130, 6 jan. 1998.

HAN, S.; MOEN, P. Clocking Out: Temporal Patterning of Retirement. American Journal of Sociology, v. 105, n. 1, p. 191-236, 1 jul. 1999.

HENDRY, D. F. Econometric methodology: a personal perspective. In: BEWLEY, T. F. (Ed.). . Advances in Econometrics: Fifth World Congress, Volume II. [s.1.] Cambridge University Press, 1987. p. 29-48.

HOLLISTER, M. Is Optimal Matching Suboptimal? Sociological Methods \& Research, v. 38, n. 2, p. 235-264, 11 jan. 2009.

ILLES, J. et al. A model for faculty mentoring in academic radiology. Academic Radiology, v. 7, n. 9, p. 717-724, 1 set. 2000.

JOSEPH, D.; BOH, W. F.; SLAUGHTER, S. The career paths less (or more) traveled: a sequence analysis of IT career histories, mobility patterns, and career success. MIS Quarterly, v. 36, n. 2, p. 427-462, 2012.

KING, T. A framework for analysing social sequences. Quality \& Quantity, v. 47, n. 1, p. 167-191, 4 set. 2011. 
KOGAN, I. A study of immigrants' employment careers in West Germany using the sequence analysis technique. Social Science Research, v. 36, n. 2, p. 491-511, jun. 2007.

LESNARD, L. Off-Scheduling within Dual-Earner Couples: An Unequal and Negative Externality for Family Time. American Journal of Sociology, v. 114, n. 2, p. 447-490, 1 set. 2008.

LESNARD, L.; KAN, M. Y. Investigating scheduling of work: a two-stage optimal matching analysis of workdays and workweeks. Journal of the Royal Statistical Society: Series A (Statistics in Society), v. 174, n. 2, p. 349-368, 1 abr. 2011.

LEVINE, J. H. But What Have You Done for Us Lately? Commentary on Abbott and Tsay. Sociological Methods \& Research, v. 29, n. 1, p. 34-40, 8 jan. 2000.

LINS, L. M. et al. Escassez de engenheiros no Brasil? uma proposta de sistematização do debate. Novos Estudos - CEBRAP, n. 98, p. 43-67, mar. 2014.

MARSHALL, G. Event-history analysisA Dictionary of Sociology. [s.1.] Encyclopedia, 1998. Disponível em: <http://www.encyclopedia.com/doc/1O88eventhistoryanalysis.html>. Acesso em: 28 out. 2015

MARTIN, P.; SCHOON, I.; ROSS, A. Beyond Transitions: Applying Optimal Matching Analysis to Life Course Research. International Journal of Social Research Methodology, 12 jun. 2008.

MASON, K. O. et al. Some Methodological Issues in Cohort Analysis of Archival Data. American Sociological Review, v. 38, n. 2, p. 242-258, 1 abr. 1973.

MCVICAR, D.; ANYADIKE-DANES, M. Predicting successful and unsuccessful transitions from school to work by using sequence methods. Journal of the Royal Statistical Society: Series A (Statistics in Society), v. 165, n. 2, p. 317-334, 1 jun. 2002.

MENEZES-FILHO, N. Apagão de mão-de-obra qualificada? As profissões e o mercado de trabalho brasileiro entre 2000 e 2010. São Paulo: BraIn Investimento e Negócios, 2012.

PEREIRA, R. H.; NASCIMENTO, P. A. M. M.; ARAÚJO, T. C. Projeções de Mão de Obra Qualificada no Brasil: Uma Proposta Inicial com Cenários Para a Disponibilidade de Engenheiros Até 2020. Brasília: IPEA, 2011. (Texto para discussao, n. 1663).

PICCARRETA, R.; BILLARI, F. C. Clustering work and family trajectories by using a divisive algorithm. Journal of the Royal Statistical Society: Series A (Statistics in Society), v. 170, n. 4, p. 1061-1078, 1 out. 2007.

POLLOCK, G. Holistic trajectories: a study of combined employment, housing and family careers by using multiple-sequence analysis. Journal of the Royal Statistical Society: Series A (Statistics in Society), v. 170, n. 1, p. 167-183, 1 jan. 2007.

POMPERMAYER, F. M. et al. Potenciais gargalos e prováveis caminhos de ajustes no mundo do trabalho no Brasil nos próximos anos. Brasília: IPEA, , fev. 2011. (Nota técnica). 
ROSENFELD, R. A. Job Mobility and Career Processes. Annual Review of Sociology, v. 18, n. 1, p. 39-61, 1992.

ROUSSEEUW, P. Silhouettes: a graphical aid to the interpretation and validation of cluster analysis. Journal of Computational and Applied Mathematics, v. 20, n. 1, p. 53-65, 11 jan. 1987.

SCHERER, S. Early Career Patterns: A Comparison of Great Britain and West Germany. European Sociological Review, v. 17, n. 2, p. 119-144, 6 jan. 2001.

SEESP, S. DOS E. NO E. DE S. P. Perfil ocupacional dos profissionais de engenharia no Estado de São PauloSão Paulo, 2014. Disponível em: <http://www.seesp.org.br/site/images/PerfilOcupacional.pdf>

SHOVAL, N.; ISAACSON, M. Sequence Alignment as a Method for Human Activity Analysis in Space and Time. Annals of the Association of American Geographers, v. 97, n. 2, p. 282-297, 1 jun. 2007.

STOVEL, K. Local Sequential Patterns: The Structure of Lynching in the Deep South, 1882-1930. Social Forces, v. 79, n. 3, p. 843-880, 3 jan. 2001.

STOVEL, K.; BOLAN, M. Residential Trajectories Using Optimal Alignment to Reveal The Structure of Residential Mobility. Sociological Methods \& Research, v. 32, n. 4, p. 559-598, 5 jan. 2004.

STUDER, M. et al. Discrepancy Analysis of State Sequences. Sociological Methods \& Research, v. 40, n. 3, p. 471-510, 1 ago. 2011.

VINKENBURG, C. J.; WEBER, T. Managerial career patterns: A review of the empirical evidence. Journal of Vocational Behavior, Career Adaptability. v. 80, n. 3, p. 592-607, jun. 2012.

WU, L. L. Some Comments on "Sequence Analysis and Optimal Matching Methods in Sociology: Review and Prospect”. Sociological Methods \& Research, v. 29, n. 1, p. 4164, 8 jan. 2000.

ZUCKERMAN, E. W. et al. Robust Identities or Nonentities? Typecasting in the FeatureFilm Labor Market. American Journal of Sociology, v. 108, n. 5, p. 1018-1073, 1 mar. 2003. 


\section{ANEXO 1: SitUAÇÃO OCUPACIONAL DOS PROFISSIONAIS FORMADOS EM ENGENHARIA A PARTIR DOS CENSOS 2010 E 2000}

Este anexo tem por objetivo detalhar o perfil ocupacional dos profissionais formados em engenharia a partir do Censo 2010, conforme discutido no capítulo 3. A conclusão é de que a maior parte dos engenheiros trabalha no mercado formal com carteira assinada, mas há uma parcela relevante de engenheiros que trabalham como conta-própria e empregadores. A informalidade (trabalho sem carteira assinada) é relativamente baixa entre os engenheiros. Consoante com Menezes-filho et al. (2012), ainda que os filtros empregados no Censo sejam diferentes, verificou-se que a taxa de desemprego dos engenheiros é baixa.

\subsection{Filtros}

Como a análise a partir da Rais estabeleceu como engenheiro jovem os profissionais com 25 anos ou menos que exerciam uma CBO de engenharia em 2003, o filtro etário para a análise a partir do Censo foi entre 29 e 32 anos - engenheiros que em 2003 tinham entre 22 e 25 anos, assumindo 22 anos uma idade mínima para se formar em engenharia. Entretanto, cabe lembrar que estes profissionais podem ter se formado posteriormente a 2003.

Sem embargo, é importante ressaltar que a comparação direta entre o Censo 2010 e a amostra de engenheiros Rais entre 2003 e 2012 não é possível devido a basicamente dois fatores:

c) A definição dos engenheiros é diferente. No Censo de 2010, os engenheiros foram definidos a partir da área de formação do curso superior, enquanto na Rais os engenheiros jovens foram definidos a partir do exercício de CBOs em engenharia em 2003. A definição da Rais é mais restritiva, pois como se trata de uma profissão regulamentada por órgão de classe, o exercício de CBO de engenharia geralmente está vinculado ao curso superior em engenharia, mas o inverso não necessariamente é verdadeiro. Em outras palavras, aqueles indivíduos jovens que começaram suas trajetórias profissionais fora da engenharia não foram capturados pelo estudo com a Rais;

d) O Censo não permite recuperar a história profissional em 2003. Além disso, ele não traz o ano de formatura dos profissionais, então pode ocorrer que alguns dos engenheiros entre 29 e 32 anos em 2010 tenham se formado depois de 2003.

Os engenheiros foram definidos como profissionais com nível superior formados na grande área 5 ("engenharia, produção e construção") e 62 ("agricultura, florestas e recursos pesqueiros"), exceto a área 581, qual seja, "arquitetura e urbanismo", de acordo 
com o arquivo "Cursos Superiores_Estrutura 2010.xls", presente da documentação de apoio do Censo 2010.

\subsection{Resultados}

Em 2010, de acordo com estes filtros, havia 21.337 profissionais. Destes, $18.344 \mathrm{ou}$ $86 \%$ trabalharam na semana de referência de 25 a 31 de julho de 2010, e 2.993 ou $14 \%$ não trabalharam, conforme a Tabela 30 a seguir.

\section{Tabela 30 - Situação de trabalho na semana de referência do Censo 2010}

\begin{tabular}{lcccc}
\hline \multicolumn{3}{c}{$\begin{array}{c}\text { V0641 - Na semana de } 25 \text { a } 31 / 07 / 10, \text { durante pelo } \\
\text { menos } 1 \text { hora, trabalhou ganhando em dinheiro, } \\
\text { produtos, mercadorias ou benefícios? }\end{array}$} \\
\hline V0641 & Frequência & $\%$ & $\begin{array}{c}\text { Frequência } \\
\text { acumulada }\end{array}$ & $\begin{array}{c}\text { Percentual } \\
\text { acumulado }\end{array}$ \\
\hline Sim & 18.344 & 85,97 & 18.344 & 85,97 \\
\hline Não & 2.993 & 14,03 & 21.337 & 100,00 \\
\hline
\end{tabular}

Fonte: elaboração própria a partir do Censo 2010.

Entretanto, dentre aqueles 2.993 que não trabalharam, apenas 447 tomaram "tomou alguma providência, de fato, para conseguir trabalho" na semana de referência (variável V0654), enquanto 500 tinham "trabalho remunerado do qual estava temporariamente afastado(a)" (variável V0642). Deste modo, considerando que o conceito de desemprego implica que o trabalhador estava procurando trabalho, os 447 engenheiros desempregados representam $2 \%$ do total de engenheiros formados, cifra compatível com o encontrado em Menezes-filho et al. (2012). Sem embargo, não é possível precisar quantos dos 2.993 engenheiros que não trabalhavam na semana de referência em 2010 tinham trabalhado anteriormente.

Outro aspecto que merece relevância é que os 500 indivíduos que não trabalharam mas que estavam temporariamente afastados de forma remunerada provavelmente apareceram na Rais de 2010, pois eles teoricamente constam nos registros das empresas declarantes.

A Tabela 31 indica a categoria do emprego no trabalho principal. São 7 possibilidades no Censo 2010. Dentre elas, a mais numerosa é justamente a dos empregados com carteira assinada, com 10.709 indivíduos ou 56,58\% das observações não-faltantes (2.410 indivíduos têm esta variável em branco, provavelmente devido ao fato de que eles não estivessem trabalhando). Quando se somam a estes trabalhadores os militares e funcionários públicos estatutários, tem-se 12.444 pessoas ou $65,75 \%$ do total. 
Este número de engenheiros no mercado formal e que seriam passíveis de representação na Rais, apesar de 37,6\% maior, é compatível com a amostra de 9.041 engenheiros jovens da Rais. Isto porque a amostra da Rais exige que os engenheiros tenham exercido uma CBO de engenharia em 2003, a enquanto a amostra do censo não faz esta exigência: os engenheiros podem ter começado a trabalhar em qualquer CBO. Também não há informação sobre o ano de formatura destes engenheiros. Assim, seria de se esperar que o número de engenheiros no mercado de trabalho formal com carteira assinada de acordo com o Censo fosse maior que o verificado na Rais.

\section{Tabela 31 - Posição na ocupação e categoria do emprego no trabalho principal, Censo 2010}

\begin{tabular}{|c|c|c|c|c|}
\hline $\begin{array}{l}\text { V6930 - Posição na } \\
\text { ocupação e categoria } \\
\text { do emprego no } \\
\text { trabalho principal da } \\
\text { semana de } 25 \text { a } 31 \text { de } \\
\text { julho de } 2010\end{array}$ & Frequência & $\%$ & $\begin{array}{l}\text { Frequência } \\
\text { acumulada }\end{array}$ & $\begin{array}{l}\text { Percentual } \\
\text { acumulado }\end{array}$ \\
\hline $\begin{array}{l}1 \text { - Empregados com } \\
\text { carteira de trabalho } \\
\text { assinada }\end{array}$ & 10.709 & 56,58 & 10.709 & 56,58 \\
\hline $\begin{array}{l}2 \text { - Militares e } \\
\text { funcionários públicos } \\
\text { estatutários }\end{array}$ & 1.735 & 9,17 & 12.444 & 65,75 \\
\hline $\begin{array}{l}3 \text { - Empregados sem } \\
\text { carteira de trabalho } \\
\text { assinada }\end{array}$ & 1.072 & 5,66 & 13.516 & 71,41 \\
\hline 4 - Conta própria & 3.559 & 18,80 & 17.075 & 90,22 \\
\hline 5 - Empregadores & 1.778 & 9,39 & 18.853 & 99,61 \\
\hline 6 - Não- remunerados & 39 & 0,21 & 18.892 & 99,82 \\
\hline $\begin{array}{l}7 \text { - Trabalhadores na } \\
\text { produção para o } \\
\text { próprio consumo }\end{array}$ & 35 & 0,18 & 18.927 & 100,00 \\
\hline Em branco & 2.410 & & & \\
\hline
\end{tabular}

Fonte: elaboração própria a partir do Censo 2010

O interesse deste trabalho com o Censo era de mapear qual a categoria de emprego (ou não) daqueles profissionais que saem da Rais. Já foi discutido que 2.993 não trabalharam na semana de referência do Censo. Em adição a estes indivíduos, de acordo com a Tabela 31 acima, 3.559 engenheiros trabalhavam como conta-própria e 1.778 como empregadores. Estes 5.337 profissionais - ou 25\% dos 21.337 engenheiros -, também não seriam retratados pela Rais. Residualmente, também não seriam representados na Rais os $5,6 \%$ dos trabalhadores sem carteira assinada.

A Tabela 32 mostra a remuneração média, no mês de referência, das diferentes categorias de emprego. Percebe-se que os conta-própria ganhavam um pouco mais do que 
os empregados com carteira assinada, e que os trabalhadores sem carteira assinada, conforme o esperado, ganhavam relativamente menos que os com carteira assinada e os conta-própria. A categoria que melhor remunerava em 2010 era a dos empregadores.

\section{Tabela 32 - Remuneração por categoria do emprego no trabalho principal, Censo 2010}

\begin{tabular}{lcccc}
\hline $\begin{array}{l}\text { V6527 - Rendimento } \\
\text { mensal total em julho } \\
\text { de } 2010, \text { em } R \$\end{array}$ & Média & Desvio-padrão & Mínimo & Máximo \\
\hline $\begin{array}{l}1 \text { - Empregados com } \\
\text { carteira de trabalho } \\
\text { assinada }\end{array}$ & $5.245,30$ & $8.552,82$ & 100 & 306.000 \\
\hline $\begin{array}{l}2-\text { Militares e } \\
\text { funcionários públicos } \\
\text { estatutários }\end{array}$ & $6.373,12$ & $11.954,76$ & 400 & 303.500 \\
\hline $\begin{array}{l}3 \text { - Empregados sem } \\
\text { carteira de trabalho }\end{array}$ & $3.679,69$ & $5.269,40$ & 0 & 102.305 \\
\begin{tabular}{l} 
assinada \\
\hline - Conta própria
\end{tabular} & $5.805,74$ & $9.809,35$ & 1 & 220.000 \\
\hline $\begin{array}{l}5 \text { - Empregadores } \\
12.161,89\end{array}$ & $48.197,38$ & 300 & 1.754 .000 \\
\hline $\begin{array}{l}\text { - Não- remunerados } \\
7 \text { - Trabalhadores na }\end{array}$ & $1.523,95$ & $4.225,86$ & 0 & 20.000 \\
\hline $\begin{array}{l}\text { produção para o } \\
\text { próprio consumo }\end{array}$ & $1.466,71$ & $2.736,15$ & 0 & 10.000 \\
\hline
\end{tabular}

Fonte: elaboração própria a partir do Censo 2010

Cabe notar que os cálculos de remuneração a partir da Rais indicam valores superiores, ainda que os dados se refiram a dois pontos no tempo (2003 e 2012). A remuneração média na Rais em 2012 era de $\mathrm{R} \$$ 10.106. Caso se faça uma imputação da remuneração média em 2010 a partir do crescimento médio anual entre 2003 e 2012, este valor seria de $\mathrm{R} \$ 8.150$ (em $\mathrm{R} \$$ de 2012). A média de remuneração das categorias 1 e 2 da Tabela 32 que, teoricamente, apareceriam na Rais, é de $\mathrm{R} \$ 6.093$ (em R $\$$ de 2012). Talvez as definições de remuneração/rendimentos nas duas bases guardem diferenças, ou mesmo o fato da Rais exigir o exercício de uma CBO de engenharia em 2003 tenha restrito um perfil mais qualificado de profissionais.

Os resultados a seguir trazem o recorte do trabalho por gênero. De uma maneira geral, a amostra tem 4.103 mulheres (19,2\% do total) e 17.234 homens (80,77\%). No entanto, dentre as 2.993 pessoas que não trabalham, 832 são mulheres, ou $27,8 \%$. Ou seja, as mulheres estão sobrerrepresentadas entre as pessoas que não trabalham, e o teste quiquadrado rejeita a menos de $1 \%$ de significância a hipótese nula de que não há sobrerrepresentação em nenhuma das células da tabela. 


\section{Tabela 33 - Situação de trabalho por gênero na semana de referência do Censo 2010}

\begin{tabular}{lccc}
\hline $\begin{array}{l}\text { V0641 - Na semana de } 25 \text { a } \\
\text { 31/07/10, durante pelo menos } 1\end{array}$ & \multicolumn{3}{c}{ V0601(Sexo) } \\
$\begin{array}{l}\text { hora, trabalhou ganhando em } \\
\text { dinheiro, produtos, mercadorias } \\
\text { ou benefícios? }\end{array}$ & \multicolumn{3}{c}{ Total } \\
\hline Frequência & Masculino & Feminino & Tot \\
Percentual & 15.073 & 3.271 & 18.344 \\
\hline Sim & 70,64 & 15,33 & 85,97 \\
\hline Não & 2.161 & 832 & 2993 \\
& 10,13 & 3,90 & 14,03 \\
\hline Total & 17.234 & 4.103 & 21.337 \\
& 80,77 & 19,23 & 100,00 \\
\hline
\end{tabular}

Fonte: elaboração própria a partir do Censo 2010

Com efeito, a amostra da Rais de jovens engenheiros também traz uma sobrerrepresentação feminina entre as pessoas que saem da Rais. Entre as explicações mais comuns para este viés de gênero está a sugestão que estas mulheres podem parar de trabalhar por razões familiares - em especial, para cuidar dos filhos.

Um possível sinal desse efeito seria um viés dos afastamentos remunerados (variável V0642) em direção às mulheres, por conta das licenças-maternidade. No entanto, as mulheres, que representam $27,8 \%$ das pessoas que não trabalham, são $25 \%$ das pessoas afastadas. De fato, o teste qui-quadrado para esta tabulação cruzada não rejeita a hipótese nula de que as células se distribuem de acordo com as probabilidades marginais.

Voltando a atenção para o viés feminino no não emprego - o que poderia, em conjunto com outros fatores, sinalizar uma saída voluntária do mercado de trabalho das mulheres por razões familiares - não se observa viés algum: as mulheres representam $27,4 \%$ dos indivíduos que não trabalham e não procuram emprego. Aliás, as mulheres estão levemente sobrerrepresentadas no grupo que não trabalha mas está procurando trabalho (os desempregados). Enquanto as mulheres representam 27,8\% da amostra de engenheiros, elas são 32,2\% dos desempregados. O teste qui-quadrado para esta tabulação cruzada rejeita a hipótese nula de ausência de viés a 4\% de significância, mas 583 indivíduos que não trabalham não responderam a esta pergunta no Censo.

Por um lado, isso sinaliza que não há um viés de gênero na saída do mercado de trabalho.

Por outro lado, um cruzamento da variável "número de filhos" (que só é respondida por mulheres no Censo 2010) com a situação ocupacional indica que as mulheres que não trabalham têm mais filhos que a média, e dentro deste subgrupo, as que não trabalham e não procuram emprego têm ainda mais filhos. 
Portanto, não é possível concluir definitivamente que o viés feminino de estar fora do mercado de trabalho esteja relacionado ao número de filhos. Como só é observado um ponto no tempo, pode ser o caso inclusive de o maior número de filhos das mulheres fora do mercado de trabalho ser uma consequência ao invés de causa da saída.

\section{Tabela 34 - Número de filhos/mulher por situação ocupacional, Censo 2010}

\begin{tabular}{|c|c|c|c|c|}
\hline V6633 & Total de filho & $\begin{array}{c}\text { nascidos vivos } \\
\text { de } 2010\end{array}$ & de teve a & 1 de julho \\
\hline & & Total das mulhe & & \\
\hline $\mathrm{N}$ & Média & Desvio-padrão & Mínimo & Máximo \\
\hline 4103 & 0,7701682 & 0,9775975 & 0 & 6 \\
\hline & Iheres que $t$ & balharam na se & Ina de re & ncia \\
\hline $\mathrm{N}$ & Média & Desvio-padrão & Mínimo & Máximo \\
\hline 3271 & 0,7156833 & 0,9384067 & 0 & 6 \\
\hline
\end{tabular}

Mulheres que não trabalharam na semana de referência

\begin{tabular}{ccccc}
\hline $\mathrm{N}$ & Média & Desvio-padrão & Mínimo & Máximo \\
\hline 832 & 0,9843750 & 1,0930240 & 0 & 5 \\
\hline \multicolumn{5}{c}{$\begin{array}{c}\text { Mulheres que não trabalharam na semana de referência e que } \\
\text { procuraram emprego }\end{array}$} \\
\hline $\mathrm{N}$ & Média & Desvio-padrão & Mínimo & Máximo \\
\hline 144 & 0,5694444 & 0,8662497 & 0 & 4 \\
\hline Mulheres que não trabalharam na semana de referência e que \\
não procuraram emprego
\end{tabular}

Fonte: elaboração própria a partir do Censo 2010.

\subsection{Comparação com o Censo 2000}

Em quem pesem algumas diferenças metodológicas, no questionário e nos códigos de algumas variáveis, o mesmo trabalho feito acima foi feita a partir do Censo 2000. Como a análise a partir da Rais também contemplou período anterior (1995-2002), a primeira adaptação diz respeito à idade: como engenheiro jovem era definido como o 
profissional com 25 anos ou menos que exerciam uma CBO de engenharia em 1995, o filtro etário para a análise a partir do Censo 2000 foi entre 27 e 30 anos. A codificação dos cursos superiores também é diferente, mas buscou-se manter a comparabilidade entre os dois Censos (a codificação está em "Cursos Superiores - Estrutura V4535.xls", na documentação de apoio aos Censos). Os códigos escolhidos foram:

11 - Agronomia - Graduação;

34 - Engenharia Civil - Graduação

35 - Engenharia Elétrica e Eletrônica - Graduação

36 - Engenharia Mecânica - Graduação

37 - Engenharia Química e Industrial - Graduação

38 - Outros cursos de Engenharia - Graduação

A exemplo do que ocorreu com a Rais 1995-2002, foram encontrados bem menos indivíduos com cursos superiores de engenharia no Censo 2000. No total, há 4.907 indivíduos com diploma em Engenharia em 2000 na faixa etária especificada, cifra menor mas bastante próxima ao encontrado na Rais (5.626). Novamente, cabe ressaltar que as bases de dados não são diretamente comparáveis, e o fato da amostra do Censo ser menor que a da Rais é surpreendente, visto que o critério para mapear os engenheiros do Censo é menos restritivo. Provavelmente, isso deve guardar relação com o fato do plano amostral do Censo 2000 não levar em conta o curso de graduação - ou seja, o plano amostral não pretende ser representativo para os engenheiros.

Destes 4.907 indivíduos, 4.394 ou 89,5\% trabalharam na semana de referência (23 a 29 de julho de 2000), e 513 ou 10,5\% não o fizeram. Esta taxa é menor do que a observada no Censo 2010.

No Censo 2010 foi visto que a ampla maioria dos que não trabalharam também não procuraram emprego na semana de referência. No Censo 2000 acontece o oposto: Daqueles que não trabalharam, 256 ou 50\% tomaram alguma providência efetiva para conseguir trabalho. Em relação ao total, os desempregados representam 5,2\%, cifra também compatível com o exposto em Menezes-filho et al. (2012). Ainda dentre os que não trabalharam, apenas 82 estavam afastados de forma remunerada, dos quais 58 eram homens. Sem embargo, as mesmas considerações a respeito das questões de gênero também se aplicam ao Censo 2000, e não serão objeto de discussão desta seção.

Como anteriormente, a Tabela 35 indica a categoria do emprego no trabalho principal. Como a codificação é diferente, são 10 possibilidades. Novamente, a mais numerosa é a dos empregados com carteira assinada, com 2.786 indivíduos ou 55,9\% das observações não-faltantes (são 90 observações faltantes). Os militares e funcionários públicos estatutários representam 6,5\% da amostra. Assim, 62,4\% do total das observações não-faltantes são passiveis de representação na Rais. 


\section{Tabela 35 - Posição na ocupação e categoria do emprego no trabalho principal, Censo 2000}

\begin{tabular}{|c|c|c|c|c|}
\hline V0447 & Frequência & $\%$ & $\begin{array}{l}\text { Frequência } \\
\text { acumulada }\end{array}$ & $\begin{array}{l}\text { Percentual } \\
\text { acumulado }\end{array}$ \\
\hline $\begin{array}{l}1 \text { - Trabalhador doméstico } \\
\text { com carteira de trabalho } \\
\text { assinada }\end{array}$ & 3 & 0,06 & 3 & 0,06 \\
\hline $\begin{array}{l}2 \text { - Trabalhador doméstico sem } \\
\text { carteira de trabalho assinada }\end{array}$ & 3 & 0,06 & 6 & 0,12 \\
\hline $\begin{array}{l}3 \text { - Empregados com carteira } \\
\text { de trabalho assinada }\end{array}$ & 2.786 & 55,87 & 2792 & 55,99 \\
\hline $\begin{array}{l}4 \text { - Empregados sem carteira } \\
\text { de trabalho assinada }\end{array}$ & 659 & 13,21 & 3451 & 69,20 \\
\hline 5 - Empregadores & 394 & 7,90 & 3845 & 77,10 \\
\hline 6 - Conta-própria & 631 & 12,65 & 4476 & 89,75 \\
\hline $\begin{array}{l}7 \text { - Aprendiz ou estagiário sem } \\
\text { remuneração }\end{array}$ & 11 & 0,22 & 4487 & 89,97 \\
\hline $\begin{array}{l}8 \text { - Não- remunerados em } \\
\text { ajuda a membro do domicílio }\end{array}$ & 12 & 0,24 & 4499 & 90,21 \\
\hline $\begin{array}{l}9 \text { - Trabalhadores na produção } \\
\text { para o próprio consumo }\end{array}$ & 3 & 0,06 & 4502 & 90,27 \\
\hline $\begin{array}{l}10-\text { Funcionários públicos ou } \\
\text { militares }^{1}\end{array}$ & 315 & 6,54 & 4817 & 100,00 \\
\hline Em branco & 90 & & & \\
\hline
\end{tabular}

Fonte: elaboração própria a partir do Censo 2000. 1 - A Codificação do Censo 2000 coloca a categoria dos militares e funcionários públicos como uma variável à parte.

Os trabalhadores domésticos, empregados sem carteira assinada, empregadores, conta-própria, aprendiz ou estagiário sem remuneração, não-remunerados e trabalhadores para o próprio consumo potencialmente não são representados pela Rais. Dentre estes, a categoria mais numerosa é a dos trabalhadores sem carteira assinada $(13,21 \%)$, seguida pelos conta-própria (12,65\%). No Censo 2010, havia poucos trabalhadores sem carteira assinada, provavelmente refletindo a tendência à formalização durante a década de 2000.

A Tabela 36 mostra a remuneração média, no mês de referência, das diferentes categorias de emprego, em R \$ de 2000. Novamente, a categoria que melhor remunera é a dos empregadores, mas os empregados com carteira assinada estão em segundo lugar em termos de remuneração. Em 2000, os conta-própria ganhavam menos que os empregados com carteira assinada. Os trabalhadores sem carteira assinada vêm em quarto lugar, seguidos pelos funcionários públicos ou militares. Novamente, os valores de remuneração estão bem abaixo do reportado na Rais no período 1995-2002. 


\section{Tabela 36 - Remuneração por categoria do emprego no trabalho principal, Censo 2000}

\begin{tabular}{|c|c|c|c|c|}
\hline $\begin{array}{l}\text { V4525 - Total de } \\
\text { rendimentos em todos } \\
\text { os trabalhos, em } R \$\end{array}$ & Média & Desvio-padrão & Mínimo & Máximo \\
\hline $\begin{array}{l}1 \text { - Trabalhador } \\
\text { doméstico com carteira } \\
\text { de trabalho assinada }\end{array}$ & 350,00 & 86,60 & 300,00 & 450,00 \\
\hline $\begin{array}{l}2 \text { - Trabalhador } \\
\text { doméstico sem carteira } \\
\text { de trabalho assinada }\end{array}$ & 134,00 & 29,44 & 100,00 & 151,00 \\
\hline $\begin{array}{l}3 \text { - Empregados com } \\
\text { carteira de trabalho } \\
\text { assinada }\end{array}$ & $2.124,28$ & $1.549,49$ & 100,00 & $30.000,00$ \\
\hline $\begin{array}{l}4 \text { - Empregados sem } \\
\text { carteira de trabalho } \\
\text { assinada }\end{array}$ & $1.581,94$ & $1.508,96$ & 0 & $22.000,00$ \\
\hline 5 - Empregadores & $3.501,68$ & $11.522,12$ & 151,00 & $200.000,00$ \\
\hline 6 - Conta-própria & $1.716,95$ & $1.691,23$ & 60,00 & $20.000,00$ \\
\hline $\begin{array}{l}7 \text { - Aprendiz ou } \\
\text { estagiário sem } \\
\text { remuneração }\end{array}$ & 0 & 0 & 0 & 0 \\
\hline $\begin{array}{l}8 \text { - Não- remunerados } \\
\text { em ajuda a membro do } \\
\text { domicílio }\end{array}$ & 0 & 0 & 0 & 0 \\
\hline $\begin{array}{l}9 \text { - Trabalhadores na } \\
\text { produção para o } \\
\text { próprio consumo }\end{array}$ & 0 & 0 & 0 & 0 \\
\hline $\begin{array}{l}10-\text { Funcionários } \\
\text { públicos ou militares }\end{array}$ & $1.263,70$ & $1.179,52$ & 80,00 & $7.000,00$ \\
\hline
\end{tabular}

Fonte: elaboração própria a partir do Censo 2000.

\subsection{Conclusão - o que acontece com os profissionais que saem da Rais?}

O objetivo do trabalho com o Censo foi ter uma ideia do que acontece com os trabalhadores que saem da Rais. A partir da análise do Censo de 2010, sabe-se que 14\% dos 21.337 profissionais formados em engenharia não trabalharam na semana de referência do Censo, e 25\% trabalharam como conta-própria ou empregadores. Finalmente, 5,6\% dos trabalhadores estavam trabalhando sem carteira assinada. Estes profissionais não seriam retratados pela Rais enquanto esta condição durasse.

Porém, voltando a atenção para os 2.993 profissionais que não trabalharam na semana de referência em 2010, 500 destes trabalhadores estavam temporariamente afastados do trabalho remunerado. Ou seja, muito provavelmente eles não saíram da Rais, uma vez que mantiveram seus vínculos profissionais. 
Dos 2493 trabalhadores restantes, 447 trabalhadores não estavam trabalhando e estavam procurando emprego, o que configura estado de desemprego. Estes 447 indivíduos representam $2 \%$ do total de engenheiros segundo o Censo.

Assim, 2.046 engenheiros formados não trabalhavam na semana de referência e que não estavam procurando emprego. Estes indivíduos representam 9,5\% do total. Cabe notar que não é possível afirmar se estes indivíduos já trabalharam algum dia, ou mesmo se estavam trabalhando em 2003. Se estes indivíduos nunca tiverem trabalhado ou não estivessem trabalhando em 2003, eles não seriam capturados pela amostra com a Rais utilizada na tese.

Aliás, pouco se pode afirmar, a partir do Censo, por que estes 2.046 indivíduos não trabalharam na semana de referência. Ou mesmo se eles voltaram ao mercado de trabalho após a semana de referência do Censo.

Portanto, dos 8.976 engenheiros potencialmente fora da Rais em um determinado ano - que representavam $42 \%$ do total de engenheiros entre 29 e 32 anos em 2010:

7) 447 ou $5 \%$ estavam desempregados;

8) 2.046 ou $23 \%$ estavam sem trabalhar e também não procuraram emprego;

9) 3.559 ou $40 \%$ eram conta-própria;

10) 1.778 ou $20 \%$ eram empregadores;

11) 1.072 ou $12 \%$ eram empregados sem carteira assinada.

12) 74 ou menos de $1 \%$ trabalhava para o próprio consumo ou sem remuneração.

Deste modo, $72 \%$ dos trabalhadores potencialmente fora da Rais continuavam no mercado de trabalho como conta-própria, empregadores ou sem carteira assinada.

Para comparação, utilizando critérios semelhantes em 2000, 2.147 ou 43,5\% dos engenheiros estavam potencialmente fora da Rais. Destes:

7) 256 ou $12 \%$ estavam desempregados;

8) 175 ou $8 \%$ estavam sem trabalhar e também não procuraram emprego;

9) 631 ou $29 \%$ eram conta-própria;

10) 394 ou $18 \%$ eram empregadores;

11) 659 ou $31 \%$ eram empregados sem carteira assinada.

12) 32 ou $2 \%$ trabalhava para o próprio consumo, sem remuneração ou como empregado doméstico (com carteira ou sem carteira).

Portanto, $78 \%$ trabalhadores potencialmente fora da Rais continuavam no mercado de trabalho como conta-própria, empregadores ou sem carteira assinada. 
10. ANEXO 2: OMA COM DISTÂNCIA DE HAMMING E COM OS FORA DA RAIS COMO MISSING Gráfico 37 - Dendograma do Hamming Dinâmico (esq.) e do OMA com os fora da Rais como missing (dir.)

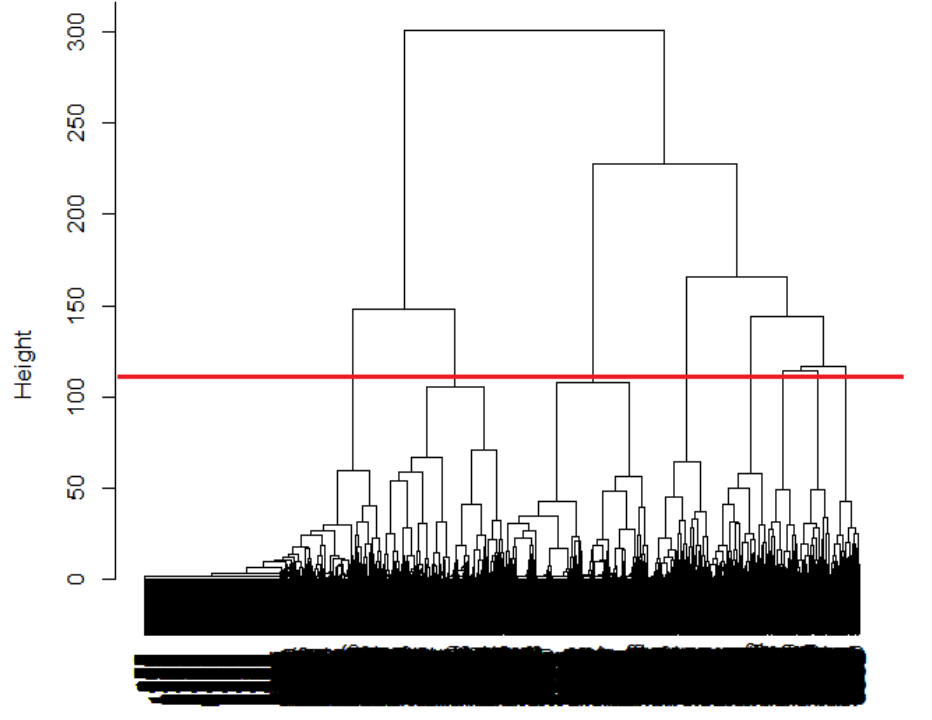

dist.om2

Agglomerative Coefficient $=1$

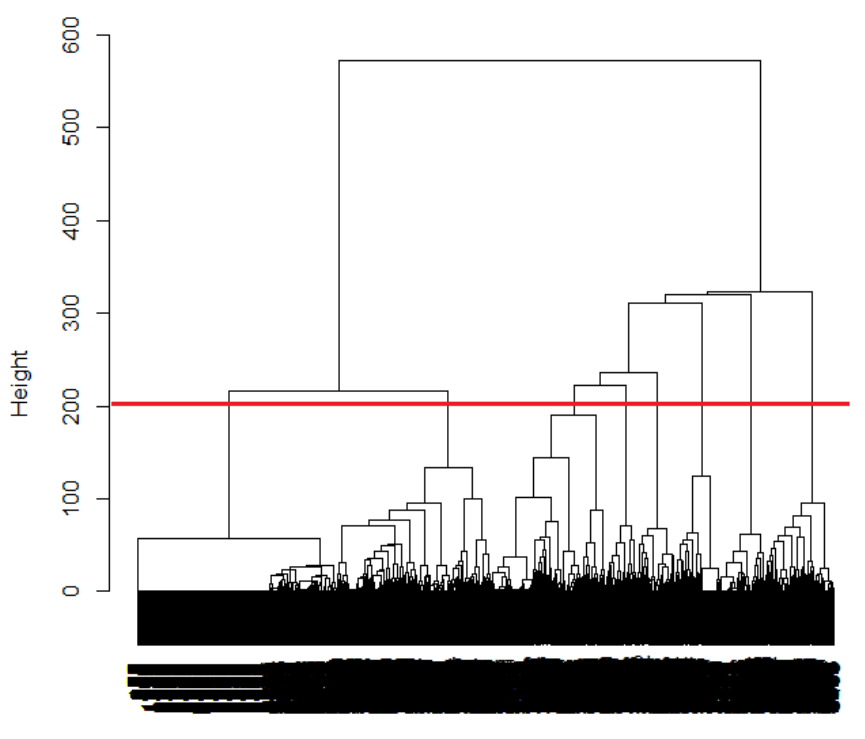

dist.om3
Agglomerative Coefficient $=1$

Fonte: Elaboração própria a partir da Rais. 
Gráfico 38 - Tempograma do Hamming Dinâmico, por tipo de trajetória, 2004-2012
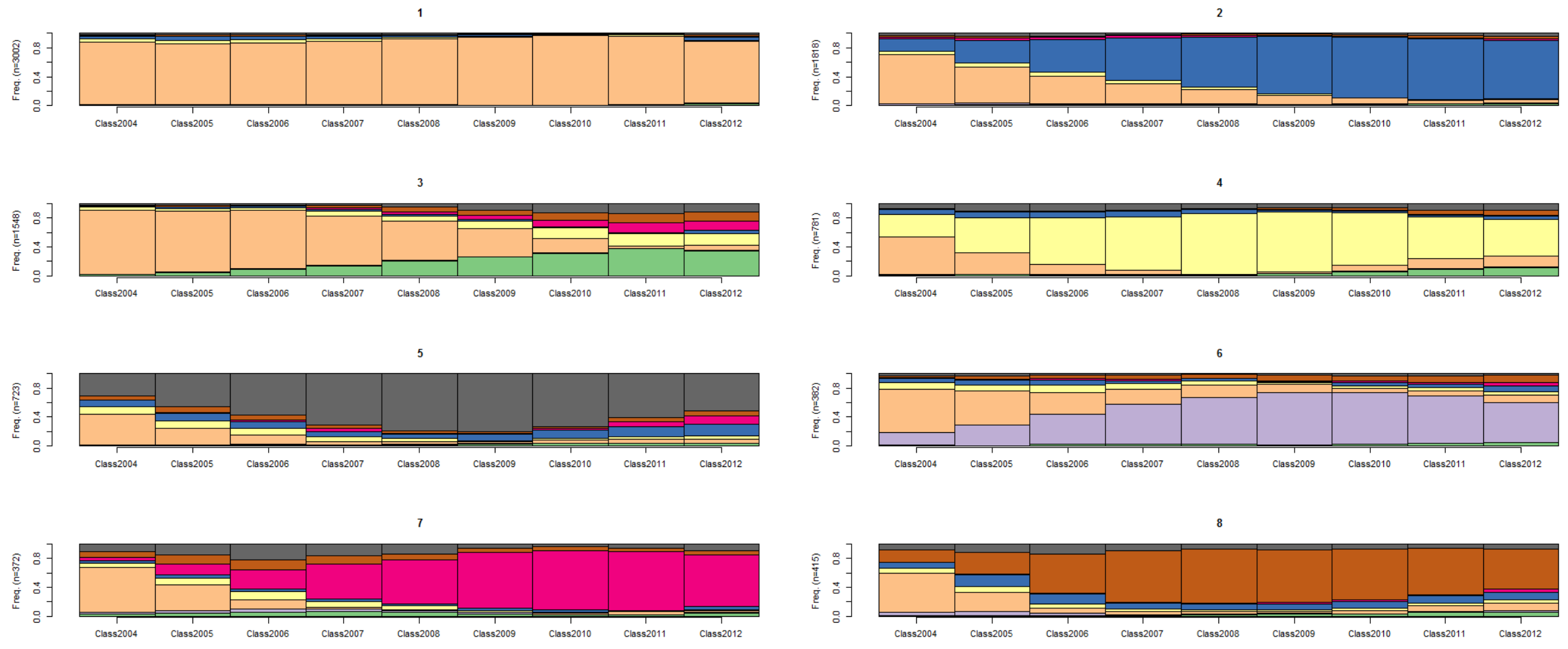

\begin{tabular}{|c|c|c|c|c|c|}
\hline$\square$ & Corr. Enga: Gestäo & $\square$ & Corr. Eng": Técnico & $\square$ & Não-Enga": Profissional \\
\hline$\square$ & Corr. Enga": Profissional & ㅁ & Fora da Rais & $\square$ & Nầ-Enga?: Técnico \\
\hline
\end{tabular}

Fonte: Elaboração própria a partir da Rais. 
Gráfico 39 - Sequências mais comuns do Hamming Dinâmico, por tipo de trajetória, 2004-2012
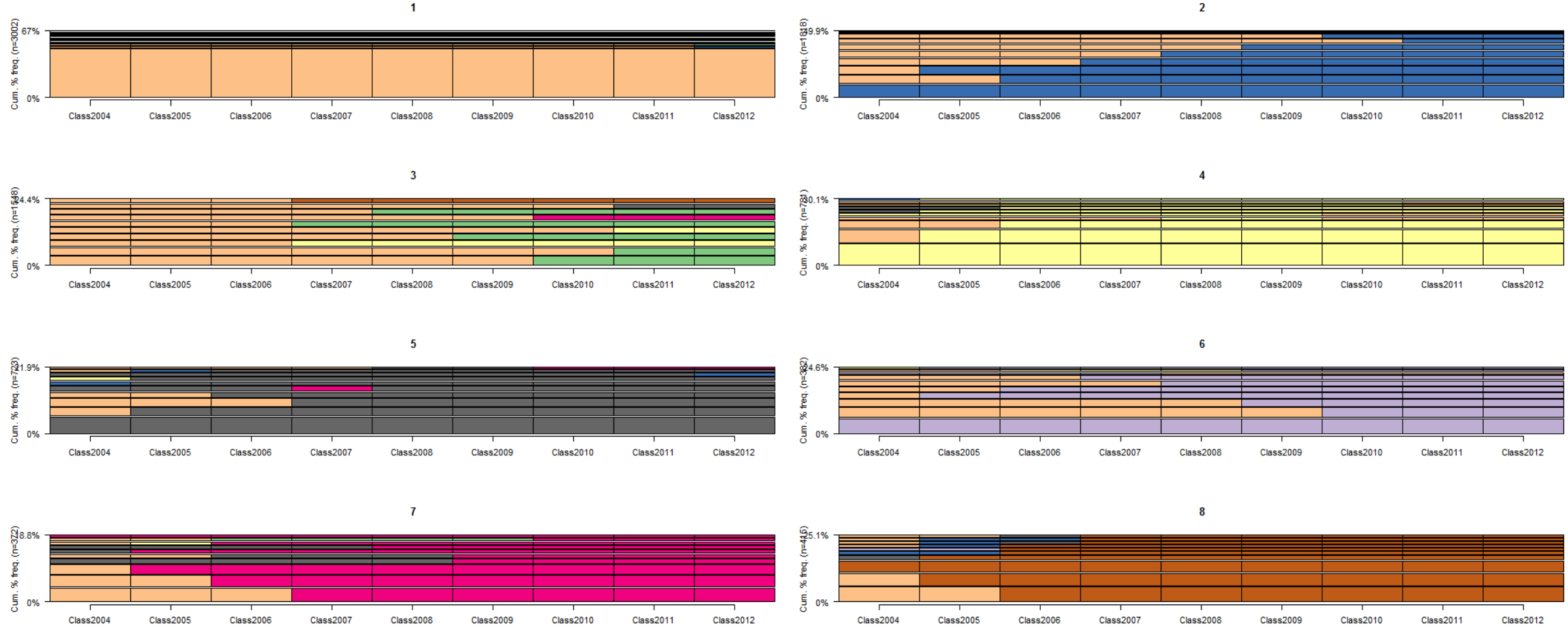

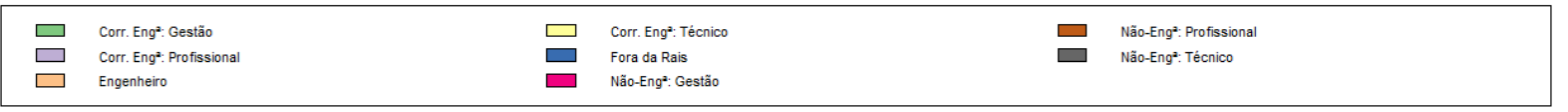

Fonte: Elaboração própria a partir da Rais. 
Gráfico 40 - Tempograma do OMA com fora da Rais como missing, por tipo de trajetória, 2004-2012
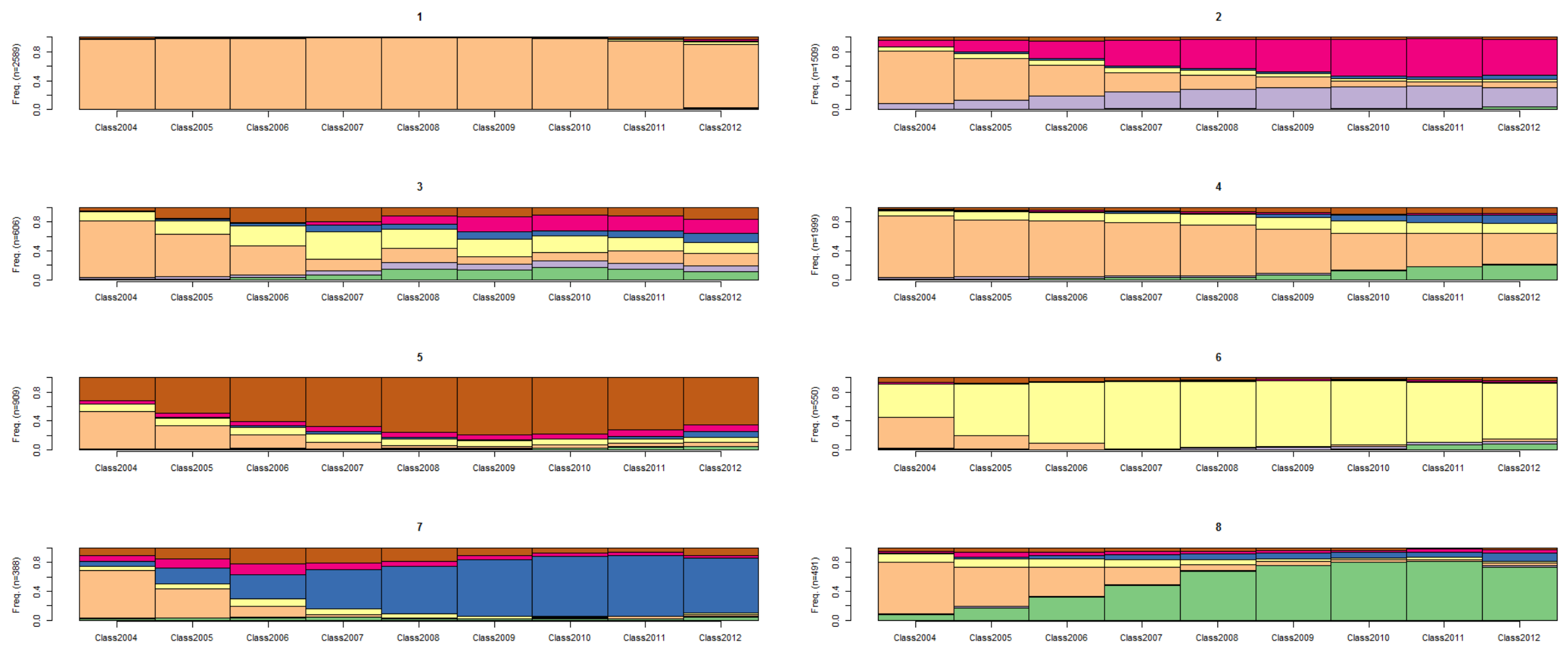

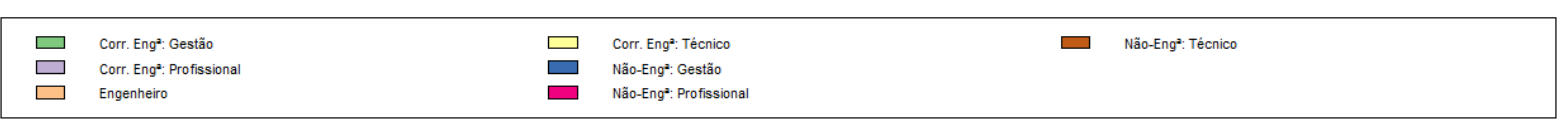

Fonte: Elaboração própria a partir da Rais. 
Gráfico 41 - Sequências mais comuns do OMA com o fora da Rais como missing, por tipo de trajetória, 2004-2012
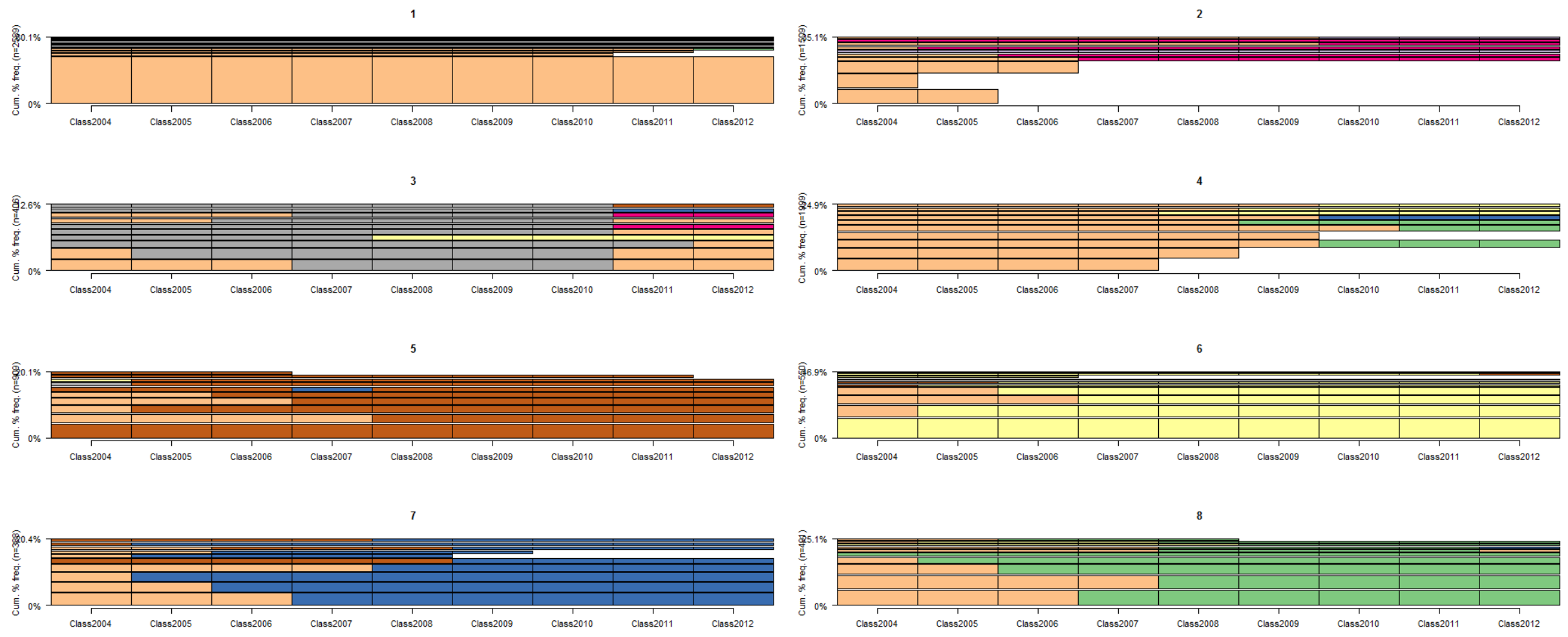

\begin{tabular}{|c|c|c|c|c|c|}
\hline $\begin{array}{l}\square \\
\square\end{array}$ & $\begin{array}{l}\text { Corr. Enga: Gestäa } \\
\text { Corr. Enga: Profissional } \\
\text { Engenheiro }\end{array}$ & 口ㅁ & $\begin{array}{l}\text { Corr. Eng": Técnico } \\
\text { Näo-Eng": Gestäo } \\
\text { Nä0-Eng": Profissional }\end{array}$ & 口 & $\begin{array}{l}\text { Nâ--Enga: Técnico } \\
\text { missing }\end{array}$ \\
\hline
\end{tabular}

Fonte: Elaboração própria a partir da Rais. 


\section{ANEXo 3: ESTADOS BIDIMENSIONAIS - OCUPAÇÃO E MACROSSETOR}

Gráfico 42 - Gráfico Silhouette por cluster: Classificação bidimensional (ocupação e macrossetor), 2004-2012

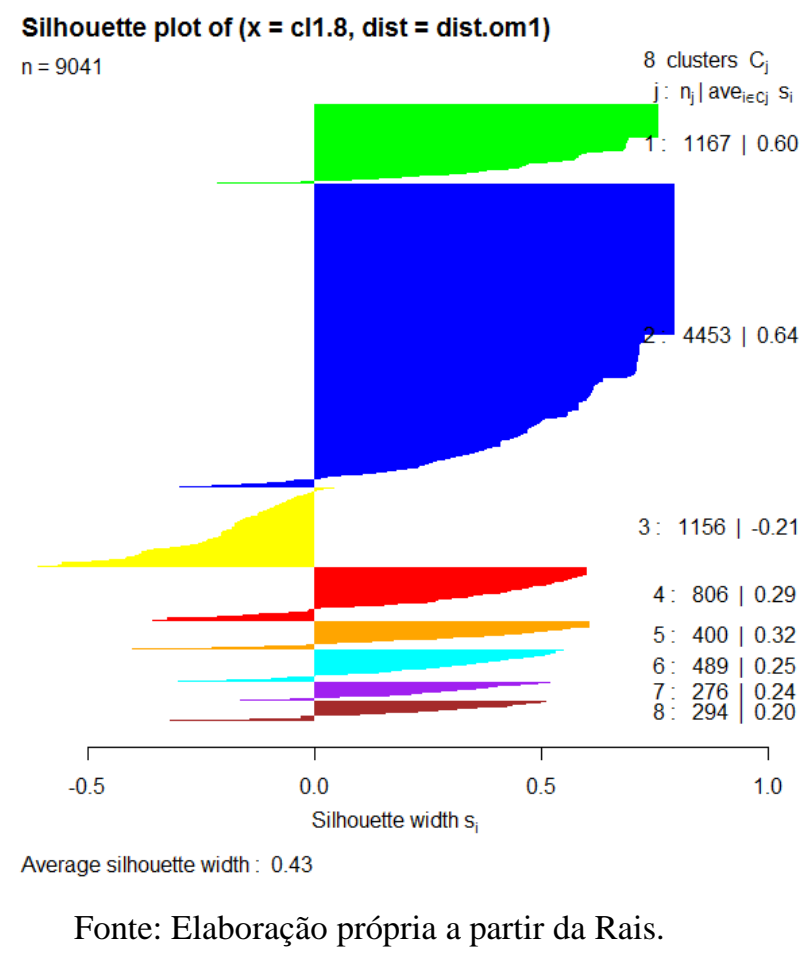

Gráfico 43 - Dendograma para análise de cluster - classificação bidimensional, 2004-2012

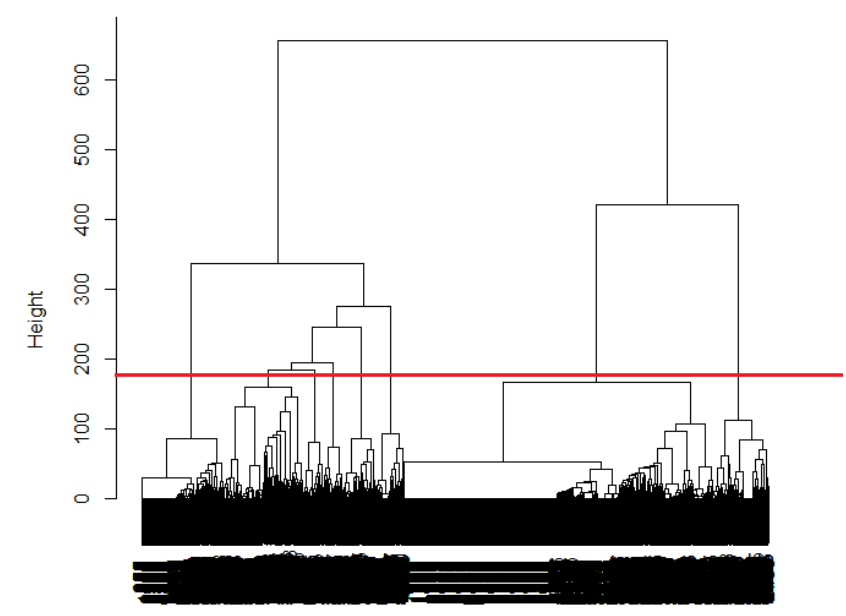

dist.om1
Agglomerative Coefficient $=1$

Fonte: Elaboração própria a partir da Rais. 


\section{Gráfico 44 - Tipos de trajetórias ocupacionais - classificação bidimensional, 2004-2012}

Tipo 1 - Engenheiros típicos na indústria (843 de 1167) Tipo 2 - Fora da Rais (1413 de 4453)
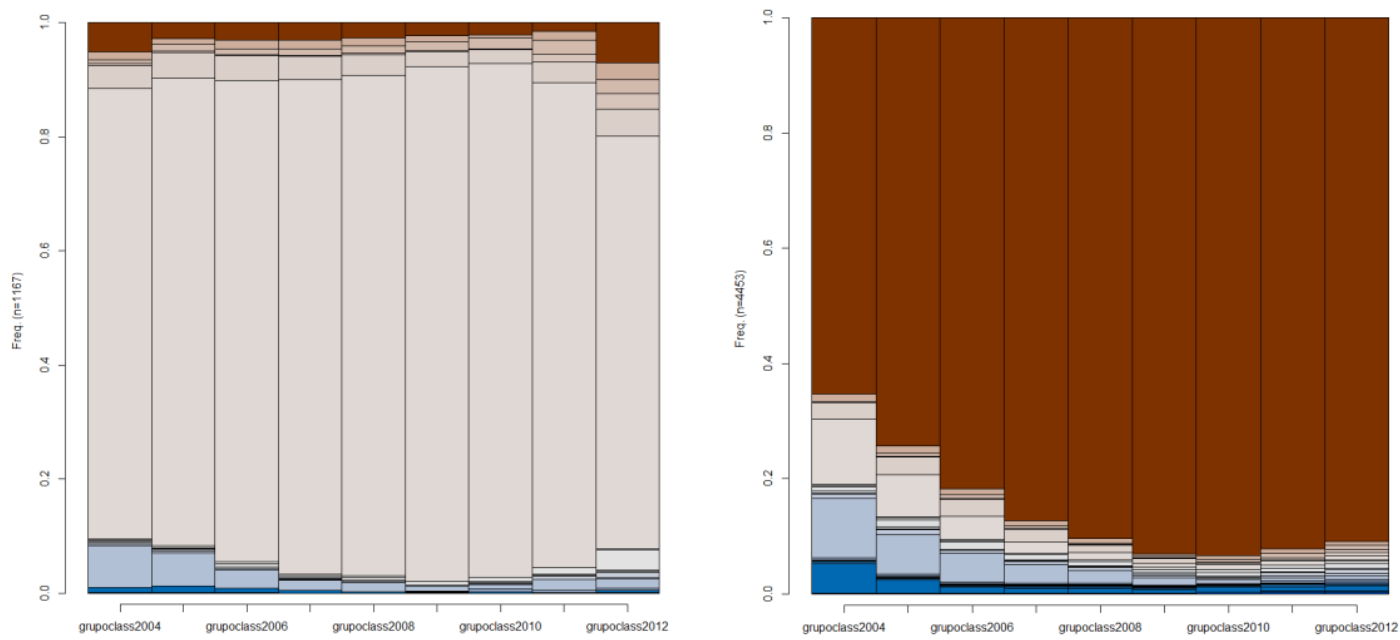

Tipo 3 - Padrão misto

Tipo 4 - Engo típico na construção (347 de 806)
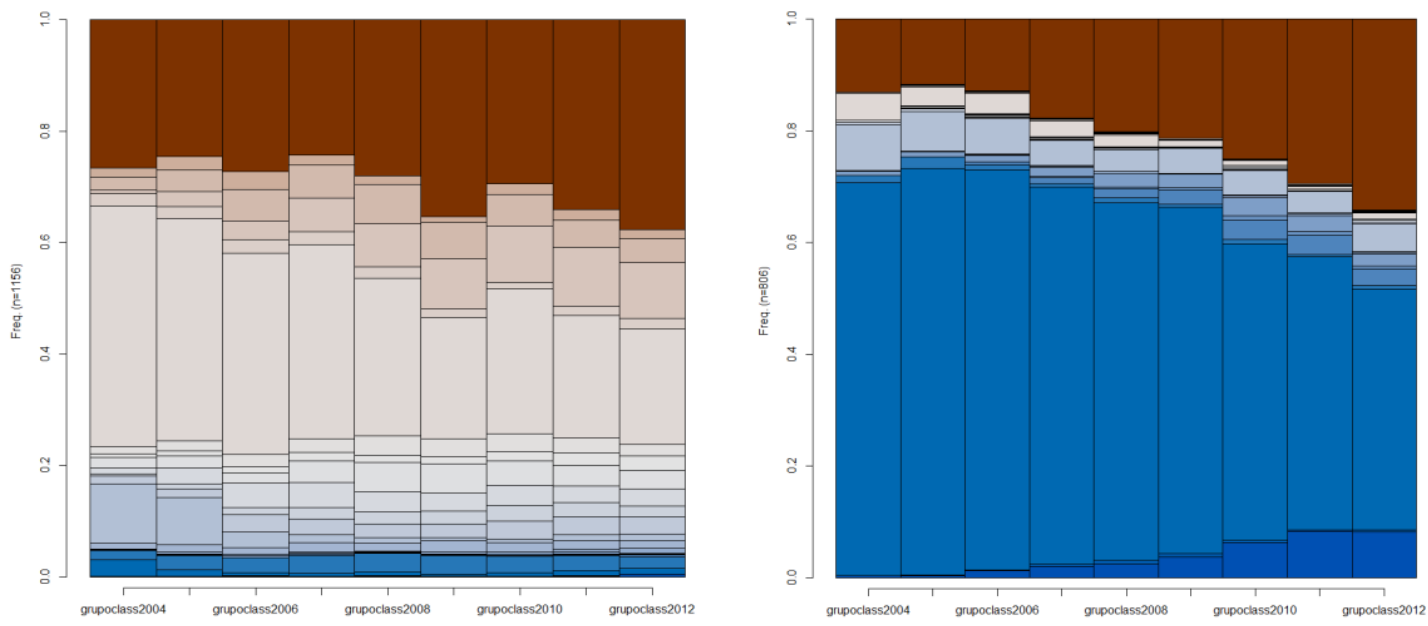

Tipo 5 - Engํo típico em serv. a emp. (220 de 400)

Tipo 6 - Téc. em eng ${ }^{\mathrm{a}}$ na indústria (261 de 489)
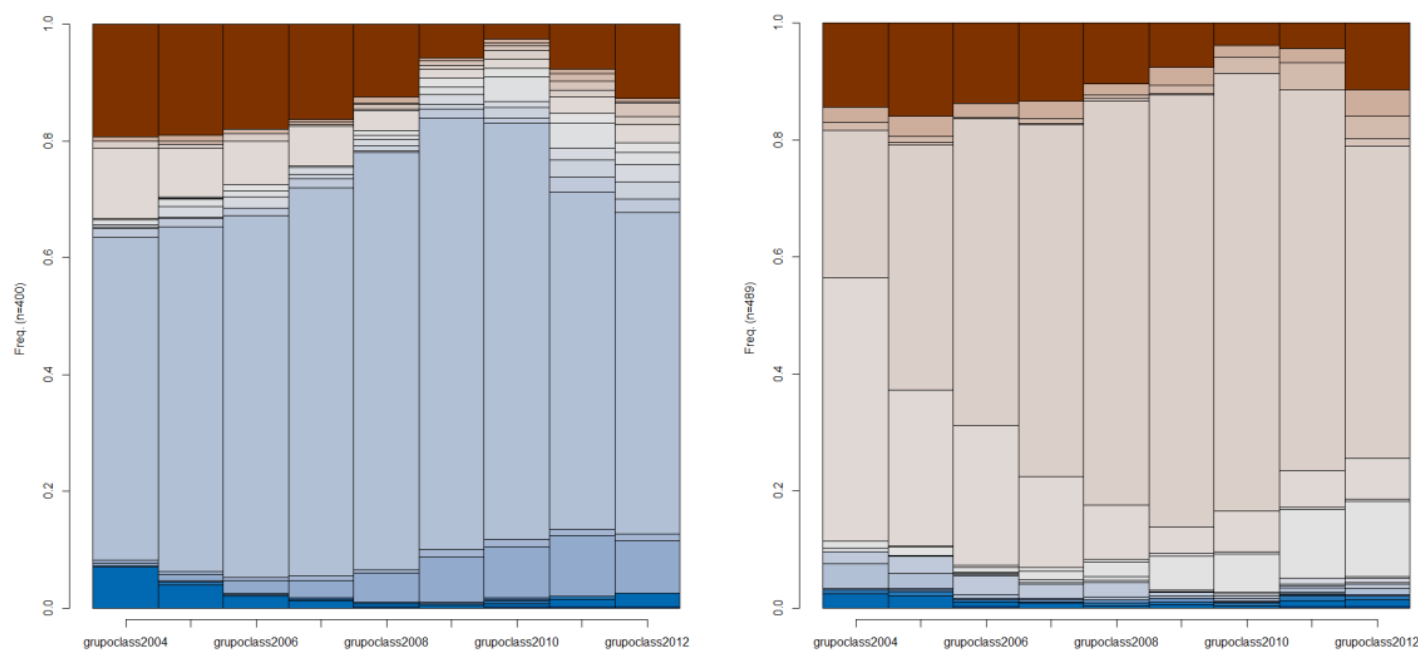

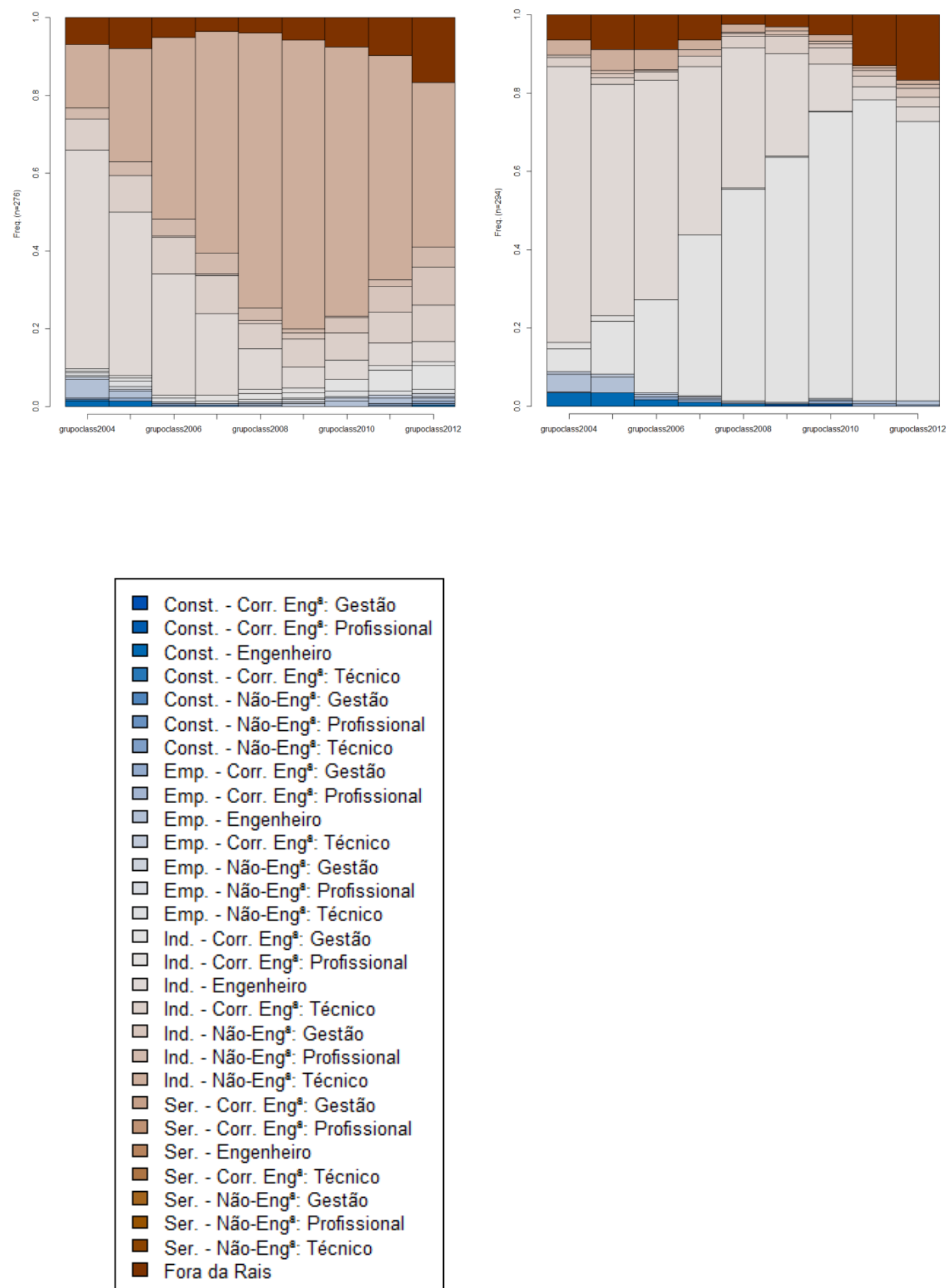

Fonte: Elaboração própria a partir da Rais. Os tipos foram nomeados a partir do estado mais comum em 2012. Como são muitos estados possíveis, de fato a distinção entre as cores é difícil. 
Tabela 37 - Remuneração, seu crescimento e tempo de emprego de acordo com classificação bidimensional, 2003 e 2012

\begin{tabular}{|c|c|c|c|c|}
\hline Rótulos de Linha & $\begin{array}{c}\text { Remuneração } \\
\text { média em } 2003 \\
\text { (em } \mathrm{R} \$ \text { de } \\
2012 \text { ) }\end{array}$ & $\begin{array}{c}\text { Remuneração } \\
\text { média em } 2003 \\
\text { (em } \mathrm{R} \$ \text { de } \\
2012)\end{array}$ & $\begin{array}{l}\text { Crescimento } \\
\text { da } \\
\text { remuneração }\end{array}$ & $\begin{array}{l}\text { Tempo de } \\
\text { emprego em } \\
2012 \text { (em } \\
\text { meses) }\end{array}$ \\
\hline $\begin{array}{l}\text { Tipo } 1 \text { - Engenheiros típicos } \\
\text { na indústria }(\mathrm{N}=1167)\end{array}$ & $4.639,75$ & $10.495,49$ & $5.858,42$ & 72,45 \\
\hline $\begin{array}{l}\text { Tipo } 2 \text { - Fora da Rais } \\
(\mathrm{N}=4453)\end{array}$ & $3.619,86$ & $9.379,64$ & $5.750,44$ & 53,04 \\
\hline $\begin{array}{l}\text { Tipo } 3 \text { - Padrão misto } \\
(\mathrm{N}=1156)\end{array}$ & $4.201,27$ & $11.391,64$ & $7.198,83$ & 51,25 \\
\hline $\begin{array}{l}\text { Tipo } 4 \text { - Engenheiros típicos } \\
\text { na construção }(\mathrm{N}=806)\end{array}$ & $3.438,01$ & $10.708,18$ & $7.290,91$ & 45,33 \\
\hline $\begin{array}{l}\text { Tipo } 5 \text { - Engenheiros } \\
\text { típicos em prestadoras de } \\
\text { serv. a emp. }(\mathrm{N}=400)\end{array}$ & $3.960,38$ & $10.771,81$ & $6.804,15$ & 58,16 \\
\hline $\begin{array}{l}\text { Tipo } 6 \text { - Téc. em eng }{ }^{\text {a }} \text { na } \\
\text { indústria }(\mathrm{N}=489)\end{array}$ & $3.320,76$ & $8.373,55$ & $5.043,96$ & 57,47 \\
\hline $\begin{array}{l}\text { Tipo } 7 \text { - Téc. em não-eng } \\
\text { na indústria }(\mathrm{N}=276)\end{array}$ & $3.848,37$ & $9.764,73$ & $5.882,69$ & 59,09 \\
\hline $\begin{array}{l}\text { Tipo } 8 \text { - Gestor eng }{ }^{\text {a }} \text { na } \\
\text { indústria }(\mathrm{N}=294)\end{array}$ & $4.337,55$ & $13.011,03$ & $8.668,71$ & 66,28 \\
\hline Total Geral & $3.838,83$ & $10.106,07$ & $6.228,65$ & 56,43 \\
\hline F- Anova & $39,02^{* * *}$ & $29,69^{* * *}$ & $23,22^{\star \star *}$ & $35,40^{\star \star *}$ \\
\hline Eta-quadrado $\left(\theta^{2}\right)$ & 0,0293 & 0,0284 & 0,0223 & 0,0335 \\
\hline
\end{tabular}

Fonte: Elaboração própria a partir da Rais. 


\section{AneXo 4: ClassificaÇões alternativas da GERAÇÃo 90 EM 2003-2012}

Gráfico 45 - Sequências mais frequentes, 1996-2012

\section{Sequências mais frequentes}

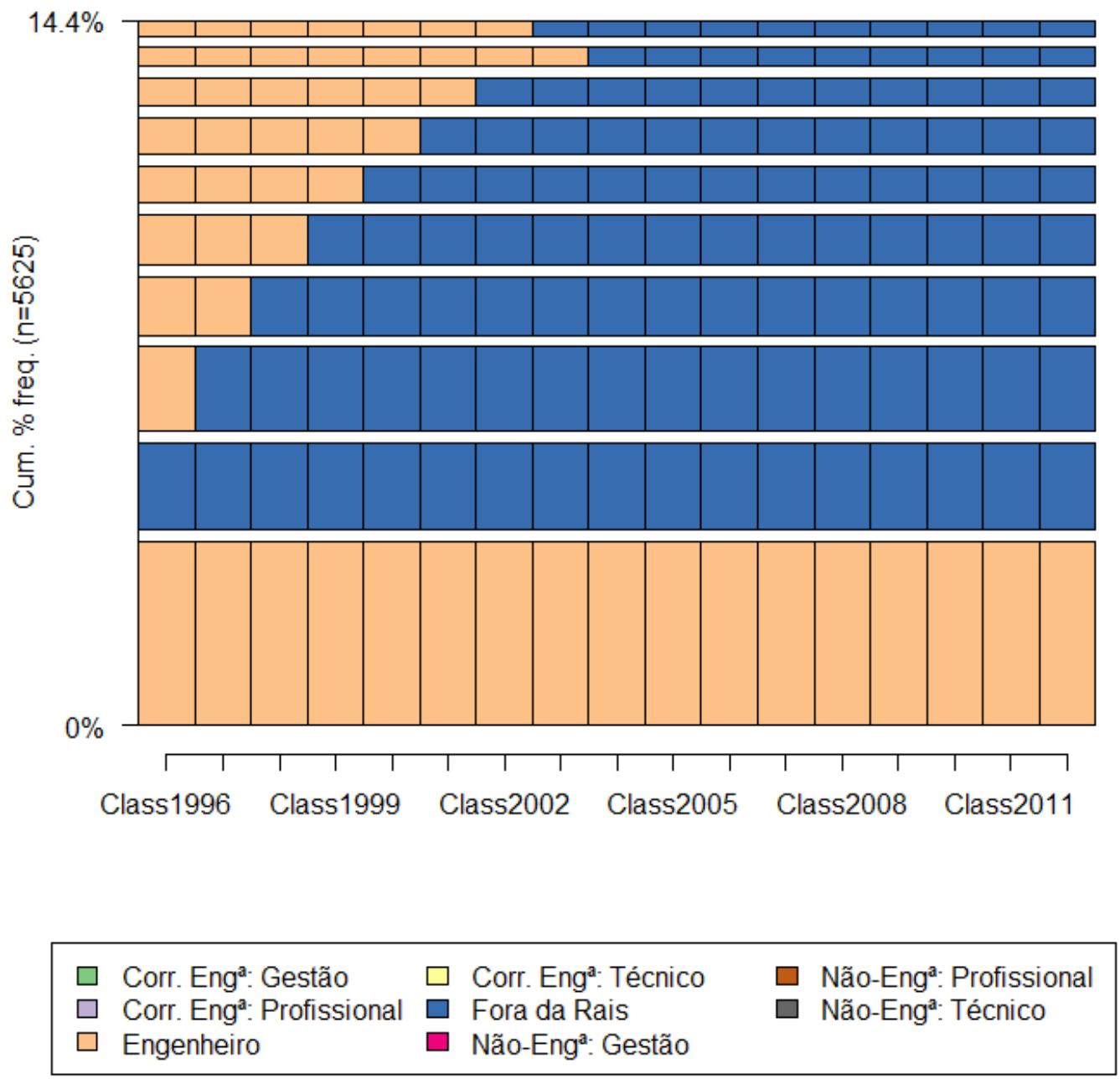

Fonte: Elaboração própria a partir da Rais. 


\section{Gráfico 46 - Distribuição dos estados, 1996-2012}

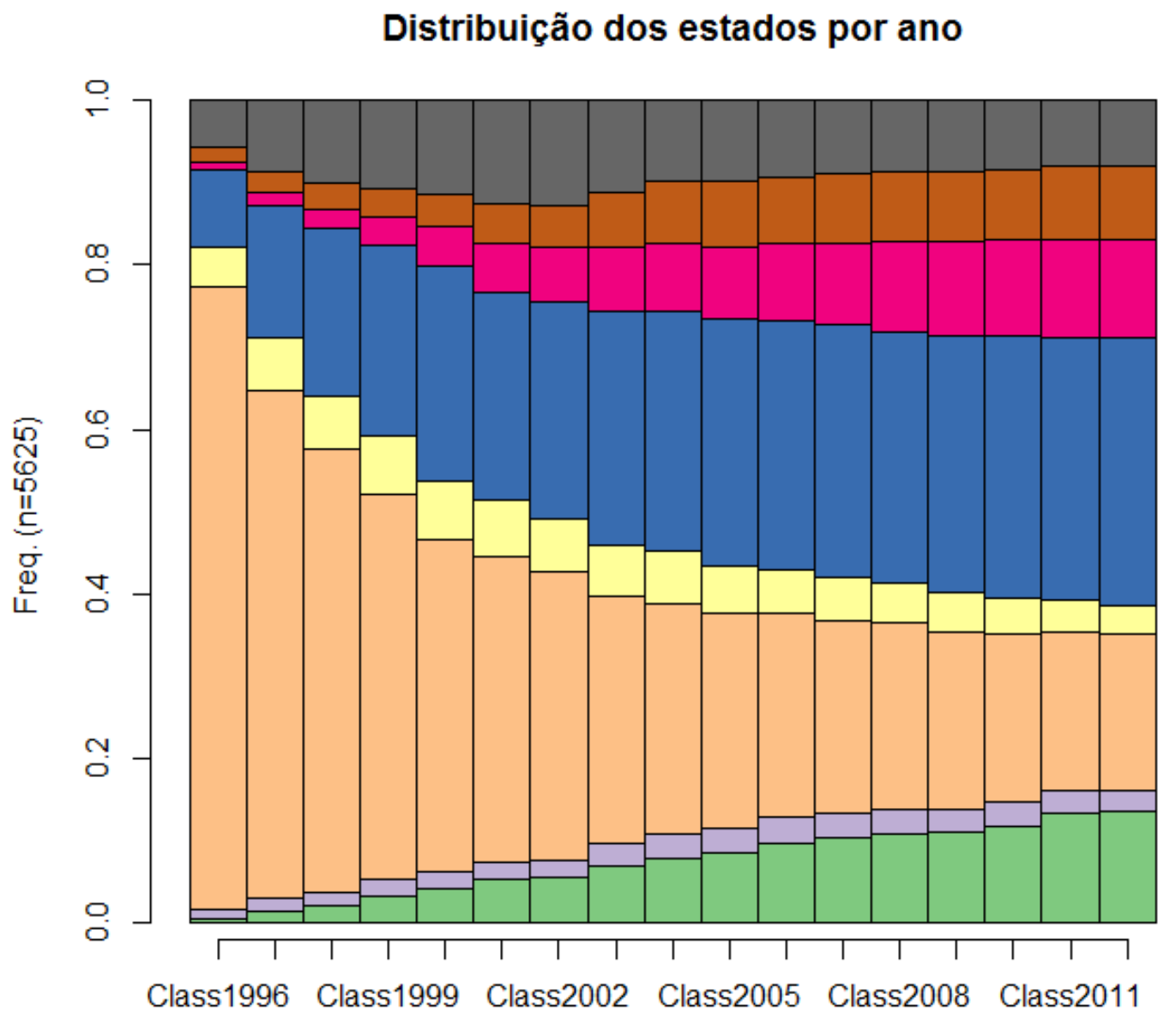

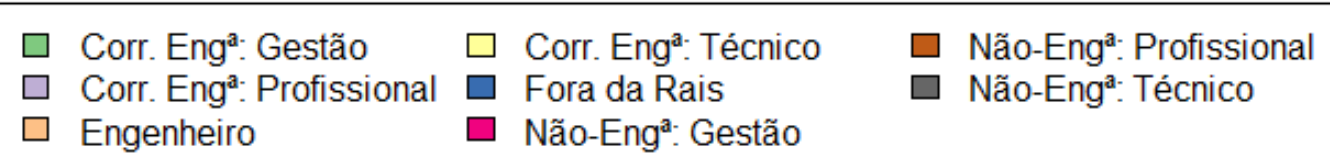

Fonte: Elaboração própria a partir da Rais. 
Gráfico 47 - Gráfico Silhouette por cluster: OMA, 1996-2012

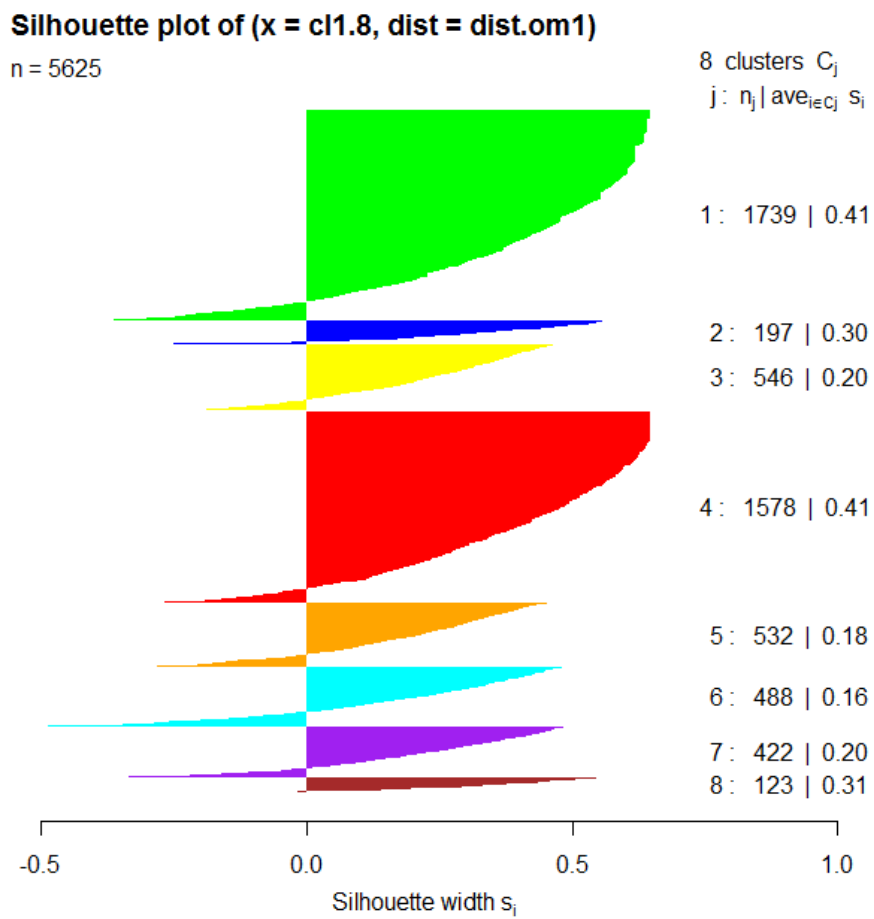

Average silhouette width : 0.33

Fonte: Elaboração própria a partir da Rais.

Gráfico 48 - Dendograma para análise de cluster, 1996-2012

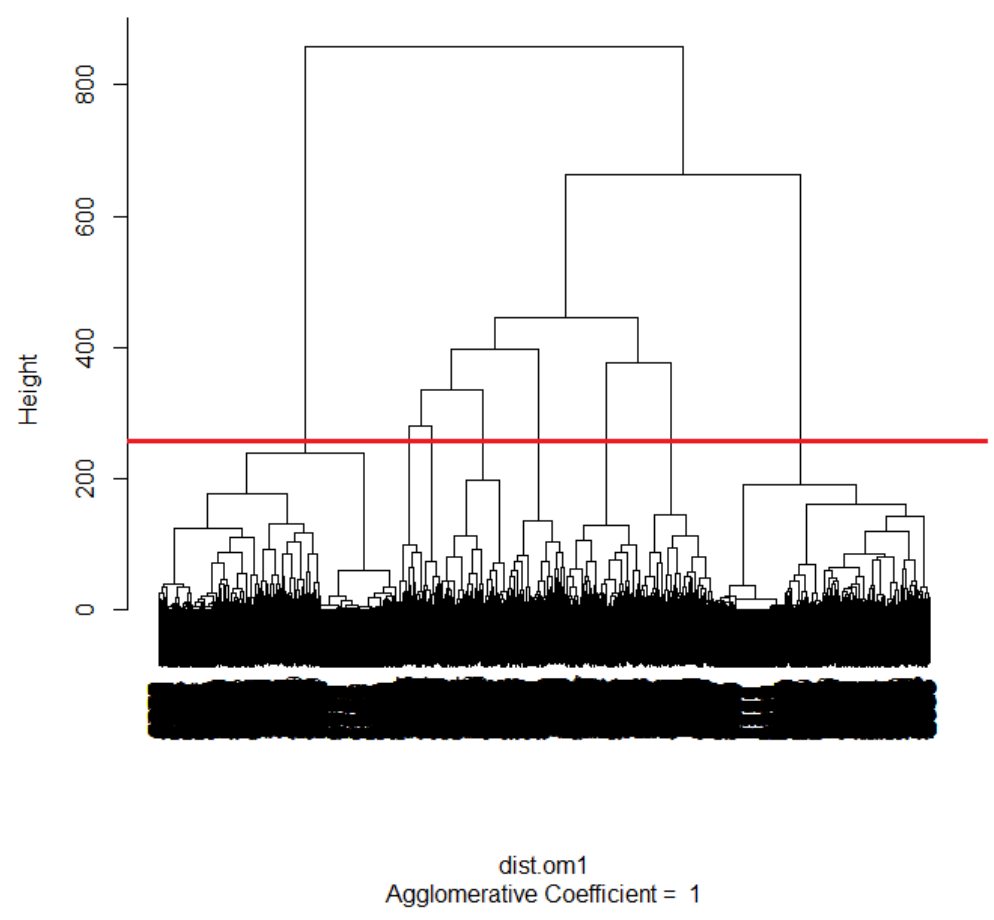

Fonte: Elaboração própria a partir da Rais. 
Gráfico 49 - Tempograma do OMA, por tipo de trajetória, 1996-2012
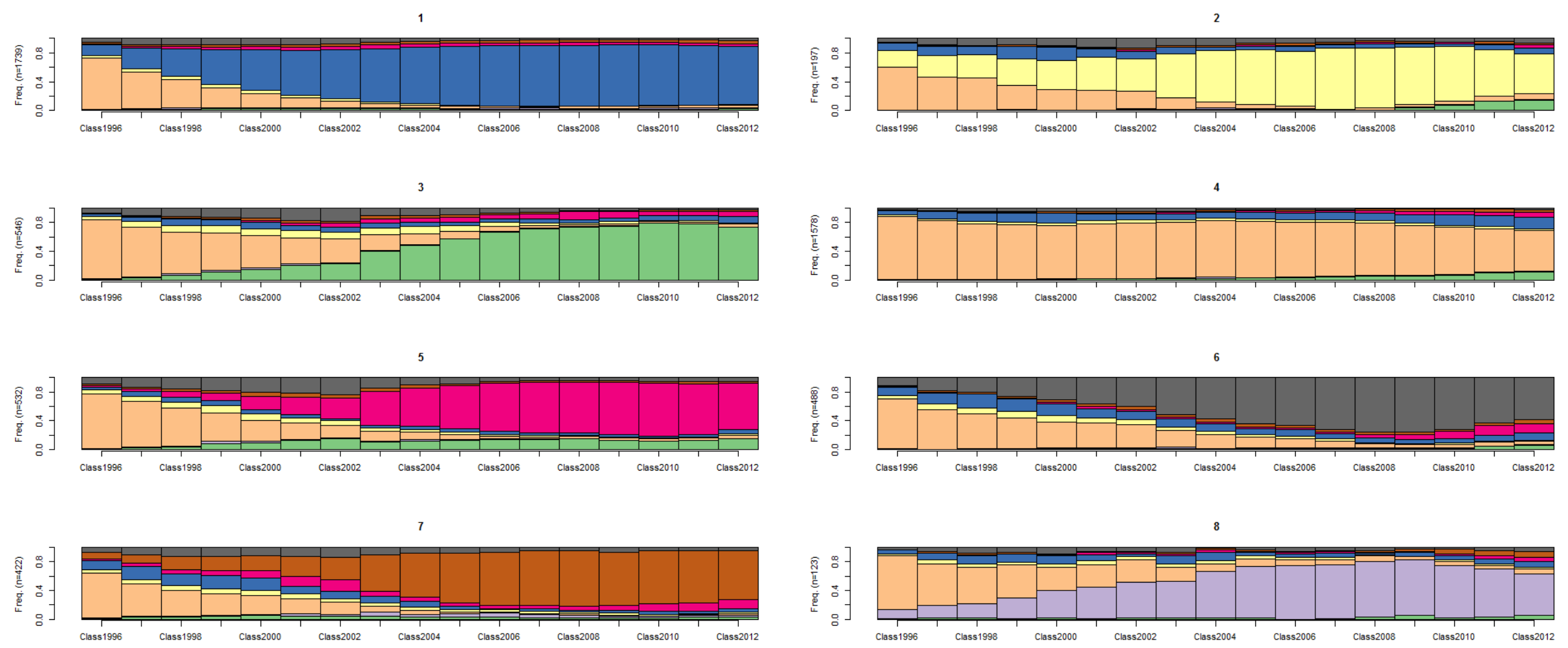

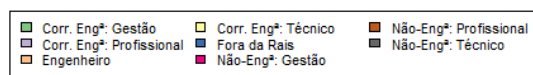

Fonte: Elaboração própria a partir da Rais. 
Gráfico 50 - Sequências mais comuns do OMA com o fora da Rais como missing, por tipo de trajetória, 2004-2012
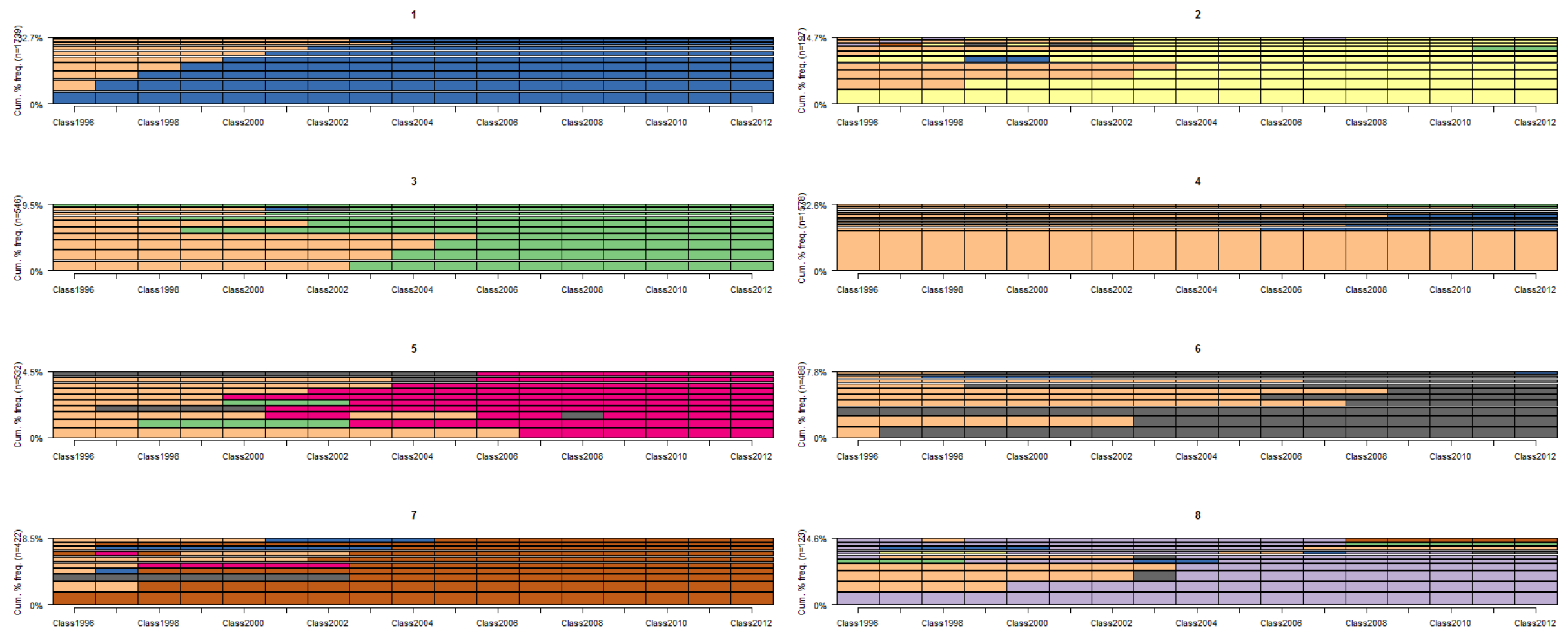

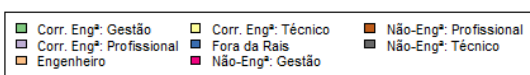

Fonte: Elaboração própria a partir da Rais. 
Tabela 38 - Remuneração média por diferentes tipos de trajetória: geração 90 em 90, geração 2000 em 2000 e geração 90 em 2000 segundo duas classificações (em $R$ \$ de 2012)

\begin{tabular}{|c|c|c|c|c|c|c|c|c|c|c|c|}
\hline & \multicolumn{2}{|c|}{ geração 90 em 90} & \multicolumn{2}{|c|}{$\begin{array}{c}\text { geração } 2000 \text { em } \\
2000\end{array}$} & \multicolumn{3}{|c|}{$\begin{array}{l}\text { geração } 90 \text { até } 2012 \\
\text { (sequência longa) }\end{array}$} & \multicolumn{2}{|c|}{$\begin{array}{l}\text { geração } 90 \text { nos } \\
\text { anos } 2000- \\
\text { classificação } \\
\text { original } \\
\end{array}$} & \multicolumn{2}{|c|}{$\begin{array}{l}\text { geração } 90 \text { nos } \\
\text { anos } 2000- \\
\text { realinhamento das } \\
\text { sequências }\end{array}$} \\
\hline & 1995 & 2002 & 2003 & 2012 & 1995 & 2003 & 2012 & 2003 & 2012 & 2003 & 2012 \\
\hline $\begin{array}{l}\text { Gestores } \\
\text { em } \\
\text { engenharia }\end{array}$ & $4.754,05$ & $12.785,39$ & $4.247,81$ & $13.680,30$ & $4.471,12$ & $11.683,04$ & $20.049,44$ & $12.543,01$ & $20.743,58$ & $12.137,67$ & $21.292,75$ \\
\hline $\begin{array}{l}\text { Profissionais } \\
\text { em } \\
\text { engenharia }\end{array}$ & - & - & $4.083,38$ & $9.280,49$ & $3.672,01$ & $8.016,81$ & $11.339,50$ & - & - & $7.216,19$ & $9.730,11$ \\
\hline $\begin{array}{l}\text { Engenheiros } \\
\text { típicos }\end{array}$ & $3.768,73$ & $8.175,57$ & $4.178,13$ & $10.832,14$ & $3.552,22$ & $7.316,99$ & $12.479,88$ & $8.088,00$ & $13.829,72$ & $7.505,45$ & $12.342,73$ \\
\hline $\begin{array}{l}\text { Fora da } \\
\text { Rais }\end{array}$ & $3.498,58$ & $6.930,23$ & $3.516,12$ & $7.616,14$ & 3.649 & $8.562,5$ & $10.887,19$ & $8.524,62$ & $13.709,31$ & $5.981,95$ & $9.077,83$ \\
\hline $\begin{array}{l}\text { Técnicos em } \\
\text { engenharia }\end{array}$ & $3.664,17$ & $8.385,67$ & $3.009,23$ & $7.446,14$ & $3.313,73$ & $6.124,46$ & $9.528,68$ & $6.705,99$ & $11.458,61$ & $8.241,71$ & $11.590,54$ \\
\hline $\begin{array}{l}\text { Gestores } \\
\text { em outras } \\
\text { áreas }\end{array}$ & $4.055,41$ & $13.338,89$ & $4.219,15$ & $13.442,94$ & $4.301,48$ & $12.047,05$ & $20.778,33$ & $12.376,42$ & $19.771,77$ & $11.446,46$ & $19.487,02$ \\
\hline $\begin{array}{l}\text { Profissionais } \\
\text { em outras } \\
\text { áreas }\end{array}$ & $3.747,60$ & $8.390,44$ & $4.014,59$ & $10.210,64$ & $3.748,71$ & $8.288,22$ & $13.861,22$ & $9.018,25$ & $13.770,35$ & $8.048,41$ & $13.430,88$ \\
\hline $\begin{array}{l}\text { Técnicos em } \\
\text { outras áreas }\end{array}$ & $3.707,67$ & $8.682,01$ & $2.730,84$ & $6.366,13$ & $3.519,35$ & $6.903,13$ & $10.643,57$ & $8.594,82$ & $14.043,32$ & $6.967,70$ & $10.410,50$ \\
\hline
\end{tabular}
2003. 
Tabela 39 - Matriz de transição: classificação original de 1995-2002 vs. Classificação 1995-2012

\begin{tabular}{|c|c|c|c|c|c|c|c|c|c|}
\hline \multirow[b]{2}{*}{$\begin{array}{l}\text { Classificação 1995- } \\
2002\end{array}$} & \multicolumn{9}{|c|}{ Classificação 1995-2012 } \\
\hline & $\begin{array}{l}\text { Enga } \\
\text { gestão }\end{array}$ & $\begin{array}{l}\text { Enga } \\
\text { prof. }\end{array}$ & $\begin{array}{l}\text { Engo } \\
\text { típico }\end{array}$ & $\begin{array}{l}\text { Enga } \\
\text { técnico }\end{array}$ & \begin{tabular}{|c|}
$\begin{array}{c}\text { Fora } \\
\text { da } \\
\text { Rais }\end{array}$ \\
\end{tabular} & $\begin{array}{l}\text { Não-eng }{ }^{\mathrm{a}} \text { : } \\
\text { gestão }\end{array}$ & $\begin{array}{l}\text { Não- } \\
\text { enga: } \\
\text { prof. }\end{array}$ & $\begin{array}{c}\text { Não-eng } \\
\text { técnico }\end{array}$ & $\begin{array}{l}\text { Total } \\
\text { Geral }\end{array}$ \\
\hline $\begin{array}{l}\text { Gestor em } \\
\text { engenharia }\end{array}$ & 103 & 2 & 27 & - & 47 & 69 & 23 & 8 & 279 \\
\hline Engenheiro típico & 211 & 37 & 1.202 & 55 & 323 & 134 & 102 & 178 & 2.242 \\
\hline $\begin{array}{l}\text { Técnico em } \\
\text { engenharia }\end{array}$ & 82 & 9 & 95 & 94 & 122 & 68 & 42 & 55 & 567 \\
\hline Fora da Rais & 45 & 61 & 130 & 22 & 918 & 24 & 60 & 70 & 1.330 \\
\hline $\begin{array}{l}\text { Gestor em outras } \\
\text { áreas }\end{array}$ & 10 & 1 & 16 & 2 & 86 & 110 & 38 & 9 & 272 \\
\hline $\begin{array}{l}\text { Profissional em } \\
\text { outras áreas }\end{array}$ & 14 & - & 12 & 2 & 56 & 18 & 94 & 9 & 205 \\
\hline $\begin{array}{l}\text { Técnico em outras } \\
\text { áreas }\end{array}$ & 81 & 13 & 96 & 22 & 187 & 109 & 63 & 159 & 730 \\
\hline Total Geral & 546 & 123 & 1578 & 197 & 1.739 & 532 & 422 & 488 & 5.625 \\
\hline
\end{tabular}

Fonte: Elaboração própria a partir da Rais. Comunalidade $=48,7 \%$, mas há uma categoria a menos em 1995.

Tabela 40 - Matriz de transição: classificação da geração 90 em 2000 (realinhamento das sequências) vs. Classificação 1995-2012

\begin{tabular}{|c|c|c|c|c|c|c|c|c|c|}
\hline \multirow[b]{2}{*}{$\begin{array}{l}\text { Geração } 90 \text { em 2003- } \\
2012\end{array}$} & \multicolumn{9}{|c|}{ Classificação 1995-2012 } \\
\hline & $\begin{array}{l}\text { Enga: } \\
\text { gestão }\end{array}$ & $\begin{array}{l}\text { Eng } \\
\text { prof. }\end{array}$ & 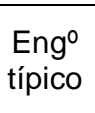 & $\begin{array}{l}\text { Eng }{ }^{\mathrm{a}} \text { : } \\
\text { técnico }\end{array}$ & $\begin{array}{l}\text { Fora } \\
\text { da } \\
\text { Rais }\end{array}$ & $\begin{array}{l}\text { Não- } \\
\text { enga: } \\
\text { gestão }\end{array}$ & $\begin{array}{l}\text { Não- } \\
\text { enga } \\
\text { prof. }\end{array}$ & $\begin{array}{l}\text { Não- } \\
\text { eng } \\
\text { técnico }\end{array}$ & $\begin{array}{l}\text { Total } \\
\text { Geral }\end{array}$ \\
\hline $\begin{array}{l}\text { Gestor em } \\
\text { engenharia }\end{array}$ & 483 & - & 30 & 5 & 35 & 99 & 14 & 10 & 676 \\
\hline $\begin{array}{l}\text { Profissional em } \\
\text { engenharia }\end{array}$ & 8 & 99 & 3 & - & 23 & 1 & 26 & 1 & 161 \\
\hline Engenheiro típico & 39 & 11 & 1.420 & 23 & 77 & 48 & 12 & 76 & 1.706 \\
\hline $\begin{array}{l}\text { Técnico em } \\
\text { engenharia }\end{array}$ & 3 & 2 & 4 & 135 & 1 & - & 4 & - & 149 \\
\hline Fora da Rais & 1 & 3 & 89 & 10 & 1.439 & 4 & 6 & 1 & 1.553 \\
\hline $\begin{array}{l}\text { Gestor em outras } \\
\text { áreas }\end{array}$ & 4 & 1 & 8 & 4 & 44 & 358 & 13 & 7 & 439 \\
\hline $\begin{array}{l}\text { Profissional em outras } \\
\text { áreas }\end{array}$ & 2 & 1 & 13 & 3 & 63 & 5 & 332 & 17 & 436 \\
\hline $\begin{array}{l}\text { Técnico em outras } \\
\text { áreas }\end{array}$ & 6 & 6 & 11 & 17 & 57 & 17 & 15 & 376 & 505 \\
\hline Total Geral & 546 & 123 & 1.578 & 197 & 1739 & 532 & 422 & 488 & 5.625 \\
\hline
\end{tabular}

Fonte: Elaboração própria a partir da Rais. Comunalidade $=82,5 \%$. 